\title{
WestVirginiaUniversity
}

THE RESEARCH REPOSITORY @ WVU

Graduate Theses, Dissertations, and Problem Reports

2004

\section{Evaluation of moment redistribution for hybrid HPS 70W bridge girders}

\author{
Lili Yang \\ West Virginia University
}

Follow this and additional works at: https://researchrepository.wvu.edu/etd

\section{Recommended Citation}

Yang, Lili, "Evaluation of moment redistribution for hybrid HPS 70W bridge girders" (2004). Graduate Theses, Dissertations, and Problem Reports. 1474.

https://researchrepository.wvu.edu/etd/1474

This Thesis is protected by copyright and/or related rights. It has been brought to you by the The Research Repository @ WVU with permission from the rights-holder(s). You are free to use this Thesis in any way that is permitted by the copyright and related rights legislation that applies to your use. For other uses you must obtain permission from the rights-holder(s) directly, unless additional rights are indicated by a Creative Commons license in the record and/ or on the work itself. This Thesis has been accepted for inclusion in WVU Graduate Theses, Dissertations, and Problem Reports collection by an authorized administrator of The Research Repository @ WVU. For more information, please contact researchrepository@mail.wvu.edu. 


\title{
EVALUATION OF MOMENT REDISTRIBUTION FOR HYBRID HPS 70W BRIDGE GIRDERS
}

\author{
Lili Yang \\ Thesis submitted to the \\ College of Engineering and Mineral Resources \\ at \\ West Virginia University \\ in partial fulfillment of the requirements \\ for the degree of \\ Master of Science \\ in \\ Civil and Environmental Engineering \\ Karl E. Barth, Ph.D., Chair \\ Julio F. Davalos, Ph.D. \\ Indrajit N. Ray, Ph.D. \\ Department of Civil and Environmental Engineering \\ Morgantown, West Virginia \\ 2004
}

Keywords: HPS hybrid bridge girders, Negative bending, Inelastic design, Moment redistribution, Finite element modeling 


\section{ABSTRACT \\ Evaluation of Moment Redistribution for Hybrid HPS 70W Bridge Girders \\ Lili Yang}

Recent studies have demonstrated that the use of hybrid steel bridge I-shaped girders (specifically sections incorporating Grade 50 webs and High Performance Steel (HPS) $70 \mathrm{~W}$ flanges) can produce steel weight savings and overall design economy for a wide range of typical steel bridge superstructures. Additionally, recent research at WVU in collaboration with others has led to proposed simplified moment redistribution techniques that have been adopted by AASHTO. These procedures are similar in nature to existing limits that permit up to $10 \%$ of the maximum factored negative bending moments to be redistributed to positive bending regions in members comprised of compact sections. However, the more recent procedures may be used for a wider range of sections, including those with non-compact webs, and specifically compute the level of redistribution moment. The primary goal of this study is to assess the suitability of simplified moment redistribution procedures to members fabricated with hybrid configurations.

In this work, refined 3D finite element analysis (FEA) tools are employed to assess the moment rotation characteristics for a wide range of hypothetical hybrid steel Ishaped girder sections. These tools are successfully calibrated against available experimental data and are capable of addressing the influences of both geometric and material non-linearity. Specific ABAQUS subroutines were developed for this effort that are used to introduce specified geometric imperfections and residual stresses in the FEA models.

Results from the parametric studies are used to assess the influence of key design parameters on the inelastic response of hybrid sections and are also used to assess the validity of proposed redistribution procedures for hybrid girders. Lastly, a design example of a two-span hybrid HPS 70W girder bridge is presented to illustrate the successful use of the simplified moment redistribution procedures for these types of members. 


\section{ACKNOWLEDGEMENT}

I would like to express my sincere gratitude to my academic and thesis advisor, Dr. Karl E. Barth. I appreciate his guidance and encouragement throughout my graduate study at West Virginia University. His insight, dedication and remarkable energy have always been a source of inspiration for me.

I would like to thanks Professor Julio F. Davalos for his kind help and his time serving on my graduate advisory committee. I would also like to thanks Dr. Indrajit N. Ray for his participation on my graduate advisory committee.

The friendship and advice of the fellow students, Jennifer Righman, Dr. Haiyong $\mathrm{Wu}$, and Weiqiao Wang, is greatly appreciated.

Special thanks go to my husband, An Chen, for his love in my life.

Funding for this research was provided by the West Virginia Department of Transportation Division of Highways. 


\section{TABLE OF CONTENTS}

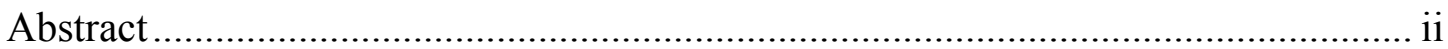

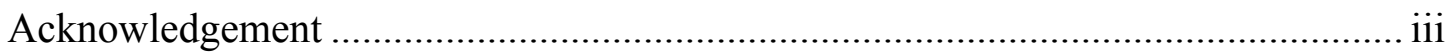

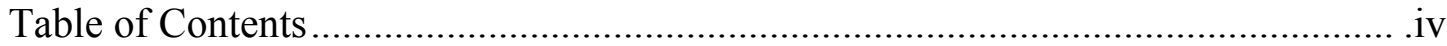

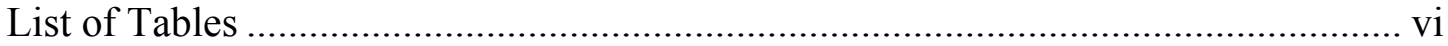

List of Figures ........................................................................................... vii

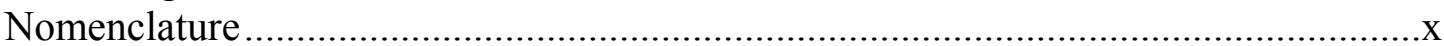

Chapter 1 Introduction..............................................................................................1

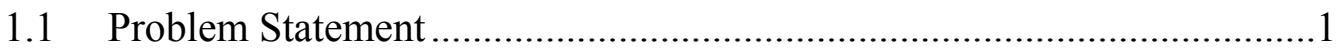

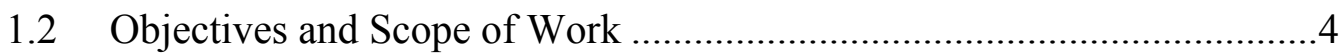

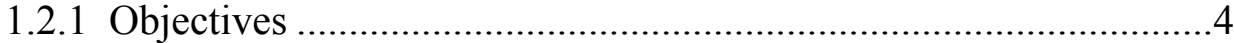

1.2.2 Scope of Work ……………………...........................................

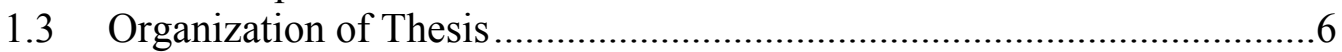

Chapter 2 Literature Review ....................................................................................9

2.1 Summary of Previous Work on Inelastic Rotation Capacity of Steel

I-shaped Girders in Negative Bending.....................................................9

2.1.1 Experimental Work by Grubb and Carskaddan ............................10

2.1.2 Effective Plastic Moment...........................................................13

2.1.3 Experimental Work by Schilling ................................................15

2.1.4 Finite Element Analysis by Barth ...............................................16

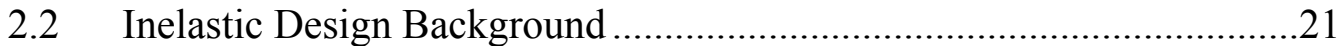

2.2.1 Summary of Inelastic Design Procedures in AASHTO

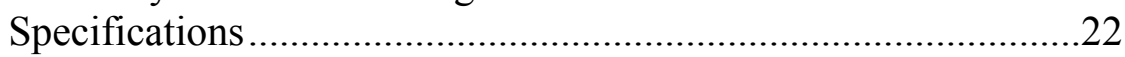

2.2.2 Currently Proposed Inelastic Design Procedures..........................26

2.2.3 Improved Effective Plastic Moment Equations ............................27

2.3 Recommended Simplified Moment Redistribution Procedures ..............29

Chapter 3 Nonlinear Finite Element Analysis Technique........................................39

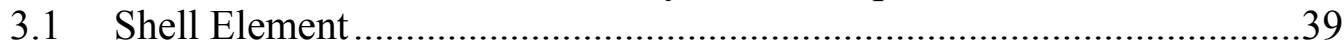

3.1.1 Element Naming Convention........................................................40

3.1.2 General-Purpose Shell Element: S4 and S4R ..............................40

3.1.3 Thin Shell Element: S4R5 …………………..........................42

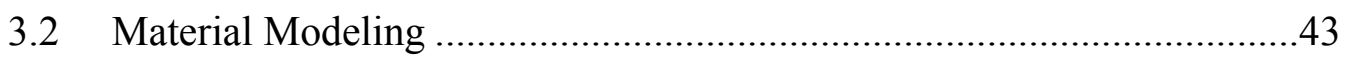

3.2.1 Von Mises Yield Criteria ..............................................................43

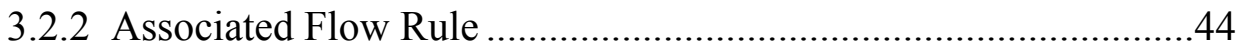

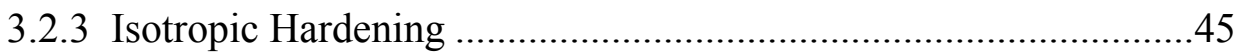

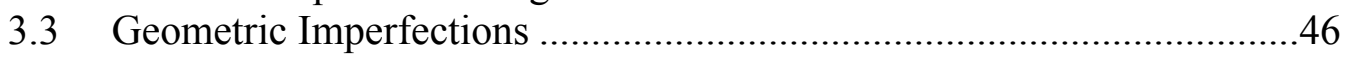

3.3.1 Definition and Specification of Imperfections................................48

3.3.2 Specification of Geometric Imperfections through

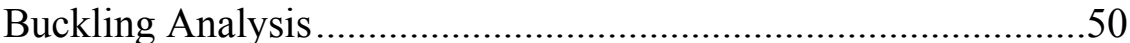


3.3.3 FORTRAN Imperfection Program Procedures..............................51

3.4 Modeling of Residual Stresses..............................................................5

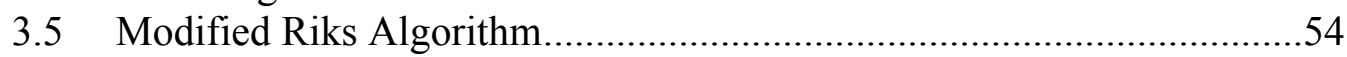

Chapter 4 Finite Element Analysis Verification Study ......................................65

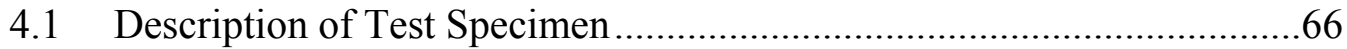

4.2 Validation Study .......................................................................6

4.2.1 Element Type ....................................................................67

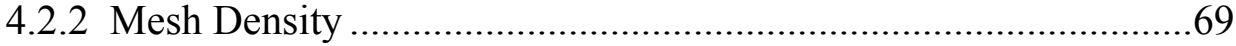

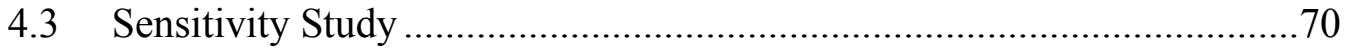

4.3.1 Initial Geometric Imperfections ................................................70

4.3.2 Material Configurations ...................................................... 72

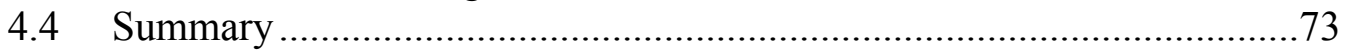

Chapter 5 Parametric Study on Moment-Rotation Behavior of HPS Hybrid Girders .............................................................................................91

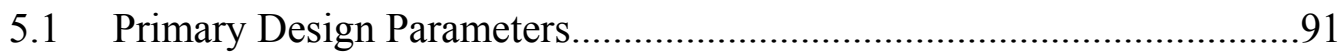

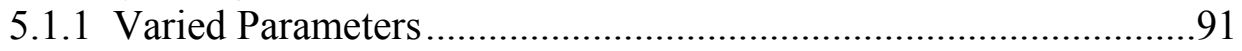

5.1.2 Constant Attributes and Parameters...........................................93

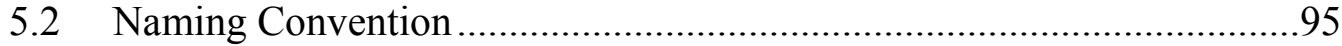

5.3 Effects of Various Parameters ............................................................96

5.3.1 Effect of Girder Material Configurations ....................................96

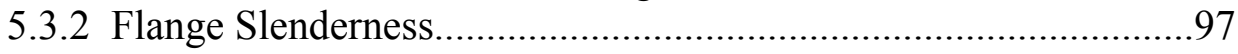

5.3.3 Depth of Web in Compression..................................................99

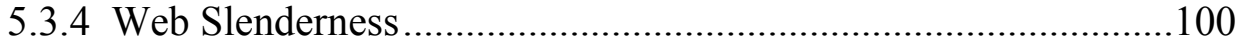

5.3.5 Cross-Section Aspect Ratio ....................................................101

5.3.6 Span-to-Girder Depth Ratio ...................................................102

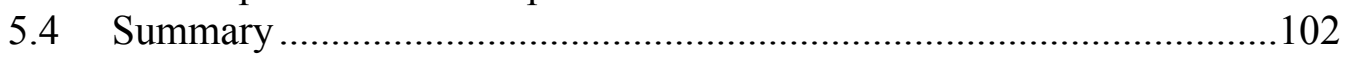

\section{Chapter 6 Evaluation of Moment Redistribution for Hybrid HPS 70W}

Bridge Girders................................................................................141

6.1 Evaluation of Effective Plastic Moment Equations .............................141

6.2 Simplified Moment Redistribution Design Example for Hybrid HPS 70W Girder Bridge .................................................................143

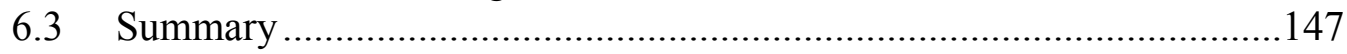

Chapter 7 Conclusions and Recommendations..................................................160

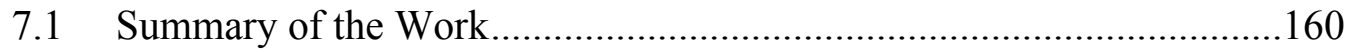

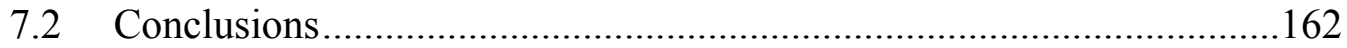

7.3 Recommendations for Future Work.................................................. 163

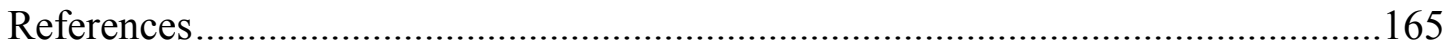




\section{LIST OF TABLES}

Table 4.1 Schilling's "D" girder initial out-of-flatness of web (Schilling and Morcos, 1988)

Table 4.2 Schilling's "D" girder material constitutive laws: -true stress vs.

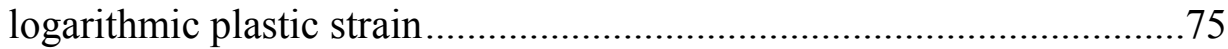

Table 4.3 Comparison of FEA results of mesh density study..................................76

Table 5.1 Summary of key design parameters of the FEA parametric studies.....104

Table 5.2 Girder properties and key FEA results: homogeneous Grade 50, HPS 70W and hybrid HPS 70W girders ............................................105

Table 5.3 Hybrid HPS 70W girder properties and the key FEA results ...............106

Table 5.4 $\quad \mathrm{D}_{\mathrm{cp}} / \mathrm{D}$ and $\mathrm{D} / \mathrm{b}_{\mathrm{fc}}$ effect on the normalized moment capacity .................108

Table 6.1 Comparison of proposed and current lateral bracing (AASHTO, 2001):

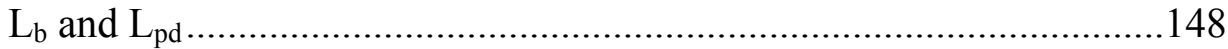

Table 6.2 Comparison of proposed (Barth, et al., 2003) and current web compactness (AASHTO, 2001): $2 \mathrm{D}_{\mathrm{cp}} / \mathrm{t}_{\mathrm{w}}=3.76 \sqrt{\mathrm{E} / \mathrm{F}_{\mathrm{yc}}}$ and $2 \mathrm{D}_{\mathrm{cp}} / \mathrm{t}_{\mathrm{w}}=\lambda_{\mathrm{pw}\left(\mathrm{D}_{\mathrm{cp}}\right)}$

Table 6.3 Effective plastic moments for the hybrid HPS 70W girders ................150

Table 6.4 Prototype girder section properties .....................................................152

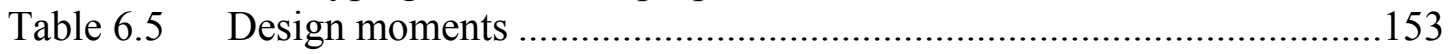




\section{LIST OF FIGURES}

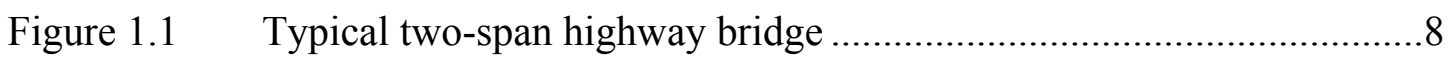

Figure 2.1 Typical moment-plastic rotation curves ...............................................34

Figure 2.2 Normalized moment-plastic rotation curve for interior-pier

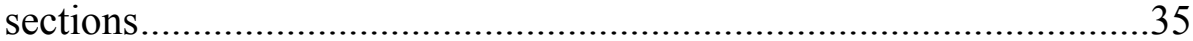

Figure 2.3 Moment redistribution for compact sections at interior piers

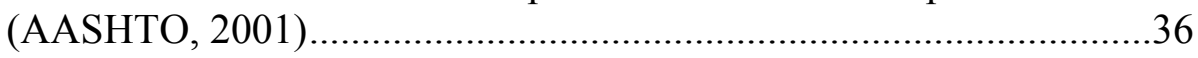

Figure 2.4 Histograms of the strength ratios, based on the effective plastic moment equations proposed by Barth et al.( 2003) ............................37

Figure 2.5 Histograms of the strength ratios, based on the effective plastic moment equations suggested by Schilling et al. (1997) .......................38

Figure 3.1 Von Mises yield criteria …………………….....................................60

Figure 3.2 Idealized stress-strain curve used in this study for $50 \mathrm{ksi}$ steel...........61

Figure 3.3 Initial geometric imperfections........................................................62

Figure 3.4 Flow chart for imperfection program ………………………............63

Figure 3.5 Modified Riks algorithm ...............................................................64

Figure 4.1 All-steel component test specimen (Schilling and Morcos, 1988) .....77

Figure 4.2 Residual stress patterns..................................................................

Figure 4.3 Schilling's "D" girder material constitutive law .................................79

Figure 4.4 Effects of element type on predicted flexure response for Schilling's

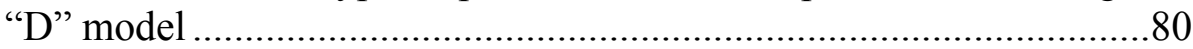

Figure 4.5 Comparison of experimental and FEA model with S4R shell element on $\mathrm{M} / \mathrm{M}_{\mathrm{p}}$ vs. $\theta_{\mathrm{p}}$ Curve for Schilling's " $\mathrm{D}$ " model .................................81

Figure 4.6 Schilling's " $D$ " model final failure mode with S4R shell element .....82

Figure 4.7 Effect of mesh density on predicted flexure response for Schilling's

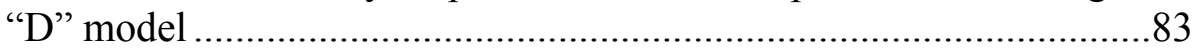

Figure 4.8 Influence of initial geometric imperfections on predicted flexure response for Schilling's " $D$ " model ..................................................... 84

Figure 4.9 Introducing imperfections using buckling analysis for Schilling's "D" girder (a) First buckling mode with doubled web thickness;

(b) Second buckling mode with doubled web thickness........................85

Figure 4.10 Introducing imperfections using FORTRAN program for Schilling's "D" girder according to AWS specifications (AWS, 1995) ................86

Figure 4.11 Influence of imperfection patterns on normalized moment capacity for Schilling's "D" model ...................................................................... 87

Figure 4.12 Material constitutive law used in this study for Grade 50 steel ..........88

Figure 4.13 Material constitutive law used in this study for HPS 70W steel from FHWA experimental tests (Wright, 1997)............................................89

Figure 4.14 Effect of material configuration on $M / \mathrm{M}_{\mathrm{p}}$ vs. $\theta_{\mathrm{p}}$ curves for Schilling's

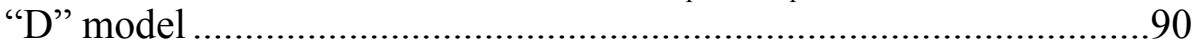

Figure 5.1 Elevation view of typical FEA girder...........................................109

Figure 5.2 Typical unstiffened FEA mesh .......................................................110

Figure 5.3 Typical transversely-stiffened FEA mesh ..........................................111 
Figure 5.4

Figure 5.5

Figure 5.6

Figure 5.7

Figure 5.8

Figure 5.9

Figure 5.10

Figure 5.11

Figure 5.12

Figure 5.13

Figure 5.14

Figure 5.15

Figure 5.16

Figure 5.17

Figure 5.18

Figure 5.19

Figure 5.20

Figure 5.21

Figure 5.22

Figure 5.23

Figure 5.24

Figure 5.25

Figure 5.26

Figure 5.27

Figure 5.28

Figure 5.29

Figure 5.30

Figure 5.31

Figure 5.32

Naming convention

Influence of girder material configurations on $\mathrm{M} / \mathrm{M}_{\mathrm{p}}$ vs. $\theta_{\mathrm{p}}$ curves

(CFCW3-30S).

Influence of girder material configurations on $\mathrm{M} / \mathrm{M}_{\mathrm{p}}$ vs. $\theta_{\mathrm{p}}$ curves

(CFCW4-30S).

Influence of girder material configurations on $\mathrm{M} / \mathrm{M}_{\mathrm{p}}$ vs. $\theta_{\mathrm{p}}$ curves

(CFCW3-30U1)

Influence of girder material configurations on $\mathrm{M} / \mathrm{M}_{\mathrm{p}}$ vs. $\theta_{\mathrm{p}}$ curves

(CFCW4-30U1)

Influence of girder material configurations on $\mathrm{M} / \mathrm{M}_{\mathrm{p}}$ vs. $\theta_{\mathrm{p}}$ curves

(CFCW3-30U2)

Influence of girder material configurations on $\mathrm{M} / \mathrm{M}_{\mathrm{p}}$ vs. $\theta_{\mathrm{p}}$ curves

(CFCW4-30U2)

Influence of girder material configurations on $\mathrm{M} / \mathrm{M}_{\mathrm{p}}$ vs. $\theta_{\mathrm{p}}$ curves

(CFSW3-30S)

Influence of girder material configurations on $M / M_{p}$ vs. $\theta_{p}$ curves

(CFSW4-30S)

Influence of girder material configurations on $\mathrm{M} / \mathrm{M}_{\mathrm{p}}$ vs. $\theta_{\mathrm{p}}$ curves

(CFSW3-30U1).

Influence of girder material configurations on $\mathrm{M} / \mathrm{M}_{\mathrm{p}}$ vs. $\theta_{\mathrm{p}}$ curves

(CFSW4-30U1).

Influence of girder material configurations on $\mathrm{M} / \mathrm{M}_{\mathrm{p}}$ vs. $\theta_{\mathrm{p}}$ curves

(CFSW3-30U2).

Influence of girder material configurations on $\mathrm{M} / \mathrm{M}_{\mathrm{p}}$ vs. $\theta_{\mathrm{p}}$ curves

(CFSW4-30U2).

Effect of ultra-compact flange on M/M $\mathrm{M}_{\mathrm{p}}$ vs. $\theta_{\mathrm{p}}$ curves (CW3-30) ....125

Effect of ultra-compact flange on $\mathrm{M} / \mathrm{M}_{\mathrm{p}}$ vs. $\theta_{\mathrm{p}}$ curves (CW4-30) ....126

Effect of ultra-compact flange on $\mathrm{M} / \mathrm{M}_{\mathrm{p}}$ vs. $\theta_{\mathrm{p}}$ curves (SW3-30).....127

Effect of ultra-compact flange on $\mathrm{M} / \mathrm{M}_{\mathrm{p}}$ vs. $\theta_{\mathrm{p}}$ curves (SW4-30).....128

Effect of $\mathrm{D}_{\mathrm{cp}} / \mathrm{D}$ on normalized moment capacity with

slender web

Effect of $\mathrm{D}_{\mathrm{cp}} / \mathrm{D}$ on normalized moment capacity with compact

web

Effect of web slenderness on $\mathrm{M} / \mathrm{M}_{\mathrm{p}}$ vs. $\theta_{\mathrm{p}}$ curves (CF4-30)

Effect of $\mathrm{D} / \mathrm{b}_{\mathrm{fc}}$ on $\mathrm{M} / \mathrm{M}_{\mathrm{p}}$ vs. $\theta_{\mathrm{p}}$ curves (CFCW-30)

Effect of $\mathrm{D} / \mathrm{b}_{\mathrm{fc}}$ on $\mathrm{M} / \mathrm{M}_{\mathrm{p}}$ vs. $\theta_{\mathrm{p}}$ curves (CFSW-30) 133

Effect of $\mathrm{L} / \mathrm{D}$ on normalized moment capacity $\left(\mathrm{D} / \mathrm{b}_{\mathrm{fc}}=3.0\right) \ldots \ldots \ldots \ldots . .134$

Effect of $\mathrm{L} / \mathrm{D}$ on normalized moment capacity $\left(\mathrm{D} / \mathrm{b}_{\mathrm{fc}}=4.25\right) \ldots \ldots \ldots \ldots . .135$

Effect of $L / D$ on $M / M_{p}$ vs. $\theta_{p}$ curves (CFCW3).

Effect of $\mathrm{L} / \mathrm{D}$ on $\mathrm{M} / \mathrm{M}_{\mathrm{p}}$ vs. $\theta_{\mathrm{p}}$ curves (CFCW4)

Effect of $L / D$ on $M / M_{p}$ vs. $\theta_{p}$ curves (CFSW3)

Effect of $\mathrm{L} / \mathrm{D}$ on $\mathrm{M} / \mathrm{M}_{\mathrm{p}}$ vs. $\theta_{\mathrm{p}}$ curves (CFSW4)

139

Typical failure mode of the girders in this study (at interior-pier 
region) 140

Figure 6.1 Histograms of the strength ratios for FEA tests, based on the effective plastic moment equations proposed by Barth et al. (2003)...............154

Figure 6.2 4-girder system prototype bridge cross section ................................155

Figure 6.3 Prototype girder elevation view and cross sections -simplified moment redistribution design girder ........................................................156

Figure 6.4 Moment envelopes for the prototype girder ....................................157

Figure 6.5 Strength I design limit moments for the prototype girder by simplified moment redistribution design .......................................158

Figure 6.6 Hybrid girder elevation view and cross sections by elastic design ...159 


\section{NOMENCLATURE}

The following symbols are used in this thesis:

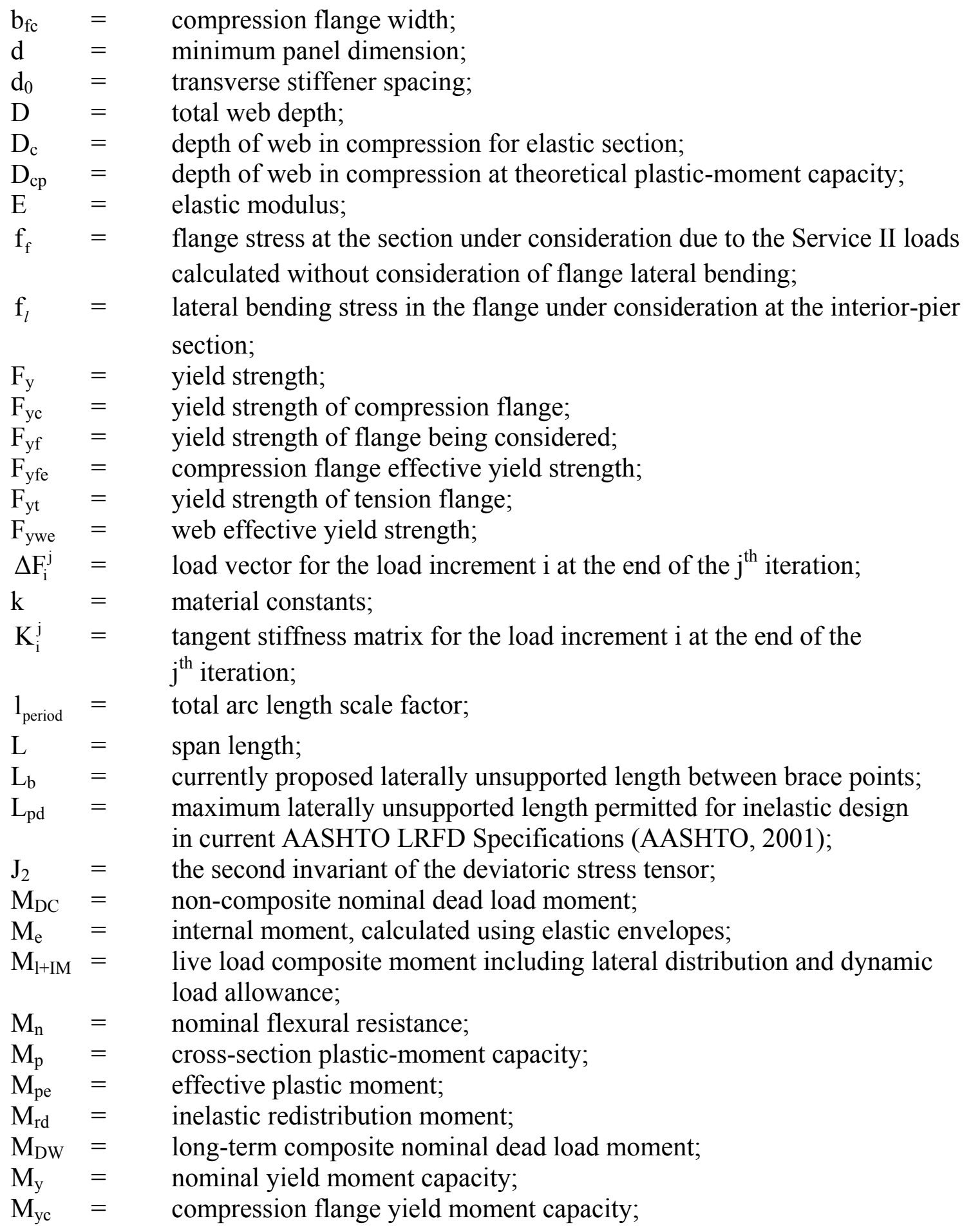




\begin{tabular}{|c|c|c|}
\hline$Q_{i}^{j}$ & $=$ & internal force vector; \\
\hline $\mathrm{r}_{\mathrm{y}}$ & $=$ & $\begin{array}{l}\text { radius of gyration of the compression flange plus one-half of the web } \\
\text { depth with respect to the weak axis of bending of the cross-section; }\end{array}$ \\
\hline$r_{t}$ & $=$ & effective radius of gyration for lateral tortional buckling; \\
\hline $\mathrm{R}_{\mathrm{b}}$ & $=$ & web bend buckling reduction factor; \\
\hline $\mathrm{R}_{\mathrm{f}}$ & $=$ & compression flange effective yield strength reduction factor; \\
\hline $\mathrm{R}_{\mathrm{h}}$ & $=$ & web hybrid reduction factor; \\
\hline $\mathrm{R}_{\mathrm{i}}^{\mathrm{j}}$ & $=$ & out-of-balance force vector; \\
\hline $\mathrm{R}_{\mathrm{W}}$ & $=$ & web effective yield strength reduction factor; \\
\hline $\mathrm{S}_{\mathrm{ij}}$ & $=$ & the deviatoric stress factor; \\
\hline $\mathrm{S}$ & $=$ & non-composite section modulus; \\
\hline $\mathrm{S}_{3 \mathrm{n}}$ & $=$ & long-term composite section modulus; \\
\hline $\mathrm{S}_{\mathrm{n}}$ & $=$ & short-term composite section modulus; \\
\hline $\mathrm{S}_{\mathrm{X}}$ & $=$ & generic elastic section modulus; \\
\hline $\mathrm{S}_{\mathrm{xc}}$ & $=$ & compression flange elastic section modulus; \\
\hline $\mathrm{S}_{\mathrm{xt}}$ & $=$ & tension flange elastic section modulus; \\
\hline$t_{\mathrm{fc}}$ & $=$ & compression flange thickness; \\
\hline$t_{\mathrm{w}}$ & $=$ & web thickness; \\
\hline$\Delta u_{i}^{j}$ & $=$ & incremental displacement vector; \\
\hline $\mathrm{V}_{\mathrm{n}}$ & $=$ & nominal web shear capacity; \\
\hline $\mathrm{V}_{\mathrm{cr}}$ & $=$ & shear buckling resistance; \\
\hline$\lambda_{\mathrm{pw}(\mathrm{Dcp})}$ & & currently proposed compact web slenderness limit; \\
\hline $\mathrm{d} \lambda$ & $=$ & $\begin{array}{l}\text { positive scalar factor of proportionality, which is nonzero only when } \\
\text { plastic deformations occurs; }\end{array}$ \\
\hline$\Delta \lambda_{\text {in }}$ & $=$ & initial load proportional factor increment; \\
\hline$\Delta \lambda_{i}^{j}$ & $=$ & increment of the load magnitude parameter; \\
\hline$\phi_{f}$ & $=$ & resistance factor for flexure; \\
\hline$\phi_{\text {sd }}$ & $=$ & shakedown resistance factor; \\
\hline$\phi_{\mathrm{v}}$ & $=$ & resistance factor for shear; \\
\hline$\theta_{\mathrm{p}}$ & $=$ & plastic rotation; \\
\hline$\theta_{\mathrm{RL}}$ & $=$ & $\begin{array}{l}\text { plastic rotation at which pier-section flexure resistance theoretically will } \\
\text { start to decrease with increasing rotations; }\end{array}$ \\
\hline$\sigma_{0}$ & $=$ & uniaxial yield stress of the material; \\
\hline$\sigma_{\text {nom }}$ & $=$ & nominal (engineering) stress; \\
\hline$\varepsilon_{\text {nom }}$ & $=$ & nominal (engineering) strain; \\
\hline$\sigma_{\text {true }}$ & $=$ & true stress; \\
\hline$\varepsilon_{\ln }^{\mathrm{pl}}$ & $=$ & logarithmic plastic strain; \\
\hline $\mathrm{d} \varepsilon_{\mathrm{ij}}^{\mathrm{p}}$ & $=$ & plastic strain increment vector; \\
\hline$\varepsilon^{\mathrm{p}}$ & $=$ & effective plastic strain; \\
\hline$\delta_{\text {of }}$ & $=$ & tilt of the compression flange; \\
\hline
\end{tabular}


$\delta_{\text {ow }}=$ out-of-flatness of the web;

$\delta_{\mathrm{oL}}=$ lateral sweep of the compression flange. 


\section{CHAPTER 1 \\ INTRODUCTION}

\subsection{Problem Statement}

Rapid advancement in construction materials has always enabled civil engineers to achieve impressive gains in the safety, economy and functionality. Through the joint efforts of the American Iron and Steel Institute (AISI), the Federal Highway Administration (FHWA), and the United States Department of Navy, High Performance Steel (HPS) was successfully introduced to produce more durable and cost effective steel bridges. The first illustration of these steels is ASTM A709 Grade HPS 70W (HPS 485W), known simply as HPS 70W, which has a higher yield strength of $70 \mathrm{ksi}$ (485 $\mathrm{MPa}$ ), higher level of fracture toughness, improved weathering properties, and reduced welding preheat requirements relative to traditional steels. More and more HPS bridges have emerged since its first application in the 1990's. According to the AISI HPS scoreboard, about 80 HPS $70 \mathrm{~W}$ bridges are in service, and about 110 are either in construction/fabrication or in design/planning phases in the United States (AISI, 2003). The advantages of utilizing HPS 70W steel, weight savings and reduced fabrication costs, are well documented in several bridge design projects:

(1) The first HPS bridge in the United States is a $150 \mathrm{ft}$ (46 m) single span bridge, opened to traffic in December 1997 in Snyder, Nebraska. It was initially designed using Grade 
50 weathering steel and later opted to use HPS 70W without performing any redesign. No increase of welding and fabrication issues with HPS 70W were reported;

(2) closely followed, an HPS bridge with two continuous spans measuring $236 \mathrm{ft}$ (72 m) on State Route 53 over Martin Creek in Jackson County, Tennessee, was completed in 1998. Utilizing HPS 70W for the girders and Grade 50 steel for the stiffeners, crossframes, and other miscellaneous steels, it was reported to have a weight saving of $25 \%$ and a total cost saving of $10 \%$;

(3) the State of Missouri built its first HPS bridge in 2002 with a weight saving of nearly $17 \%$ and a cost saving of approximately $11 \%$ compared with the conventional Grade 50 bridge.

Despite the benefits mentioned above, several researchers (Horton et al., 2000; Barker and Schrage, 2000; and Clingenpeel, 2001) reported that, although using homogeneous HPS 70W generally allows less steel weight than conventional steel bridge designs, the additional cost of HPS 70W material may result in, for some cases, approximately no total cost savings or even an increased cost, because HPS 70W is currently more expensive than Grade 50 material. Thus, they proposed that the hybrid designs, using HPS 70W in bottom flange throughout the span and top flange in the negative moment region, and conventional Grade 50 steel elsewhere can show potential benefits of utilizing HPS in bridges both in weight savings and in considerable cost savings. Therefore, the use of HPS hybrid bridges is more promising than traditional homogeneous configurations in order to achieve the design of durable and cost effective steel bridges. 
While hybrid HPS 70W configurations show great promise for bridge economy, current AASHTO LRFD specifications (AASHTO, 2001) inelastic design procedures for continuous-span bridges are only applicable for girders with yield strengths not exceeding $50 \mathrm{ksi}$, and proportioned with compact cross sections. They may also require significant iterative calculation procedures, which make them difficult to apply in practice. Therefore, great efforts have been devoted to simplify the inelastic design. Several researchers (Schilling et al., 1997; Baker et al., 1997; Barth et al., 2000 a) proposed more simplified inelastic design procedures based on shakedown (a limit state whereby the deformations stabilize and future loads are resisted elastically), rather than plastic collapse. It was applicable for girders with ultra-compact or compact flange and compact to slender web, while the maximum girder strength was still confined to $50 \mathrm{ksi}$ because of relatively limited research on HPS 70W steel girders. These proposed design procedures were further refined with a series of more accurate effective plastic moment equations calculated from a moment-rotation prediction model (Barth et al., 2003) and extended to the girders fabricated from HPS 70W. Based on their work, the simplified moment redistribution procedures will be incorporated in the future edition of AASHTO LRFD specifications.

However, the newly proposed simplified moment redistribution procedures (Barth et al., 2003), are currently only applicable to homogeneous girders. Therefore, there is a need to investigate the moment-rotation behavior of HPS hybrid girders in negative bending regions and evaluate the applicability of proposed effective plastic moment equations and simplified moment redistribution procedures to HPS hybrid girders. 


\subsection{Objectives and Scope of Work}

\subsubsection{Objectives}

This research is focused on the finite element analysis (FEA) study of hybrid HPS $70 \mathrm{~W}$ girders in negative bending regions. Specifically, the primary objectives of the work are:

1. To develop FEA models to simulate the nonlinear material and geometric behavior of steel girders, which can be verified by existing experimental data;

2. To model a broad spectrum of hypothetical HPS hybrid girders and to explore the effects of various parameters on the strength and flexural ductility of HPS hybrid girders in negative bending regions;

3. To study the inelastic rotation capacity of HPS hybrid girders with ultra-compact to compact flanges, and compact to slender webs;

4. To verify the applicability of currently proposed web compactness limit and lateral bracing requirement for HPS hybrid girders;

5. To compare the effective plastic moments from FEA models with those from currently proposed prediction equations, and to demonstrate the applicability of the recommended simplified moment redistribution procedures for HPS hybrid girders.

\subsubsection{Scope of Work}

Followed by a review of key developments pertaining to inelastic design of steel I-shaped girder bridge, a reasonably comprehensive set of FEA parametric studies is 
carried out aimed at evaluating moment-rotation characteristics of HPS hybrid girders in negative bending regions. The negative bending region of a continuous-span I-shaped plate girder subjected to moment gradient can be simulated using a simply-supported beam under three-point loading, where the concentrated load acting at the mid-span represents the pier reaction and the two supports at both ends represent the contra-flexure points in the prototype bridge, as illustrated in Fig. 1.1.

The nonlinear finite element model, considering both residual stresses and geometric imperfections, is outlined and validated by experimental results. This FEA model is then adopted to carry out a parametric study focused on assessing the influence of a variety of key design variables which include compression flange slenderness $\left(b_{\mathrm{fc}} / 2 \mathrm{t}_{\mathrm{fc}}\right)$, web slenderness $\left(2 \mathrm{D}_{\mathrm{cp}} / \mathrm{t}_{\mathrm{w}}\right)$, cross-section aspect ratio $\left(\mathrm{D} / \mathrm{b}_{\mathrm{fc}}\right)$, depth of web in compression $\left(\mathrm{D}_{\mathrm{cp}} / \mathrm{D}\right)$, and span-to-depth ratio $(\mathrm{L} / \mathrm{D})$. The effects of various parameters on the inelastic behavior of HPS hybrid girders are discussed.

The effective plastic moments from FEA models are further compared with those from the prediction equations to evaluate the applicability of these prediction equations for hybrid HPS 70W steel girders.

Lastly a two-span hybrid HPS 70W girder bridge is designed using the recommended moment redistribution procedures, illustrating how such simplified procedures can be applied to HPS hybrid bridge girders to achieve significant weight and cost savings without extraneous design efforts. 


\section{3 Organization of Thesis}

There are seven chapters in this thesis. Chapter 1 includes the problem statement, objective and scope of work, and the organization of the thesis.

A literature review on inelastic rotation properties of steel I-shaped girders, including both experimental investigations and FEA parametric studies, is presented in Chapter 2. An overview of historical and current inelastic design procedures in AASHTO bridge design specifications is also introduced. The simplified moment redistribution method based on proposed inelastic design procedures by Schilling (Schilling et al., 1997; Barth and White, 2000 a) and improved effective plastic moment equations by Barth (Barth et al., 2003) are described in detail.

Chapter 3 introduces nonlinear finite element techniques employed in this work, such as nonlinear shell elements, plasticity model considerations, modeling of geometric imperfections and residual stresses, nonlinear solution techniques, etc.

Chapter 4 presents a verification study using the FEA method discussed in Chapter 3. Numerical analysis is conducted on an all-steel component specimen tested previously by Schilling and Morcos (1988). Detail comparisons between test results and FEA results are summarized and aspects that can affect the FEA modeling are addressed.

Chapter 5 presents the primary results of the parametric study. The effects of various parameters on the inelastic behavior of HPS hybrid girders are concluded.

In Chapter 6, the effective plastic moments obtained from FEA models are compared with those from the currently proposed prediction equations. A moment redistribution design example of a two-span bridge with hybrid HPS 70W girders is given 
to illustrate the advantages of simplified moment redistribution procedures for HPS hybrid bridge girders.

Chapter 7 provides the conclusions drawn from this study. Suggestions for future investigation are also presented. 


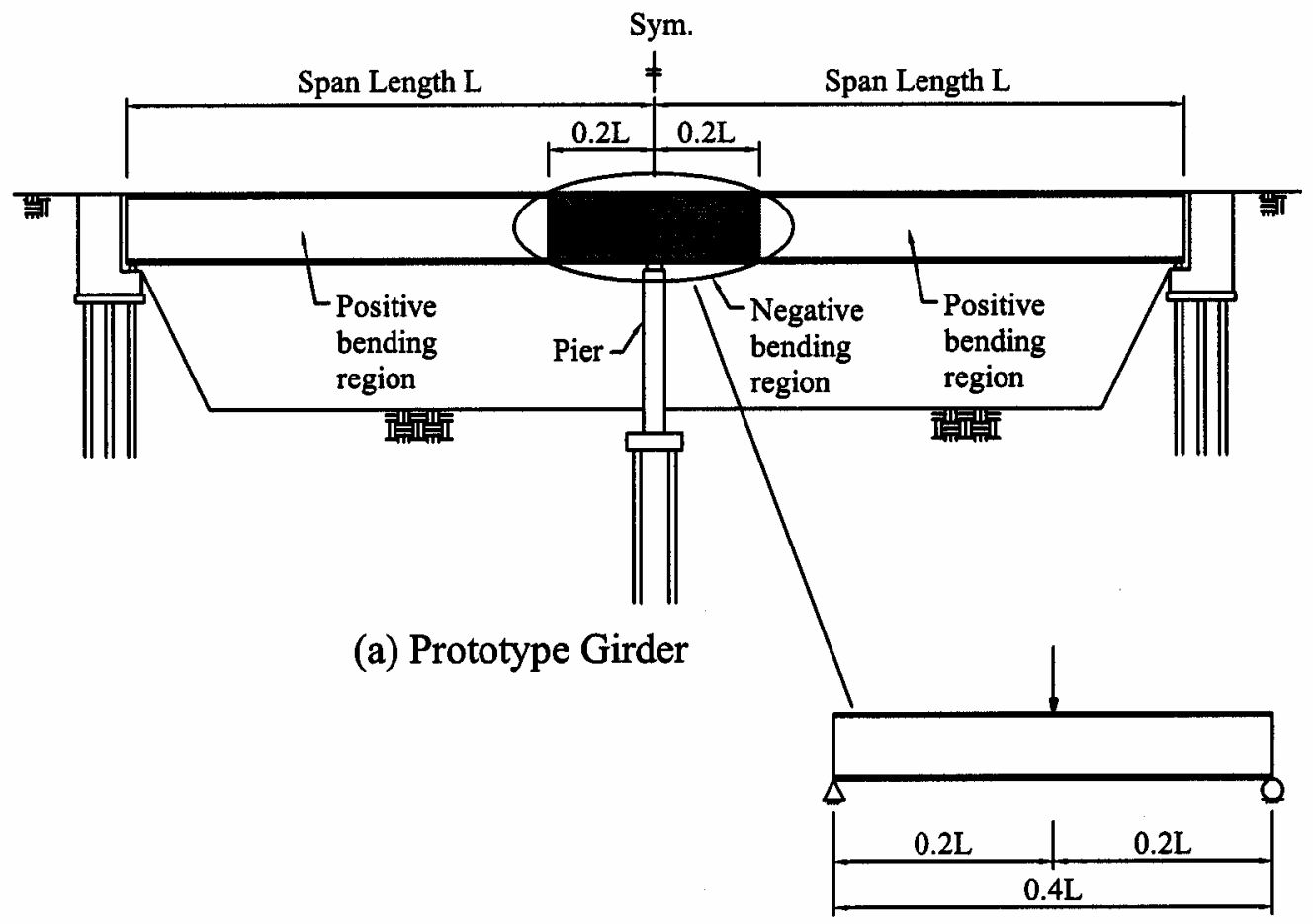

(b) Test Specimen

Figure 1.1 Typical two-span highway bridge 


\section{CHAPTER 2}

\section{LITERATURE REVIEW}

Serving as the background of this research, three sections will be included in this chapter: a summary review of previous experimental and finite element study pertaining to the inelastic behavior of steel I-shaped girders in negative bending; a historical overview of inelastic design procedures and their incorporation into AASHTO specifications, followed by discussions on proposed simplified inelastic design methods; and a detail description of the new design provisions for simplified moment redistribution in negative bending regions.

\subsection{Summary of Previous Work on Inelastic Rotation Capacity of Steel I-Shaped Girders in Negative Bending}

Inelastic design accounts for the redistribution of excess elastic moment in negative bending regions to positive bending regions which are caused by the inelastic rotation behavior of continuous-span I-shaped girders at interior supports. Thus, inelastic design analysis and procedures involve an explicit study of inelastic rotation capacity, as discussed below. 


\subsubsection{Experimental Work by Grubb and Carskaddan}

Early tests specifically devoted to assessing steel bridge girder inelastic design can be dated back to the late 1970's, when Grubb and Carskaddan (Grubb and Carskaddan 1979, 1981; Carskaddan, 1980) carried out a series of tests on seven singly symmetric all steel beams and one composite beam under AISI Project 188-Phase 3, labeled as 188-3-1 to 188-3-8. All the tests were conducted as simply-supported beams under three-point loading. The specific objective of these tests was to determine the flange and web compactness requirements for the economic rolled shapes at the $50 \mathrm{ksi}$ yield strength level and to study their interior-pier behavior for inelastic design (originally referred to as Autostress design).

In their first set of tests (188-1-1 to 188-1-3), three girders were initially designed considering that the flange and web compactness requirements in building specifications may be too severe for bridge design. A continuous bridge is usually less redundant than a building, thus it may require fewer plastic hinges to form a mechanism. However, it was found that all the three girders with $\mathrm{D} / \mathrm{t}_{\mathrm{w}}=58\left(\mathrm{D} / \mathrm{t}_{\mathrm{w}}=2.5 \sqrt{\mathrm{E} / \mathrm{F}_{\mathrm{y}}}\right.$, which was slightly more liberal than building code requirement for plastic design, $D / t_{w}=2.3 \sqrt{E / F_{y}}$ ) had essentially no rotation capacity or were barely able to reach the plastic moment $M_{p}$. The low rotation capacities, attributed to the high $\mathrm{D}_{\mathrm{cp}} / \mathrm{D}$ of the specimens due to a shift in the neutral axis, led to web and flange buckling before the girders reached $M_{p}$. To address the effect of such shifts in the neutral axis, Grubb and Carskaddan (1981) introduced the concept of effective web depth, which was defined as twice the depth of the web in compression $\left(2 \mathrm{D}_{\mathrm{cp}}\right)$ in order to more reasonably compute the web slenderness for bridge 
girders. Based on this definition, their second set of tests (188-1-5 to 188-1-8) had significant rotation capacity and exceeded $\mathrm{M}_{\mathrm{p}}$. Along with the results from 42 previously tested beams which were designed particularly for buildings, they defined the compact web limit as

$$
\frac{2 D_{c p}}{t_{w}}=\frac{608}{\sqrt{F_{y}}}
$$

which is equivalent to the form

$$
\frac{2 \mathrm{D}_{\mathrm{cp}}}{\mathrm{t}_{\mathrm{w}}}=3.57 \sqrt{\frac{\mathrm{E}}{\mathrm{F}_{\mathrm{y}}}}
$$

if $\mathrm{E}$ is assumed to be $29000 \mathrm{ksi}$.

Current AASHTO LRFD specifications (AASHTO, 2001) makes Eq. 2.1b more liberal based on Croce's work (Croce, 1970) as

$$
\frac{2 \mathrm{D}_{\mathrm{cp}}}{\mathrm{t}_{\mathrm{w}}}=3.76 \sqrt{\frac{\mathrm{E}}{\mathrm{F}_{\mathrm{y}}}}
$$

For the flange compactness limit, Grubb and Carskaddan (1981) suggested the following equation, which was originally based on the test work of Lukey (Lukey et al., 1969),

$$
\frac{\mathrm{b}_{\mathrm{fc}}}{2 \mathrm{t}_{\mathrm{fc}}}=0.382 \sqrt{\frac{\mathrm{E}}{\mathrm{F}_{\mathrm{y}}}}
$$

Additionally, they found that the sections having the combination of higher flange and web slenderness ratios resulted in a maximum moment below $\mathrm{M}_{\mathrm{p}}$. To exclude these sections that failed to reach $\mathrm{M}_{\mathrm{p}}$, interaction boundaries were drawn at the flange and web limits up to a point equal to 75 percent of these limited values, where a straight line was 
drawn diagonally between the two points. Consequently, they proposed the following interaction equation as

$$
\frac{2 \mathrm{D}_{\mathrm{cp}}}{\mathrm{t}_{\mathrm{w}}}+9.35 \frac{\mathrm{b}_{\mathrm{fc}}}{2 \mathrm{t}_{\mathrm{fc}}} \leq 150.5
$$

By replacing the value of 150.5 with a function of $\sqrt{E / F_{y}}$, the above equation is presently incorporated into AASHTO LRFD specifications (AASHTO, 2001) as

$$
\frac{2 \mathrm{D}_{\mathrm{cp}}}{\mathrm{t}_{\mathrm{w}}}+9.35 \frac{\mathrm{b}_{\mathrm{fc}}}{2 \mathrm{t}_{\mathrm{fc}}} \leq 6.25 \sqrt{\frac{\mathrm{E}}{\mathrm{F}_{\mathrm{y}}}}
$$

In summary, Eqs. 2.2 and 2.3 must be satisfied in order for girders to reach $\mathrm{M}_{\mathrm{p}}$. If both the web and compression flange slenderness are greater than 75 percent of those two compactness limits, additional restriction, Eq. $2.4 \mathrm{~b}$ must be satisfied.

The tests discussed above were all-steel tests, whereas another AISI Project 188 test, termed as 188-3-4, was a twin composite beam which was conducted by Carskaddan (1980). The steel girders in 188-3-4 closely matched 188-3-2 in their design proportions, and they exhibited similar experimental behavior. Based on this study, Carskaddan (1980) concluded that the composite girders were sufficiently similar to permit additional testing for compactness requirements to be performed with simpler all-steel specimens with an increased tension flange to account for the shift of the neutral axis.

The above AISI Project 188 test also served as the basis for the concept of "effective plastic moment" which was proposed in the early Autostress design. 


\subsubsection{Effective Plastic Moment}

Another concept that benefits the bridge girder inelastic design is the "effective plastic moment", $\mathrm{M}_{\mathrm{pe}}$. As shown in the upper curve in Fig. 2.1, in the conventional mechanism method, cross sections are proportioned so that they can sustain the full plastic moment $\mathrm{M}_{\mathrm{p}}$, through a sufficient plastic rotation to form a mechanism (ASCE, 1973), where the required compactness limits for plastic design are specified as

$$
\begin{aligned}
& \frac{\mathrm{b}_{\mathrm{fc}}}{2 \mathrm{t}_{\mathrm{fc}}} \leq 0.291 \sqrt{\frac{\mathrm{E}}{\mathrm{F}_{\mathrm{yf}}}} \\
& \frac{2 \mathrm{D}_{\mathrm{cp}}}{\mathrm{t}_{\mathrm{w}}} \leq 2.3 \sqrt{\frac{\mathrm{E}}{\mathrm{F}_{\mathrm{yf}}}}
\end{aligned}
$$

Haaijer et al. (1980) observed that cross sections with flange and/or web slenderness ratios too high to satisfy the requirement in Eqs. 2.5 and 2.6 may also exhibit significant rotation capacity, although with a reduced moment level lower than $\mathrm{M}_{\mathrm{p}}$, as shown in the lower curve in Fig. 2.1. Therefore, it is reasonable to assume that for any section that can achieve a sufficient plastic rotation to form a mechanism at a particular level of moment would be suitable for inelastic design at that moment capacity, which was termed as the effective plastic moment $M_{p e}$. The effective plastic moment $M_{p e}$ is calculated from the effective yield strengths $\mathrm{F}_{\mathrm{yfe}}, \mathrm{F}_{\mathrm{ywe}}$ and the section geometry. The effective strengths are obtained by substituting $F_{y f e}$ and $F_{y w e}$ for $F_{y f}$ in Eqs. 2.5 and 2.6 respectively, and simplified as

$$
\mathrm{F}_{\mathrm{yfe}}=0.085 \mathrm{E}\left(\frac{\mathrm{t}_{\mathrm{fc}}}{\mathrm{b}_{\mathrm{fc}}}\right)^{2} \leq \mathrm{F}_{\mathrm{yf}}
$$




$$
\mathrm{F}_{\mathrm{yfw}}=1.32 \mathrm{E}\left(\frac{\mathrm{t}_{\mathrm{w}}}{\mathrm{D}_{\mathrm{cp}}}\right)^{2} \leq \mathrm{F}_{\mathrm{yf}}
$$

where $\mathrm{E}$ is taken as $29000 \mathrm{ksi}$.

These effective yield strengths are then normalized with respect to the actual yield strength of the compression flange to obtain the reduction factors for compression flange and web as follows,

$$
\begin{aligned}
& \mathrm{R}_{\mathrm{f}}=\frac{\mathrm{F}_{\mathrm{yfe}}}{\mathrm{F}_{\mathrm{yf}}} \\
& \mathrm{R}_{\mathrm{w}}=\frac{\mathrm{F}_{\mathrm{ywe}}}{\mathrm{F}_{\mathrm{yf}}}
\end{aligned}
$$

Two methods are available for determining the effective plastic moment with these factors. One was given by Haaijer (Haaijer et al., 1980),

$$
M_{p e}=\frac{R_{f}+R_{w}}{2} M_{p}
$$

An alternative method which considered the flange and web contributed to $M_{p e}$ separately was suggested by Grabb and Carskaddan (1981) as

$$
\begin{aligned}
& M_{p e}=R_{f} \cdot M_{p f}+R_{w} \cdot M_{p w} \\
& M_{p w}=\frac{F_{y w} \cdot t_{w}}{2}\left[\left(D-D_{c p}\right)^{2}+D_{c p}{ }^{2}\right] \\
& M_{p f}=M_{p}-M_{p w}
\end{aligned}
$$

Compared with previous experimental results of 49 beams, Grubb and Carskaddan (1981) showed that bridge beams with compact sections satisfying the compact web limits in Eq. 2.2 demonstrated a rotation capacity of 63.3 mrads. Therefore, 
it was concluded that a section could be valid for inelastic design if its rotation capacity at $\mathrm{M}_{\mathrm{pe}}$ was greater than 63.3 mrads. Furthermore, it was concluded that Eqs. 2.12 through 2.14 were more rational and yielded a higher $\mathrm{M}_{\mathrm{pe}}$ than those proposed by Haaijer et al. (1980). Therefore, Eqs. 2.12 through 2.14 were adopted by the original AASHTO Guide specifications for Alternate Load Factor Design (AASHTO, 1986), where the procedure was simplified by making directly use of the effective yield stress in Eqs. 2.7 and 2.8. This procedure is also used to calculate $\mathrm{M}_{\mathrm{pe}}$ in the present AASHTO LRFD specifications (AASHTO, 2001) with minor changes.

\subsubsection{Experimental Work by Schilling}

The early tests, labeled as "US", "UL", and "SL", were conducted to investigate the pier moment-plastic rotation behavior of transversely-stiffened girders proportional at AASHTO maximum slenderness limits (Schilling, 1985). The transverse stiffeners were spaced at $1.5 \mathrm{D}$ which is the maximum spacing permitted by AASHTO specifications. Two specimens ("US", "UL") were proportioned such that $70 \%$ of the web was in compression at the plastic moment $\mathrm{M}_{\mathrm{p}}$. The three specimens were tested using threepoint bending tests, which included a variety of conditions that affect rotation characteristics: (1) symmetric and unsymmetrical cross sections, (2) long and short spans, (3) relatively large and small amounts of initial out-of-flatness, and (4) relatively large shear stresses. From the results, a lower-bound moment-rotation curve was developed for transversely-stiffened plate girders proportioned with slender webs and compression flanges. 
Latter work (Schilling, 1986) with 50 exploratory designs using Autostress design showed that although the lower-bound curve obtained in the early test (Schilling, 1985) would permit economical Autostress designs for non-compact plate girders, even more economical Autostress designs could be achieved by improving the inelastic momentrotation characteristics. Therefore, latter tests, termed as "S", "M" and "D" (Schilling and Morcos, 1988), were conducted to develop moment-rotation curves for non-compact plate girders with improved $\mathrm{M}-\theta_{\mathrm{p}}$ characteristics. Summarily, three changes were made: (1) the flange slenderness ratios $b_{\mathrm{fc}} / 2 t_{\mathrm{fc}}$ were reduced from the maximum limits to traditional plastic design limits (referred to by Schilling and Morcos as ultra-compact limits), (2) the web slenderness ratios were reduced for "S" and " $M$ " girders, and (3) additional one-sided transverse stiffeners were placed at a distance of $0.5 \mathrm{D}$ on each side of the simulated pier section. The moment-plastic rotation characteristics were significantly improved, particularly because the girders were proportioned with the ultracompact flanges and stockier webs. Based on the results, the lower-bound momentrotation curve was modified for transversely-stiffened plate girders proportioned with slender webs and compact compression flanges.

\subsubsection{Finite Element Analysis by Barth}

Obviously, the experimental tests discussed could represent only a sparse sampling throughout the full ranges of design characteristics possible in actual bridge griders. Consequently, additional finite element studies were carried out extensively to study the moment-rotation characteristics of steel I-shaped girders in negative bending 
regions (Barth and White, 1998; White and Barth, 1998; Barth et al., 2000 b; Barth et al., 2003). Based on their earlier finite element parametric study results, moment-rotation relationships were investigated and outlined using a set of prediction equations suitable for a wide range of typical I-shaped beams and plate girders. Their overall effort was to extend inelastic procedures to the design and the rating of bridge plate girders with noncompact webs and HPS 70W girders.

\section{Moment-Plastic Rotation Model}

In parallel with the research efforts by Schilling (Schilling et al., 1989, 1997), White, Ramirez and Barth (1997) conducted experimental testing and extensive finite element parametric studies aimed at characterizing the moment-rotation behavior of the hogging moment region in continuous-span bridge I-shaped girders. A moment-plastic rotation response of composite and non-composite girders with non-compact webs and compact or ultra-compact flanges was proposed, as illustrated in Fig. 2.2, where it was divided into three regions, namely (1) a linear pre-peak curve from zero plastic rotation at $\mathrm{M}=0.7 \mathrm{M}_{\mathrm{n}}$ to a $\theta_{\mathrm{p}}$ of 0.005 rads at $\mathrm{M}_{\mathrm{n}}$, where $\mathrm{M}_{\mathrm{n}}$ is the nominal flexural capacity, (2) a

plateau at the nominal resistance $\mathrm{M}_{\mathrm{n}}$ from $\theta_{\mathrm{p}}=0.005$ rads to a value denoted by the parameter $\theta_{\mathrm{RL}}$, and (3) a quadratic unloading curve given by Eq. 2.15.

$$
\frac{\mathrm{M}}{\mathrm{M}_{\mathrm{n}}}=1-16\left(\theta_{\mathrm{p}}-\theta_{\mathrm{RL}}\right)+100\left(\theta_{\mathrm{p}}-\theta_{\mathrm{RL}}\right)^{2}
$$

The plastic rotational onset of unloading in the suggested $M-\theta_{p}$ model was expressed as 


$$
\theta_{\mathrm{RL}}=0.128-0.0119 \frac{\mathrm{b}_{\mathrm{fc}}}{2 \mathrm{t}_{\mathrm{fc}}}-0.0216 \frac{\mathrm{D}}{\mathrm{b}_{\mathrm{fc}}}-0.002 \frac{\mathrm{b}_{\mathrm{fc}}}{2 \mathrm{t}_{\mathrm{fc}}} \frac{\mathrm{D}}{\mathrm{b}_{\mathrm{fc}}} \geq 0.005
$$

For ultra-compact webs satisfying $2 \mathrm{D}_{\mathrm{cp}} / \mathrm{t}_{\mathrm{w}}=2.3 \sqrt{\mathrm{E} / \mathrm{F}_{\mathrm{y}}}$ or transverse stiffeners spaced at $\mathrm{D} / 2$ or less over a minimum distance of $\mathrm{D} / 2$ on each side of the interior-pier sections, the first coefficient in Eq. 2.16 may be increased from 0.128 to 0.137 (Barth et al., 2003).

The above $\mathrm{M}-\theta_{\mathrm{p}}$ equations were obtained based on a statistical regression analysis of the results from a large finite element parametric study (Barth and White, 1998), followed by verification against experimental test data (White and Barth, 1998). These equations are a fit to a suite of finite element studies in which transverse stiffeners are placed such that the applied shear is less than $0.6 \mathrm{~V}_{\mathrm{n}}$ in the web and cross frames are spaced at the inelastic limit defined in the current AASHTO specifications in Eq. 2.20. The cross sections are restricted to $2 \mathrm{D}_{\mathrm{cp}} / \mathrm{t}_{\mathrm{w}} \leq 6.77 \sqrt{\mathrm{E} / \mathrm{F}_{\mathrm{yc}}}, \mathrm{b}_{\mathrm{fc}} / 2 \mathrm{t}_{\mathrm{fc}} \leq 0.4 \sqrt{\mathrm{E} / \mathrm{F}_{\mathrm{yc}}}$, $\mathrm{D} / \mathrm{b}_{\mathrm{fc}} \leq 4.25$, and $\mathrm{D}_{\mathrm{cp}} / \mathrm{D} \leq 0.75$.

The $\mathrm{M}-\theta_{\mathrm{p}}$ model was initially developed from the study of girders fabricated from Grade 50 steel. Based on finite element studies with HPS 70W, these equations were concluded to be applicable to HPS 70W girders (Barth et al., $2000 \mathrm{~b}$ ).

\section{Proposed Compact Web Limit in Negative Bending Region}

In present AASHTO LRFD specifications (AASHTO, 2001), Eq. 2.2 is suitable for composite or non-composite sections at positive or negative bending regions to reach $\mathrm{M}_{\mathrm{p}}$. However, White and Barth (1998) reviewed the results from 17 experimental tests 
and refined finite element parametric study, and concluded that the web slenderness need to be smaller for singly symmetric I-shaped girders with larger $\mathrm{M}_{\mathrm{p}} / \mathrm{M}_{\mathrm{y}}$ in order to develop their plastic moment capacity $\mathrm{M}_{\mathrm{p}}$. Therefore, they derived another compact web limit that mainly accounted for the high demands on the web in non-composite singly symmetric I-shaped sections and in composite section in negative bending with large shape factors, i.e., $\mathrm{M}_{\mathrm{p}} / \mathrm{M}_{\mathrm{y}}$ (Barth et al., 2003). This limit took the form as

$$
\frac{2 \mathrm{D}_{\mathrm{cp}}}{\mathrm{t}_{\mathrm{w}}} \leq \lambda_{\mathrm{pw}\left(\mathrm{D}_{\mathrm{cp}}\right)}
$$

in which

$$
\lambda_{p w\left(D_{c p}\right)}=\frac{\sqrt{\frac{E}{F_{y c}}}}{\left(0.54 \frac{M_{p}}{R_{h} M_{y}}-0.1\right)^{2}}
$$

where

$\lambda_{\mathrm{pw}\left(\mathrm{D}_{\mathrm{cp}}\right)}=\quad$ limiting slenderness ratio for a compact web corresponding to $2 \mathrm{D}_{\mathrm{cp}} / \mathrm{t}_{\mathrm{w}}$;

$\mathrm{D}_{\mathrm{cp}}=$ depth of the web in compression at the plastic moment;

$\mathrm{M}_{\mathrm{y}}=$ yield moment;

$\mathrm{R}_{\mathrm{h}}=$ hybrid factor.

It was concluded that sections satisfying the above proposed compact web limit were ensured to develop the full plastic moment capacity $M_{p}$ provided that other flange slenderness and lateral torsion bracing requirements were satisfied. 


\section{Proposed Lateral Bracing Requirement at Negative Bending Region}

The currently proposed lateral bracing limit, which is also adopted in this

research, is given as

$$
\mathrm{L}_{\mathrm{b}} \leq\left[0.1-0.06\left(\frac{\mathrm{M}_{1}}{\mathrm{M}_{2}}\right)\right] \frac{\mathrm{r}_{\mathrm{t}} \mathrm{E}}{\mathrm{F}_{\mathrm{yc}}}
$$

where

$\mathrm{M}_{1}=$ bending moment at the brace point with the lower moment due to the factored loads, taken as either the maximum or minimum moment envelope value, whichever produces the smallest permissible unbraced length;

$\mathrm{M}_{2}=$ bending moment at the brace point with the higher moment due to the factored loads, taken as the critical moment envelope value;

$r_{t}=$ effective radius of gyration for lateral torsional buckling, determined from the following equation,

$$
\mathrm{r}_{\mathrm{t}}=\frac{\mathrm{b}_{\mathrm{fc}}}{12\left(1+\frac{\mathrm{D}_{\mathrm{c}} \mathrm{t}_{\mathrm{w}}}{3 \mathrm{~b}_{\mathrm{fc}} \mathrm{t}_{\mathrm{fc}}}\right)}
$$

where $D_{c}$ is the depth of web in compression in elastic range.

The current lateral bracing for reaching $\mathrm{M}_{\mathrm{p}}$ given in AASHTO LRFD specifications Section 6.10.4.1.7 (AASHTO, 2001) is

$$
\mathrm{L}_{\mathrm{pd}} \leq\left[0.124-0.0759\left(\frac{\mathrm{M}_{1}}{\mathrm{M}_{\mathrm{p}}}\right) \frac{\mathrm{r}_{\mathrm{y}} \mathrm{E}}{\mathrm{F}_{\mathrm{yc}}}\right.
$$

The proposed equation is expressed in terms of $r_{t}$, rather than $r_{y}$, as used in Eq. 2.20. It is believed that the proposed equation can more accurately address the bracing 
requirements of composite sections in negative flexure because $r_{t}$ focuses strictly on the compression flange regions and thus does not involve in the tension flanges or the deck

for a composite section in negative flexure. A detailed comparison between the required bracing distances specified by the two equations for the representative girders from this study will be discussed in Chapter 6.

The proposed web compactness limit Eq. 2.17 and proposed lateral bracing limit Eq. 2.19 will be incorporated into the future edition of AASHTO LRFD specifications.

\subsection{Inelastic Design Background}

Due to the inherent ductility of steel, it is well known that continuous-span Ishaped girders exhibit the characteristics of inelastic rotation behavior at interior supports, which allows the inelastic redistribution of excess elastic moment in negative bending regions to positive bending regions. These inelastic redistribution capacities account for the true strength of the steel I-shaped girders and are exploited using inelastic design procedures in bridge design. Through inelastic design, significant cost savings can be achieved by (1) reducing girder cross section sizes at interior-pier region, (2) avoiding the addition of cover plates for rolled beams which may introduce details that often have low fatigue resistance, and (3) greatly reducing the number of flange transitions in welded girders which can result in additional fabrication costs. In summary, inelastic design practice can provide material and fabrication cost savings and improve overall fatigue resistance.

Various methods have been used in the past editions of AASHTO bridge 
specifications to account for the increase in strength due to inelastic behavior. An overview of these procedures is presented below.

\subsubsection{Summary of Inelastic Design Procedures in AASHTO Specifications}

A limited empirical way to account for the inelastic behavior was first introduced into Load Factor Design (LFD) specifications (AASHTO, 1973). Specifically, two simple provisions were provided. First, compact sections were permitted to reach the plastic moment capacity $\mathrm{M}_{\mathrm{p}}$ rather than being limited to the yield moment capacity $\mathrm{M}_{\mathrm{y}}$; second, negative moments over piers due to the factored loading, as determined by elastic procedures, was permitted to be reduced by a maximum of $10 \%$ before the strength at these locations were checked. The second provision gives potential recognition to the philosophy of plastic design, and it is still recommended in the current AASHTO LRFD specifications in Section 6.10.4.4 (AASHTO, 2001). Figure 2.3 illustrates the application of this provision in a two-span continuous beam.

Relative comprehensive inelastic design procedures were first given in the guide specification for ALFD (AASHTO, 1986). These design procedures (originally referred to as Autostress design) were only allowable for compact sections. A permanent deflection check by inelastic procedures at overload and a strength check by the plastic design mechanism method at maximum load were required. Specifically, (1) in the overload check in ALFD, the moment capacity at the pier is obtained using the beam-line method (Carskaddan et. al., 1982; Disgue, 1964; and Haaijer et. al., 1987), which makes use of a continuity relationship (which is a function of the applied loading) and a 
moment-rotation relationship (which is based on experimental results). A simultaneous solution of these two expressions yields the moment capacity and corresponding rotation at that load level. Because of the increase moment capacity achieved using ALFD specifications, excessive permanent deformations were of concern. As in traditional elastic design, AASHTO maximum stress limits were also imposed for positive bending regions in ALFD. These limits require that at the overload level the maximum flange stress due to the combined moment (i.e., elastic moments plus redistribution moments) in positive bending regions are limited to $95 \%$ and $80 \%$ of the yield stress $\mathrm{F}_{\mathrm{y}}$ in composite and non-composite girders, respectively. (2) The maximum load check in ALFD is based on a plastic design mechanism method approach (AISC, 1973). The design requirements at this load level are simplified by using the concept of effective plastic moment $\mathrm{M}_{\mathrm{pe}}$ as suggested by Grubb and Carskaddan (1981). Specifically, if the ultimate applied moment is less than the effective plastic moment multiplied with the resistant factor $\phi_{f}$, then the maximum load check is satisfied.

Previous specifications presented above are all limited to the design of compact beams. This limits the potential savings because economical continuous-span bridges often have non-compact or slenderness webs at their interior supports. As a result of the work by Schilling (1989) aiming to extend the applicability of the existing specifications to girders with slender webs, the Unified Autostress method was proposed and incorporated into ALFD (AASHTO, 1991) as an alterative design method. In this method, the correct plastic rotations and moments at all yield locations are determined by satisfying two relations: a continuity relationship and a rotation relationship. The 
continuity relationship depends on the stiffness properties of the girder and interrelates the plastic rotations at all yield locations and the moments at all interior-support locations, which is obtained by conceptually cutting the continuous span into simple spans and then calculating the end moments necessary to restore continuity with all plastic rotations in place. The rotation relationship interrelates the plastic rotation and moment at each yield location and depends on the properties of the cross section at that location. The unknown inelastic qualities are the redistribution moments at all piers and the plastic rotations at all yield locations. A unique solution is achieved by satisfying a continuity relationship at each pier and a rotation relationship at each yield location. The number of these relationships matches the number of unknowns. Once the inelastic unknowns have been determined, the elastic moments, redistribution moments, elastic deflections, and permanent deflections throughout the girders can be determined by wellknown elastic analytical methods.

The Unified Autostress method is better than mechanism method in that it determines the actual moments at all plastic hinge locations for any given load, thereby the Unified Autostress method can be applied in both the maximum load and overload check in AASHTO ALFD specifications (AASHTO, 1991).

The AASHTO ALFD procedures described above serve as the foundation for inelastic design in AASHTO LRFD specifications. The present AASHTO LRFD specifications (AASHTO, 2001) utilize the similar procedures, but the terms "auto moment" or "auto stress" used in the past have been replaced by "redistribution moment" and "redistribution stress" respectively, which were considered to reflect the fact that the 
moments and stresses they refer to result from inelastic redistribution of moments in continuous spans.

The inelastic design procedures are limited to the sections proportioned as the flowing requirements:

- Compact flange limit is given in Eq. 2.3;

- Compact web limit is given in Eq. 2.2;

- When both flange and web slenderness limit exceed $75 \%$ of the upper two compact limits, the girders shall satisfy Eq. 2.4 b;

- Lateral bracing is given in Eq. 2.20;

- Yield strength shall not exceed $50 \mathrm{ksi}$.

Similar to ALFD (AASHTO, 1991) and with minor modification, the current LRFD Service II limit state check may be evaluated using the beam-line or the Unified Autostress methods; the Strength I limit state may be evaluated using mechanism or Unified Autostress methods, as introduced previously.

Both Service II and Strength I limit state require the use of moment rotation curves for Unified Autostresss method. However, in the current AASHTO LRFD specifications (AASHTO, 2001), only the ascending portion of the moment-rotation curve for Service II limit check is specified. And there is no available moment-rotation curve for Strength I limit state. This is one of the reasons for the limited use of inelastic design in practice, since bridge engineers generally do not have these kinds of curves by hand. 


\subsubsection{Currently Proposed Inelastic Design Procedures}

The use of inelastic design procedures in AASHTO specifications has been very limited in bridge engineering practice in the past over two decades. The main reason of limited usage of inelastic design provisions is due to the fact that the past and current provisions require significant additional efforts for engineers ( i.e., complex iterative calculation procedures are needed to consider both the girder continuity relationship and the moment-rotation relationship.) and apply only to a limited rang of girder geometries. Therefore, Schilling (Schilling et al., 1997) proposed a simplified procedure based on shakedown (a limit state whereby the deformations stabilize and future loads are resisted elastically) rather than plastic collapse. This led to a straightforward procedure where an elastic procedure was modified by using redistribution moments which was calculated according to effective plastic moment $\mathrm{M}_{\mathrm{pe}}$. As discussed above, the concept of effective plastic moment $\mathrm{M}_{\mathrm{pe}}$ was initially introduced to extend the traditional plastic design procedures to a broader range of cross sections. In the proposed procedures, it was calculated depending on the flange and web slenderness at different design limits (Schilling et al., 1997; Barker et al., 1997, 2000; Barth and White, 2000 a).

In summary, the proposed procedures are essentially as easy to apply as elastic design methods and are applicable to the girders with compact or slender webs. However, the proposed procedures are limited that the girder yield strength is not exceeded to $50 \mathrm{ksi}$ because of the limited research on higher yield strength girders. The detail proposed design procedures will be introduced in Section 2.3. 


\subsubsection{Improved Effective Plastic Moment Equations}

With the advent of HPS 70W, the incorporation of High Performance Steel (HPS) into bridge industry has become more popular in recent years due to their significant material property improvement. Therefore, further development of the proposed inelastic design procedures with improved effective plastic moment equations and to include HPS 70W girders is investigated (Barth et al., 2000 b; Barth et al., 2003).

As suggested by Schilling (1985), design procedures can be simplified by assuming that a given value of rotation is sufficient for all girders. In the fifty design studies conducted by Schilling (1986), the required plastic rotations for the girders ranged from 0 to 29 mrads at the maximum load (Strength I) level. Therefore, a plastic rotation of 30 mrads is assumed to be sufficient for all girders under this loading. Also, as a result of trial designs conducted by Schilling (1989), the maximum plastic rotation under overload (Service II) conditions for composite girders was found to be 8.9 mrads (maximum plastic rotation when considering only the steel girders along was 9.6 mrads); consequently, a plastic rotation of 9 mrads is assumed to be sufficient for Service II limit state. With effective plastic moment approach in the conjunction with the pier continuity relationship, the redistribution moment may be calculated directly by bridge engineers. The proposed effective plastic moment equations for the Strength I and Service II limit states can be derived from Eqs. 2.15 and 2.16 using the assumed values of plastic rotations discussed above. Specifically, the quadratic term of $\theta_{\mathrm{p}}$ is approximated by $(0.03-0.005=0.025 \mathrm{rads})$ or $(0.009-0.005=0.004 \mathrm{rads})$ and either $0.03 \mathrm{rads}$ or $0.009 \mathrm{rads}$ is substituted for $\theta_{\mathrm{p}}$ in the linear term. For general I-shaped girders this procedure yields: 
for Service II limit,

$$
M_{p e}=\left(2.90-2.3 \frac{b_{f c}}{t_{f c}} \sqrt{\frac{F_{y c}}{E}}-0.35 \frac{D}{b_{f c}}+0.39 \frac{b_{f c}}{t_{f c}} \sqrt{\frac{F_{y c}}{E}} \frac{D}{b_{f c}}\right) M_{n} \leq M_{n}
$$

for Strength I limit,

$$
M_{p e}=\left(2.63-2.3 \frac{b_{f c}}{t_{f c}} \sqrt{\frac{F_{y c}}{E}}-0.35 \frac{D}{b_{f c}}+0.39 \frac{b_{f c}}{t_{f c}} \sqrt{\frac{F_{y c}}{E}} \frac{D}{b_{f c}}\right) M_{n} \leq M_{n}
$$

For ultra-compact webs satisfying $2 \mathrm{D}_{\mathrm{cp}} / \mathrm{t}_{\mathrm{w}}=2.3 \sqrt{\mathrm{E} / \mathrm{F}_{\mathrm{y}}}$ or transverse stiffeners spaced at $\mathrm{D} / 2$ or less over a minimum distance of $\mathrm{D} / 2$ on each side of the interior-pier sections, the effective plastic moments are:

for Service II limit,

$$
\mathrm{M}_{\mathrm{pe}}=\mathrm{M}_{\mathrm{n}}
$$

for Strength I limit,

$$
M_{p e}=\left(2.78-2.3 \frac{b_{f c}}{t_{f c}} \sqrt{\frac{F_{y c}}{E}}-0.35 \frac{D}{b_{f c}}+0.39 \frac{b_{f c}}{t_{f c}} \sqrt{\frac{F_{y c}}{E}} \frac{D}{b_{f c}}\right) M_{n} \leq M_{n}
$$

$\mathrm{M}_{\mathrm{n}}=$ nominal flexural resistance of the interior-pier section calculated according to web slenderness.

The effective plastic moments predicted by the equations derived above are compared with the measured values at rotations of 9 and 30 mrads from 68 experimental tests which represent a wide range of loading conditions, girder geometries, and material properties (Barth et al., 2003). Histograms of the strength ratio (predicted/experimental values) by the proposed effective plastic moment equations are shown in Fig. 2.4. It can be seen that the proposed equations are appropriately conservative for most of the girders 
considered with average strength ratios of 0.97 and 0.92 for Service II and Strength I limit, respectively. For comparison purposes, Barth et al. (2003) also computed the strength ratios for each of the same experimental girders using the effective plastic moment equations suggested by Schilling et al. (1997), as shown in Fig. 2.5. The average strength ratio predicted by Schilling et al. (1997) was 0.93 and 0.80 for the Service II and Strength I limit, respectively. Comparing these two methods, the effective plastic equations proposed by Barth et al. (2003) gives a larger strength ratio and a smaller standard deviation, thus it is evident that the proposed equations by Barth et al. (2003) can more accurately and consistently predict the behavior of the actual test girders.

These modified effective plastic moment procedures developed by Barth et al. (2003) were recently adopted by AASHTO for inclusion in the future edition of steel bridge specifications.

\subsection{Recommended Simplified Moment Redistribution Procedures}

The recommended moment redistribution procedures (Barth et al., 2003) may currently be applied to straight continuous-span homogeneous I-shaped section members with a specified minimum yield strength not exceeding $70 \mathrm{ksi}$. The cross-section shall be proportioned as follows.

- Web proportions

$$
\begin{aligned}
& \frac{2 \mathrm{D}_{\mathrm{c}}}{\mathrm{t}_{\mathrm{w}}} \leq 6.8 \sqrt{\frac{\mathrm{E}}{\mathrm{F}_{\mathrm{yc}}}} \\
& \frac{\mathrm{D}}{\mathrm{t}_{\mathrm{w}}} \leq 150
\end{aligned}
$$


and

$$
\frac{\mathrm{D}_{\mathrm{cp}}}{\mathrm{D}} \leq 0.75
$$

- Compression flange proportion

$$
\frac{\mathrm{b}_{\mathrm{fc}}}{2 \mathrm{t}_{\mathrm{fc}}} \leq 0.38 \sqrt{\frac{\mathrm{E}}{\mathrm{F}_{\mathrm{yc}}}}
$$

and

$$
\frac{\mathrm{D}}{\mathrm{b}_{\mathrm{fc}}} \leq 4.25
$$

- Lateral bracing should satisfy Eq. 2.19.

- Tension-field action is not permitted for redistribution of the negative bending moments. Shear force shall satisfy

$$
\mathrm{V}_{\mathrm{u}}<\phi_{\mathrm{v}} \mathrm{V}_{\mathrm{cr}}
$$

where $\phi_{\mathrm{v}}=$ resistance factor for shear;

$$
\mathrm{V}_{\mathrm{cr}}=\text { shear buckling resistance. }
$$

\section{Service II Limit State}

The Service II limit state is intended to prevent permanent deformations due to localized yielding. The Service II load combination is $1.0(\mathrm{DC}+\mathrm{DW})+1.3 \mathrm{~L}(1+\mathrm{IM})$. Positive moment stresses are limited to $95 \%$ of $\mathrm{F}_{\mathrm{y}}$ for composite sections and $80 \%$ of $\mathrm{F}_{\mathrm{y}}$ for non-composite sections after redistribution of the interior-support moment.

The redistribution moment, $\mathrm{M}_{\mathrm{rd}}$, at each interior support at Service II limit state shall be taken as,

$$
\mathrm{M}_{\mathrm{rd}}=\left|\mathrm{M}_{\mathrm{e}}\right|-\mathrm{M}_{\mathrm{pe}}
$$

where $0 \leq \mathrm{M}_{\mathrm{rd}} \leq 0.2\left|\mathrm{M}_{\mathrm{e}}\right|$ 
$\mathrm{M}_{\mathrm{e}}=$ critical elastic moment envelope value at the interior-pier section due to the Service II loads (k-in).

$\mathrm{M}_{\mathrm{pe}}=$ negative flexure effective plastic moment for the Service II limit state (k-in), as specified below:

for ultra-compact webs satisfying $2 \mathrm{D}_{\mathrm{cp}} / \mathrm{t}_{\mathrm{w}}=2.3 \sqrt{\mathrm{E} / \mathrm{F}_{\mathrm{y}}}$ or transverse stiffeners spaced at $\mathrm{D} / 2$ or less over a minimum distance of $\mathrm{D} / 2$ on each side of the interiorpier sections, $M_{p e}$ is taken as Eq. 2.23; for other interior-pier sections, $M_{p e}$ is taken as Eq. 2.21.

At all other locations $\mathrm{M}_{\mathrm{rd}}$ shall be determined by straight lines connecting the redistribution moments at adjacent interior-pier sections. The lines shall be extended to any points of zero redistribution moment at adjacent supports, including at the abutments.

Because the Service II limit are based on flanges stresses rather than moments, it is necessary to compute the flange stresses in positive bending regions calculated from the sum of the elastic and redistribution moments.

\section{Strength I Limit State}

The Strength I load combination is $1.25 \mathrm{DC}+1.5 \mathrm{DW}+1.75 \mathrm{~L}(1+\mathrm{IM})$. At flexural resistances of sections within the unbraced lengths immediately adjacent to the interiorpier sections satisfying the requirement Eqs. 2.25 through 2.29 shall not be checked.

At all other locations, sections shall satisfy the provisions of elastic design, as applicable, after redistribution. For composite sections in positive flexure, the 
redistribution moments shall be applied to the long-term composite sections when computing flexural stresses in the steel sections.

The redistribution moment, $\mathrm{M}_{\mathrm{rd}}$, at each interior support at the Strength I limit state shall be taken as the larger of:

$$
\begin{aligned}
& \mathrm{M}_{\mathrm{rd}}=\left|\mathrm{M}_{\mathrm{e}}\right|+\frac{1}{3} \mathrm{f}_{l} \mathrm{~S}_{\mathrm{xc}}-\phi_{f} \mathrm{M}_{\mathrm{pe}} \\
& \mathrm{M}_{\mathrm{rd}}=\left|\mathrm{M}_{\mathrm{e}}\right|+\frac{1}{3} \mathrm{f}_{l} \mathrm{~S}_{\mathrm{xt}}-\phi_{f} \mathrm{M}_{\mathrm{pe}}
\end{aligned}
$$

in which $0 \leq \mathrm{M}_{\mathrm{rd}} \leq 0.2\left|\mathrm{M}_{\mathrm{e}}\right|$

where:

$\mathrm{f}_{l}=$ lateral bending stress in the flange under consideration at the interior-pier section (ksi). For continuously braced tension or compression flanges, $\mathrm{f}_{l}$ shall be taken as zero.

$\phi_{f}=$ resistance factor for flexure. This resistance factor was originally given as a resistance factor for shakedown of $\phi_{\mathrm{sd}}=1.1$ (Barker et al., 1997). The resistance factor for shakedown of $\phi_{\mathrm{sd}}=1.1$ is justified generally less than the maximum plastic resistance. The resistance factor for flexure $\phi_{f}$ is selected to account for the fact that yielding within regions of positive flexure and the corresponding redistribution of positive bending moments to the interior-pier sections is not considered.

$\mathrm{M}_{\mathrm{e}}=$ critical elastic moment envelope value at the interior-pier sections due to the factored loads (k-in). 
$\mathrm{M}_{\mathrm{pe}}=$ Negative-flexure effective plastic moment for the Strength I limit state determined as follows: for ultra-compact webs satisfying $2 \mathrm{D}_{\mathrm{cp}} / \mathrm{t}_{\mathrm{w}}=2.3 \sqrt{\mathrm{E} / \mathrm{F}_{\mathrm{y}}}$ or transverse stiffeners spaced at $\mathrm{D} / 2$ or less over a minimum distance of $\mathrm{D} / 2$ on each side of the interior-pier sections. $\mathrm{M}_{\mathrm{pe}}$ is taken as Eq. 2.24; for other interior pier sections, $\mathrm{M}_{\mathrm{pe}}$ is taken as Eq. 2.22.

The redistribution moment, $\mathrm{M}_{\mathrm{rd}}$, at all other interior support shall be determined using the same procedure specified for the Service II load combination.

After moment redistribution, the design procedures for constructability and fatigue limit sate check are the same as traditional elastic design. 


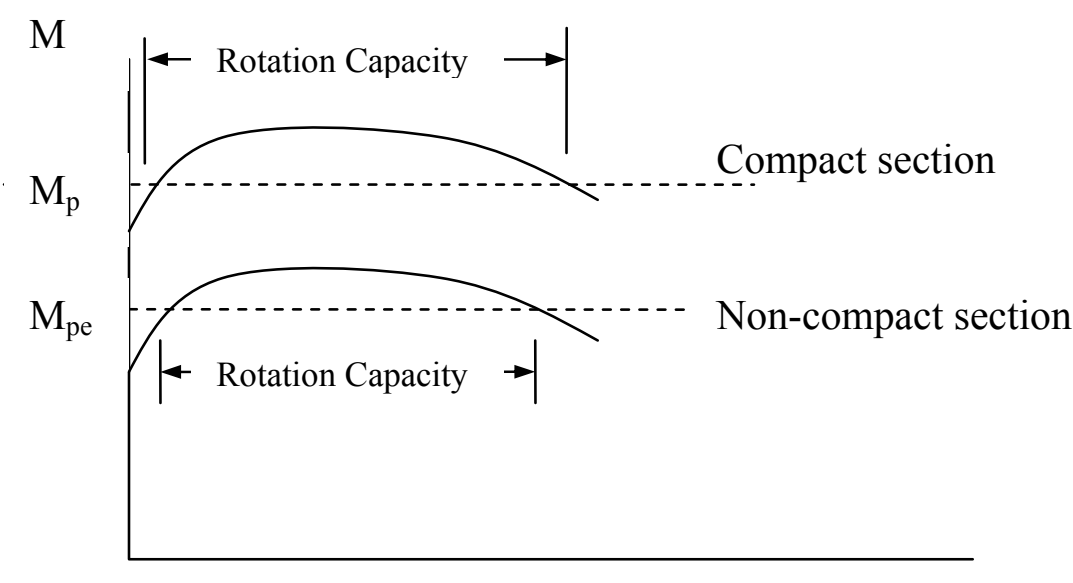

Plastic Rotation, $\theta_{\mathrm{p}}$

Figure 2.1 Typical moment-plastic rotation curves 


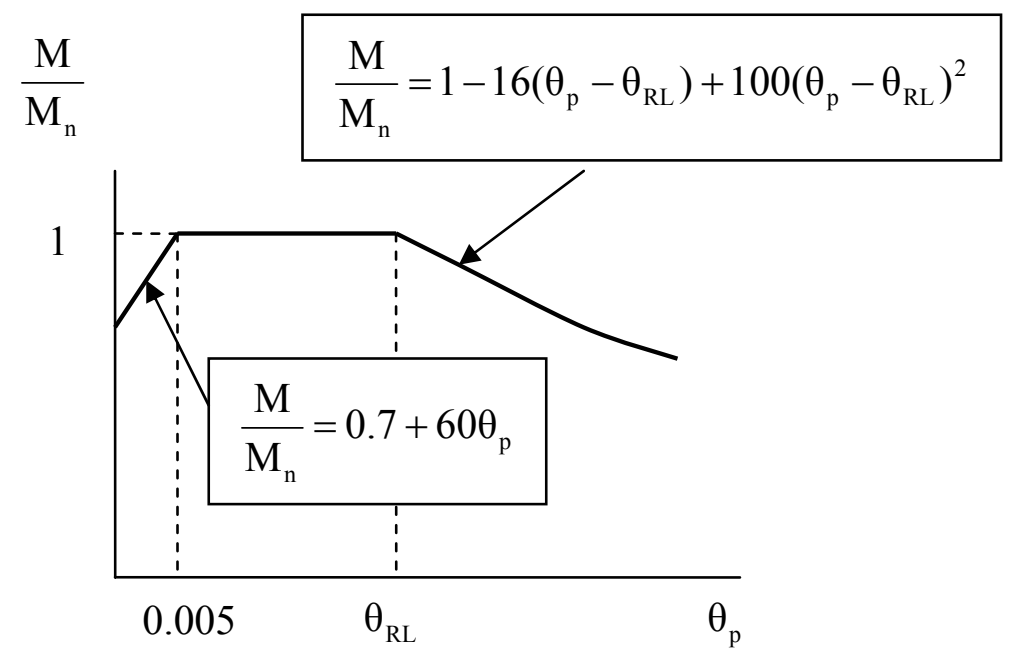

Figure 2.2 Normalized moment-plastic rotation curve for interior-pier sections 

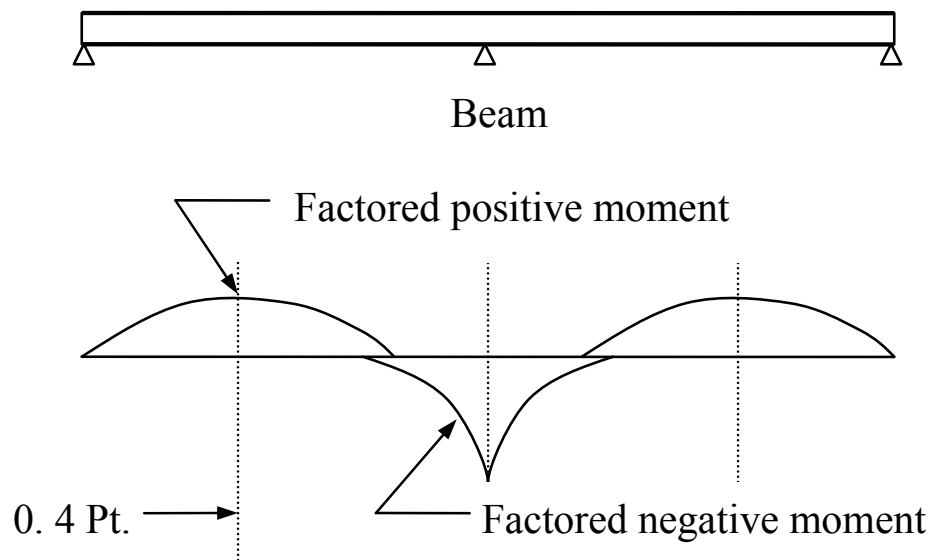

Maximum moments by elastic theory
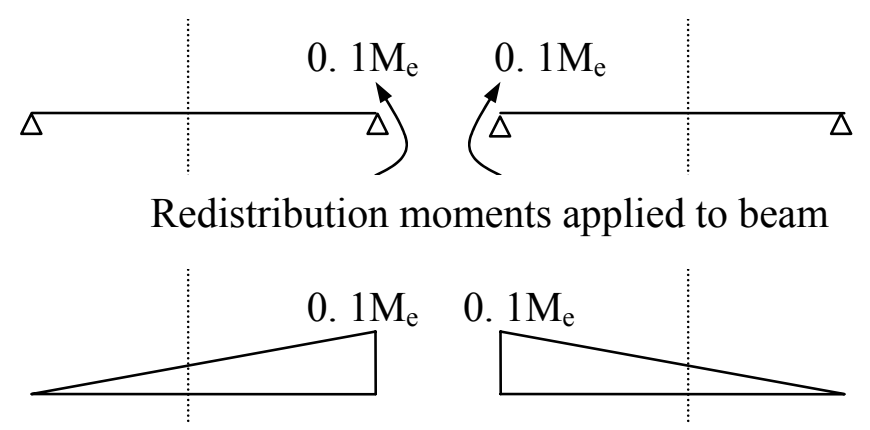

Moment diagram for redistribution

Figure 2.3 Moment redistribution for compact sections at interior piers (AASHTO, 2001) 


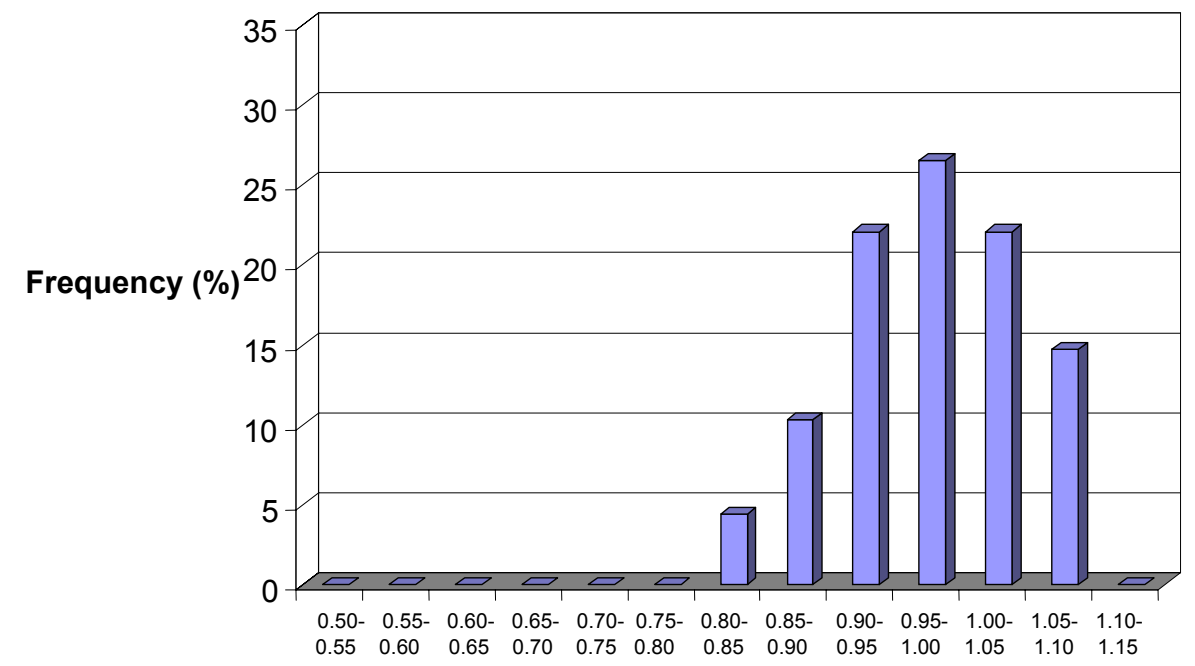

Strength Ratio

(a) Service II limit state

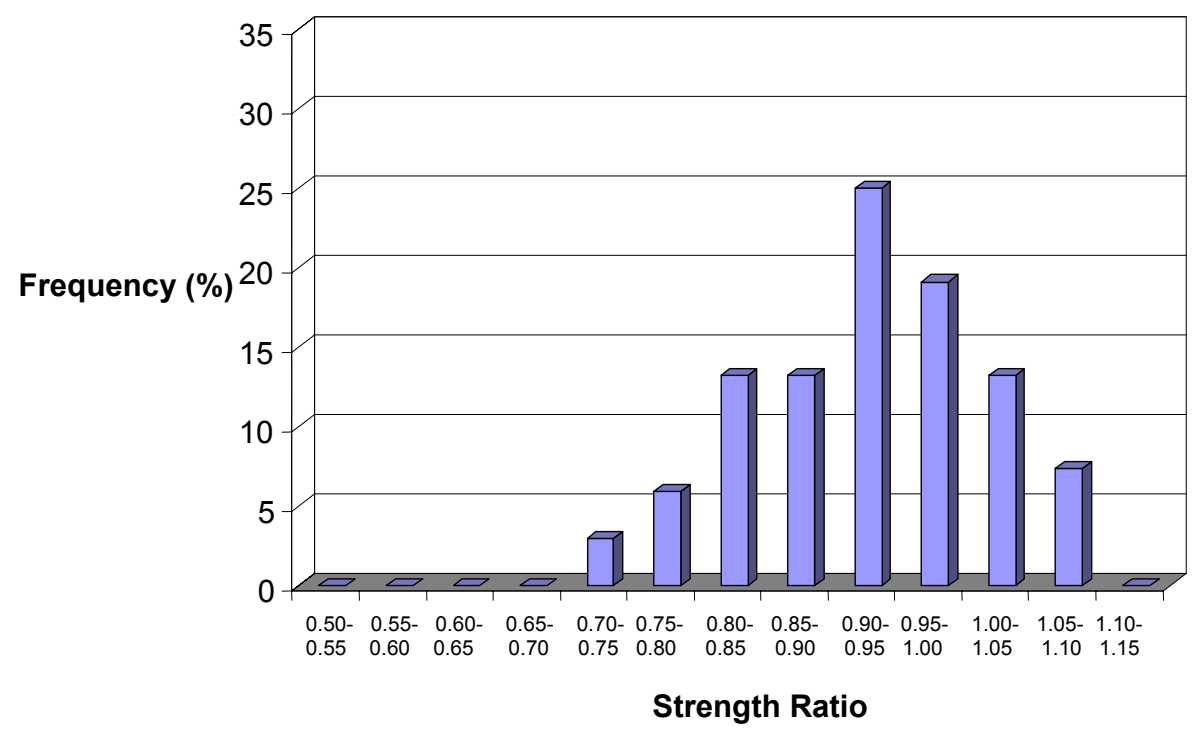

(b) Strength I limit state

Strength ratio $=$ predicted strength/ experimental strength, 68 tests.

Figure 2.4 Histograms of the strength ratios, based on the effective plastic moment equations proposed by Barth et al. (2003). 


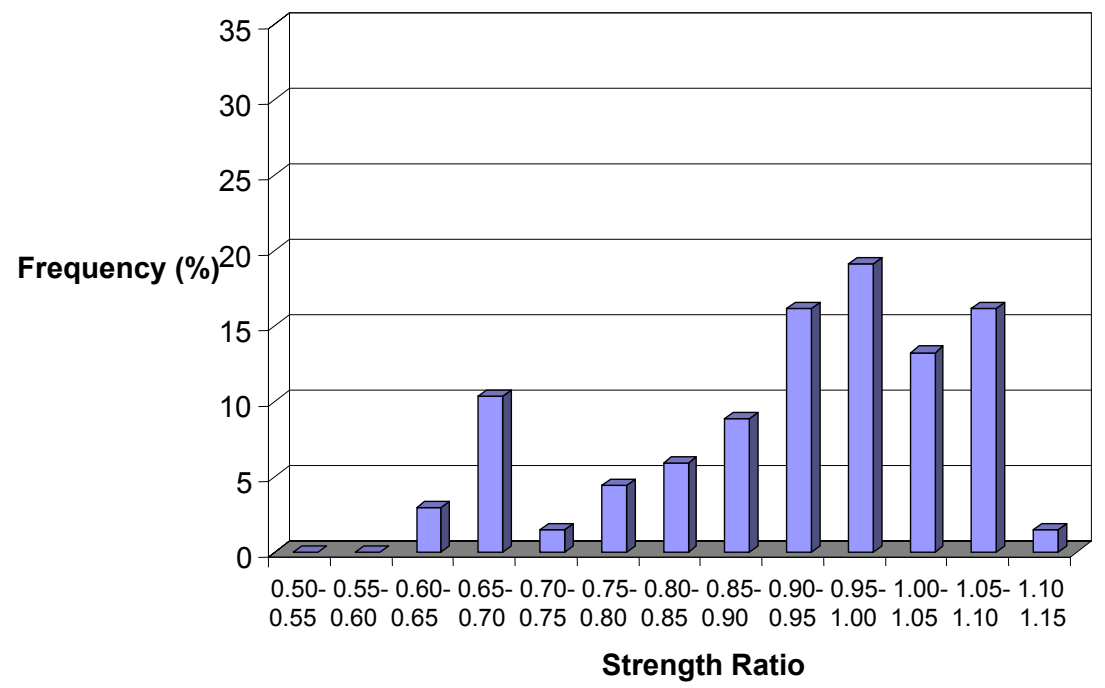

(a) Service II limit state

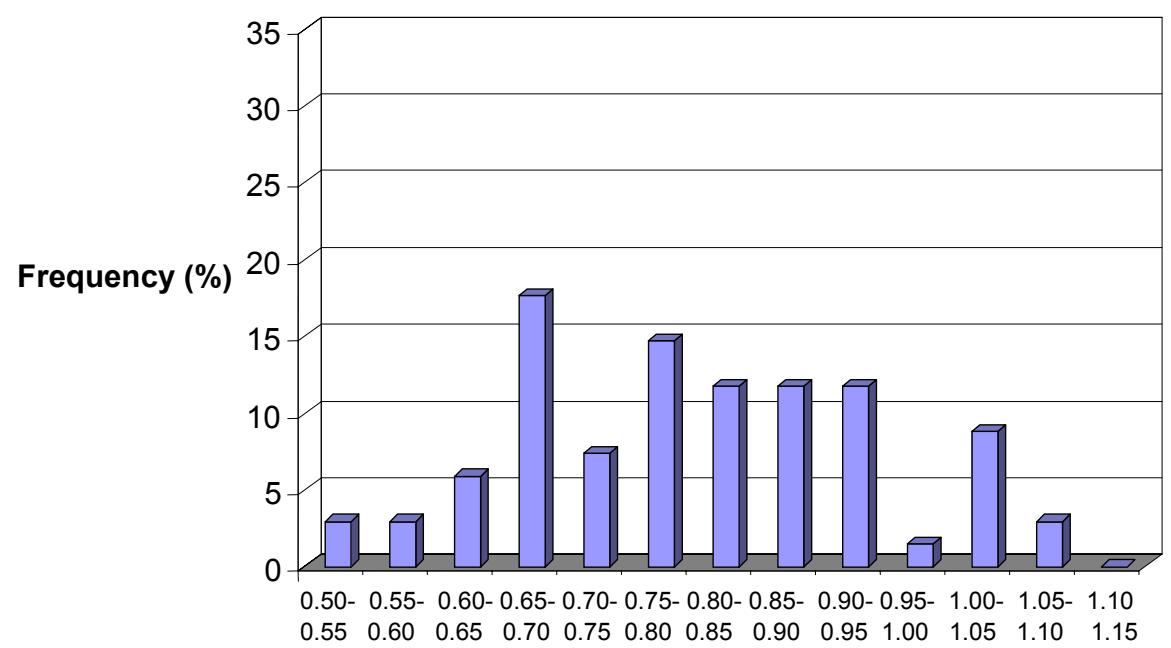

Strength Ratio

(b) Strength I limit state

Strength ratio= predicted strength/ experimental strength, 68 tests.

Figure 2.5 Histograms of the strength ratios, based on the effective plastic moment equations suggested by Schilling et al. (1997). 


\section{CHAPTER 3}

\section{NONLINEAR FINITE ELEMENT ANALYSIS TECHNIQUE}

This chapter will discuss the methods and procedures employed to conduct nonlinear finite element analysis (FEA) in this research. In summary, FEA was performed using commercially available FEA software ABAQUS (2002). Initially, FEMAP software (versions 8. 0 and 8. 1) was used to create the geometry (nodes and elements) for each girder being analyzed. FEMAP is then capable of writing this information in the form of an ABAQUS input file, which, in addition to the node and element attributes, is modified by the user to include material, load and analysis information. The nodal coordinates in the input file are then modified to account for initial geometric imperfections using a FORTRAN program specially developed in this study. The new input file and a user-defined subroutine specifying residual stresses are analyzed by ABAQUS using the modified Riks method. Thorough details of these procedures are presented herein. Throughout this chapter reference is made to specific commands which are given by the notation * command in ABAQUS (2002).

\subsection{Shell Elements}

ABAQUS/STANDARD (2002) provides complete geometric modeling capability, providing the user with a large number of available element types. Therefore, it is necessary to investigate the suitability of a given element type for the problem 
studied. As shown by several researchers (White et. al., 1993; Huang, 1994; Barth, 1996; Earls and Shah, 2000), a shell finite element approach is both sufficient and necessary for modeling the physical behavior of the I-shaped plate girders analyzed in this study. This section will describe the characteristics of three types of shell elements considered, namely S4, S4R, and S4R5, while a verification study aimed at determining the most appropriate element type for this work will be presented in Chapter 4. Of key importance to the accurate modeling of a structure is an appropriately selected mesh density which will also be examined in the verification study presented in Chapter 4.

\subsubsection{Element Naming Convention}

The element naming convention used in ABAQUS (2002) conveys several important attributes of the element. The first letter of the element name refers to the general element type, with "S" representing a shell element. This is followed by a number indicating the number of nodes in the element. This number may be followed by

the letter " $R$ ", which indicates that reduced integration is used. Lastly, a "5" at the end of an element name indicates that the element only contains five degrees of freedom (three translations and two in-surface rotations), otherwise all six degrees of freedom are considered.

\subsubsection{General-Purpose Shell Elements: S4 and S4R}

Elements S4 and S4R are 4-node general-purpose shell elements. These elements are intended to provide robust, accurate solutions for both thin and thick shells, using 
classical (Kirchhoff) shell theory when appropriate for relatively thin shells and thick (Mindlin) shell theory as the shell thickness increases. These elements allow for finite membrane strains and rotations of the shell. Therefore, they are suitable for large strain analysis involving inelastic deformation of materials with nonzero effective Poisson's ratio. These elements allow for change in shell thickness as a function of the membrane strain. Transverse shear deformation is also included. These elements are not subject to hourglass effects or transverse shear locking.

The only difference between the S4 and S4R elements is the number of integration points used in the analysis; "full" integration is used for S4 elements, while "reduced" integration is used for S4R elements. In full integration, a sufficient number of integration points is selected such that integration of the element stiffness matrices is exact, i. e., for second order elements, such as S4, each element has four integration points. However, reduced integration elements use one order less than that required for exact integration of the element stiffness matrix. Thus, S4R is a first order element and only one integration point is used to form the element stiffness matrix. The mass matrix and force matrix are still integrated exactly.

S4R elements offer many advantages over the fully integrated S4 elements. For example, in reduced integration of isoparametric elements, strains and stresses are computed at the locations known to provide optimal accuracy, thus reduced integration usually produces more accurate results provided the elements are not disturbed or loaded in in-plane bending. Furthermore, reduced integration typically softens the response of the elements, which also leads to increased accuracy by countering the overly stiff 
response generally encountered in FEA. The use of fewer integration points benefits the user by resulting in reduced CPU time and storage requirements; this is further illustrated in the verification study in Chapter 4 .

The primary disadvantage of using reduced integration is that deformation modes that cause no strain at the integration points may develop. This may lead to inaccurate results if these zero-energy modes propagate through the structures in a phenomenon commonly known as hourglassing. However, ABAQUS prevents hourglassing for S4R elements by introducing a small artificial stiffness associated with zero-energy deformation modes.

\subsubsection{Thin Shell Elements: S4R5}

S4R5 is three-dimensional shell elements whose behavior is governed by classical (Kirchoff) shell theory. Thus, this element is only appropriate for cases where transverse shear flexibility is negligible and the shell normal remains orthogonal to the shell reference surface, i. e., for relatively thin plates or shells. Because thin shell elements neglect transverse shear, S4R5 element has only five degrees of freedom (three displacement components and two in-surface rotation components) at each node. Consequently, use of this element to model thick shells may give inaccurate results. ABAQUS (2002) suggests that thin shell elements are appropriate when the shell thickness is less than approximately $1 / 15$ of the characteristic length (distance between supports) of the shell. 
As suggested by the names of the elements, S4R5 is a reduced integration element. S4R5 has 4 nodes and employs reduced integration.

\subsection{Material Modeling}

An elastic-plastic constitutive law including strain hardening effects is used in this work. From a numerical viewpoint, the implementation of a constitutive model involves the integration of the state of the material at an integration point over a time increment. Therefore, ABAQUS utilizes the incremental plasticity form of the elastic-plastic model, in which the increment of plastic strain is related to the state of stress and the stress increment. Incremental models are formulated in terms of: a yield surface, a flow rule, and a hardening rule. Of many material modeling options available in ABAQUS, an elastic-plastic constitutive model with standard von Mises yield surface, associate plastic flow rule and isotropic work hardening, has been found to be suitable to represent rateindependent behavior of metal materials subjected to a relatively monotonic loading, where creep effects are not important. The basic concepts of this elastic-plastic material model are briefly explained below while the numerical values used in the constitutive model are discussed in Chapter 4.

\subsubsection{Von Mises Yield Criteria}

The yield criteria defines the elastic limit of a material under combined states of stress. In general, the elastic limit, or yield stress, is a function of the state of stress, $\sigma_{\mathrm{ij}}$, and one or more material constants, which can be expressed as 


$$
f\left(\sigma_{\mathrm{ij}}, \mathrm{k}_{1}, \mathrm{k}_{2}, \ldots\right)=0
$$

where $\mathrm{k}_{1}, \mathrm{k}_{2}, \ldots$ are material constants determined experimentally.

Dating from 1913, the von Mises yield criteria is one of the most commonly used yield criteria for metal materials. It is a pressure-independent yield criteria and states that yielding begins when the strain energy of distortion reaches a critical value, $\mathrm{k}$,

$$
f\left(\mathrm{~J}_{2}\right)=\mathrm{J}_{2}-\mathrm{k}=0
$$

where $\mathrm{J}_{2}=\frac{1}{2} \mathrm{~S}_{\mathrm{ij}} \mathrm{S}_{\mathrm{ij}}$ is the second invariant of the deviatoric stress tensor, $\mathrm{s}_{\mathrm{ij}}$, and $\mathrm{k}=\frac{\sigma_{0}}{\sqrt{3}}$, in which $\sigma_{0}$ is the uniaxial yield stress of the material. If $f\left(\mathrm{~J}_{2}\right)<0$, the material behaves elastically; however, if $f\left(\mathrm{~J}_{2}\right)=0$, yielding occurs. Von Mises criteria represents a circular cylinder in principle stress space, as shown in Fig. 3.1 (a).

\subsubsection{Associated Flow Rule}

The flow rule defines both the direction and the relative magnitudes of the plastic strain increment vector $\mathrm{d} \varepsilon_{\mathrm{ij}}^{\mathrm{p}}$ once the elastic limit has been exceeded. In 1928, von Mises proposed the concept of the plastic potential function, $g\left(\sigma_{\mathrm{ij}}\right)$, which is a scalar function of the stresses. Then the plastic flow equations can be written in the form of

$$
\mathrm{d} \varepsilon_{\mathrm{ij}}^{\mathrm{p}}=\mathrm{d} \lambda \frac{\partial g}{\partial \sigma_{\mathrm{ij}}}
$$

where $d \lambda$ is a positive scalar factor of proportionality, which is nonzero only when plastic deformations occurs. 
The simplest flow rule is termed as associated flow rule, which means that the yield function and the plastic potential function coincide, i.e. $f=g$. Thus,

$$
\mathrm{d} \varepsilon_{\mathrm{ij}}^{\mathrm{p}}=\mathrm{d} \lambda \frac{\partial f}{\partial \sigma_{\mathrm{ij}}}
$$

This implies that the plastic flow develops normal to the yield surface $\frac{\partial f}{\partial \sigma_{\mathrm{ij}}}$. For the von Mises criteria, the associated flow rule has the simple form,

$$
\mathrm{d} \varepsilon_{\mathrm{ij}}^{\mathrm{p}}=\mathrm{d} \lambda \frac{\partial f}{\partial \sigma_{\mathrm{ij}}}=\mathrm{d} \lambda s_{\mathrm{ij}}
$$

\subsubsection{Isotropic Hardening}

The hardening rule specifies the manner in which the initial yield surface changes during the process of plastic flow. Three primary used flow rules are those of isotropic hardening, kinematic hardening, and mixed hardening (which is a combination of isotropic and kinematic hardening). Isotropic hardening is the simplest hardening rule and is based on the assumption that the initial yield surface expands uniformly without distortion or translation as plastic flow occurs. This hardening rule generally gives realistic results except for cases where complex loading paths with stress reversals are considered.

For isotropic hardening, the size of the yield surface is governed by the value of $\mathrm{k}^{2}$, which is expressed as a function of effective strain, $\varepsilon^{\mathrm{p}}$, where the value of $\varepsilon^{\mathrm{p}}$ depends on the loading history. The equation for the subsequent yield surface can be written in the general form, 


$$
F\left(\sigma_{\mathrm{ij}}\right)=\mathrm{k}^{2}\left(\varepsilon^{\mathrm{p}}\right)
$$

For the von Mises yield function, $F\left(\sigma_{\mathrm{ij}}\right)=\mathrm{J}_{2}$, Eq. 3.6 becomes

$$
\mathrm{J}_{2}=\frac{1}{2} \mathrm{~S}_{\mathrm{ij}} \mathrm{S}_{\mathrm{ij}}=\mathrm{k}^{2}\left(\varepsilon^{\mathrm{p}}\right)
$$

Von Mises criteria with associated plastic flow rule and isotropic work hardening is illustrated in deviatoric space in Fig. 3.1 (b).

Figure 3.2 shows an idealized multi-line stress-strain curve used in this study (The values shown in Fig. 3.2 are those values employed for $F_{y}=50 \mathrm{ksi}$ ). It should be noted that this curve represents the engineering stress-strain relationship. To perform a nonlinear material model in ABAQUS (2002), one must use the true stress. Therefore, ABAQUS makes use of the following equations to transform engineering stress into "true" stress (Caucy stress) and logarithmic strain, where the plasticity of the model is defined by von Mises yield criteria with associated flow rule and isotropic hardening rule in this study as discussed above.

$$
\begin{aligned}
& \sigma_{\text {true }}=\sigma_{\text {nom }}\left(1+\varepsilon_{\text {nom }}\right) \\
& \varepsilon_{\text {ln }}^{\mathrm{pl}}=\ln \left(1+\varepsilon_{\text {nom }}\right)-\frac{\sigma_{\text {true }}}{E}
\end{aligned}
$$

\subsection{Geometric Imperfections}

The nonlinearity in response due to the presence of initial imperfections of the girder has a measurable impact on girder ductility, especially on the maximum moment capacity and unloading shape of moment-plastic rotation curves. Furthermore, from the 
numerical analysis point of view, the modified Riks analysis method used in this work is a type of post-buckling analysis. Thus, we must have a continuous response, as opposed to bifurcation. This can be accomplished by introducing a geometric imperfection pattern in the "perfect" geometry so that some degree of buckling occurs before the critical load is reached, as would occur in actual girders. Therefore, introduction of geometric imperfections is a critical step in this type of analysis, and consequently, the application of geometric imperfections is carefully studied in this work.

In welded plate girders, initial geometric imperfections are generally generated during the fabrication and welding process and/or due to initial out-of-flatness of the steel plates. Three types of geometric imperfections are considered in this work in order to capture these characteristics: an out-of-flatness of the web, a tilt of the compression flange, and a lateral sweep of the compression flange. These imperfections are illustrated in Fig. 3.3.

Several approaches may be used to implement these imperfections, all of which involve various methods of altering the initial coordinates of each node. One commonly employed approach is to define imperfections as a linear superposition of buckling eigenmodes from a previous buckling analysis. This approach can be accomplished by first running a buckling analysis to establish probable lower energy collapse buckling modes; then specifying the output file of the buckling analysis, one or more buckling modes multiplied by the scale factor corresponding to each mode are introduced as initial imperfection by the way of *imperfection command in Riks analysis. A similar 
approach may be based on the solution obtained from a previous * static analysis.

Alternatively, geometric imperfections can be directly specified in the input file.

In the initial stages of this research, the buckling analysis method was used to apply initial geometric imperfections. However, for the reasons discussed below, this approach was later abandoned in favor of directly specifying imperfections in the input file by using a FORTRAN program. Both of these methods are discussed in detail below, along with a presentation of the target values for the three types of geometric imperfections considered.

\subsubsection{Definition and Specification of Imperfections}

As mentioned above, three types of imperfections are considered in this work. These are based on maximum allowable tolerances specified by the American Welding Society (AWS, 1995) and engineering judgment. These imperfection values indicated below are the exact values applied when directly specifying the imperfections in the input file and the targeted values of imperfections desired when using the buckling analysis approach.

AWS specifies alternative tolerances for the initial out-of-flatness of the web, depending on whether the girders are stiffened. For girders with one-sided transverse stiffeners, the maximum allowable value of $\delta_{\text {ow }}$ (see Fig. 3.3 (a)) is $d / 67$, where $d$ is the minimum panel dimension, either the web depth (D) or distance between stiffeners $\left(d_{o}\right)$. Alternatively, the maximum allowable value is $\mathrm{D} / 150$ for unstiffened girders. In this study, $\delta_{\text {ow }}$ is prescribed to be equal to $d / 100$, which is chosen to represent a midpoint 
between the above two requirements. This maximum value of distortion occurs at the center of each web panel and the amount of out-of-flatness at all other locations in the web panel decreases in a half sine wave pattern, in both the X-and Y-directions (see Fig. 3.3 (a)). Furthermore, the direction of $\delta_{\text {ow }}$ alternates in adjacent web panels.

The maximum allowable tilt of the compression flanges, $\delta_{\text {of }}$, specified by AWS is equal to $b_{f} / 100$ or $1 / 4$ in., whichever is greater. However, it is felt that it is unlikely that the distortion of the flanges would be this severe in girders with relatively short panel lengths. Therefore, $\delta_{\text {of }}$ is assigned to be the lesser value of $b_{f d} / 150$ or $0.3 d_{o} / 150=d_{o} / 500$. This results in values slightly less than that permitted by AWS for girders with long panel lengths (i.e., $b_{\mathrm{fc}}<0.3 \mathrm{~d}_{0}$ ), while for short panels, $\delta_{\text {of }}$ may be significantly less than AWS tolerances. The tilt of the compression flange is defined using a sine function with the peak amplitude, $\delta_{\text {of }}$, being specified at the horizontal center of each web panel along the flange edge and the direction alternating in adjacent panels (See Fig. 3.3 (b)).

AWS limits the variation in straightness of welded girders to $1 / 960^{\text {th }}$ of the girder length. In this work, a lateral sweep of the compression flange $\left(\delta_{\mathrm{oL}}\right)$ is specified to be somewhat less than this limit, with a maximum value equal to $\mathrm{L}_{b} / 1500$, where $\mathrm{L}_{b}$ is the distance between lateral brace points. This value is prescribed at the horizontal center of the lateral bracing segment at the web-compression flange junction. The value of $\delta_{\mathrm{oL}}$ varies in a sine wave pattern along the Z-direction of the girders and varies linearly in the Y-direction (see Fig. 3.3 (c)). As with the other imperfections, the direction of $\delta_{o L}$ 
alternates in adjacent lateral bracing segments. Furthermore, in this analysis, $\delta_{\mathrm{oL}}$ and $\delta_{\mathrm{ow}}$ within each web panel are cumulative.

\subsubsection{Specification of Geometric Imperfections through Buckling Analysis}

Although the buckling analysis approach is widely used in the nonlinear analysis of plate girders, the resulting buckling mode shapes are generally too localized to represent the initial shape of the girders at a global level and as such, do not represent proper initial geometry. Furthermore, the predominant buckling eigenmodes resulting from a buckling analysis included in this study are associated with buckling of girders with relatively slender webs. In order to obtain a more suitable buckled shape, it was deemed necessary to increase the web thickness used in the buckling analysis (usually twice the thickness of the actual girders), which usually gave a reasonable global deformed shape. At the beginning of this work, this approach was adopted and initially worked well for the girders with relatively short lateral bracing distances. However, when girders with larger lateral bracing distances were later studied, it was difficult to obtain buckling modes giving a desired geometric imperfection patterns (i.e., those imperfections as specified in Section 3.3.1).

Other disadvantages of this method also become evident. First, it is not possible to control the values of the three different types of imperfections simultaneously, even if several different buckling modes are superimposed. For instance, high values are normally obtained for out-of-flatness of the web, but the desired values for the tilt of the compression flange can not be obtained at the same time. Furthermore, it is not possible 
to separate these three types of imperfections to study their effects on the momentrotation capacity of the girders independently. Secondly, it is not possible to have a uniform degree of imperfections along the length of the girder as would be encountered in actual girder; with the buckling analysis, generally, imperfections were found to be most severe near mid-span of the girders and minimal near the supports. Additionally, this method is time consuming due to the need to first run a buckling analysis and then carry out the separate nonlinear analysis.

Because the objective of performing the buckling analysis is to simply modify the nodal coordinates, the same outcome can also be achieved through the use of a FORTRAN program developed to fulfill the same function. This FORTRAN program eliminates the shortcomings of the buckling analysis approach described above and is described in detail in the following section.

\subsubsection{FORTRAN Imperfection Program Procedures}

The purpose of the program is to apply initial geometric imperfections to the girders by changing the initial global coordinates of each node to give the desired imperfections outlined in Section 3.3.1. The program is compiled using the FORTRAN2000 language and functions by reading the data from the input file generated by FEMAP and processing user input to create a new input file with modified nodal coordinates. The basic structure of the program is presented as follows.

1. Because different parts of the girders (webs, flanges, etc.) have different imperfection modes, it must first be determined whether a given node is a web node, a compression 
flange node, or neither. The program accomplishes this by first reading the coordinates of the "reference node", which is defined as the node at the junction of the web and bottom flange at one end of the girders. A given node is then determined to be on the web if the X-coordinate of the node is the same as the reference node. The user also specifies the web depth and if the top or bottom flange is in compression in order to identify the compression flange nodes.

2. The distance between stiffeners is given by the user and then the out-of-flatness of the web is introduced to all nodes previously identified as web nodes according to the value of $\delta_{\text {ow }}$ provided by the user. Furthermore, the user may specify different values of $\delta_{\text {ow }}$ to be used within each panel if warranted.

3. If a node is on the compression flange, the tilt of the compression flange is added based on user input for the flange width and $\delta_{\text {of. }}$ Again, the user may specify the same value of $\delta_{\text {of }}$ for every panel or, vary the values each panel in any manner desired.

4. After finishing the previous procedures, the lateral sweep of the compression flange is superimposed within each lateral bracing segment, resulting in additional modification of the coordinates of all web and the compression flange nodes. These imperfections are based on user input regarding the number of lateral bracing segments, the length of each segment, and the value of $\delta_{\mathrm{oL}}$ for each segment.

5. Lastly, the node coordinates that have been changed together with all other unchanged parts of the original ABAQUS input file are saved as a new ABAQUS input file. A text file is also generated for the user's convenience that provides information on the applied imperfection modes as a convenient check of user input. 
The procedure descried above is illustrated in the program flow chart in Fig. 3.3.

\subsection{Modeling of Residual Stresses}

The longitudinal residual stresses in welded I-shaped girders are primarily caused by flame cutting of the plates and longitudinal welding between the flanges and the webs. Typically, the tensile residual stresses are essentially equal to the yield stress of the material within a small area, termed the heat affected zones, while a smaller, nearconstant self-equilibrating compression stress is developed within the other regions of the plates. The residual stress distribution may be idealized by assuming that when the section is free of external forces, the resultant forces due to the sum of the residual stresses over the entire cross-section must be zero (i.e., the residual stresses must be selfequilibrating.).

In this study, residual stresses effects are represented by specifying initial stress conditions at the beginning of the analysis through a user-defined subroutine, which automatically applies a prescribed magnitude of initial (residual) stress to each element depending on the elements location in the girders. When initial stresses are given, the initial stress state may not be in exact equilibrium for the finite element matrix.

Therefore, an initial step is included to allow ABAQUS to check for equilibrium and iterate, if necessary to achieve equilibrium. Specifically, a *static step, where girder dead load is also applied, is implemented before the Riks analysis to insure that equilibrium is satisfied once residual stresses have been included.

The residual stress patterns that are used in this study will be given in Chapter 4 . 


\subsection{Modified Riks Algorithm}

The girders studied in this work are analyzed using the modified Riks algorithm available in ABAQUS (2002). Because it was of key importance to obtain information on girder behavior once maximum loads had been exceeded for this research, it was necessary to employ a solution method capable of capturing this response. The modified Riks method was selected for use because it has been shown to be one of the most versatile and efficient of such methods (Huang, 1994), capable of obtaining a complete nonlinear solution and giving information on girder behavior in both the loading and unloading regions.

The modified Riks method was initially introduced by Riks (1979), and later improved by several researchers (Crisfield, 1981, 1983; Ramm, 1981; Powell and Simons, 1981). In addition to the ability to pass beyond the limit point and trace the unloading portion of the nonlinear equilibrium path, the modified Riks method also allows solutions to be achieved regardless of whether the response is stable or unstable. This method also provides efficient usage of computational resources during the nonlinear solution process. In short, the modified Riks method may be considered as a combination of the displacement control procedure, the arc-length method, and Newton iteration techniques.

One basic assumption used in the modified Riks method is that the loading is proportional, i.e., all load magnitudes vary with a single scalar parameter. Furthermore, the load magnitude is used as an additional unknown during the solution. Because the progress of the solution is independent of the load increment, ABAQUS uses the "arc 
length", which is the distance along the static equilibrium path in load-displacement space, to control the increment size. This value is initially provided by the user and is later adjusted by ABAQUS automatic load increment algorithm based on the convergence rate. The essence of the method is then to find the solution of a single equilibrium path in a space that is defined by the nodal variables and the loading parameter. The solution during each increment is found by moving a given distance along the tangent line to the current solution point and then searching for equilibrium in the plane that not only passes through the point thus obtained, but also is orthogonal to the same tangent line. Once this plane is determined, Newton's method remains the basic algorithm to solve the equilibrium equations. Additionally, it is assumed that the response is reasonably smooth, i.e., sudden bifurcations do not occur.

The algorithm of modified Riks method is shown in Fig. 3.4 and is briefly described as follows:

The initial arc length increment along the static equilibrium path, $\Delta \mathrm{l}_{\text {in }}$, is given in the input file of ABAQUS (2002). The initial load proportional factor increment, $\Delta \lambda_{i n}$, is computed as

$$
\Delta \lambda_{\text {in }}=\frac{\Delta 1_{\text {in }}}{1_{\text {period }}}
$$

where $1_{\text {period }}$ is the total arc length scale factor that is also given in the ABAQUS input file. This value of $\Delta \lambda_{\text {in }}$ is only used during the first iteration of the initial increment. For subsequent iterations and increments the value of $\Delta \lambda_{i}$ is computed as described below. 
Suppose the solution has already been obtained at point $A_{i}\left(u_{i}^{0}, \lambda_{i}^{0}\right)$. Next the equilibrium state of the structure at the $(i+1)^{\text {th }}$ load increment is sought as shown in Fig. 3.4. First, the arc length is used to determine $\Delta \mathrm{l}_{\mathrm{i}}$, the distance traveled along a line tangent to the current solution point. As discussed above, Newton's method is then used to obtain a solution on the plane orthogonal to $\overrightarrow{\mathrm{A}_{\mathrm{i}} \mathrm{A}_{\mathrm{k}}}$. The incremental equilibrium equation after the $j^{\text {th }}$ iteration may be expressed as a linear system of equations:

$$
\mathrm{K}_{\mathrm{i}}^{\mathrm{j}} \Delta \mathrm{u}_{\mathrm{i}}^{\mathrm{j}}=\Delta \mathrm{F}_{\mathrm{i}}^{\mathrm{j}}
$$

where $\mathrm{K}_{\mathrm{i}}^{\mathrm{j}}$ is the tangent stiffness matrix for the load increment $i$ at the end of the $j^{\text {th }}$ iteration; $\Delta \mathrm{u}_{\mathrm{i}}^{\mathrm{j}}$ is the incremental displacement vector; and $\Delta \mathrm{F}_{\mathrm{i}}^{\mathrm{j}}$ is a load vector which may be described as

$$
\Delta \mathrm{F}_{\mathrm{i}}^{\mathrm{j}}=\Delta \mathrm{P}_{\mathrm{i}}^{\mathrm{j}}+\mathrm{R}_{\mathrm{i}}^{\mathrm{j}}
$$

in which $\Delta \mathrm{P}_{\mathrm{i}}^{\mathrm{j}}$ is the load increment at the $j^{\text {th }}$ iteration of load increment $i$ which can be expressed as a fraction of the total applied load P as:

$$
\Delta \mathrm{P}_{\mathrm{i}}^{\mathrm{j}}=\Delta \lambda_{\mathrm{i}}^{\mathrm{j}} \mathrm{P}
$$

where $\Delta \lambda_{i}^{j}$ is the increment of the load magnitude parameter. $R_{i}^{j}$ is the out-of-balance force vector which equals the difference between the external and internal forces at the beginning of iteration $j$, i.e.

$$
R_{i}^{j}=P_{i}^{j}-Q_{i}^{j}
$$

where $Q_{i}^{j}$ is the internal force vector. $R_{i}^{j}$ is then used to check equilibrium within the prescribed equilibrium tolerances. If the equilibrium tolerances are satisfied, then the solution is assumed to have converged. Otherwise additional iterations are performed 
until the out-of-balance force vector (as computed using Eqs. 3.11 through 3.14) is within the prescribed tolerances.

The incremental load magnitude parameter can be obtained by first substituting Eqs. 3.12 and 3.13 into the equilibrium equation, Eq. 3.11, giving

$$
\mathrm{K}_{\mathrm{i}}^{\mathrm{j}} \Delta \mathrm{u}_{\mathrm{i}}^{\mathrm{j}}=\Delta \lambda_{\mathrm{i}}^{\mathrm{j}} \mathrm{P}+\mathrm{R}_{\mathrm{i}}^{\mathrm{j}}
$$

Furthermore, two displacement vectors, $\Delta \mathrm{u}_{\mathrm{i}}^{\mathrm{aj}}$ and $\Delta \mathrm{u}_{\mathrm{i}}^{\mathrm{bj}}$, may be defined corresponding to the two load vectors $\mathrm{P}$ and $\mathrm{R}_{\mathrm{i}}^{\mathrm{j}}$,

$$
\begin{aligned}
& \mathrm{K}_{\mathrm{i}}^{\mathrm{j}} \Delta \mathrm{u}_{\mathrm{i}}^{\mathrm{aj}}=\mathrm{P} \\
& \mathrm{K}_{\mathrm{i}}^{\mathrm{j}} \Delta \mathrm{u}_{\mathrm{i}}^{\mathrm{bj}}=\mathrm{R}_{\mathrm{i}}^{\mathrm{j}}
\end{aligned}
$$

Substituting $\Delta \mathrm{u}_{\mathrm{i}}^{\text {aj }}$ and $\Delta \mathrm{u}_{\mathrm{i}}^{\text {bj }}$ into Eq. 3.15, we have

$$
\Delta u_{i}^{j}=\Delta \lambda_{i}^{j} \Delta u_{i}^{\text {aj }}+\Delta u_{i}^{b j}
$$

For the first iteration $(j=1)$ at $i^{\text {th }}$ increment, the structure is in an equilibrium state at the beginning of the increment. Thus, the out-of-balance force vanishes at this stage, and consequently

$$
\Delta \mathrm{u}_{\mathrm{i}}^{\mathrm{b} 0}=0
$$

Substituting it into Eq. 3.18 gives

$$
\Delta \mathrm{u}_{\mathrm{i}}^{0}=\Delta \lambda_{\mathrm{i}}^{0} \Delta \mathrm{u}_{\mathrm{i}}^{\mathrm{a} 0}
$$

Also, from Fig. 3.4, it is shown that

$$
\Delta \mathrm{l}_{\mathrm{i}}^{2}=\left(\Delta \lambda_{\mathrm{i}}^{0}\right)^{2}+\left\{\Delta \mathrm{u}_{\mathrm{i}}^{0}\right\}^{\mathrm{T}}\left\{\Delta \mathrm{u}_{\mathrm{i}}^{0}\right\}
$$

The incremental load parameter for the first iteration can thus be obtained by substituting Eq. 3.19 into Eq. 3.20, 


$$
\Delta \lambda_{\mathrm{i}}^{0}=\frac{ \pm \Delta \mathrm{l}_{\mathrm{i}}}{\sqrt{\left\{\Delta \mathrm{u}_{\mathrm{i}}^{\mathrm{a} 0}\right\}^{\mathrm{T}}\left\{\Delta \mathrm{u}_{\mathrm{i}}^{\mathrm{a} 0}\right\}+1}}
$$

Because the vector $\overrightarrow{A_{k} A_{i+1}}$ must be orthogonal to $\overrightarrow{A_{i} A_{k}}$, the dot product of these two vectors must equal zero, or symbolically,

$$
\Delta \lambda_{i}^{0} \Delta \lambda_{i}^{\mathrm{j}}+\left\{\Delta u_{i}^{0}\right\}^{T}\left\{\Delta u_{i}^{\mathrm{j}}\right\}=0
$$

Substituting Eq. 3.18 for $\Delta \mathrm{u}_{\mathrm{i}}^{\mathrm{j}}$ and Eq. 3.19 for $\Delta \mathrm{u}_{\mathrm{i}}^{0}$ into Eq. 3.22 gives the incremental load parameter for subsequent iterations to be

$$
\Delta \lambda_{i}^{\mathrm{j}}=\frac{-\left\{\Delta \mathrm{u}_{\mathrm{i}}^{\mathrm{a} 0}\right\}^{\mathrm{T}}\left\{\Delta \mathrm{u}_{\mathrm{i}}^{\mathrm{bj}}\right\}}{\left\{\Delta \mathrm{u}_{\mathrm{i}}^{\mathrm{a} 0}\right\}^{\mathrm{T}}\left\{\Delta \mathrm{u}_{\mathrm{i}}^{\mathrm{a}}\right\}+1}
$$

Finally, the solution point for load increment $i$ at $(j+1)^{\text {th }}$ iteration can be expressed as

$$
\begin{aligned}
& u_{i}^{j+1}=u_{i}^{0}+\sum_{i=1}^{j} \Delta u_{i}^{j} \\
& \lambda_{i}^{j+1}=\lambda_{i}^{0}+\sum_{i=1}^{j} \Delta \lambda_{i}^{j}
\end{aligned}
$$

Or, by multiplying by P, Eq. 3.25 may be written as

$$
\mathrm{P}_{\mathrm{i}}^{\mathrm{j}+1}=\mathrm{P}_{\mathrm{i}}^{0}+\sum_{\mathrm{i}=1}^{\mathrm{j}} \mathrm{P}_{\mathrm{i}}^{\mathrm{j}}
$$

The stiffness matrix is then updated and multiplied by the displacements obtained above Eq. 3.24 to find the forces at the current solution point. These forces are in turn used along with the loads obtained above Eq. 3.26 to calculate the out-of-balance force 
vector. This iteration algorithm is repeated until the equilibrium solution is considered to be converged for increment $i+1$, when all the entries in $\mathrm{R}_{\mathrm{i}}^{\mathrm{N}}$ are sufficiently small.

It is also noteworthy to point out that ABAQUS scales the above loaddisplacement solution space such that the dimensions are approximately the same magnitude on each axis. 


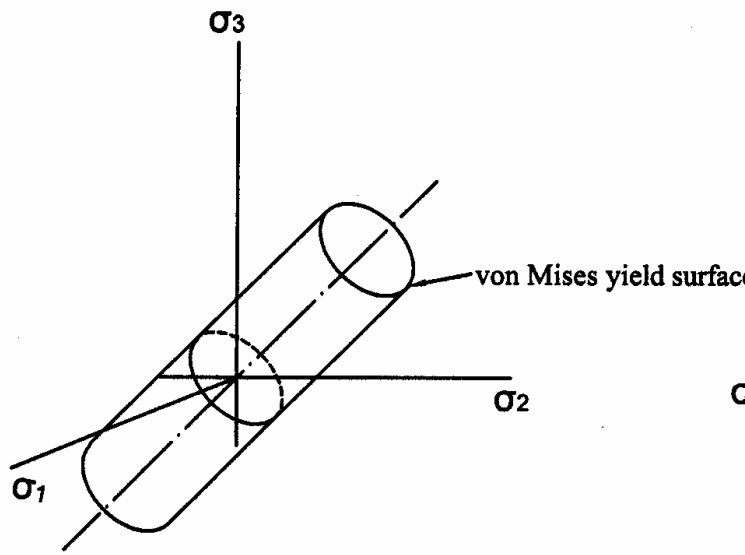

(a) Von Mises yield surface in principal stress space

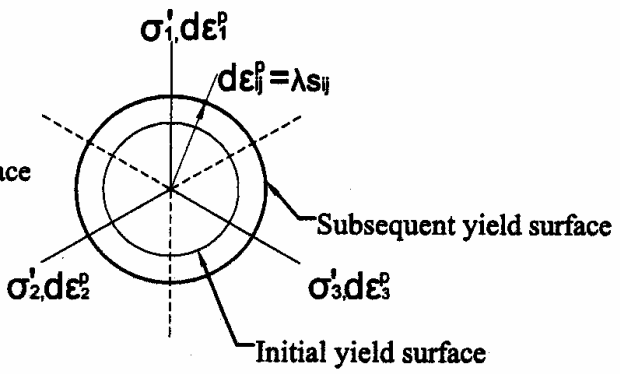

(b) Subsequent von Mises yield surface with isotropic hardening and associate flow rule in deviatoric space

Figure 3.1 Von Mises yield criteria 
Grade 50

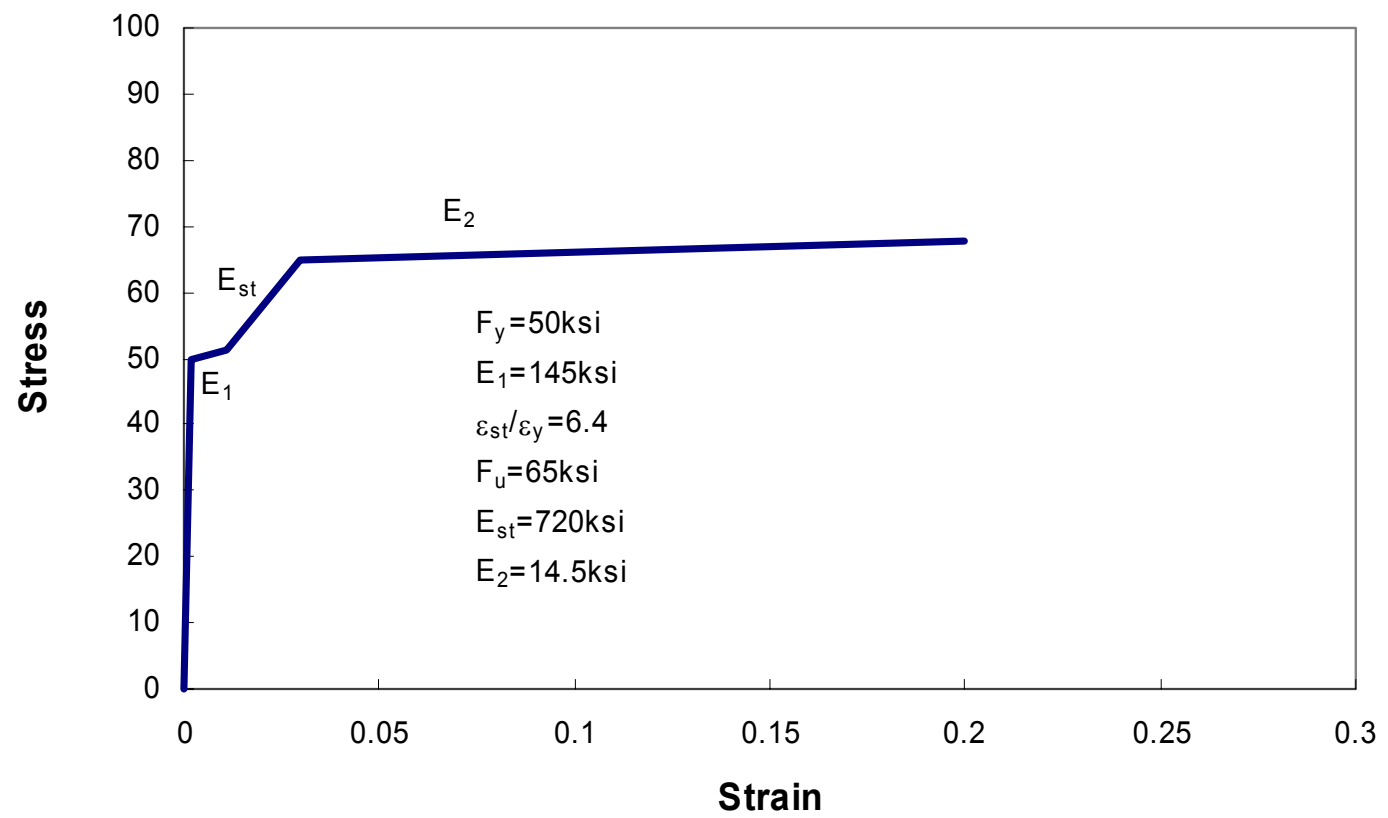

Figure 3.2 Idealized stress-train curve used in this study for $50 \mathrm{ksi}$ steel 

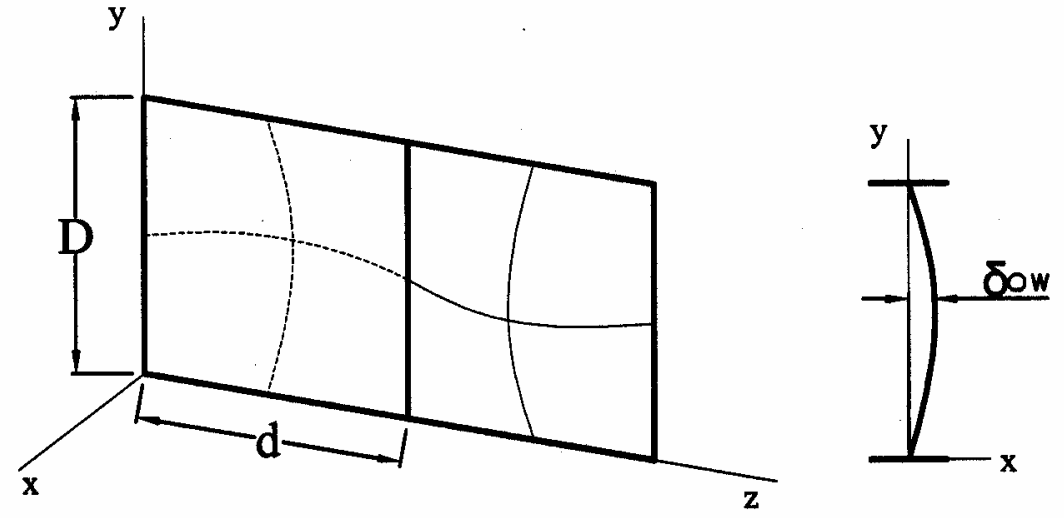

(a) Initial out-of-flatness of the web
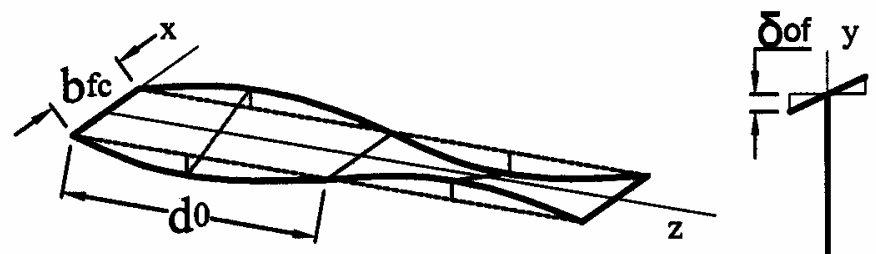

(b) Initial tilt of the compression flange

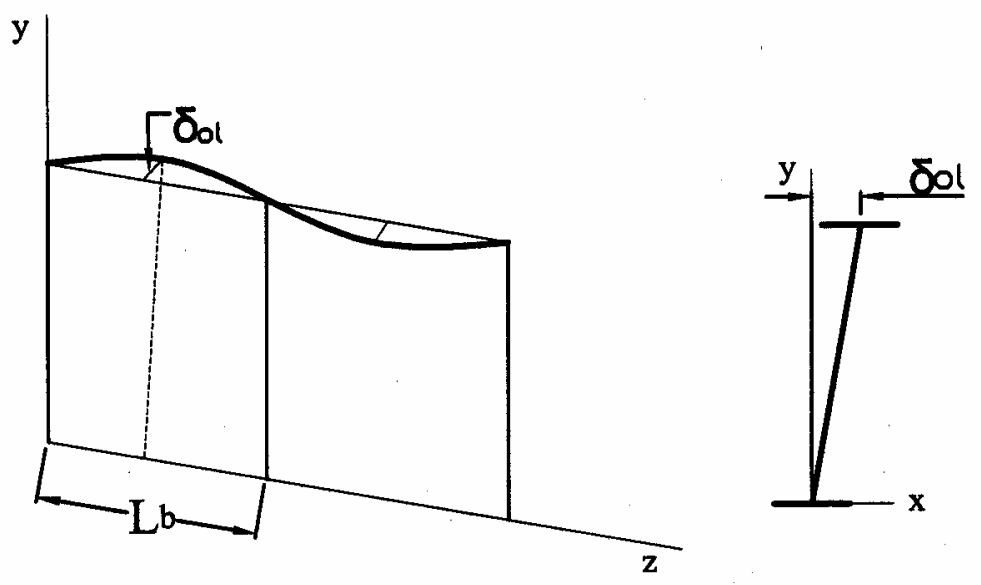

(c) Initial lateral sweep of the compression flange

Figure 3.3 Initial geometric imperfections 


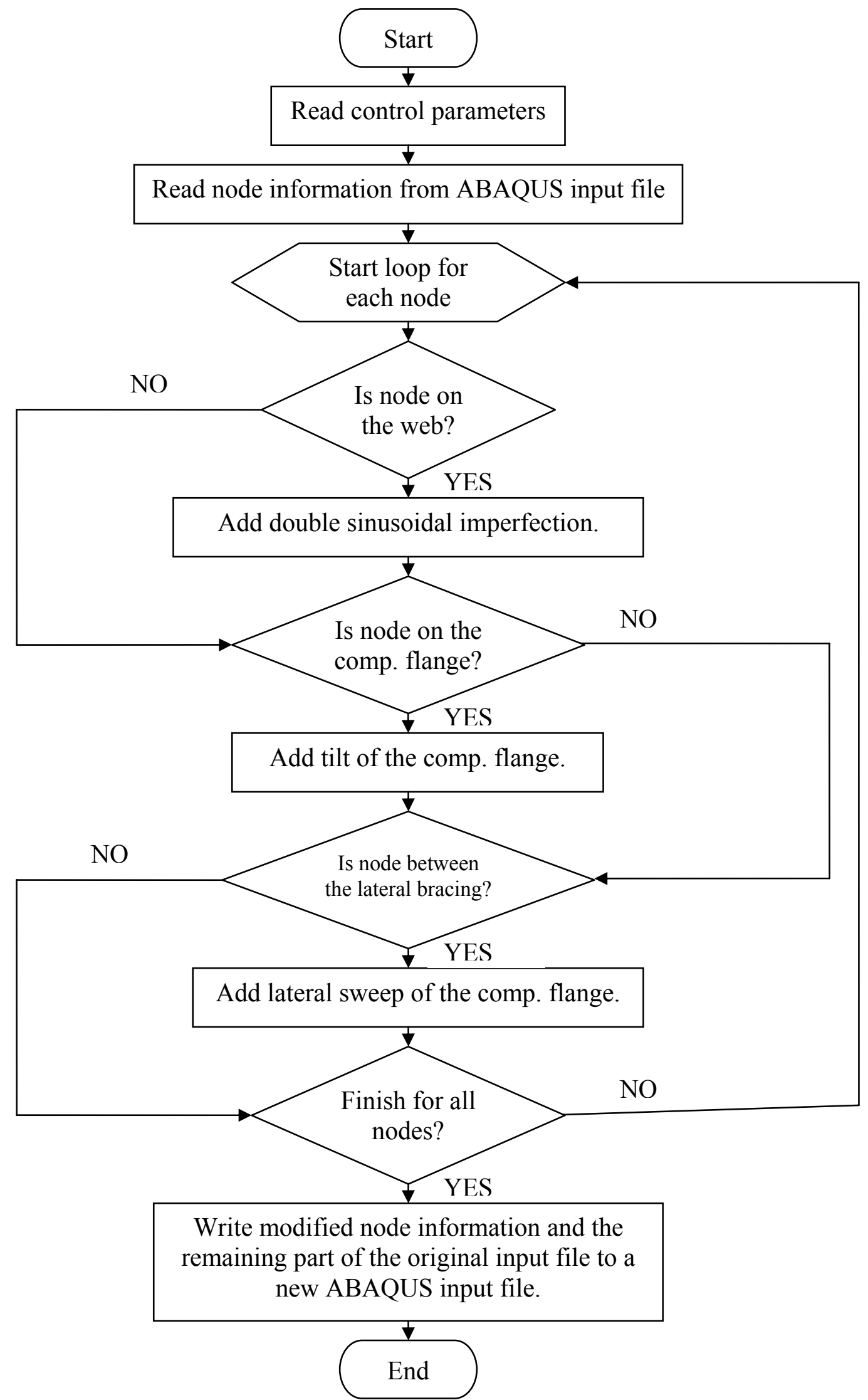

Figure 3.4 Flow chart for imperfection program 


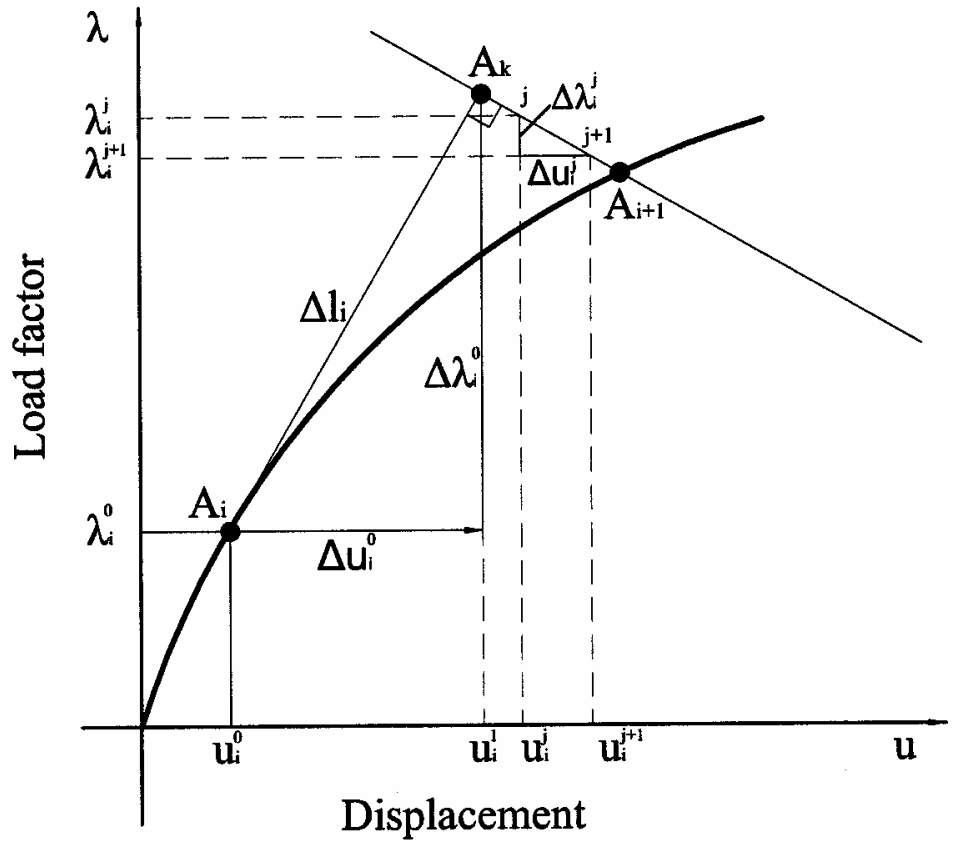

Figure 3.5 Modified Riks algorithm 


\section{CHAPTER 4}

\section{FINITE ELEMENT ANALYSIS VERIFICATION STUDY}

Numerical results are generally affected by the assumptions inherent in the formulation of the analytical technique. In particular, assumptions related to the types of stress-strain curve, initial imperfections, residual stresses, etc., could potentially influence the numerical results of moment-rotation relationship of steel I-shaped plate girders. Consequently, it is always a good practice to verify the results of numerical modeling techniques by some experimental data to ensure its reliability and accuracy. The focus of this chapter is on the correlation of finite element analysis (FEA) predictions with results from a representative experimental test, termed as "D" girder, which was conducted by Schilling and Morcos (Schilling and Morcos, 1988).

In this chapter, various modeling techniques are first investigated using the value of parameters in their report to verify the accuracy of nonlinear finite element methods for realistically modeling the flexural strength and ductility of steel I-shaped girders.

Secondly, a sensitivity study is carried out, where the modeling parameters are arbitrarily assumed, to investigate the effect of various parameters, including geometric imperfection values and patterns, and material configurations. At the end of this chapter, the validated results are discussed, and the FEA modeling techniques that will be used in the subsequent study are summarized. 


\subsection{Description of Test Specimen}

Three steel I-shaped plate girder specimens, labeled as "S" (Shallow), "M" (Medium) and "D" (Deep) were reported by Schilling and Morcos (Schilling and Morcos, 1988), which were designed to study the behavior of continuous-span bridge girders within the negative moment regions. Three-point bending tests were carried out with simply supported conditions at both ends and a concentrated load at mid-span, approximating the negative moment regions over the pier in continuous girder bridges, as discussed in Section 1.2.2.

All the three girders were fabricated using ASTM A572 Grade 50 steel. The girders were designed with ultra-compact flange and the web slenderness was varied from a value that was nearly compact for specimen " $\mathrm{S}$ " to a value that was at the upper limit for classification as non-compact for specimen "D". Specimen "M" had a web slenderness approximately mid-way between that of specimen "S" and "D". Specimen " $D$ " is chosen for the verification purpose in this study since the web slenderness value tends to be more representative of girders assessed in this study and at the upper limit of web slenderness limits for proposed design limits subsequently addressed in this work. The configurations of "D" girder are illustrated in Fig. 4.1, where bearing stiffeners were put both at the center and supports; close-spaced one-sided transverse stiffeners within the peak moment region were provided; and additional one-sided transverse stiffeners were given between the peak moment region and the end of the girder to avoid shear buckling. 


\subsection{Validation Study}

The general purpose finite element software, ABAQUS/STANDARD (versions 6.2-1 and 6.3-1), is employed in the research. Both geometric and material nonlinearity are considered in the finite element modeling. Incremental solution strategies are necessary to accurately trace the nonlinear equilibrium path in the inelastic analysis of Ishaped girders. Thus, the ABAQUS modified Riks solution strategy is used as discussed previously in Chapter 3. Different modeling parameters considered are as follows:

- Different types of 3-D shell elements

- Mesh density

- Geometric imperfections

- Girder material configurations

The element types and mesh density are considered firstly in the validation study for Schilling's " $\mathrm{D}$ " girder and then the last two modeling parameters are used in a sensitivity study to assess the effects of these parameters.

\subsubsection{Element Type}

Three different types of elements are considered: S4, S4R and S4R5. Detailed descriptions of these element types are presented in Section 3.1. The following modeling attributes are used:

- Mesh density is chosen as 10 elements across the width of the flanges and 20 elements along the depth of the webs. The element length to width ratio 
approximately equals 1.0 at the mid-span and increases to 1.5 towards the two ends where the plastic deflection becomes less significant.

- The imperfections are provided as reported in Table 4.1.

- Residual stress patterns used in this study are presented in Fig. 4.2.

- The constitutive model is shown in Fig. 4.3, where the yield stress and ultimate stress is proportioned from the tension test reported by Schilling and Morcos (1988). Other parameters are taken from previous research by Barth and White (1998). The engineering stress-strain curve is accordingly changed to true stress and logarithmic strain as calculated from Eqs. 3.8 and 3.9, as shown in Table 4.2.

Figure 4.4 illustrates the load-deflection relationship both from the test and FEA using three different element types, from which we can see that S4 and S4R yield almost the same result except that S4 element has a slightly stiffener elastic region due to the full integration technique adopted in the formation of this element. Furthermore, the S4 element was found to use almost twice the CPU time as the S4R element. The S4R5 element poorly captures the inelastic response. Therefore, from this group of elements, the S4R is deemed to be the most robust element and is employed in all subsequent modeling in this study.

In Fig. 4.5, the normalized moment $\mathrm{M} / \mathrm{M}_{\mathrm{p}}$ at the mid-span of the test specimen is plotted versus the plastic rotation $\theta_{\mathrm{p}}$ of Schilling's "D" girder at the load point. The plastic rotation is calculated by subtracting the elastic component of deflection due to both flexure and shear from the total deflection at the mid-span for each load level. The 
FEA results are shown by the solid curve and the experimental results are plotted as a dashed line with highlighted open boxes. The plastic rotation correlates well with the actual inelastic rotation. The different between the normalized maximum moment capacity predicted in FEA and that obtained in the experimental results is less than $1 \%$. The final failure mode involves a combined local instability of the web and compression flange in the short panel adjacent to mid-span, as shown in Fig. 4.6, and these analytical displacement patterns were quite similar to these obtained by Schilling and Morcos (1988) in the experimental testing.

\subsubsection{Mesh Density}

More refined models can better capture girder local and global response. However, the computing time required grows exponentially with mesh density. Therefore, a feasible mesh density should give a reasonably accurate result at an acceptable time cost. For this purpose, a mesh density study is carried out. Three mesh density models with $4 \times 6,6 \times 10$ and $10 \times 20$ elements across flange width and web depth respectively are compared; other modeling attributes are the same as described in Section 4.2.1 except that no residual stresses are considered in the models herein since residual stress patterns are varied with element width.

The load-deflection curves from both FEA and test results are plotted in Fig. 4.7, and the maximum moment and CPU time are listed in Table 4.3. It clearly demonstrates the sensitivity to mesh density used in the analysis. The coarse meshes of $4 \times 6$ and $6 \times 10$ apparently overestimate the strength of the girder, while the mesh of $10 \times 20$ can yield a 
result within $0.3 \%$ difference. Therefore, the mesh with $10 \times 20$ is deemed to a reasonable mesh density with an acceptable CPU time and hence will be used for subsequent studies.

\subsection{Sensitivity Study}

To evaluate the influence of initial geometric imperfections and girder material configurations on the strength and ductility of steel I-shaped girder, a sensitivity study is performed. Similarly, all these comparisons are made using Schilling's "D" girder geometry as the basic FEA model.

\subsubsection{Initial Geometric Imperfections}

Geometric imperfections can provide a perturbation of the perfect model geometry so as to initialize an unloading response for the post buckling analysis. To assess the importance of including geometric imperfections in FEA modeling technique, "D" model is first analyzed with a perfect geometry, i.e., no imperfection considered. In this case, no tendency to develop local and global buckling is encountered near the plastic

moment. As a result, the strength and rotation capacity are much higher than expected, as can be seen from Fig. 4.8, indicating the importance of including imperfections in the finite element model for the moment-rotation study.

The effects of geometric imperfections are investigated by running several analyses with different geometric imperfection patterns and assumed values. As discussed in Section 3.3, although introducing imperfections using buckling analysis is widely used in the nonlinear analysis of plate girders, the resulting buckling modes are 
generally too localized to represent the initial shape of the geometric imperfections, which can be demonstrated as follows. Figures 4.9 (a) and (b) show the first two modes from buckling analysis of "D" girder with doubled web thickness. Superimposing these two modes, we still cannot obtain the AWS type geometric imperfections as discussed in Section 3.3.1. Therefore, a FORTRAN program is developed to give desired imperfection patterns and values for each panel according to AWS specifications (1995), as illustrated in Fig. 4.10. Detailed descriptions of the methods of introducing imperfections are presented in Section 3.3.

The FORTRAN program is used to add imperfection for all the following girders. The sensitivity study is carried out with three imperfection patterns and four different values. Specifically, the three patterns are (1) tilt of the compression flange, (2) out-offlatness of the web, and (3) initial lateral sweep of the compression flange, as shown in Fig. 3.3. Four particular values are chosen as $0.1,0.2,0.3$ and 0.4 in. It should be noted that the assumed values are for illustration purposes and they are different from those used in the primary parametric FEA studies in Chapter 5, which are based on AWS specifications (AWS, 1995).

The results are shown in Fig. 4.8, from which it can be seen that strength and ductility of the girder decrease significantly with increased imperfection values; for imperfections with the same value, as shown in Fig. 4.11, the tilt of the flange has the largest effect on moment capacity compared to the other two patterns. 


\subsubsection{Material Configurations}

The material stress-strain behavior can be characterized by the following parameters: the yield strength $\mathrm{F}_{\mathrm{y}}$, the yield ratio $\mathrm{F}_{\mathrm{y}} / \mathrm{F}_{\mathrm{u}}$, the ratio of the strain at strain hardening to the yield strain $\varepsilon_{\mathrm{st}} / \varepsilon_{\mathrm{y}}$, and the strain hardening modulus $\mathrm{E}_{\mathrm{st}}$.

The idealized multi-line stress-strain responses utilized in this study are presented in Fig. 4.12 for $F_{y}=50$ ksi (note that Fig. 4.12 is a repeat of Fig. 3.2) and Fig. 4.13 for $F_{y}=70 \mathrm{ksi}$, respectively. The values used to define key points for Grade 50 steel in Fig. 4.12 are from values reported by Alpsten (1972), and those for HPS 70W steel in Fig. 4.13 are obtained from tests conducted by the Federal Highway Administration (Wright, 1997). As the specimens in Wright's tests exhibited yield strength higher than $70 \mathrm{ksi}$, the data adopted in this study are scaled such that $\mathrm{F}_{\mathrm{y}}$ is equal to $70 \mathrm{ksi}$. Both of these two models have been used in previous studies (Barth and White, 1998; Barth et al., 2000 b), where the reliability of the data was validated. The constitutive laws shown in Fig. 4.12 and 4.13 are converted into true stress and logarithmic strain in the analysis as required by ABAQUS.

In order to compare the yield strength effect, three girders are studied using FEA model with "D" girder geometry, namely homogeneous Grade 50 case, homogeneous HPS 70W, and hybrid HPS 70W (HPS 70W flanges with Grade 50 web). Curves in Fig. 4.14 show that hybrid HPS 70W girder achieves the highest normalized strength while HPS 70W girder has the lowest normalized strength. The ratio of normalized moment capacity is 1.04 and 0.97 for HPS hybrid and HPS 70W versus Grade 50 respectively. Comparisons between homogeneous HPS 70W girder and hybrid HPS 70W indicate that 
the hybrid girders perform better than HPS 70W girders with respect to normalized moment capacity and rotation capacity for the girders with similar geometry.

\subsection{Summary}

1. The finite element analysis developed utilizing S4R shell element can accurately capture the moment-rotation behavior of the girders. Ten elements across the width of both top and bottom flanges and twenty elements through the depth of the web provide converged results while utilizing an acceptable amount of CPU time to complete the analysis.

2. A FORTRAN program is successfully employed to account for the AWS types of initial geometric imperfections (AWS, 1995). The imperfection patterns provided in Section 3.3.1 will be used in the parametric study in Chapter 5. With the same imperfection values, the tilt of the flange has more significant effect on the normalized moment capacity compared with out-of-flatness of the web and the lateral sweep of the compression flange.

3. Residual stresses patterns shown in Fig. 4.2 will be adopted in Chapter 5, where different values of residual stresses may be assigned to different girders based on their flange and web yield strength $\mathrm{F}_{\mathrm{y}}$.

5. For girders with the similar geometry, both normalized strength and ductility of the hybrid HPS 70W girders are improved compared to homogeneous Grade 50 and HPS 70W girders. Thus, hybrid HPS 70W girder design is deemed to be a competitive configuration when inelastic design is considered. 
Table 4.1 Schilling's "D" girder initial out-of-flatness of the web (Schilling and Morcos, 1988)

\begin{tabular}{|c|c|c|}
\hline Specimen & Panel $^{*}$ & $\begin{array}{c}\text { Out-of-flatness } \\
\text { (in) }\end{array}$ \\
\hline \multirow{3}{*}{ "D" girder } & Second left & 0.03 \\
\cline { 2 - 3 } & First left & 0.08 \\
\cline { 2 - 3 } & First right & 0.012 \\
\cline { 2 - 3 } & Second right & 0.022 \\
\hline
\end{tabular}

* The first panel is next to the center bearing stiffeners; the second panel is next to the first panel. 
Table 4.2 Schilling's "D" girder material constitutive Laws: -true stress vs. logarithmic plastic strain

(a) Flange material properties

\begin{tabular}{|c|c|c|c|c|}
\hline & \multicolumn{2}{|c|}{ Nominal(Engineering) stress-strain } & \multicolumn{2}{c|}{ True stress and logarithmic plastic strain } \\
\hline & $\sigma_{\text {nom }}(\mathrm{ksi})$ & $\varepsilon_{\text {nom }}$ & $\sigma_{\text {true }}(\mathbf{k s i})$ & $\varepsilon_{\text {ln }}^{\text {pl }}$ \\
\hline Yielding $\mathrm{F}_{\mathrm{y}}$ & 58.8 & 0.0020 & 58.9 & 0.0000 \\
\hline Strain Hardening $\mathrm{F}_{\mathrm{st}}$ & 60.1 & 0.0110 & 60.8 & 0.0088 \\
\hline Ultimate $\mathrm{F}_{\mathrm{u}}$ & 84.3 & 0.0446 & 88.1 & 0.0406 \\
\hline Rupture $\mathrm{F}_{\mathrm{r}}$ & 87.2 & 0.2000 & 104.6 & 0.1787 \\
\hline
\end{tabular}

(b) Web material properties

\begin{tabular}{|c|c|c|c|c|}
\hline & \multicolumn{2}{|c|}{ Nominal(Engineering) stress-strain } & \multicolumn{2}{c|}{ True stress and logarithmic plastic strain } \\
\hline & $\sigma_{\text {nom }}(\mathrm{ksi})$ & $\varepsilon_{\text {nom }}$ & $\sigma_{\text {true }}(\mathbf{k s i})$ & $\varepsilon_{\text {ln }}^{\text {pl }}$ \\
\hline Yielding $\mathrm{F}_{\mathrm{y}}$ & 56.2 & 0.0019 & 56.3 & 0.0000 \\
\hline Strain Hardening $\mathrm{F}_{\mathrm{st}}$ & 57.5 & 0.0110 & 58.1 & 0.0089 \\
\hline Ultimate $\mathrm{F}_{\mathrm{u}}$ & 71.4 & 0.0303 & 73.6 & 0.0273 \\
\hline Rupture $\mathrm{F}_{\mathrm{r}}$ & 74.3 & 0.2000 & 89.2 & 0.1792 \\
\hline
\end{tabular}


Table 4.3 Comparison of the FEA results of mesh density study

\begin{tabular}{|c|c|c|c|l|}
\hline \multirow{2}{*}{$\begin{array}{c}\text { No. of elements } \\
\text { along the width of } \\
\text { flange and web }\end{array}$} & \multirow{2}{*}{$\begin{array}{c}\text { Total elements No. } \\
\text { of FEA model }\end{array}$} & \multicolumn{2}{|c|}{$\mathrm{M}_{\max (\mathrm{FEA})} / \mathrm{M}_{\max (\text { Test })}$} & \multirow{2}{\text{CPUtime}}{ (Seconds) } \\
\cline { 3 - 5 } & & Prediction & error & \\
\hline $4 \times 6$ & 1650 & 1.032 & $\mathbf{0 . 0 3 2}$ & 1022 \\
\hline $6 \times 10$ & 3959 & 1.013 & $\mathbf{0 . 0 1 3}$ & 1990 \\
\hline $10 \times 20$ & 8360 & 0.997 & $\mathbf{- 0 . 0 0 3}$ & 6872 \\
\hline
\end{tabular}



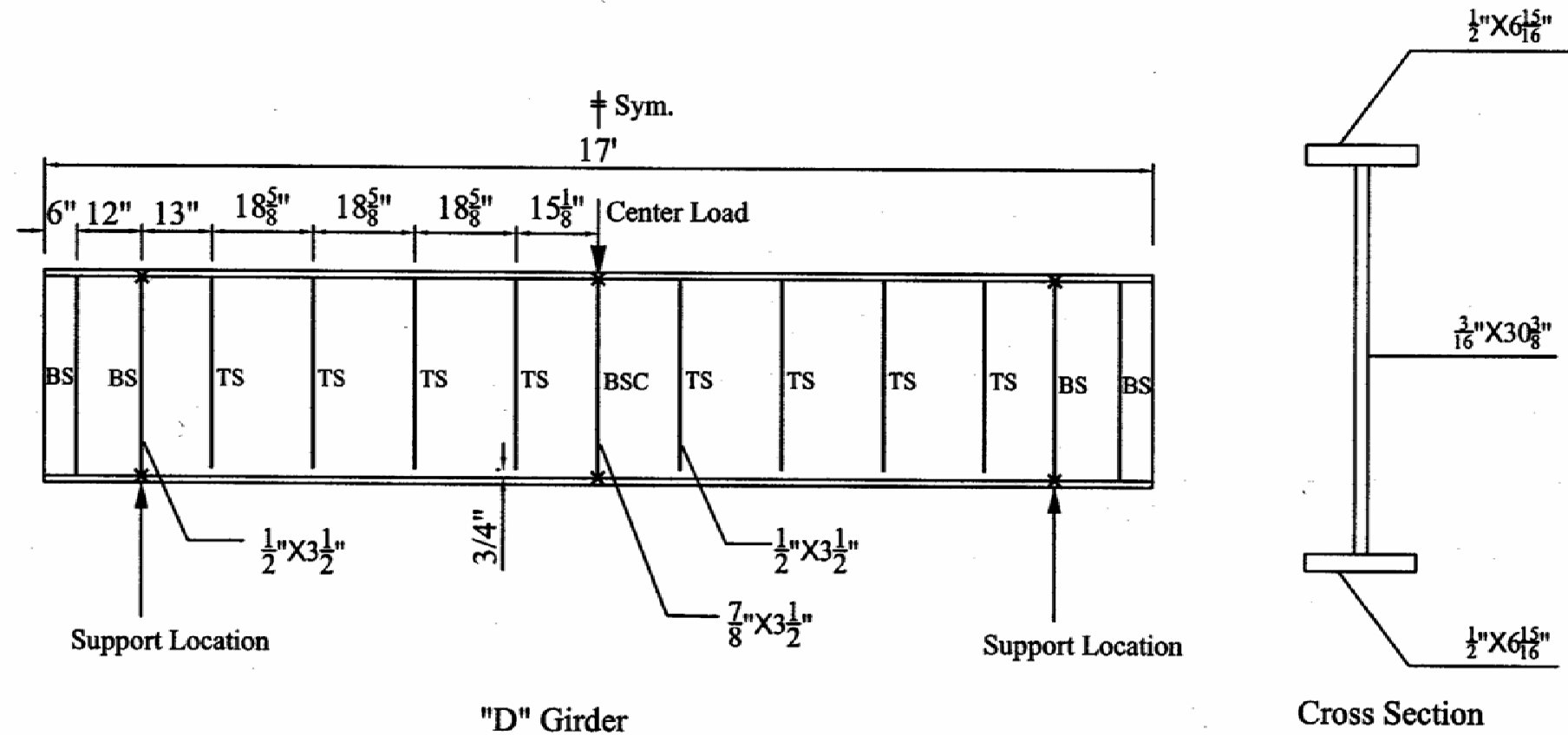

Cross Section

BS: Bearing Stiffener, each side

TS: Transverse Stiffener, one side

Figure 4.1 All-steel component test specimen (Schilling and Morcos, 1988) 


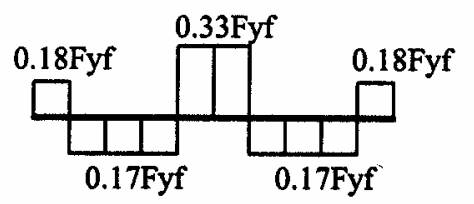

Top and Bottom Flange (10 Elements)

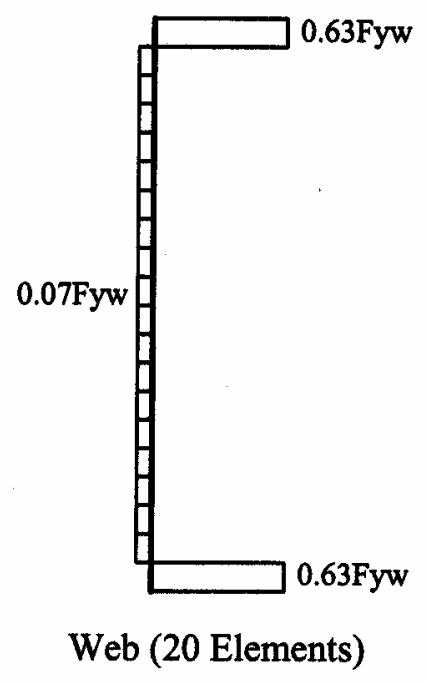

Figure 4.2 Residual stress patterns 


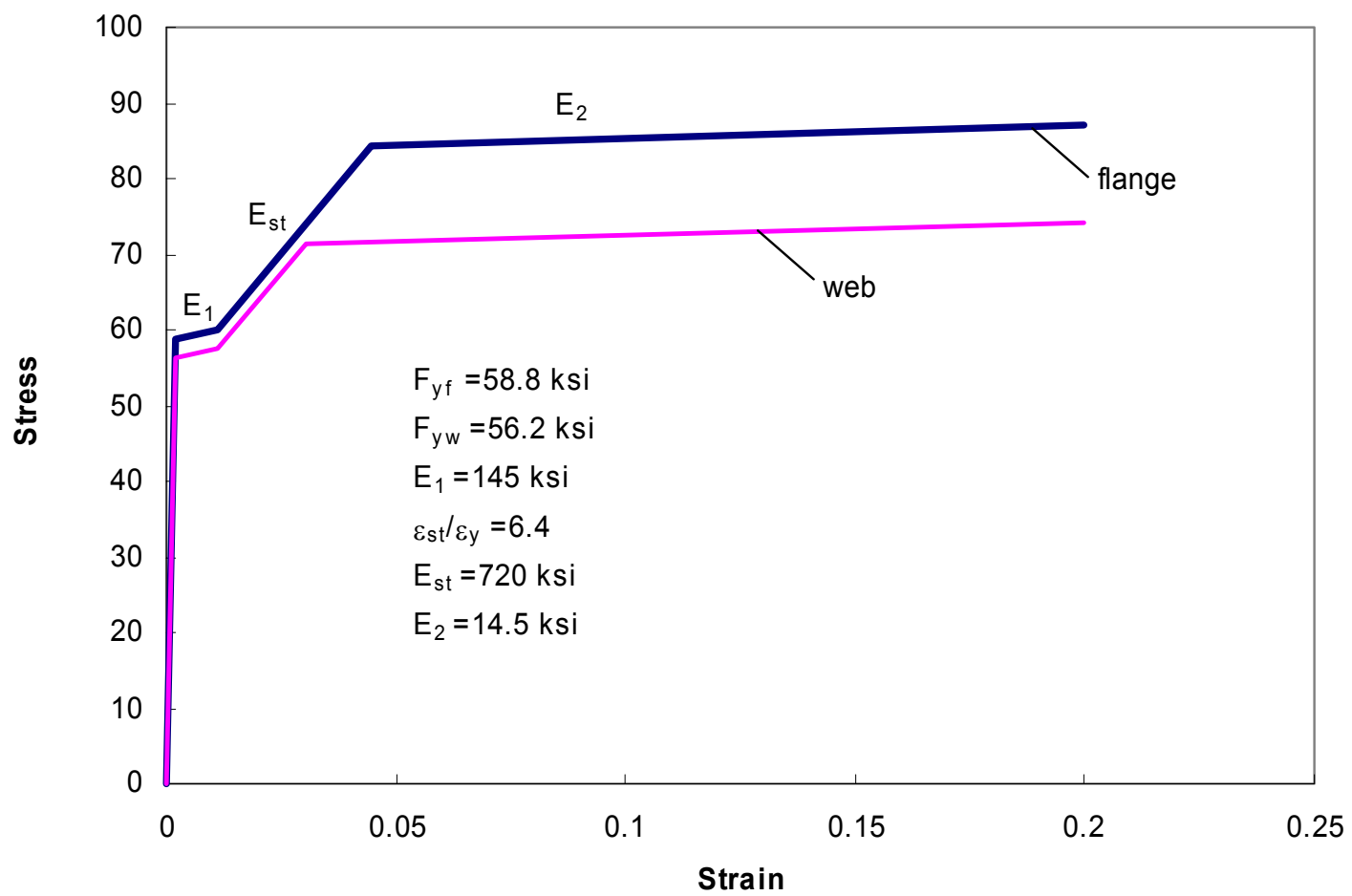

Figure 4.3 Schilling's "D" girder material constitutive law 


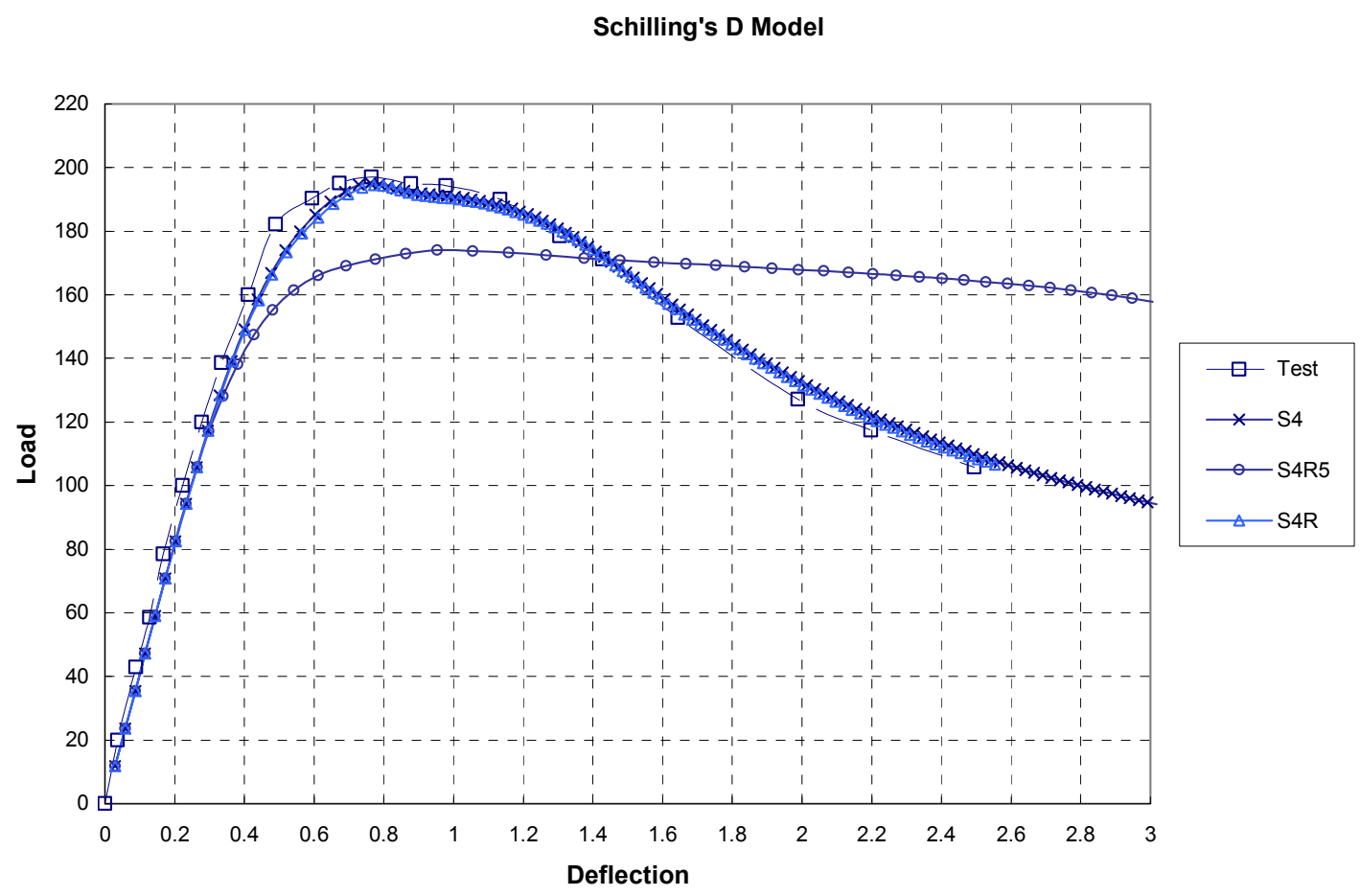

Figure 4.4 Effect of element type on predicted flexure responses for Schilling's "D" model 


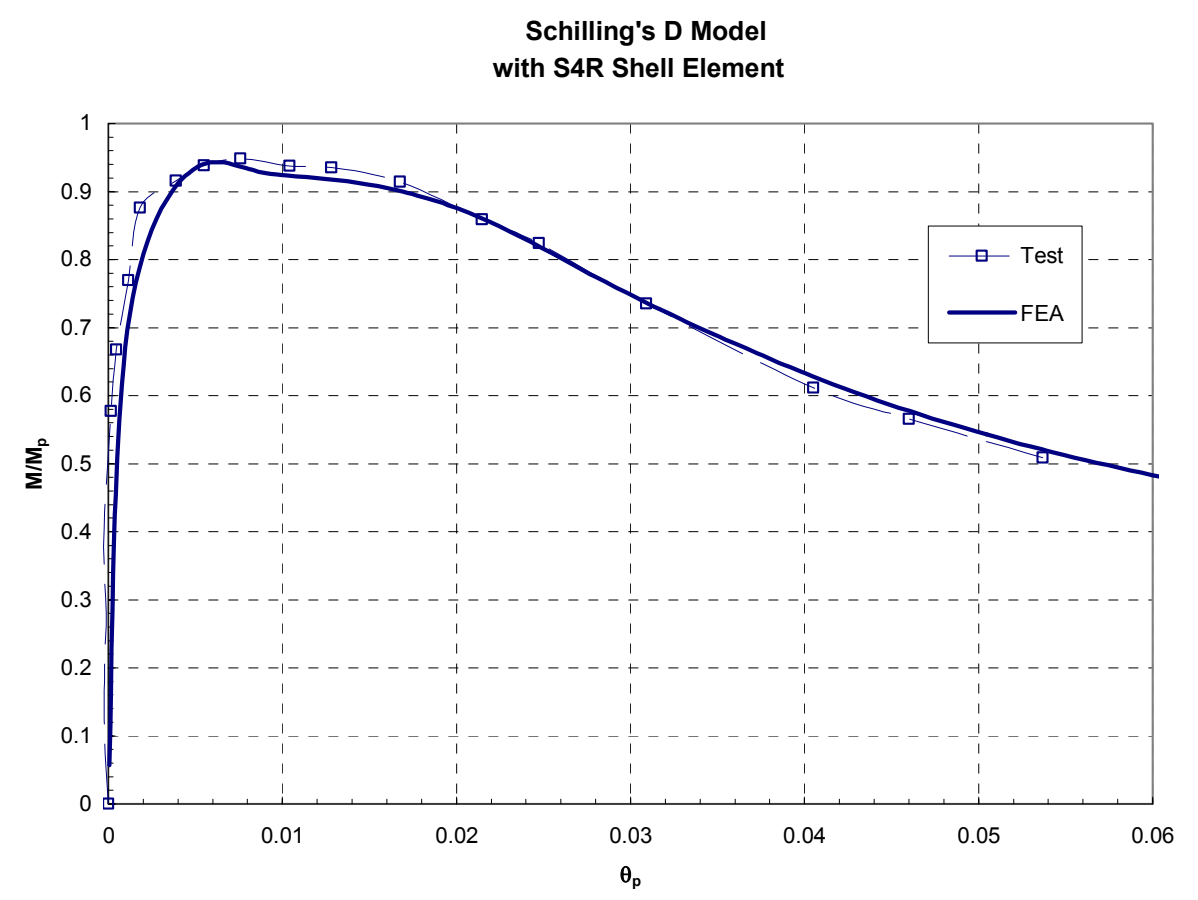

Figure 4.5 Comparison of experimental and FEA model with S4R shell element on $\mathrm{M} / \mathrm{M}_{\mathrm{p}}$ vs. $\theta_{\mathrm{p}}$ curve for Schilling's " $\mathrm{D}$ ” model 


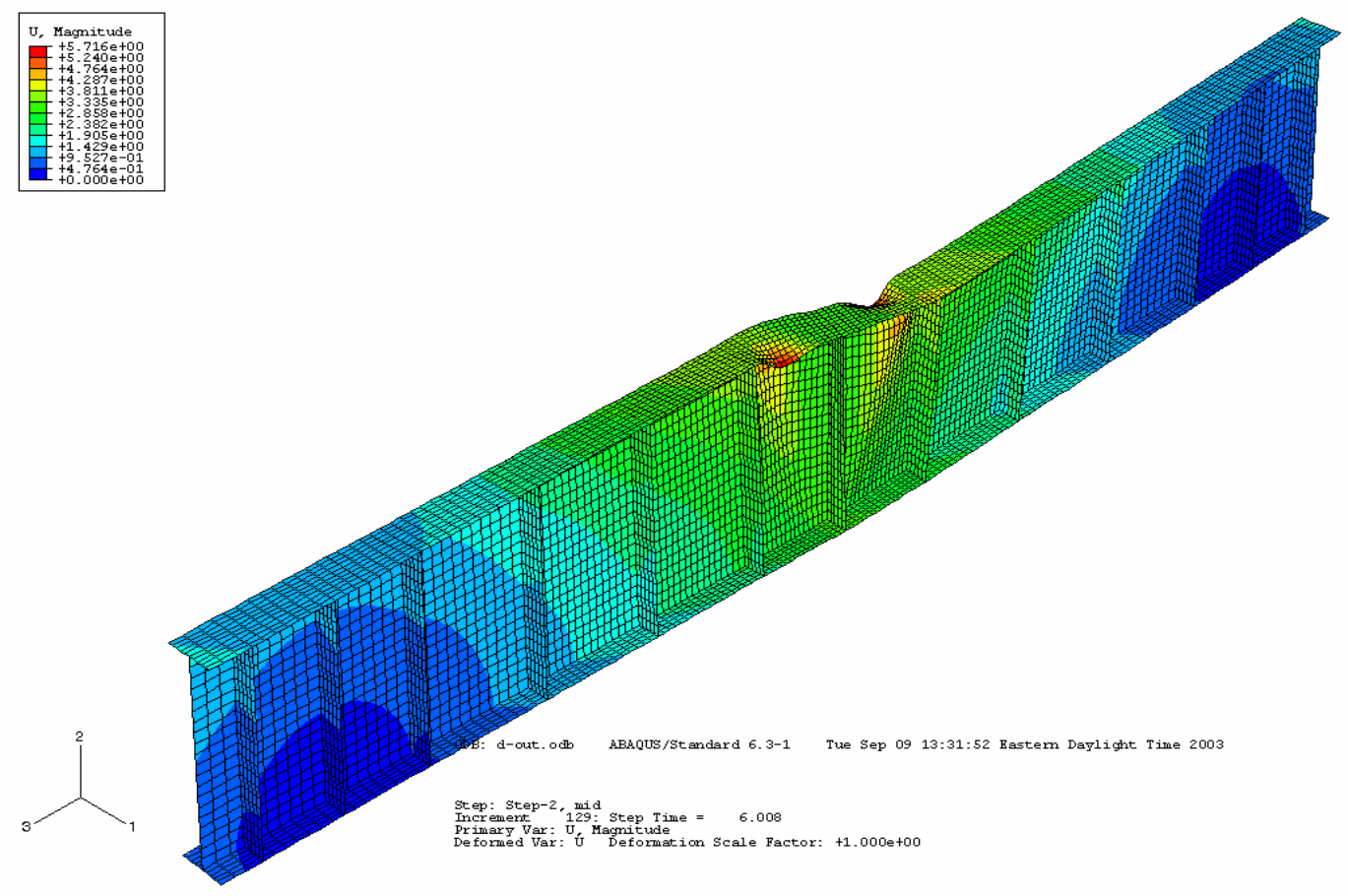

Figure 4.6 Schilling's "D" model final failure mode with S4R shell element 


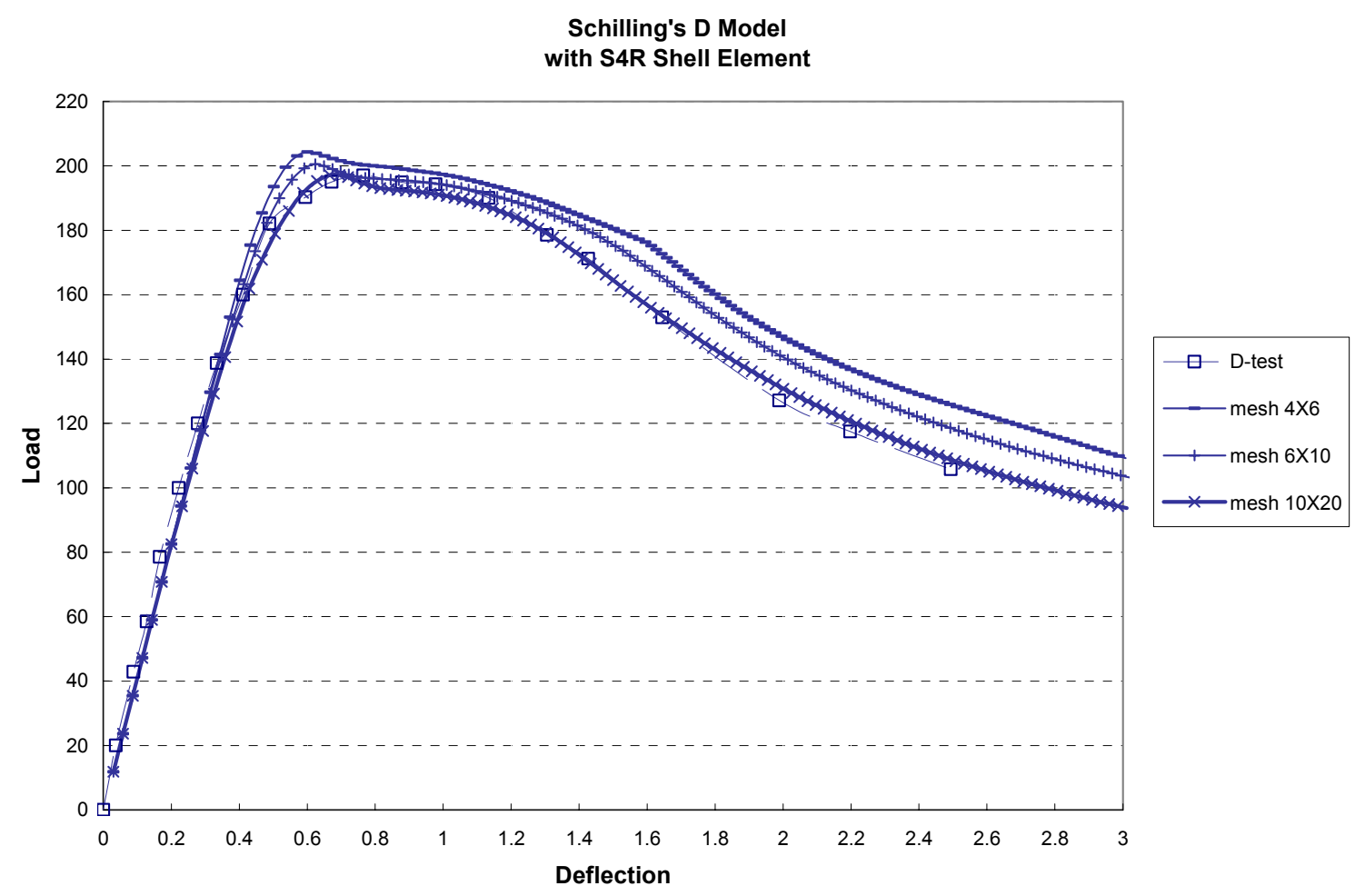

Figure 4.7 Effect of mesh density on predicted flexure responses for Schilling's "D" model 


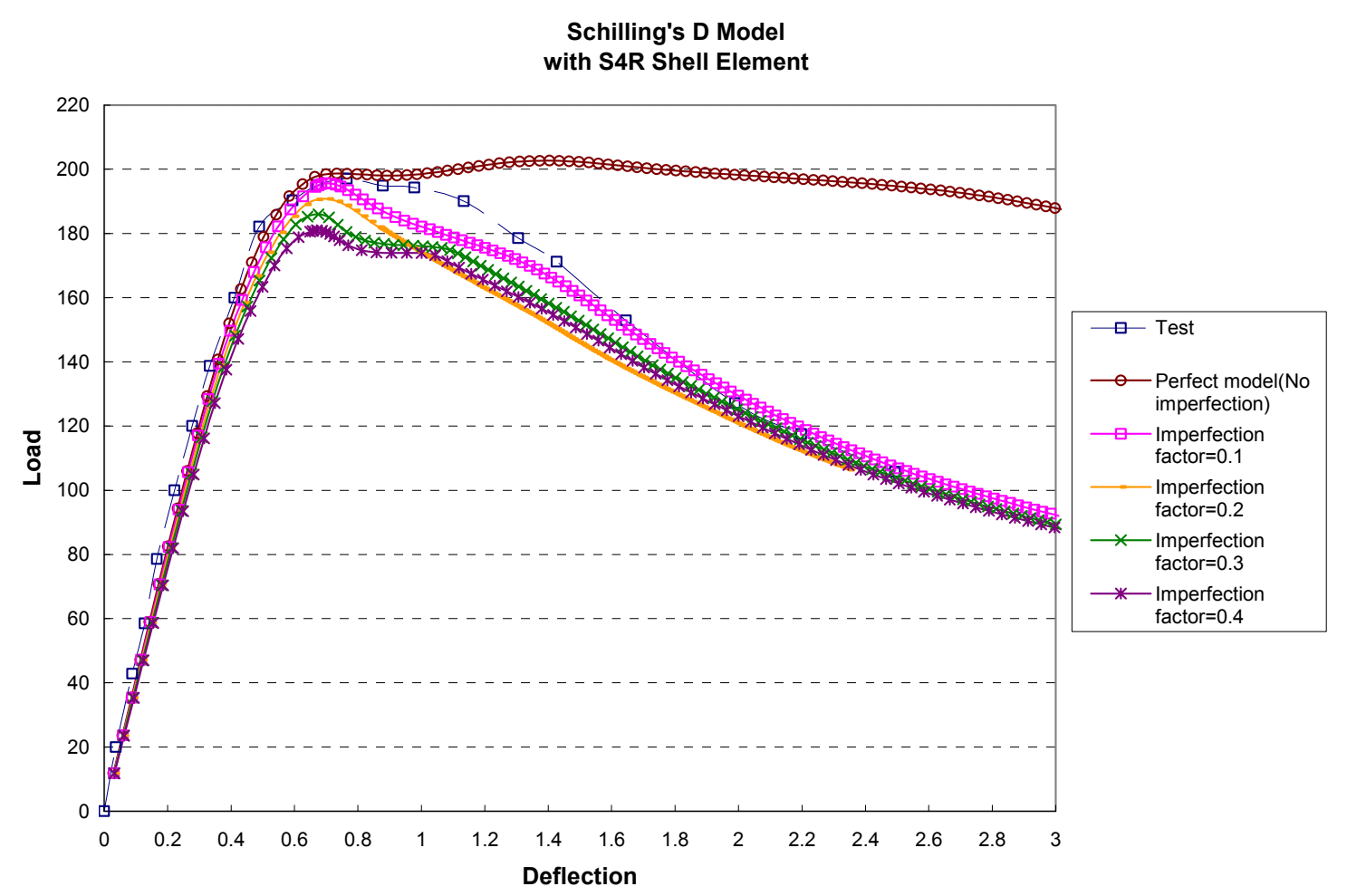

Figure 4.8 Influence of initial geometric imperfections on predicted flexure responses for Schilling's "D" model 


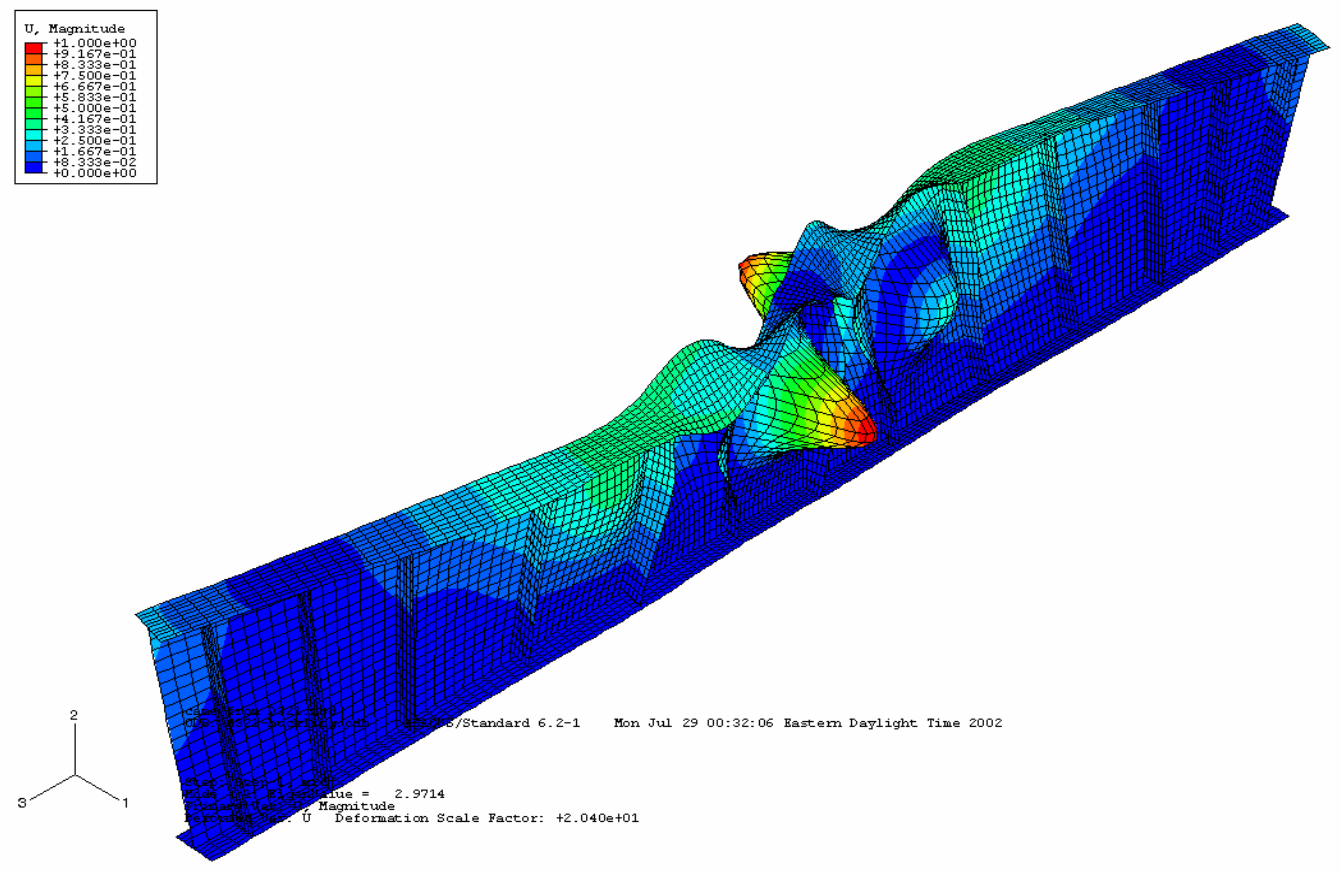

(a)

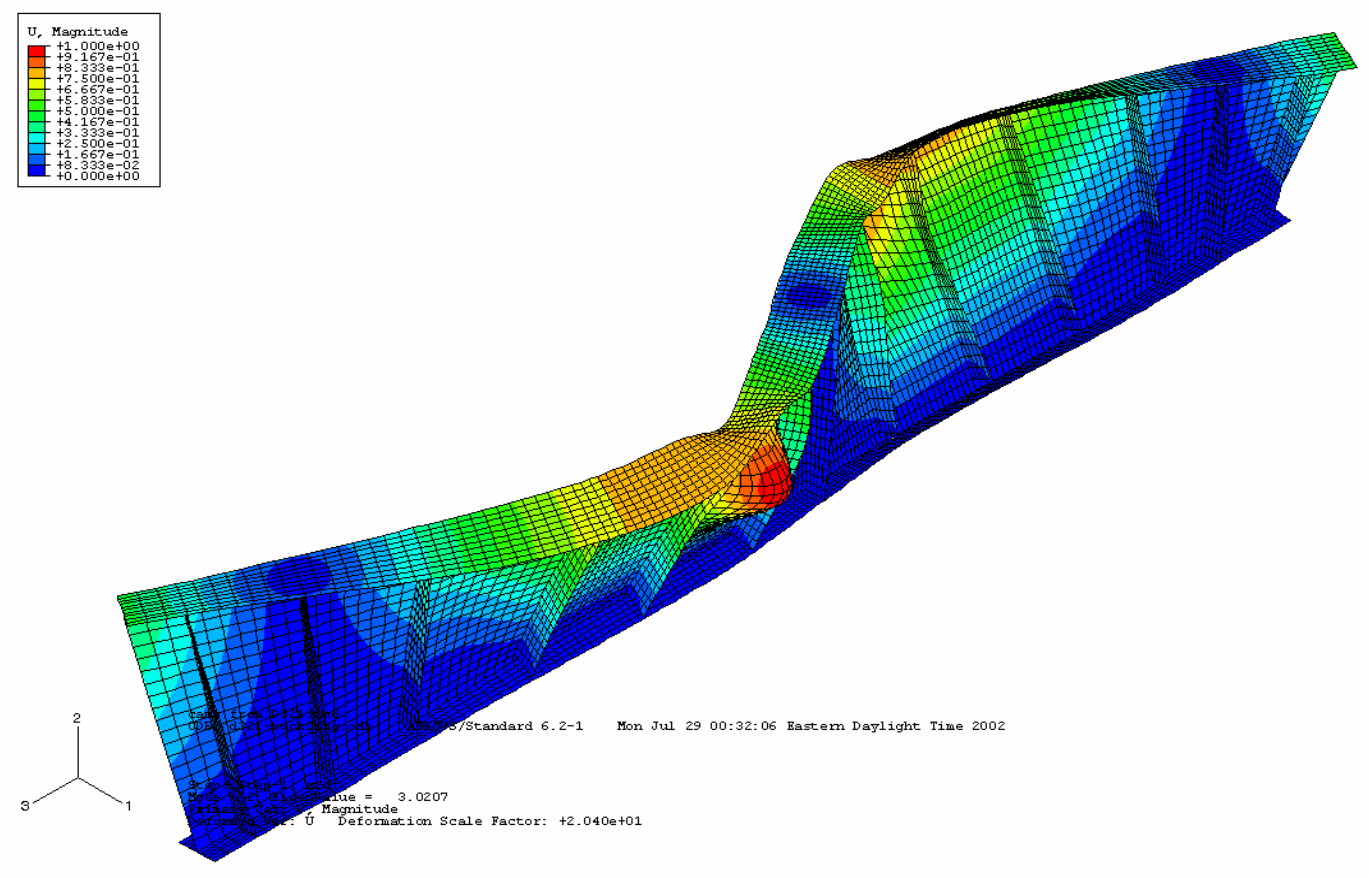

(b)

Figure 4.9 Introducing imperfections using buckling analysis for Schilling's " $D$ " girder

(a) First buckling mode with doubled web thickness;

(b) Second buckling mode with doubled web thickness. 


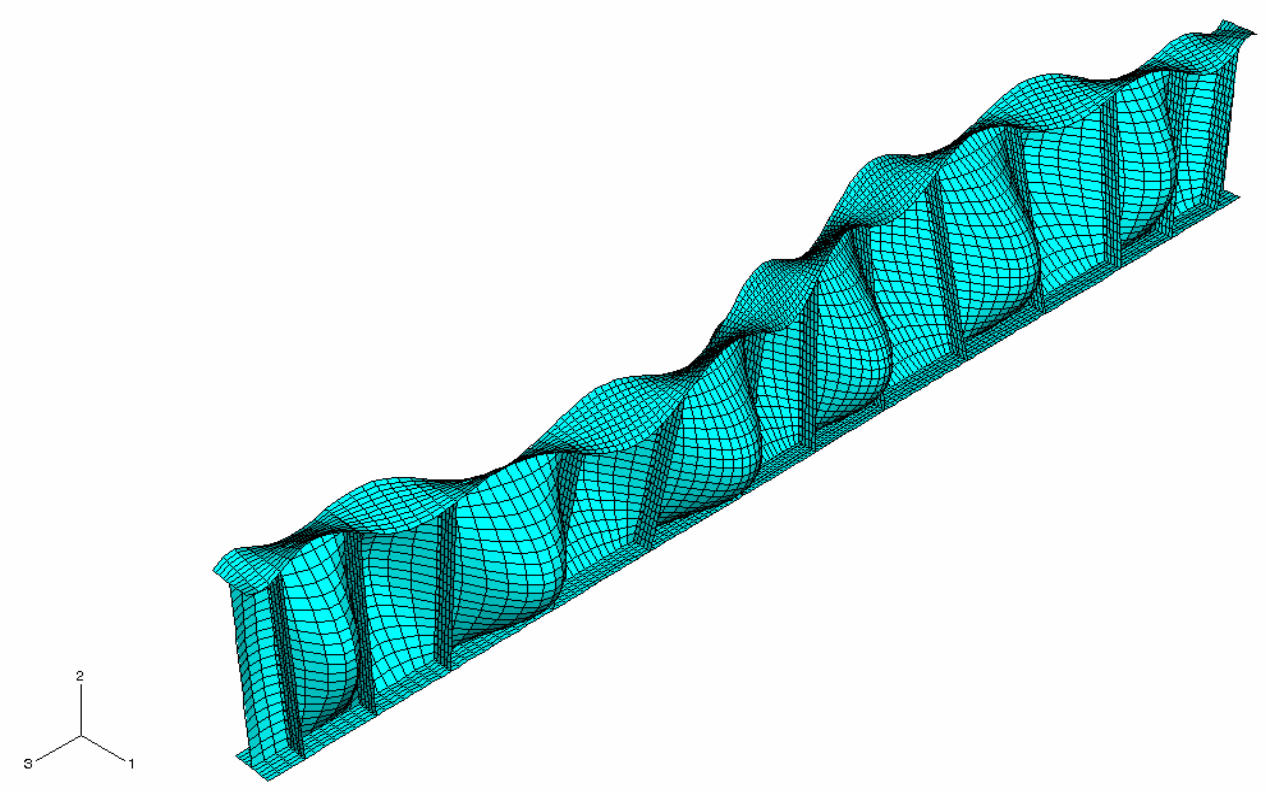

Figure 4.10 Introducing imperfections using FORTRAN program for Schilling's "D" girder according to AWS specifications (AWS, 1995)

(Deformation scale factor: 100) 
Schilling's D Model

with S4R Shell Element

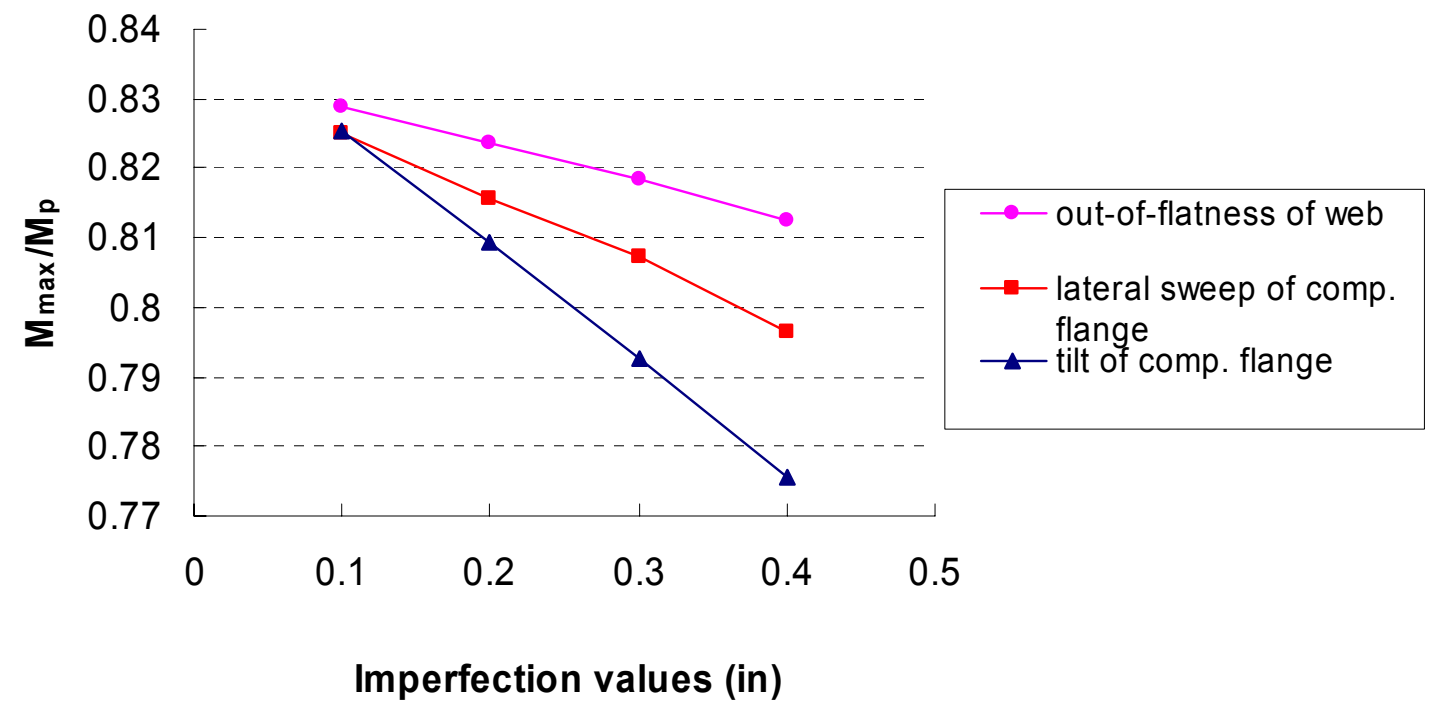

Figure 4.11 Influence of imperfection patterns on normalized moment capacity for Schilling's "D" model 
Grade 50

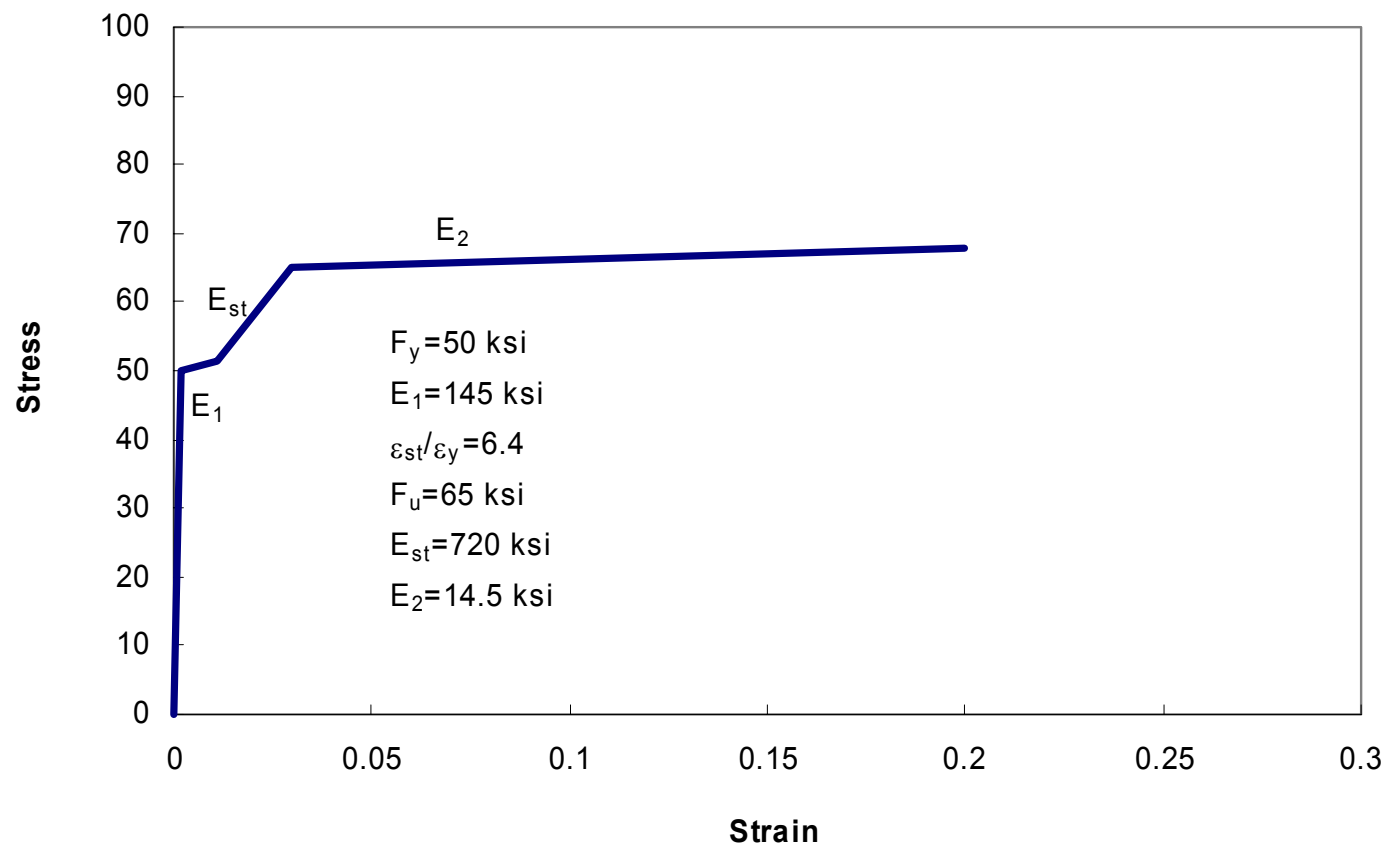

Figure 4.12* Material constitutive law used in this study for Grade 50 steel

* This figure is a repeat of Fig. 3.2. 
HPS 70W

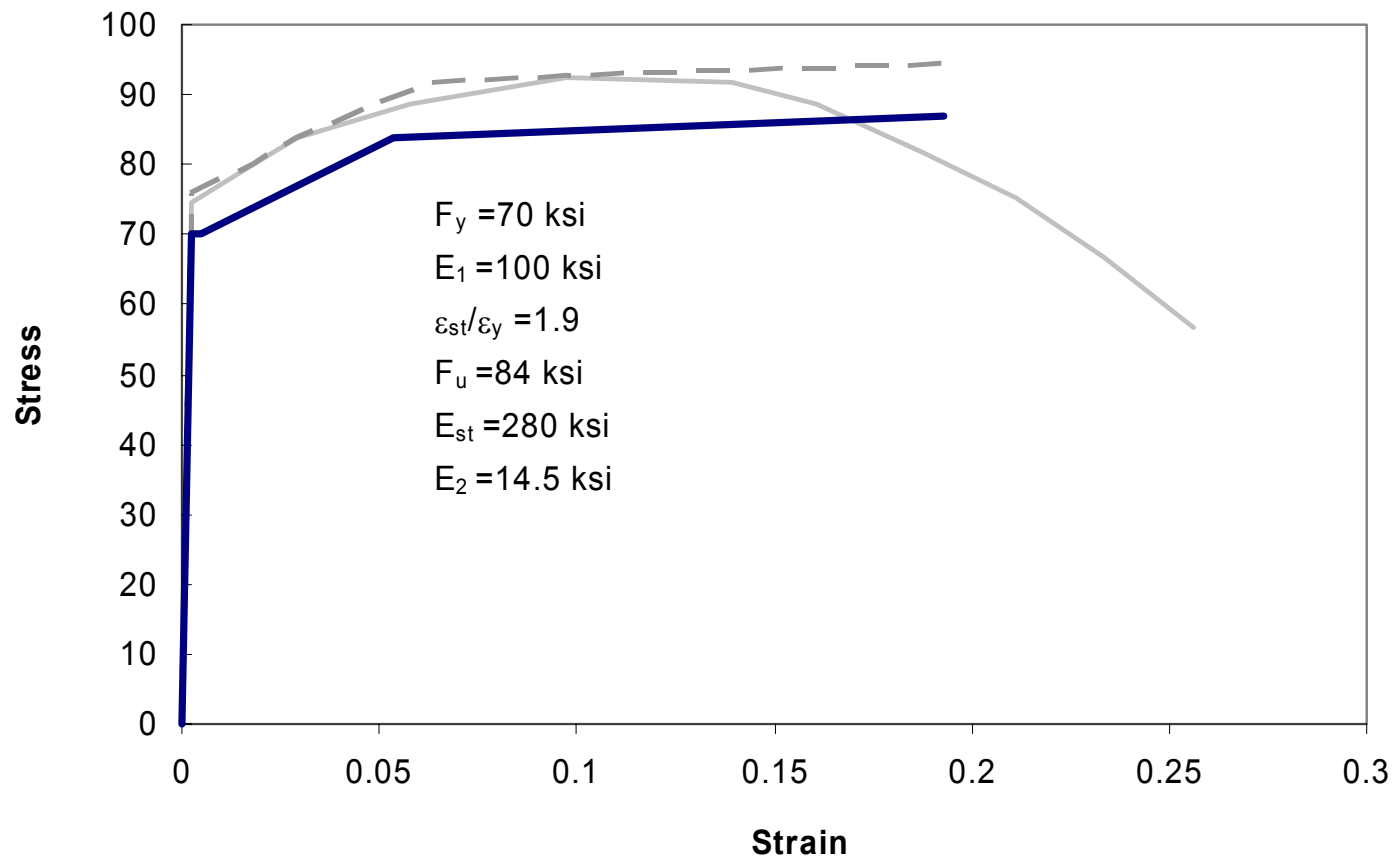

Figure 4.13 Material constitutive law used in this study for HPS 70W steel from FHWA experimental tests (Wright, 1997) 
Schilling's D Model

with S4R Shell Element

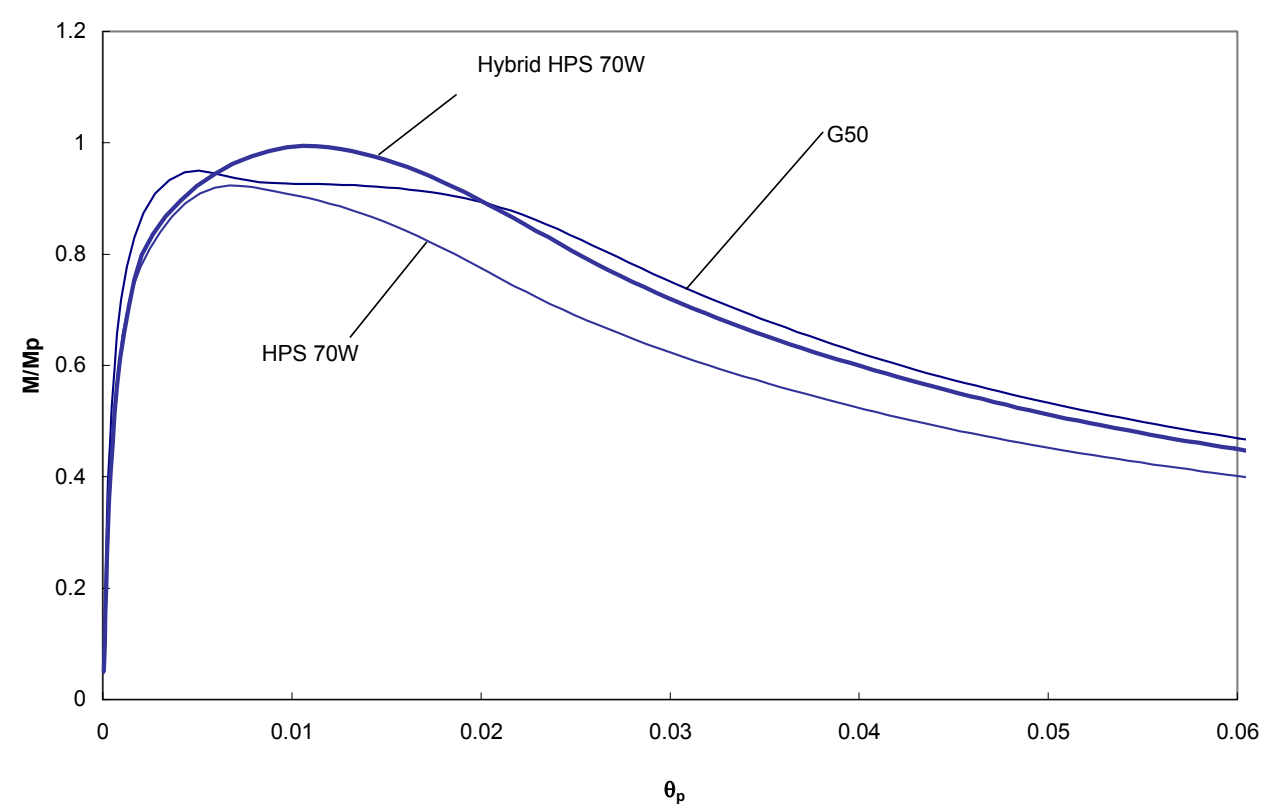

Figure 4.14 Effect of material configuration on $\mathrm{M} / \mathrm{M}_{\mathrm{p}}$ vs. $\theta_{\mathrm{p}}$ curves for Schilling's "D" model 


\title{
CHPATER 5
}

\section{PARAMETRIC STUDY ON MOMENT-ROTATION BEHAVIOR OF HPS HYBRID GIRDERS}

\author{
A reasonably comprehensive set of parametric studies, using the FEA model \\ described in Chapter 4, are conducted in this chapter. Two groups of parameters are \\ varied: girder material configurations and cross-section geometric properties. The effects \\ of various parameters on the moment-rotation behavior of HPS hybrid girders are \\ discussed in detail.
}

\subsection{Primary Design Parameters}

The parametric girder is represented by a $60 \mathrm{ft}$ segment based on a hypothetical two-span continuous girder bridge with $150 \mathrm{ft}$ spans having negative bending regions represented by $20 \%$ of the span length. Three-point loading is used to simulate the moment variation within the negative bending region of the continuous-span girders, as described in Section 1.2.2. The varied and constant parameters are listed as follows.

\subsubsection{Varied Parameters}

\section{Girder Material Configurations}

Three options are considered: homogenous Grade 50, homogenous HPS 70W, and hybrid girders with HPS 70W flanges and Grade 50 webs. 
2. Flange Slenderness $\left(\mathrm{b}_{\mathrm{fc}} / 2 \mathrm{t}_{\mathrm{fc}}\right)$

Two values of flange slenderness are selected for this study: (1) the ultra-compact flange limit (Schilling and Morcos, 1988), $\mathrm{b}_{\mathrm{fc}} / \mathrm{t}_{\mathrm{fc}}=0.29 \sqrt{\mathrm{E} / \mathrm{F}_{\mathrm{yc}}}$, and (2) the compact

flange limit, $\mathrm{b}_{\mathrm{fc}} / \mathrm{t}_{\mathrm{fc}}=0.38 \sqrt{\mathrm{E} / \mathrm{F}_{\mathrm{yc}}}$, of the current AASHTO LRFD specifications

(AASHTO, 2001).

3. Web Slenderness $\left(2 \mathrm{D}_{\mathrm{cp}} / \mathrm{t}_{\mathrm{w}}\right)$

Three values of web slenderness are considered corresponding to (1) the proposed compact web limit, $2 \mathrm{D}_{\mathrm{cp}} / \mathrm{t}_{\mathrm{w}}=\lambda_{\mathrm{pw}\left(\mathrm{D}_{\mathrm{cp}}\right)}$ (Barth et al., 2003), (2) current compact web limit, $2 \mathrm{D}_{\mathrm{cp}} / \mathrm{t}_{\mathrm{w}}=3.76 \sqrt{\mathrm{E} / \mathrm{F}_{\mathrm{yc}}}$, and (3) the maximum web slenderness allowed for transverselystiffened girders in the AASHTO LRFD specifications (AASHTO, 2001), $2 \mathrm{D}_{\mathrm{cp}} / \mathrm{t}_{\mathrm{w}}=6.8 \sqrt{\mathrm{E} / \mathrm{F}_{\mathrm{yc}}}$

4. Cross-Section Aspect Ratios $\left(\mathrm{D} / \mathrm{b}_{\mathrm{fc}}\right)$

Cross-section aspect ratios equal to 3 and 4.25 are considered. A D/ $\mathrm{b}_{\mathrm{fc}}$ value of 3 is representative of typical rolled beam sections, whereas the value of 4.25 represents the aspect ratio for typical plate girders. A D/ $\mathrm{b}_{\mathrm{fc}}$ value of 4.25 is also the upper limit specified in the recommended simplified moment redistribution procedures (Barth et al., 2003).

5. Depth of Web in Compression $\left(\mathrm{D}_{\mathrm{cp}} / \mathrm{D}\right)$

Depth of web in compression $\left(D_{\mathrm{cp}} / \mathrm{D}\right)$ is varied from $0.5,0.625$ to 0.75 , where 0.5 represents doubly symmetric girders, 0.625 and 0.75 represent singly symmetric girders. 
6. Span-to-Depth Ratio (L/D)

Span-to-depth ratio (L/D) of the prototype bridge girders is designed based on $\mathrm{L} / \mathrm{D}$ equal to 20 or 30 . These two $\mathrm{L} / \mathrm{D}$ ratios are considered as the typical range of $\mathrm{L} / \mathrm{D}$ ratios for the plate girders in negative bending regions, where the value of 30 corresponds to approximate upper bound on $\mathrm{L} / \mathrm{D}$ values in actual bridge design.

\subsubsection{Constant Attributes and Parameters}

In addition to the parameters listed above, the following considerations are also employed.

1. Lateral bracing equals to the proposed lateral bracing limit, Eq. 2.19, as discussed in Section 2.1.4, i.e.,

$$
\mathrm{L}_{\mathrm{b}} \leq\left[0.1-0.06\left(\frac{\mathrm{M}_{1}}{\mathrm{M}_{2}}\right)\right] \frac{\mathrm{r}_{\mathrm{t}} \mathrm{E}}{\mathrm{F}_{\mathrm{yc}}}
$$

When $L_{b}$ is not an even multiple of girder length $L$, cantilevered ends of the girder extend beyond the vertical supports for another $\mathrm{L}_{\mathrm{b}}$, such that additional supported segments provide torsional restraint consistent with that in actual continuous-span members.

2. Geometric imperfections are specified as in Section 3.3. These initial geometric imperfections include: web out-of-flatness and compression flange tilt within each web panel, and a longitudinal sweep of the compression flange within each unbraced length. The layout of these imperfections is shown in Fig. 3.3. 
3. Longitudinal residual stresses are modeled based on the heat input from the welding and flame cutting processes as described in Section 3.4. The residual stress patterns are shown in Fig. 4.2.

4. Several researchers (Climenhaga and Johnson, 1972; Carskaddan, 1980; Grubb and Carskaddan, 1981) reported that strength and flexural ductility characteristics of composite girders at interior-pier regions can be approximated conservatively, and reasonably well, by equivalent all-steel tests with an increased size of tension flanges to represent the effect of the reinforcing steel in the cracked concrete slab sections. Therefore, only all-steel I-shaped girders are considered in this study.

Table 5.1 summarizes key parameters associated with all the combinations, where the terms are defined in the nomenclature. Figure 5.1 demonstrates typical FEA models adopted in this study. Figure 5.1 (a) shows the FEA model for a girder with an unstiffened web. The dashed lines represent the lateral brace locations. One may notice that this girder does not require any transverse stiffeners other than the bearing stiffeners at the mid-span and end supports. Figure 5.1 (b) shows the FEA model for a girder that has a transversely-stiffened web. Transverse stiffeners are placed if necessary to satisfy $\mathrm{V}_{\mathrm{u}}<\phi_{\mathrm{v}} \mathrm{V}_{\mathrm{cr}}$. Typical unstiffened and transversely-stiffened FEA meshes are shown in Figs. 5.2 and 5.3 respectively. There are ten elements across the width of the flange and twenty elements through the web depth. All current studies are performed using the commercial FEA package ABAQUS/STANDARD versions 6.2-1 and 6.3-1. 
Subsequent sections describe the naming convention and summarize the effects due to the changes of respective parameters.

\subsection{Naming Convention}

Figure 5.4 shows the naming convention used in the parametric study. The corresponding specific parameter values associated with each of the abbreviated parts of the names are summarized as follows:

- Flange Slenderness

$\mathrm{UC} \equiv$ ultra-compact flange $\left(\mathrm{b}_{\mathrm{fc}} / 2 \mathrm{t}_{\mathrm{fc}}=0.29\left(\mathrm{E} / \mathrm{F}_{\mathrm{y}}\right)^{1 / 2}\right)$

$\mathrm{CF} \equiv$ compact flange $\left(\mathrm{b}_{\mathrm{fc}} / 2 \mathrm{t}_{\mathrm{fc}}=0.38\left(\mathrm{E} / \mathrm{F}_{\mathrm{y}}\right)^{1 / 2}\right)$.

- Web Slenderness

$\mathrm{CW} \equiv$ proposed compact web $\left(2 \mathrm{D}_{\mathrm{cp}} / \mathrm{t}_{\mathrm{w}}=\lambda_{\mathrm{pw}\left(\mathrm{D}_{\mathrm{cp}}\right)}\right)$;

$\mathrm{CW} 1 \equiv \operatorname{compact} w e b\left(2 \mathrm{D}_{\mathrm{cp}} / \mathrm{t}_{\mathrm{w}}=3.76\left(\mathrm{E} / \mathrm{F}_{\mathrm{y}}\right)^{1 / 2}\right)$

$\mathrm{SW} \equiv$ slender web $\left(2 \mathrm{D}_{\mathrm{cp}} / \mathrm{t}_{\mathrm{w}}=6.8\left(\mathrm{E} / \mathrm{F}_{\mathrm{y}}\right)^{1 / 2}\right)$.

- Cross-Section Aspect Ratio

$3 \equiv \mathrm{D} / \mathrm{b}_{\mathrm{fc}}=3$

$4 \equiv \mathrm{D} / \mathrm{b}_{\mathrm{fc}}=4.25$

- Symmetry

$\mathrm{S} \equiv$ doubly symmetric girders $\left(\mathrm{D}_{\mathrm{cp}} / \mathrm{D}=0.5\right)$;

$\mathrm{U} 1 \equiv$ singly symmetric girders $\left(\mathrm{D}_{\mathrm{cp}} / \mathrm{D}=0.625\right)$;

$\mathrm{U} 2 \equiv$ singly symmetric girders $\left(\mathrm{D}_{\mathrm{cp}} / \mathrm{D}=0.75\right)$. 
- Span-to-Depth Ratio

$$
\begin{aligned}
& 30 \equiv L / D=30 \\
& 20 \equiv L / D=20
\end{aligned}
$$

It is noted that if any of the parameters in Fig. 5.4 is omitted, it means that the name includes all the cases presented by the missed parameters. For instance, for CFCW3-30 cases (the last parameter missed in the name convention), it includes all the three following cases: CFCW3-30S, CFCW3-30U1, CFCW3-30U2.

\subsection{Effects of Various Parameters}

Table 5.2 summarizes the FEA girder properties and key analytical results for the study of the girder material configuration effect. Table 5.3 summarizes all the FEA HPS hybrid girder properties and key analytical results for the study of geometric parameter effect in this work. The following sections will discuss the effects of the various representative parameters in details.

\subsubsection{Effect of Girder Material Configurations}

Two sets of representative girders, CFCW-30 and CFSW-30 cases, are compared in the same design condition with three girder material configurations: homogenous Grade 50, homogeneous HPS 70W and hybrid HPS 70W girders. The girder properties and key results for the girder material configuration study are summarized in Table 2. The results of CFCW-30 cases are given in Figs. 5.5 through 5.10, which indicate that for both CFCW3-30 and CFCW4-30 cases, girder configuration has little effect on the 
normalized strength except CFCW4-30U1(Hyb). For doubly symmetric girders, hybrid girders exhibit the highest normalized strength and the largest rotation capacity, whereas with $\mathrm{D}_{\mathrm{cp}} / \mathrm{D}$ increases to 0.75 , the hybrid girder ductility degrades faster compared to homogeneous Grade 50 and HPS 70W girders. It is worth noting that homogeneous HPS $70 \mathrm{~W}$ always have higher normalized strength and larger rotation capacity compared to homogeneous Grade 50 girders for CFCW-30 cases. Figures 5.11 through 5.16 illustrate the results of CFSW-30 cases, where we can observe that hybrid HPS 70W girders always have the highest normalized moment capacity. Homogeneous Grade 50 and HPS $70 \mathrm{~W}$ girders have almost the same normalized strength but HPS 70W girders are more ductile than Grade 50 girders, especially for CFSW4-30 cases.

From the above comparison, it is concluded that hybrid HPS70W girders have the significant potential benefits for normalized strength (CFSW cases) and ductility (both CFCW and CFSW cases) compared with homogeneous Grade 50 and HPS 70W girders. These benefits decrease only for the CFCW-30U cases which are characterized as girders with compact flanges and compact webs, $\mathrm{L} / \mathrm{D}=30$, and $\mathrm{D}_{\mathrm{cp}} / \mathrm{D}=0.625,0.75$. For this case, homogeneous HPS 70W girders are more ductile than hybrid HPS 70W and Grade 50 girders.

\subsubsection{Flange Slenderness $\left(b_{\mathrm{fc}} / 2 t_{\mathrm{fc}}\right)$}

Figures 5.17 through 5.20 summarize the influence of changes of flange slenderness on the moment-rotation behavior of steel I-shaped girders in this study. As the results from $D_{\mathrm{cp}} / \mathrm{D}=0.625$ have the same tendency as those from $\mathrm{D}_{\mathrm{cp}} / \mathrm{D}=0.75$, only 
$D_{\mathrm{cp}} / \mathrm{D}=0.75$ cases are shown in these figures, which, together with $\mathrm{D}_{\mathrm{cp}} / \mathrm{D}=0.5$, can be used to study the ultra-compact flange effect with different $\mathrm{D}_{\mathrm{cp}} / \mathrm{D}$ ratios. Figures 5.17 and 5.18 show the results for CW-30 cases, from which it can be seen that the ultracompact flange has almost no effect on the normalized moment capacity (The largest normalized moment capacity decrease $2 \%$ for UCCW4-30S versus CFCW4-30S.). For SW-30 cases, as shown in Figs. 5.19 and 5.20, the normalized moment capacity only has slightly increase, with the ratio of the maximum strengths to be 1.02 (UCSW3-30U2 versus CFSW3-30U2). The only reduction of normalized moment capacity for SW cases is UCSW3-30S, where the moment capacity decreases 4\% compared with CFSW3-30S. For both CW-30 and SW-30 cases, the moment-rotation shape is significantly improved by the change from a compact to an ultra-compact flange, as shown from Figs. 5.17 through 5.20.

Therefore, it is reasonable to conclude that: (1) the change from a compact flange to an ultra-compact flange has either positive or negative effect on the normalized moment capacity, depending on the other parameters, particularly on web slenderness , $\mathrm{D}_{\mathrm{cp}} / \mathrm{D}$ ratio, etc., (2) girders with ultra-compact flange and compact web (CW cases) generally have little strength increase compared to those with compact flange and compact web, and (3) the girders with ultra-compact flanges and slender webs (SW cases) can gain some strength increase with maximum of $2 \%$ (UCSW3-30U2 versus CFSW3-30U2) as observed, while the strength decrease 4\% for one case (UCSW3-30S versus CFSW3-30S) in this study. 
However, the girders with ultra-compact flange generally have a smoother postpeak region on the moment-rotation curve compared with the compact flange girders. This shows that girders with ultra-compact flanges are able to accommodate larger plastic rotations prior to significant loss of stability due to local buckling. This effect becomes more significant for doubly symmetric cases and for UCSW-30U2 cases.

\subsubsection{Depth of Web in Compression $\left(D_{\mathrm{cp}} / \mathrm{D}\right)$}

As discussed in Section 2.1.1, composite bridge sections at interior supports may be unsymmetrical because of the contribution from the rebar in the bridge deck when computing the section properties of a steel section, which is caused by the upward shifts of the neutral axis. As shown in Figs. 5.17 and 5.18 (for CW cases) and Figs. 5.19 and 5.20 (for $\mathrm{SW}$ cases), $\mathrm{D}_{\mathrm{cp}} / \mathrm{D}$ has no important effect on the shape of moment-rotation curves for both $\mathrm{CW}$ and $\mathrm{SW}$ in most cases, this behavior is more evident between girders CFSW-30U2 and CFSW-30S as shown in Figs. 5.19 and 5.20. However, the moment capacity decreases sharply as $\mathrm{D}_{\mathrm{cp}} / \mathrm{D}$ increases for $\mathrm{SW}$ cases, as shown in Fig. 5.21 for $\mathrm{SW}$ cases which also includes $\mathrm{D}_{\mathrm{cp}} / \mathrm{D}=0.625$. The maximum normalized strength difference is $15 \%$ for CFSW4-20U2 versus CFSW4-20S. The reason for the moment capacity decrease with $\mathrm{D}_{\mathrm{cp}} / \mathrm{D}$ increase is clearly that for a singly symmetric section in which the compression flanges are smaller than equivalent tension flanges, thus the yield moment to plastic moment ratio is less than that for a symmetric section, i.e., $M_{p} / M_{y}$ increases as $\mathrm{D}_{\mathrm{cp}} / \mathrm{D}$ increases. Therefore, in the moment-rotation curve which is normalized by 
dividing the plastic moment, the values for a singly symmetric section are much lower than those for a symmetric section.

It is also noticed that the web slenderness needs to be smaller for singly symmetric I-shaped girders with large $\mathrm{M}_{\mathrm{p}} / \mathrm{M}_{\mathrm{y}}$, in order to develop their plastic moment capacity $M_{p}$. This is one of the underlying phenomena leading to the development of the newly proposed web compactness (Barth et al., 2003). From the FEA result, for CW cases, with proposed web compactness, $\lambda_{\mathrm{pw}\left(\mathrm{D}_{\mathrm{cp}}\right)}$, the maximum moment capacity does not decrease; conversely, it increases by $10 \%$ for CFCW4-20U2 versus CFCW4-20S, as shown in Fig.5.22 for $\mathrm{CW}$ cases including $\mathrm{D}_{\mathrm{cp}} / \mathrm{D}=0.5,0.625$, and 0.75 . It is evident that web compactness with $\lambda_{\mathrm{pw}\left(\mathrm{D}_{\mathrm{cp}}\right)}$ can successfully incorporates web slenderness requirements for increasing $\mathrm{D}_{\mathrm{cp}} / \mathrm{D}$ ratio. Furthermore, it is observed that larger values of $\mathrm{D}_{\mathrm{cp}} / \mathrm{D}$ ratio generate relatively earlier yielding.

Therefore, it is concluded that $\mathrm{D}_{\mathrm{cp}} / \mathrm{D}$ has significant effect on normalized strength for SW cases but have a slightly improved or no effect on $\mathrm{CW}$ cases. Its influence on moment-rotation shape was found to be relatively insignificant.

\subsubsection{Web Slenderness $\left(2 \mathrm{D}_{\mathrm{cp}} / \mathrm{t}_{\mathrm{w}}\right)$}

Different web slenderness, compact limit $\lambda_{\mathrm{pw}\left(\mathrm{D}_{\mathrm{cp}}\right)}$ and slender limit $6.8 \sqrt{\mathrm{E} / \mathrm{F}_{\mathrm{yc}}}$, are studied to assess the effect of web slenderness on I-shaped girder moment-rotation behavior. As discussed previously, the incorporation of the proposed web compactness limit Eq. 2.17 is to increase web slenderness requirements for singly symmetric girders which have larger $M_{p} / M_{y}$ ratios to reach $M_{p}$. From the FEA results, most of the girders 
studies herein with proposed compact web can reach $\mathrm{M}_{\mathrm{p}}$, as shown in Fig. 5.22. Different

web slenderness, compact limit $\lambda_{\mathrm{pw}\left(\mathrm{D}_{\mathrm{cp}}\right)}$ and slender limit $6.8 \sqrt{\mathrm{E} / \mathrm{F}_{\mathrm{yc}}}$, have significant effect on normalized moment capacity. This effect increases as $\mathrm{D}_{\mathrm{cp}} / \mathrm{D}$ increases, where the maximum ratio of moment capacity for compact web versus slender web is 1.04 (for CFCW4-20S versus CFSW4-20S), 1.21 (for CFCW4-20U1 versus CFSW4-20U1), and 1.35 (for CFCW4-20U2 versus CFSW4-20U2) respectively, as listed in Table 5.3. It is also found that web slenderness has little effect on the moment-rotation shape, as an example as shown in Fig. 5.23 for CF4-30 cases.

\subsubsection{Cross-Section Aspect Ratio ( $\left.\mathrm{D} / \mathrm{b}_{\mathrm{fc}}\right)$}

From Table 5.4, it can also be seen that the variation of aspect ratio produces a little effect on the moment capacity for $\mathrm{CW}$ cases. The maximum difference of strength capacity is $\pm 3 \%$ for CFCW-20S and CFCW-20U2 cases, respectively. However, the $\mathrm{D} / \mathrm{b}_{\mathrm{fc}}$ effect on girder strength becomes more significant for SW cases, with the maximum difference to be $-9 \%$ (CFSW4-20U2 versus CFSW3-20U2). The post-peak moment-rotation curve drops more rapidly as $\mathrm{D} / \mathrm{b}_{\mathrm{fc}}$ increases, and once again, this effect becomes more significant for SW cases, as can be seen from Figs. 5.24 and 5.25 for CFCW-30 and CFSW-30 cases, respectively. For the same reason mentioned previously, $\mathrm{D}_{\mathrm{cp}} / \mathrm{D}=0.625$ is not included in the figures.

The detrimental effect of the larger $\mathrm{D} / \mathrm{b}_{\mathrm{fc}}$ to the slender web can be explained as follows. Consider CFSW3-30S and CFSW4-30S, both of these girders have identical web dimensions. The difference is that the flanges of CFSW4-30S have significantly less 
area than those of CFSW3 (since the width of the flanges is smaller for CFSW4-30S while $b_{\mathrm{fc}} / 2 \mathrm{t}_{\mathrm{fc}}$ is the same for both girders), resulting in CFSW4 be more aversely affected by the instability behavior of the webs.

\subsubsection{Span-to-Depth Ratio (L/D)}

The L/D ratio represents the variation of moment along the length of the girders, which is termed as moment gradient. A larger value of L/D represents a flat moment gradient and a small L/D value represents a steep moment gradient. From Figs. 5.26 and 5.27 , it can be seen that lower value of L/D corresponds to a smaller normalized strength (except CFCW4-20U2 whose strength increase 2\% compared with CFCW4-30U2), where the maximum strength reduction is 5\% for CFSW4-20S versus CFSW4-30S. For both $\mathrm{CW}$ and $\mathrm{SW}$ cases, the girders with $\mathrm{L} / \mathrm{D}=20$ will yield earlier and have a relatively larger ductility than $\mathrm{L} / \mathrm{D}=30$ cases, as can be observed in Figs. 5.28 through 5.31. The larger moment gradient would result in a smaller strain for a given rotation and thereby improve the rotation capacity.

\subsection{Summary}

Through a series of parametric studies performed in this chapter, the following conclusions can be drawn:

1. Hybrid HPS70W girders have larger normalized strength (with slender webs) and improved ductility (with slender or compact webs) compared with homogeneous Grade 50 and HPS 70W girders. For the hybrid girders with compact flanges and webs, 
these benefits decrease with increased $\mathrm{D}_{\mathrm{cp}} / \mathrm{D}$.

2. Flange slenderness $2 b_{\mathrm{fc}} / \mathrm{t}_{\mathrm{fc}}$ has significant effect on post-peak regions on the momentrotation curves but little effect on normalized strength.

3. As $\mathrm{D}_{\mathrm{cp}} / \mathrm{D}$ increases, normalized strength decreases for slender webs. However, with proposed compact web, effect of $\mathrm{D}_{\mathrm{cp}} / \mathrm{D}$ can be neglected. $\mathrm{D}_{\mathrm{cp}} / \mathrm{D}$ has no important effect on moment-rotation shape.

4. Web slenderness $2 \mathrm{D}_{\mathrm{cp}} / \mathrm{t}_{\mathrm{w}}$ has significant effect on girder strength while the effect on moment-rotation shape is less significant.

5. Girders with proposed web compactness limit $2 \mathrm{D}_{\mathrm{cp}} / \mathrm{t}_{\mathrm{w}} \leq \lambda_{\mathrm{pw}\left(\mathrm{D}_{\mathrm{p} p}\right)}$ can reach $\mathrm{M}_{\mathrm{p}}$ for most cases at $L / D=30$ especially for singly symmetric girders.

6. Cross-section aspect ratio $\mathrm{D} / \mathrm{b}_{\mathrm{fc}}$ has significant influence on both strength and moment-rotation shape for girders with slender web. For those girders with compact web, the effect becomes less significant.

7. Larger span-to-depth ratio $\mathrm{L} / \mathrm{D}$ will lead an earlier yielding of the girders. Its influence on moment-rotation response is relatively small compared with flange slenderness and cross-section aspect ratio $\mathrm{D} / \mathrm{b}_{\mathrm{fc}}$.

8. Typical final failure modes of the girders studied herein are inelastic buckling of the compression flanges and possible destabilizing web buckling ultimately leading to lateral torsional buckling, as shown in Fig. 5.32. 
Table 5.1 Summary of key design parameters of the FEA parametric studies

\begin{tabular}{|l|l|l|c|}
\hline \multicolumn{1}{|c|}{ Notations } & \multicolumn{1}{|c|}{ Symbol } & \multicolumn{1}{c|}{ Varied Parameters } & $\begin{array}{c}\text { No. of varied } \\
\text { parameters }\end{array}$ \\
\hline Girder length & $\mathrm{L}$ & $60 \mathrm{ft}$ & 1 \\
\hline $\begin{array}{l}\text { Girder material } \\
\text { configurations }\end{array}$ & $\begin{array}{l}\mathrm{G} 50 \\
\mathrm{H} 70\end{array}$ & $\begin{array}{l}\text { Homogeneous Grade } 50 \text { and HPS } \\
70 \mathrm{~W} \text { girders; hybrid girders with } \\
70 \mathrm{ksi} \text { flanges and } 50 \mathrm{ksi} \text { webs }\end{array}$ & 3 \\
\hline $\begin{array}{l}\text { Compression flange } \\
\text { slenderness }\end{array}$ & $\mathrm{b}_{\mathrm{fc}} / 2 \mathrm{t}_{\mathrm{fc}}$ & $0.29 \sqrt{\mathrm{E} / \mathrm{F}_{\mathrm{y}}}, 0.38 \sqrt{\mathrm{E} / \mathrm{F}_{\mathrm{y}}}$ & 2 \\
\hline Web slenderness & $2 \mathrm{D}_{\mathrm{cp}} / \mathrm{t}_{\mathrm{w}}$ & $\lambda_{\mathrm{pw}\left(\mathrm{D}_{\mathrm{cp}}\right)}, 3.76 \sqrt{\mathrm{E} / \mathrm{F}_{\mathrm{y}}}, 6.8 \sqrt{\mathrm{E} / \mathrm{F}_{\mathrm{y}}}$ & 3 \\
\hline Cross-section aspect ratio & $\mathrm{D} / \mathrm{b}_{\mathrm{fc}}$ & $3,4.25$ & 2 \\
\hline $\begin{array}{l}\text { Depth of web in } \\
\text { compression }\end{array}$ & $\mathrm{D}_{\mathrm{cp}} / \mathrm{D}$ & $0.5,0.625,0.75$ & 3 \\
\hline Span-to-depth ratio & $\mathrm{L} / \mathrm{D}$ & 20,30 & 2 \\
\hline Lateral bracing & $\mathrm{L}_{\mathrm{b}}$ & $\left.0.1-0.06\left(\frac{\mathrm{M}_{1}}{\mathrm{M}_{2}}\right)\right] \frac{\mathrm{r}_{\mathrm{t}} \mathrm{E}}{\mathrm{F}_{\mathrm{yc}}}$ & 1 \\
\hline
\end{tabular}


Table 5.2 Girder properties and key FEA results: homogeneous Grade 50, HPS 70W and hybrid HPS 70W girder

\begin{tabular}{|c|c|c|c|c|c|c|c|c|c|c|c|c|c|c|c|c|c|c|c|c|c|c|}
\hline \multirow[b]{2}{*}{ LID } & \multirow[b]{2}{*}{ Naming Convention } & \multirow{2}{*}{$\begin{array}{c}\text { Flange } \\
\text { Slenderness }\end{array}$} & \multirow{2}{*}{$\begin{array}{c}\text { Web } \\
\text { Slenderness }\end{array}$} & \multirow[b]{2}{*}{$\mathrm{D} / \mathrm{b}_{\mathrm{tc}}$} & \multirow[b]{2}{*}{$D_{c p} / D$} & \multirow[b]{2}{*}{$\begin{array}{c}\text { Web Slenderness } \\
2 \mathrm{D}_{\mathrm{c} p} / \mathrm{t}_{\mathrm{w}}\end{array}$} & \multicolumn{3}{|c|}{ Material Constants } & \multicolumn{6}{|c|}{ Girder Dimensions } & \multirow{2}{*}{$\begin{array}{c} \\
\begin{array}{c}L_{b} \\
(E q, 2.19)\end{array} \\
\end{array}$} & \multirow{2}{*}{$2 \mathrm{D}_{\mathrm{cp}} / \mathrm{t}_{\mathrm{w}}$} & \multirow{2}{*}{$b_{t_{t} /\left(2 t^{2} t_{t}\right)}$} & \multirow{2}{*}{$R_{n}$} & \multirow[b]{2}{*}{$\mathrm{M}_{\mathrm{y}}$} & \multirow[b]{2}{*}{$m_{p}$} & \multirow[b]{2}{*}{$M_{\text {FEA_mar }} / M_{p}$} \\
\hline & & & & & & & $F_{y c}$ & $F_{y t}$ & $F_{\mathrm{yw}}$ & $b_{\text {to }}$ & $t_{10}$ & $b_{t h}$ & $t_{n}$ & D & $t_{w}$ & & & & & & & \\
\hline \multirow{11}{*}{$\begin{array}{l}L \mathrm{LD}=30 \\
\text { (Hybrid) }\end{array}$} & & & & \multirow{6}{*}{$\mathrm{D} / \mathrm{b}_{\mathrm{te}}=4.25$} & & & (ksi) & (ksi) & (ksi) & (in) & (in) & (in) & (in) & (in) & (in) & (in) & & & & (in-kips) & (in-kips) & \\
\hline & CFCW4-30S(Hyb) & compact & Compact & & $\mathrm{Dcp} / \mathrm{D}=0.5$ & $\lambda_{\text {pmo(pop) }}$ & 70 & 70 & 50 & 14.12 & 0.913 & 14.12 & 0.913 & 60 & 0.701 & 67 & 85.61 & 7.73 & 0.96 & 82697 & 86476 & 1.010 \\
\hline & CFSW4-30S(Hyb) & compact & non-compact & & & $6.8^{*} \operatorname{sant}(E / F y)$ & 70 & 70 & 50 & 14.12 & 0.913 & 14.12 & 0.913 & 60 & 0.434 & 72 & 138.41 & 7.73 & 0.97 & 71800 & 74445 & 0.933 \\
\hline & CFSW4-30U1(Hyb) & compact & non-compact & & & $6.8^{*}$ sart(E/Fy) & 70 & 70 & 50 & 14.12 & 0.913 & 20.00 & 0.935 & 60 & 0.542 & 69 & 138.45 & 7.73 & 0.97 & 80176 & 90206 & 0.859 \\
\hline & CFCW4-30U2(Hyb) & compact & Compact & & $\mathrm{Dcp} / \mathrm{D}=0.75$ & $\lambda_{\text {pom(oce) }}$ & 70 & 70 & 50 & 14.12 & 0.913 & 20.00 & 2.550 & 60 & 1.778 & 50 & 50.61 & 7.73 & 0.93 & 157462 & 199129 & 1.026 \\
\hline & CFSW4-30U2(Hyb) & compact & non-compact & & & $6.8^{*} \mathrm{sart}(\mathrm{E} / \mathrm{Fy})$ & 70 & 70 & 50 & 14.12 & 0.913 & 20.00 & 1.340 & 60 & 0.650 & 66 & 138.35 & 7.73 & 0.96 & 89545 & 106971 & 0.825 \\
\hline & CFCW3-30S(Hyb) & compact & Compact & & $\mathrm{Dcp} / \mathrm{D}=0.5$ & $\lambda_{\mathrm{pm}(\mathrm{DPp})}$ & 70 & 70 & 50 & 20.00 & 1.293 & 20.00 & 1.293 & 60 & 0.664 & 133 & 90.35 & 7.73 & 0.98 & 135408 & 140828 & 1.015 \\
\hline & CFCW3-30U1(Hyb) & compact & Compact & $\mathrm{D} / \mathrm{b}=3$ & $D c p / D=0.625$ & $\lambda_{p m(0)(p)}$ & 70 & 70 & 50 & 20.00 & 1.293 & 20.00 & 1.850 & 60 & 1.039 & 120 & 72.17 & 7.73 & 0.97 & 158887 & 179413 & 1.020 \\
\hline & CFsW3-30U1(Hyb) & compact & non-compact & & & $6.8 * \mathrm{sart}(\mathrm{E} / \mathrm{Fy})$ & 70 & 70 & 50 & 20.00 & 1.293 & 20.00 & 1.585 & 60 & 0.542 & 135 & 138.58 & 7.73 & 0.98 & 133844 & 146642 & 0.923 \\
\hline & CFCW3-30U2(Hyb) & compact & Compact & & $\mathrm{Dcp} / \mathrm{D}=0.75$ & $\lambda_{\text {pomplop) }}$ & 70 & 70 & 50 & 20.00 & 1.293 & 20.00 & 2.920 & 60 & 1.521 & 106 & 59.15 & 7.73 & 0.95 & 194115 & 235456 & 1.023 \\
\hline & CFSW3-30U2(Hyb) & compact & non-compact & & & $6.8^{*} \operatorname{sart}(E / F y)$ & 70 & 70 & 50 & 20.00 & 1.293 & 20.00 & 1.990 & 60 & 0.650 & 130 & 138.43 & 7.73 & 0.98 & 142699 & 163762 & 0.894 \\
\hline & CFCW4-30S(G50) & compact & Compact & & $\mathrm{Dcp} / \mathrm{D}=0.5$ & $\lambda_{\mathrm{pum}(\mathrm{Cop})}$ & 50 & 50 & 50 & 14.12 & 0.771 & 14.12 & 0.771 & 60 & 0.795 & 104 & 75.47 & 9.15 & 1.00 & 55927 & 68863 & 0.985 \\
\hline & CFSW4-30s(G50) & compact & non-compact & & & $6.8^{*}$ sart(E/Fy) & 50 & 50 & 50 & 14.12 & 0.771 & 14.12 & 0.771 & 60 & 0.400 & 124 & 150.00 & 9.15 & 1.00 & 44374 & 51088 & 0.889 \\
\hline & CFCW4-30U1(G50) & compact & Compact & $\mathrm{D} / \mathrm{b}_{\mathrm{t}}=4.25$ & $\mathrm{Dcp} / \mathrm{D}=0.625$ & $\lambda_{\mathrm{pm}(\mathrm{O}(\mathrm{cos})}$ & 50 & 50 & 50 & 14.12 & 0.771 & 20.00 & 1.565 & 60 & 1.522 & 77 & 48.22 & 9.15 & 1.00 & 90290 & 129798 & 1.050 \\
\hline & CFSW4-30U1(G50) & compact & non-compact & & & $6.8 * \mathrm{sart}(E / F \mathrm{~F})$ & 50 & 50 & 50 & 14.12 & 0.771 & 20.00 & 0.890 & 60 & 0.458 & 117 & 163.96 & 9.15 & 1.00 & 49241 & 62945 & 0.802 \\
\hline & CFCW4-30U2(G50) & compact & Compact & & $\mathrm{Dcp} / \mathrm{D}=0.75$ & $\lambda_{\text {pompocos) }}$ & 50 & 50 & 50 & 14.12 & 0.771 & 28.00 & 2.765 & 60 & 2.216 & 65 & 40.63 & 9.15 & 1.00 & 132057 & 212758 & 1.030 \\
\hline & CFCW3-30S(G50) & compact & Compact & & $\mathrm{Dcp} / \mathrm{D}=0.5$ & $\lambda_{\text {pumpoco }}$ & 50 & 50 & 50 & 20.00 & 1.093 & 20.00 & 1.093 & 60 & 0.661 & 229 & 90.78 & 9.15 & 1.00 & 84722 & 96498 & 1.020 \\
\hline & CFSW3-30S(G50) & compact & non-compact & & & $6.8^{*}$ sart $(E \mathbb{F} y)$ & 50 & 50 & 50 & 20.00 & 1.093 & 20.00 & 1.093 & 60 & 0.400 & 252 & 150.00 & 9.15 & 1.00 & 77168 & 84756 & 0.957 \\
\hline & CFCW3-30U1(G50) & compact & Compact & $D / b_{t a j}$ & $\mathrm{Dcp} / \mathrm{D}=0.625$ & $\lambda_{\mathrm{pm}(\mathrm{Cos})}$ & 50 & 50 & 50 & 20.00 & 1.093 & 20.00 & 1.970 & 60 & 1.167 & 188 & 64.29 & 9.15 & 1.00 & 108917 & 143642 & 1.010 \\
\hline & CFSW3-30U1(G50) & compact & non-compact & & & $6.8^{*} \mathrm{sart}(\mathrm{E} / \mathrm{Fy})$ & 50 & 50 & 50 & 20.00 & 1.093 & 20.00 & 1.435 & 60 & 0.458 & 243 & 163.65 & 9.15 & 1.00 & 81476 & 96787 & 0.902 \\
\hline & CFCW3-30U2(G50) & compact & Compact & & $\mathrm{Dcp} / \mathrm{D}=0.75$ & $\lambda_{\text {pom }(0 \mathrm{cos})}$ & 50 & 50 & 50 & 20.00 & 1.093 & 28.00 & 2.765 & 60 & 1.851 & 151 & 48.63 & 9.15 & 1.00 & 145996 & 217309 & 1.030 \\
\hline & CFSW3-30U2(G50) & compact & non-compact & & & $6.8^{*} \operatorname{sant}(E / F y)$ & 50 & 50 & 50 & 20.00 & 1.093 & 20.00 & 1.915 & 60 & 0.550 & 230 & 163.63 & 9.15 & 1.00 & 87462 & 111240 & 0.856 \\
\hline & CFCW4-30S(H70) & compact & Compact & & $\mathrm{Dcp} / \mathrm{D}=0.5$ & $\lambda_{\mathrm{pm}(\mathrm{DPO})}$ & 70 & 70 & 70 & 14.12 & 0.913 & 14.12 & 0.913 & 60 & 0.949 & 66 & 63.20 & 7.73 & 1.00 & 92827 & 114747 & 0.995 \\
\hline & CFSW4-30S(H70) & compact & non-compact & & & $6.8^{*}$ sart(t//Fy) & 70 & 70 & 70 & 14.12 & 0.913 & 14.12 & 0.913 & 60 & 0.434 & 79 & 138.41 & 7.73 & 1.00 & 71800 & 82248 & 0.893 \\
\hline & CFCW4-30U1(H70) & compact & Compact & $\mathrm{D} / \mathrm{b}_{\mathrm{t} t}=4.25$ & $\mathrm{Dcp} / \mathrm{D}=0.625$ & $\lambda_{\mathrm{pm}(\mathrm{Dop})}$ & 70 & 70 & 70 & 14.12 & 0.913 & 20.00 & 1.920 & 60 & 1.712 & 53 & 43.77 & 7.73 & 1.00 & 146380 & 211860 & 1.030 \\
\hline & CFSW4-30U1(H70) & compact & non-compact & & & $6.8^{*}$ sart(E/EFy) & 70 & 70 & 70 & 14.12 & 0.913 & 20.00 & 1.050 & 60 & 0.542 & 74 & 138.36 & 7.73 & 1.00 & 81487 & 104352 & 0.800 \\
\hline & CFCW4-30U2(H70) & compact & Compact & & $D c p / D=0.75$ & $\lambda_{\text {pup(Dop) }}$ & 70 & 70 & 70 & 14.12 & 0.913 & 28.00 & 3.300 & 60 & 2.636 & 43 & 34.20 & 7.73 & 1.00 & 220608 & 356289 & 1.070 \\
\hline LD $=30$ & CFSW4-30U2(H70) & compact & non-compact & & & $6.8 \mathrm{sart(E/Fy)}$ & 70 & 70 & 70 & 14.12 & 0.913 & 20.00 & 1.620 & 60 & 0.650 & 69 & 138.43 & 7.73 & 1.00 & 91986 & 128062 & 0.904 \\
\hline & CFCW3-30S(H70) & compact & Compact & & $\mathrm{Dcp} / \mathrm{D}=0.5$ & $\lambda_{\mathrm{pm}(\mathrm{pop})}$ & 70 & 70 & 70 & 20.00 & 1.293 & 20.00 & 1.293 & 60 & 0.790 & 129 & 75.91 & 7.73 & 1.00 & 140494 & 160740 & 1.010 \\
\hline & CFSW3-30S $(\mathrm{H} 70)^{*}$ & compact & non-compact & & & $6.8^{*}$ sant $(E|F| F)$ & 70 & 70 & 70 & 20.00 & 1.293 & 20.00 & 1.293 & 60 & 0.434 & 140 & 138.41 & 7.73 & 1.00 & 126123 & 138255 & 0.955 \\
\hline & CFCW3-30U1(H70) & compact & Compact & $\mathrm{D} / \mathrm{b}_{\mathrm{t} t}=3$ & Dep $1 \mathrm{D}=0.625$ & $\lambda_{p m(0 p)}$ & 70 & 70 & 70 & 20.00 & 1.293 & 20.00 & 2.340 & 60 & 1.394 & 110 & 53.83 & 7.73 & 1.00 & 181177 & 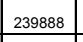 & 1.020 \\
\hline & CFSW3-30U1(H70) & compact & non-compact & & & $6.8^{*} \mathrm{sart}(\mathrm{E} / \mathrm{Fy})$ & 70 & 70 & 70 & 20.00 & 1.293 & 20.00 & 1.700 & 60 & 0.542 & 135 & 138.45 & 7.73 & 1.00 & 134987 & 160893 & 0.900 \\
\hline & CFCW3-30U2(H70) & compact & Compact & & $\mathrm{Dcp} / \mathrm{D}=0.75$ & $\lambda_{p(p(D p)}$ & 70 & 70 & 70 & 20.00 & 1.293 & 28.00 & 3.295 & 60 & 2.209 & 91 & 40.77 & 7.73 & 1.00 & 243696 & 364105 & 1.050 \\
\hline & CFSW3-30U2(H70) & compact & non-compact & & & $6.8^{*}$ sart $(E|F| F)$ & 70 & 70 & 70 & 20.00 & 1.293 & 20.00 & 2.270 & 60 & 0.650 & 129 & 138.49 & 7.73 & 1.00 & 145073 & 185108 & 0.848 \\
\hline
\end{tabular}

"The analysis for the girder CFSW3-30S $(1 \mathrm{H} 70)$ was not completed. 
Table 5.3 Hybrid HPS 70W girder properties and the key FEA results

\begin{tabular}{|c|c|c|c|c|c|c|c|c|c|c|c|c|c|c|c|c|c|c|c|c|c|c|}
\hline \multirow[b]{2}{*}{ L/D } & \multirow[b]{2}{*}{$\begin{array}{c}\text { Naming } \\
\text { Convention }\end{array}$} & \multirow[b]{2}{*}{$\begin{array}{c}\text { Flange } \\
\text { Slenderness }\end{array}$} & \multirow[b]{2}{*}{$\begin{array}{c}\text { Web } \\
\text { Slenderness } \\
\end{array}$} & \multirow[b]{2}{*}{$\mathrm{D} / \mathrm{b}_{\mathrm{fc}}$} & \multirow[b]{2}{*}{$D_{c p} / D$} & \multirow[b]{2}{*}{$\begin{array}{c}\text { Web Slenderness } \\
2 D_{c p} / t_{w}\end{array}$} & \multicolumn{3}{|c|}{ Material Constants } & \multicolumn{6}{|c|}{ Girder Dimensions } & \multirow[b]{2}{*}{$\begin{array}{c}\mathrm{L}_{\mathrm{b}} \\
\text { (Eq. 2.19) }\end{array}$} & \multirow[b]{2}{*}{$2 \mathrm{D}_{\mathrm{cp}} / \mathrm{t}_{\mathrm{w}}$} & \multirow[b]{2}{*}{$\mathrm{b}_{\mathrm{rd}}\left(2^{2} \mathrm{t}_{\mathrm{t}_{\mathrm{c}}}\right)$} & \multirow[b]{2}{*}{$\mathbf{R}_{\mathrm{h}}$} & \multirow[b]{2}{*}{$M_{y}$} & \multirow[b]{2}{*}{$\mathrm{M}_{\mathrm{p}}$} & \multirow[b]{2}{*}{$M_{F E A_{-} \max } / M_{\mathrm{p}}$} \\
\hline & & & & & & & $F_{y c}$ & $F_{y t}$ & $F_{y w}$ & $b_{\mathrm{fc}}$ & $t_{t c}$ & $b_{t t}$ & $t_{t h}$ & D & $t_{w}$ & & & & & & & \\
\hline & & & & & & & (ksi) & (ksi) & (ksi) & (in) & (in) & (in) & (in) & (in) & (in) & (in) & & & & (in-kips) & (in-kips) & \\
\hline \multirow{23}{*}{$L / D=30$} & CFCW4-30S & compact & Compact & \multirow{6}{*}{$\mathrm{D} / \mathrm{b}_{\mathrm{tc}}=4.25$} & $\mathrm{Dcp} / \mathrm{D}=0.5$ & $\lambda_{\text {pw(Dcp) }}$ & 70 & 70 & 50 & 14.12 & 0.913 & 14.12 & 0.913 & 60 & 0.701 & 67 & 85.61 & 7.73 & 0.96 & 82697 & 86476 & 1.010 \\
\hline & CFSW4-30S & compact & non-compact & & & $6.8^{*} \mathrm{sart}(\mathrm{E} / \mathrm{F} \mathrm{y})$ & 70 & 70 & 50 & 14.12 & 0.913 & 14.12 & 0.913 & 60 & 0.434 & 72 & 138.41 & 7.73 & 0.97 & 71800 & 74445 & 0.933 \\
\hline & CFCW4-30U1 & compact & Compact & & $\mathrm{Dcp} / \mathrm{D}=0.625$ & $\lambda_{\mathrm{pw}(\mathrm{DCp})}$ & 70 & 70 & 50 & 14.12 & 0.913 & 20.00 & 1.290 & 60 & 1.189 & 58 & 63.24 & 7.73 & 0.94 & 113819 & 132889 & 1.007 \\
\hline & CFSW4-30U1 & compact & non-compact & & & $6.8^{*} \mathrm{sqr}(\mathrm{E} / \mathrm{Fy})$ & 70 & 70 & 50 & 14.12 & 0.913 & 20.00 & 0.935 & 60 & 0.542 & 69 & 138.45 & 7.73 & 0.97 & 80176 & 90206 & 0.859 \\
\hline & CFCW4-30U2 & compact & Compact & & $\mathrm{Dcp} / \mathrm{D}=0.75$ & $\lambda_{\mathrm{pw}(\mathrm{Dcp})}$ & 70 & 70 & 50 & 14.12 & 0.913 & 20.00 & 2.550 & 60 & 1.778 & 50 & 50.61 & 7.73 & 0.93 & 157462 & 199129 & 1.026 \\
\hline & CFSW4-30U2 & compact & non-compact & & & $6.8^{*} \mathrm{sqr}(\mathrm{E} / \mathrm{Fy})$ & 70 & 70 & 50 & 14.12 & 0.913 & 20.00 & 1.340 & 60 & 0.650 & 66 & 138.35 & 7.73 & 0.96 & 89545 & 106971 & 0.825 \\
\hline & CFCW3-30S & compact & Compact & \multirow{6}{*}{$\mathrm{D} / \mathrm{b}_{\mathrm{tc}}=3$} & $\mathrm{Dcp} / \mathrm{D}=0.5$ & $\lambda_{\text {pM(Dcp) }}$ & 70 & 70 & 50 & 20.00 & 1.293 & 20.00 & 1.293 & 60 & 0.664 & 133 & 90.35 & 7.73 & 0.98 & 135408 & 140828 & 1.015 \\
\hline & CFSW3-30S & compact & non-compact & & & $6.8^{*} \mathrm{sqrt}(\mathrm{E} / \mathrm{Fy})$ & 70 & 70 & 50 & 20.00 & 1.293 & 20.00 & 1.293 & 60 & 0.434 & 140 & 138.41 & 7.73 & 0.98 & 126123 & 130452 & 0.976 \\
\hline & CFCW3-30U1 & compact & Compact & & $D c p / D=0.625$ & $\lambda_{\text {pw(Dop) }}$ & 70 & 70 & 50 & 20.00 & 1.293 & 20.00 & 1.850 & 60 & 1.039 & 120 & 72.17 & 7.73 & 0.97 & 158887 & 179413 & 1.020 \\
\hline & CFSW3-30U1 & compact & non-compact & & & $6.8^{\star} \mathrm{sart}(\mathrm{E} / \mathrm{Fy})$ & 70 & 70 & 50 & 20.00 & 1.293 & 20.00 & 1.585 & 60 & 0.542 & 135 & 138.58 & 7.73 & 0.98 & 133844 & 146642 & 0.923 \\
\hline & CFCW3-30U2 & compact & Compact & & $\mathrm{Dcp} / \mathrm{D}=0.75$ & $\lambda_{\text {pw(Dop) }}$ & 70 & 70 & 50 & 20.00 & 1.293 & 20.00 & 2.920 & 60 & 1.521 & 106 & 59.15 & 7.73 & 0.95 & 194115 & 235456 & 1.023 \\
\hline & CFSW3-30U2 & compact & non-compact & & & $6.8^{\star} \operatorname{sqr}(E / F y)$ & 70 & 70 & 50 & 20.00 & 1.293 & 20.00 & 1.990 & 60 & 0.650 & 130 & 138.43 & 7.73 & 0.98 & 142699 & 163762 & 0.894 \\
\hline & UccW4-30S & ultra-compact & Compact & \multirow{5}{*}{$\mathrm{D} / \mathrm{b}_{\mathrm{ic}}=4.25$} & $\mathrm{Dcp} / \mathrm{D}=0.5$ & $\lambda_{\text {pw(Dcp) }}$ & 70 & 70 & 50 & 14.12 & 1.192 & 14.12 & 1.192 & 60 & 0.690 & 75 & 87.00 & 5.92 & 0.97 & 98559 & 103103 & 0.991 \\
\hline & UcsW4-30S & ultra-compact & non-compact & & & $6.8^{*} \mathrm{sgrt}(E / F \mathrm{~F})$ & 70 & 70 & 50 & 14.12 & 1.192 & 14.12 & 1.192 & 60 & 0.434 & 81 & 138.41 & 5.92 & 0.98 & 88212 & 91576 & 0.949 \\
\hline & UCSW4-30U1 & $\begin{array}{l}\text { ultra-compact } \\
\end{array}$ & non-compact & & & $6.8^{*} \mathrm{sqr}(E / F \mathrm{~F})$ & 70 & 70 & 50 & 14.12 & 1.192 & 20.00 & 1.130 & 60 & 0.542 & 77 & 138.26 & 5.92 & 0.97 & 96121 & 107264 & 0.876 \\
\hline & UCCW4-30U2 & \begin{tabular}{|l|} 
ultra-compact \\
\end{tabular} & Compact & & $\mathrm{Dcp} / \mathrm{D}=0.75$ & $\lambda_{\text {pw(Dop })}$ & 70 & 70 & 50 & 14.12 & 1.192 & 20.00 & 2.660 & 60 & 1.699 & 56 & 52.95 & 5.92 & 0.94 & 167874 & 210086 & 1.030 \\
\hline & UCSW4-30U2 & \begin{tabular}{|l|} 
ultra-compact \\
\end{tabular} & $\begin{array}{l}\text { non-compact } \\
\end{array}$ & & & $6.8^{\star} \mathrm{sgrt}(E / F y)$ & 70 & 70 & 50 & 14.12 & 1.192 & 20.00 & 1.540 & 60 & 0.650 & 73 & 138.54 & 5.92 & 0.97 & 105343 & 124277 & 0.829 \\
\hline & UCCW3-30S & ultra-compact & Compact & \multirow{6}{*}{$D / b_{t c}=3$} & $\mathrm{Dcp} / \mathrm{D}=0.5$ & $\lambda_{\text {pw(Dcp) }}$ & 70 & 70 & 50 & 20.00 & 1.688 & 20.00 & 1.688 & 60 & 0.662 & 137 & 90.63 & 5.92 & 0.98 & 168285 & 175602 & 1.010 \\
\hline & ucsw3-30S & ultra-compact & non-compact & & & $6.8^{*} \mathrm{sart}(\mathrm{E} / \mathrm{Fy})$ & 70 & 70 & 50 & 20.00 & 1.688 & 20.00 & 1.688 & 60 & 0.434 & 144 & 138.41 & 5.92 & 0.99 & 159198 & 165318 & 0.933 \\
\hline & UCCW3-30U1 & \begin{tabular}{|l|} 
ultra-compact \\
\end{tabular} & \begin{tabular}{|l|} 
Compact \\
\end{tabular} & & $\mathrm{Dcp} / \mathrm{D}=0.625$ & $\lambda_{\text {pw(Dop) }}$ & 70 & 70 & 50 & 20.00 & 1.688 & 20.00 & 2.225 & 60 & 1.003 & 127 & 74.77 & 5.92 & 0.97 & 189366 & 212132 & 1.020 \\
\hline & UCsW3-30U1 & ultra-compact & non-compact & & & $6.8^{\star} \mathrm{sgrt}(\mathrm{E} / \mathrm{Fy})$ & 70 & 70 & 50 & 20.00 & 1.688 & 20.00 & 1.980 & 60 & 0.542 & 140 & 138.54 & 5.92 & 0.98 & 166625 & 181655 & 0.945 \\
\hline & UCCW3-30U2 & ultra-compact & Compact & & $D \mathrm{cpp} / \mathrm{D}=0.75$ & $\lambda_{\text {pw(Dcp) }}$ & 70 & 70 & 50 & 20.00 & 1.688 & 20.00 & 3.230 & 60 & 1.439 & 115 & 62.52 & 5.92 & 0.96 & 221174 & 264454 & 1.020 \\
\hline & UCSW3-30U2 & ultra-compact & non-compact & & & $6.8^{\star} \operatorname{sart}(E / F y)$ & 70 & 70 & 50 & 20.00 & 1.688 & 20.00 & 2.385 & 60 & 0.650 & 136 & 138.41 & 5.92 & 0.98 & 175263 & 199004 & 0.916 \\
\hline
\end{tabular}


Table 5.3 Hybrid HPS 70W girder properties and the key FEA results (Cont'd)

\begin{tabular}{|c|c|c|c|c|c|c|c|c|c|c|c|c|c|c|c|c|c|c|c|c|c|c|}
\hline \multirow[b]{2}{*}{ LID } & \multirow[b]{2}{*}{$\begin{array}{c}\begin{array}{c}\text { Naming } \\
\text { Convention }\end{array} \\
\end{array}$} & \multirow[b]{2}{*}{$\begin{array}{c}\text { Flange } \\
\text { Slenderness }\end{array}$} & \multirow[b]{2}{*}{$\begin{array}{c}\text { Web } \\
\text { Slenderness }\end{array}$} & \multirow[b]{2}{*}{$\mathrm{D} / \mathrm{b}_{\mathrm{fc}}$} & \multirow[b]{2}{*}{$D_{c p} / D$} & \multirow[b]{2}{*}{$\begin{array}{l}\text { Web Slenderness } \\
2 D_{c_{p} / t_{w}}\end{array}$} & \multicolumn{3}{|c|}{ Material Constants } & \multicolumn{6}{|c|}{ Girder Dimensions } & \multirow[b]{2}{*}{\begin{tabular}{|c|}
$L_{b}$ \\
(Eq. 2.19)
\end{tabular}} & \multirow[b]{2}{*}{$2 \mathrm{D}_{\mathrm{cp}} / \mathrm{t}_{\mathrm{w}}$} & \multirow[b]{2}{*}{$b_{i d}\left(2^{\star} t_{t c}\right)$} & \multirow[b]{2}{*}{$\mathbf{R}_{\mathrm{h}}$} & \multirow[b]{2}{*}{$M_{y}$} & \multirow[b]{2}{*}{$M_{p}$} & \multirow[b]{2}{*}{$M_{F E A \_ \text {max }} / M_{p}$} \\
\hline & & & & & & & $F_{y c}$ & $F_{y t}$ & $F_{y w}$ & $b_{f c}$ & $t_{\text {tc }}$ & $b_{t t}$ & $t_{t h}$ & D & $t_{w}$ & & & & & & & \\
\hline & & & & & & & (ksi) & (ksi) & (ksi) & (in) & (in) & (in) & (in) & (in) & (in) & (in) & & & & (in-kips) & (in-kips) & \\
\hline \multirow{12}{*}{$L / D=20$} & CFCW4-20S & compact & Compact & \multirow{6}{*}{$\mathrm{D} / \mathrm{b}_{\mathrm{tc}}=4.25$} & $\mathrm{Dcp} / \mathrm{D}=0.5$ & $\lambda_{\text {pw }(0 \mathrm{cp})}$ & 70 & 70 & 50 & 21.18 & 1.369 & 21.18 & 1.369 & 90 & 1.051 & 124 & 85.61 & 7.73 & 0.96 & 279103 & 291855 & 0.957 \\
\hline & CFSW4-20S & compact & non-compact & & & $6.8^{*} \mathrm{sqrt}(\mathrm{E} / \mathrm{Fy})$ & 70 & 70 & 50 & 21.18 & 1.369 & 21.18 & 1.369 & 90 & 0.650 & 138 & 138.41 & 7.73 & 0.97 & 242325 & 251251 & 0.921 \\
\hline & CFCW4-20U1 & compact & Compact & & $\mathrm{Dcp} / \mathrm{D}=0.625$ & $\lambda_{\mathrm{pw}(\mathrm{Dcp})}$ & 70 & 70 & 50 & 21.18 & 1.369 & 35.00 & 1.648 & 90 & 1.781 & 101 & 63.19 & 7.73 & 0.94 & 382846 & 446749 & 0.990 \\
\hline & CFSW4-20U1 & compact & non-compact & & & $6.8^{*} \mathrm{sart}(\mathrm{E} / \mathrm{Fy})$ & 70 & 70 & 50 & 21.18 & 1.369 & 35.00 & 1.203 & 90 & 0.813 & 129 & 138.52 & 7.73 & 0.97 & 270290 & 304223 & 0.819 \\
\hline & CFCW4-20U2 & compact & Compact & & $\mathrm{Dcp} / \mathrm{D}=0.75$ & $\lambda_{\mathrm{pw}(\mathrm{Dcp})}$ & 70 & 70 & 50 & 21.18 & 1.369 & 35.00 & 3.280 & 90 & 2.671 & 83 & 50.53 & 7.73 & 0.93 & 529801 & \begin{tabular}{|l|}
670422 \\
\end{tabular} & 1.050 \\
\hline & CFSW4-20U2* & compact & non-compact & & & $6.8^{*} \mathrm{sgrt}(\mathrm{E} / \mathrm{Fy})$ & 70 & 70 & 50 & 21.18 & 1.369 & 35.00 & 1.725 & 90 & 0.975 & 120 & 138.46 & 7.73 & 0.96 & 301690 & 360548 & 0.780 \\
\hline & CFCW3-20S & compact & Compact & \multirow{6}{*}{$\mathrm{D} / \mathrm{b}_{\mathrm{t} t}=3$} & $\mathrm{Dcp} / \mathrm{D}=0.5$ & $\lambda_{\mathrm{pw}(\mathrm{DCp})}$ & 70 & 70 & 50 & 30.00 & 1.939 & 30.00 & 1.939 & 90 & 0.996 & 275 & 90.36 & 7.73 & 0.98 & 456991 & 475283 & 0.991 \\
\hline & CFSW3-20S & compact & non-compact & & & $6.8^{*} \operatorname{sqrt}(\mathrm{E} / \mathrm{Fy})$ & 70 & 70 & 50 & 30.00 & 1.939 & 30.00 & 1.939 & 90 & 0.650 & 297 & 138.41 & 7.73 & 0.98 & 425666 & 440275 & 0.937 \\
\hline & CFCW3-20U1 & compact & Compact & & $\mathrm{Dcp} / \mathrm{D}=0.625$ & $\lambda_{\mathrm{pw}(\mathrm{Dcp})}$ & 70 & 70 & 50 & 30.00 & 1.939 & 35.00 & 2.385 & 90 & 1.563 & 239 & 72.07 & 7.73 & 0.97 & 535559 & 605374 & 1.010 \\
\hline & CFSW3-20U1 & compact & non-compact & & & $6.8^{\star} \mathrm{sqrt}(\mathrm{E} / \mathrm{Fy})$ & 70 & 70 & 50 & 30.00 & 1.939 & 35.00 & 2.038 & 90 & 0.813 & 282 & 138.59 & 7.73 & 0.98 & 450794 & 494082 & 0.902 \\
\hline & CFCW3-20U2 & compact & Compact & & $\mathrm{Dcp} / \mathrm{D}=0.75$ & $\lambda_{\text {pw(Dop) }}$ & 70 & 70 & 50 & 30.00 & 1.939 & 40.00 & 3.290 & 90 & 2.288 & 202 & 58.98 & 7.73 & 0.95 & 651149 & 790820 & 1.020 \\
\hline & CFSW3-20U2 & compact & non-compact & & & $6.8^{*} \operatorname{sqrt}(\mathrm{E} / \mathrm{Fy})$ & 70 & 70 & 50 & 30.00 & 1.939 & 35.00 & 2.560 & 90 & 0.975 & 268 & 138.51 & 7.73 & 0.98 & 480336 & 551448 & 0.867 \\
\hline \multirow{12}{*}{$L / D=30$} & CFCW14-30S & $\begin{array}{l}\text { compact } \\
\end{array}$ & Compact & \multirow{3}{*}{$\mathrm{D} / \mathrm{bfc}=4.25$} & $\mathrm{Dcp} / \mathrm{D}=0.5$ & $\lambda_{\text {pw(10p) }}$ & 70 & 70 & 50 & 14.12 & 0.913 & 14.12 & 0.913 & 60 & 0.784 & 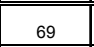 & 76.53 & 7.73 & 0.96 & 86086 & 90217 & 1.270 \\
\hline & CFCW14-30U1 & compact & compact & & & $6.8^{*} \operatorname{sqrt}(E / F y)$ & 70 & 70 & 50 & 14.12 & 0.913 & 20.00 & 1.165 & 60 & 0.980 & 63 & 76.41 & 7.73 & 0.95 & 102719 & 118736 & 1.120 \\
\hline & CFCW14-30U2 & compact & Compact & & $\mathrm{Dcp} / \mathrm{D}=0.625$ & $\lambda_{\mathrm{pw}(\mathrm{Dcp})}$ & 70 & 70 & 50 & 14.12 & 0.913 & 20.00 & 1.900 & 60 & 1.176 & 58 & 76.45 & 7.73 & 0.94 & 120785 & 149574 & 1.080 \\
\hline & CFCW13-30S & compact & compact & \multirow{3}{*}{$\mathrm{D} / \mathrm{bf}=3$} & & $6.8^{*} \mathrm{sqrt}(\mathrm{E} / \mathrm{Fy})$ & 70 & 70 & 50 & 20.00 & 1.293 & 20.00 & 1.293 & 60 & 0.784 & 129 & 76.53 & 7.73 & 0.97 & 140236 & 146224 & 1.03 \\
\hline & CFCW13-30U1 & compact & Compact & & Dcp/D $=0.75$ & $\lambda_{\mathrm{pw}(\mathrm{Dcp})}$ & 70 & 70 & 50 & 20.00 & 1.293 & 20.00 & 1.815 & 60 & 0.980 & 121 & 76.45 & 7.73 & 0.97 & 155814 & 175382 & 1.010 \\
\hline & CFCW13-30U2 & compact & compact & & & $6.8^{*} \mathrm{sqrt}(\mathrm{E} / \mathrm{Fy})$ & 70 & 70 & 50 & 20.00 & 1.293 & 20.00 & 2.550 & 60 & 1.176 & 114 & 76.47 & 7.73 & 0.96 & 173395 & 206874 & 0.981 \\
\hline & UCCW14-30S & ultra-compact & Compact & \multirow{3}{*}{$\mathrm{D} / \mathrm{bfc}=4.25$} & $\mathrm{Dcp} / \mathrm{D}=0.5$ & $\lambda_{\mathrm{pm}(\mathrm{Dpp})}$ & 70 & 70 & 50 & 14.12 & 1.192 & 14.12 & 1.192 & 60 & 0.784 & 73 & 76.53 & 5.92 & 0.96 & 102370 & 107348 & 1.290 \\
\hline & UCCW14-30U1 & ultra-compact & compact & & & $6.8^{*} \mathrm{sqrt}(\mathrm{E} / \mathrm{Fy})$ & 70 & 70 & 50 & 14.12 & 1.192 & 20.00 & 1.360 & 60 & 0.980 & 68 & 76.35 & 5.92 & 0.96 & 118372 & 135857 & 1.160 \\
\hline & UCCW14-30U2 & ultra-compact & Compact & & $\mathrm{Dcp} / \mathrm{D}=0.625$ & $\lambda_{\mathrm{pw}(\mathrm{Dcp})}$ & 70 & 70 & 50 & 14.12 & 1.192 & 20.00 & 2.095 & 60 & 1.176 & 63 & 76.40 & 5.92 & 0.95 & 136244 & 166917 & 1.120 \\
\hline & UCCW13-30S & ultra-compact & compact & \multirow{3}{*}{$\mathrm{D} / \mathrm{bfc}=3$} & & $6.8^{*} \mathrm{sart}(\mathrm{E} / \mathrm{Fy})$ & 70 & 70 & 50 & 20.00 & 1.688 & 20.00 & 1.688 & 60 & 0.784 & 135 & 76.53 & 5.92 & 0.98 & 173135 & 181090 & 1.020 \\
\hline & UCCW13-30U1 & ultra-compact & Compact & & $\mathrm{Dcp} / \mathrm{D}=0.75$ & $\lambda_{\mathrm{pm}(\mathrm{CPp})}$ & 70 & 70 & 50 & 20.00 & 1.688 & 20.00 & 2.210 & 60 & 0.980 & 128 & 76.43 & 5.92 & 0.97 & 188186 & 210522 & 1.020 \\
\hline & UccW13-30U2 & ultra-compact & compact & & & $6.8^{*} \mathrm{sqrt}(\mathrm{E} / \mathrm{Fy})$ & 70 & 70 & 50 & 20.00 & 1.688 & 20.00 & 2.940 & 60 & 1.176 & 122 & 76.36 & 5.92 & 0.97 & 205459 & 242300 & 0.992 \\
\hline
\end{tabular}

* The analysis for girder CFSW4-20U2 was not completed. 
Table $5.4 \mathrm{D}_{\mathrm{cp}} / \mathrm{D}$ and $\mathrm{D} / \mathrm{b}_{\mathrm{fc}}$ effect on the normalized moment capacity

\begin{tabular}{|c|c|c|c|c|c|}
\hline \multirow[b]{4}{*}{ No. } & \multirow{4}{*}{$\begin{array}{l}\text { Naming } \\
\text { convention }\end{array}$} & \multicolumn{2}{|c|}{$\mathrm{CW}$} & \multicolumn{2}{|c|}{ SW } \\
\hline & & \multicolumn{2}{|c|}{$\mathbf{D} / \mathbf{b}_{\mathrm{fc}}$} & \multicolumn{2}{|c|}{$\mathbf{D} / \mathbf{b}_{\mathrm{fc}}$} \\
\hline & & 4.25 & 3 & 4.25 & 3 \\
\hline & & $M_{\max } / M_{p}$ & $M_{\max } / M_{p}$ & $\mathbf{M}_{\max } / \mathbf{M}_{\mathbf{p}}$ & $\mathbf{M}_{\max } / \mathbf{M}_{\mathrm{p}}$ \\
\hline 1 & CF-30S & 1.01 & 1.02 & 0.93 & 0.98 \\
\hline 2 & CF-30U1 & 1.01 & 1.02 & 0.86 & 0.92 \\
\hline 3 & CF-30U2 & 1.03 & 1.02 & 0.83 & 0.89 \\
\hline 4 & CF-20S & 0.96 & 0.99 & 0.92 & 0.94 \\
\hline 5 & CF-20U1 & 0.99 & 1.01 & 0.82 & 0.90 \\
\hline 6 & CF-20U2 & 1.05 & 1.02 & 0.78 & 0.87 \\
\hline
\end{tabular}




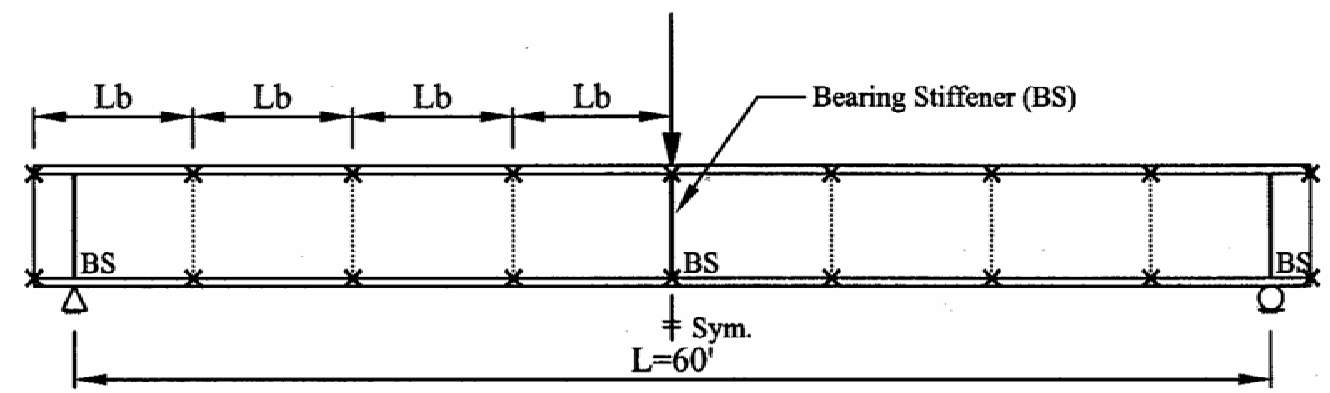

( a ) FEA girder with unstiffened web *

* 1 . There is no transform stiffener placed on the lateral bracing location.

2. The number of $\mathrm{Lb}$ is changed for different girders according to the calculaltion from Eq. 2.19.

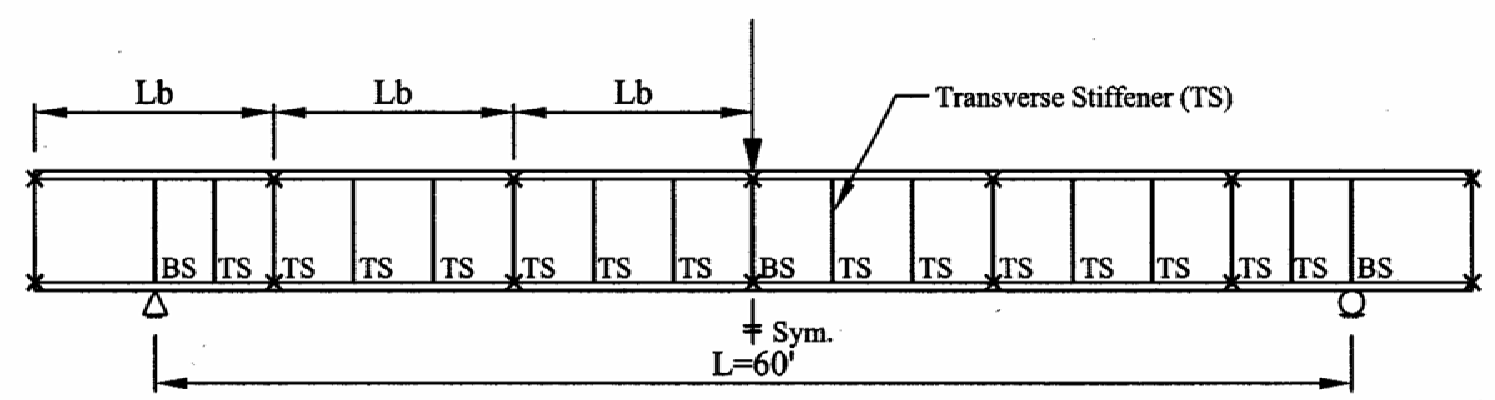

(b ) FEA girder with transversely-stiffened web *

* Transverse stiffeners are placed if necessary to satisfy $V u<=\Phi_{v} V c r$, No tention field action is considered as required in the future edition of AASHTO LRFD specification.

Figure 5.1 Elevation view of typical finite element girders 


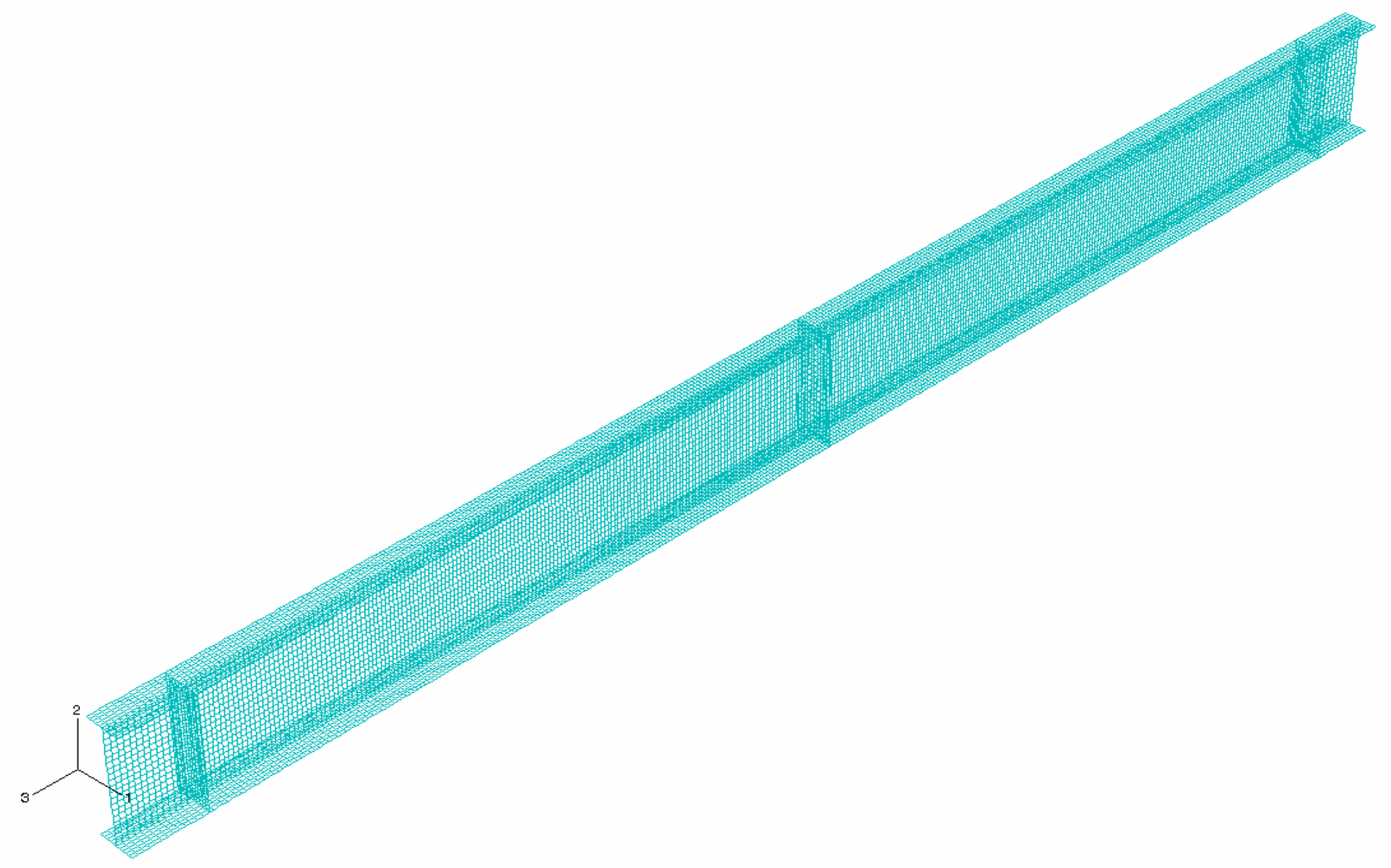

Figure 5.2 Typical unstiffened FEA mesh 


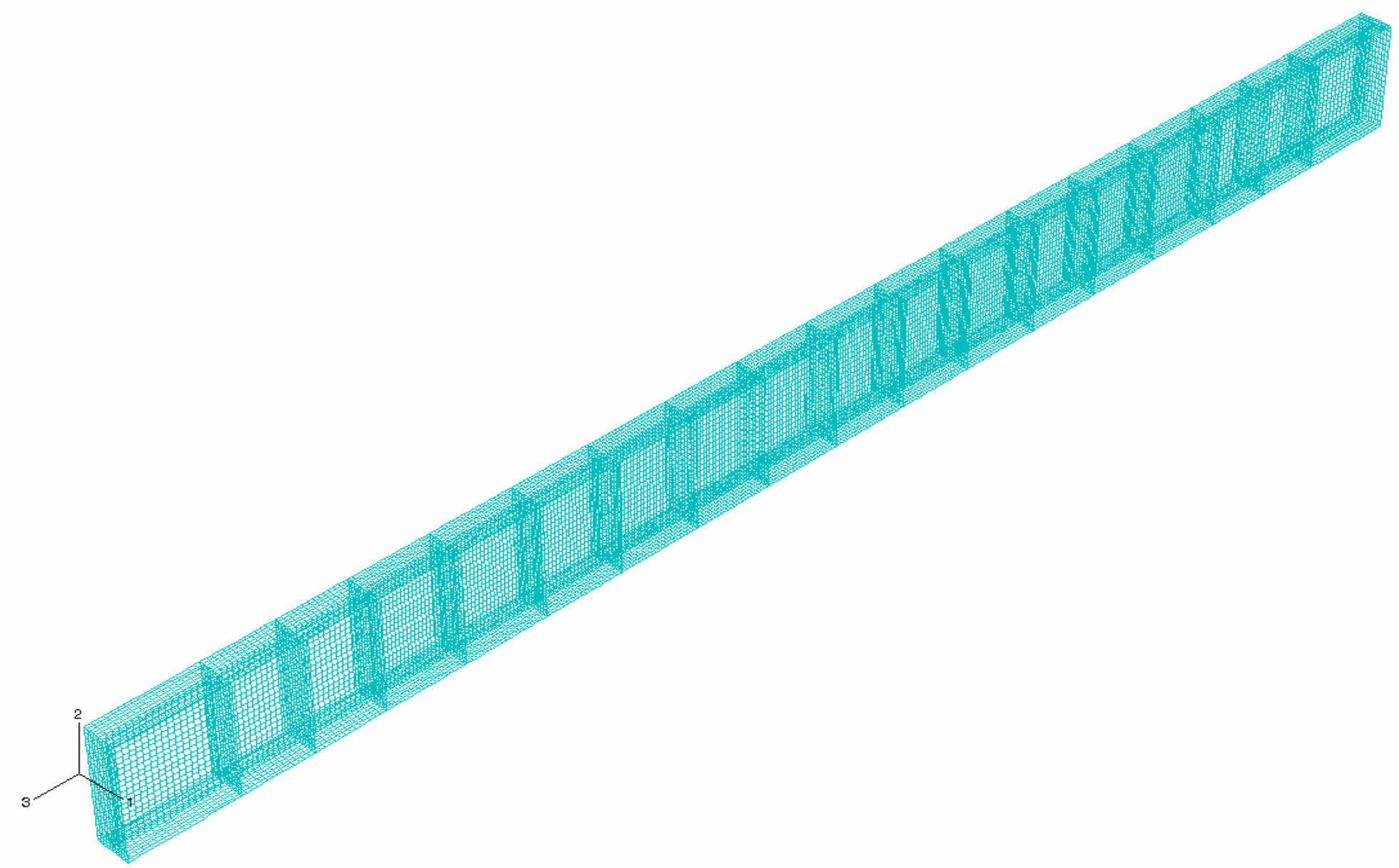

Figure 5.3 Typical transversely-stiffened FEA mesh 


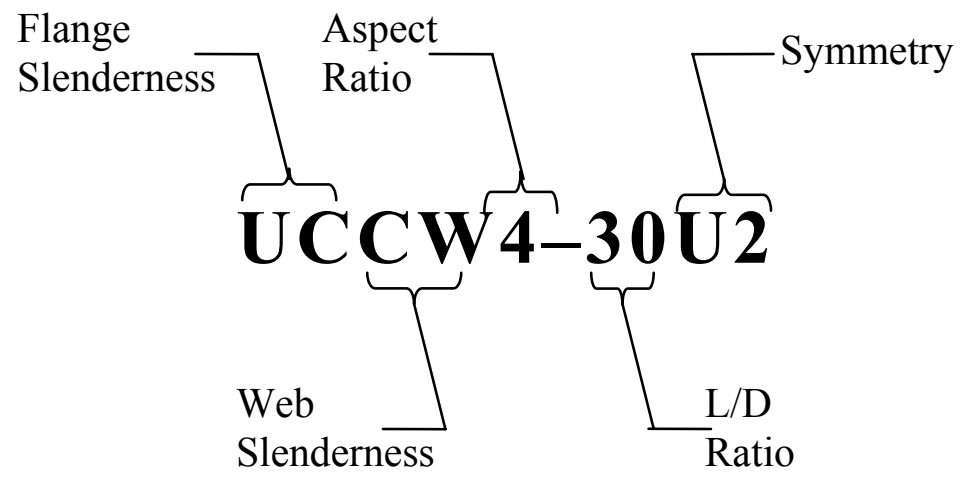

Figure 5.4 Naming convention 


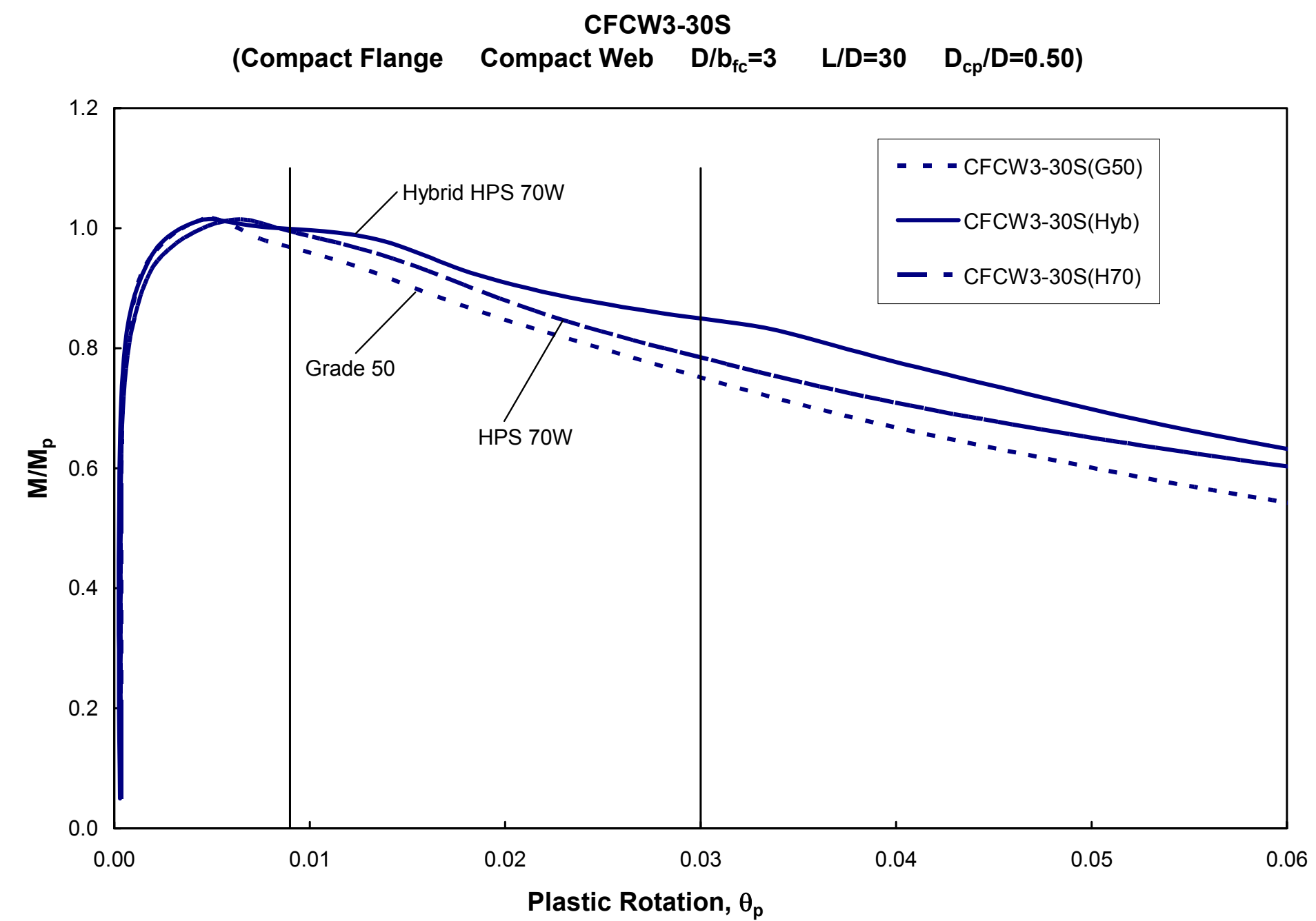

Figure 5.5 Influence of girder material configurations on $\mathrm{M} / \mathrm{M}_{\mathrm{p}}$ vs. $\theta_{\mathrm{p}}$ curves $(\mathrm{CFCW} 3-30 \mathrm{~S})$ 


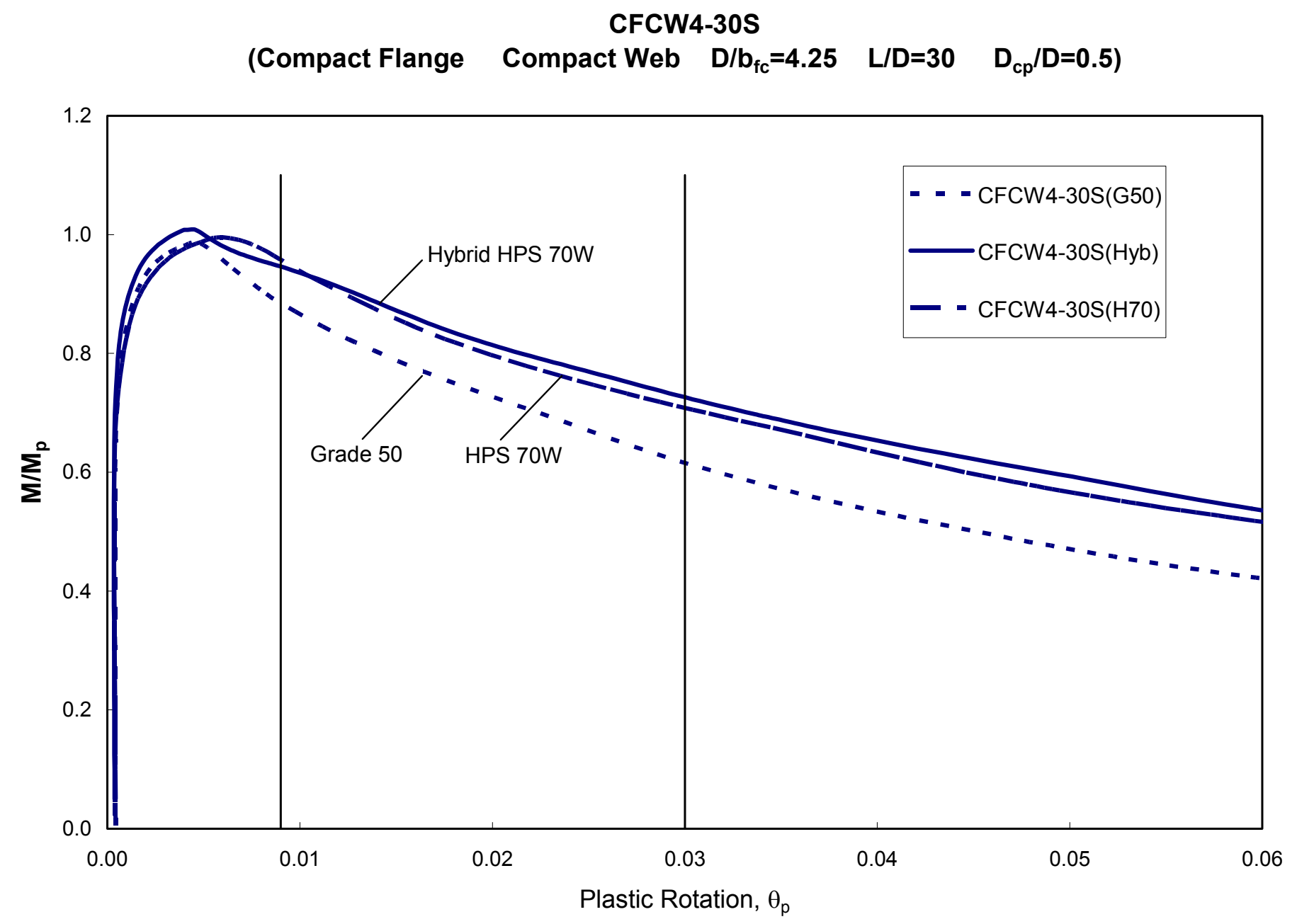

Figure 5.6 Influence of girder material configurations on $\mathrm{M} / \mathrm{M}_{\mathrm{p}}$ vs. $\theta_{\mathrm{p}}$ curves (CFCW4-30S) 


\section{CFCW3-30U1 \\ (Compact Flange Compact Web $\quad D / b_{f c}=3.0 \quad L / D=30 \quad D_{c p} / D=0.625$ )}

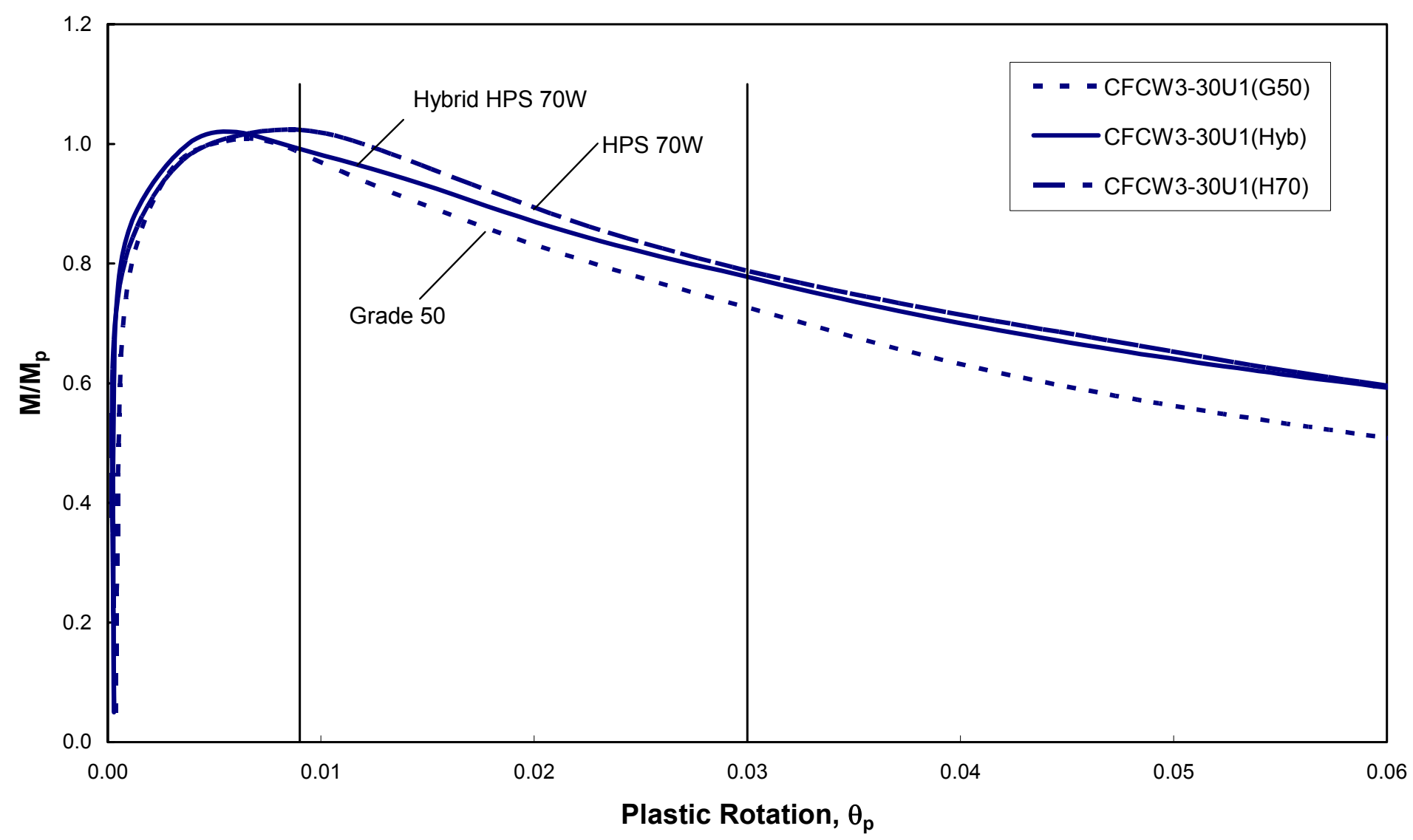

Figure 5.7 Influence of girder material configurations on $M / M_{p}$ vs. $\theta_{p}$ curves (CFCW3-30U1) 


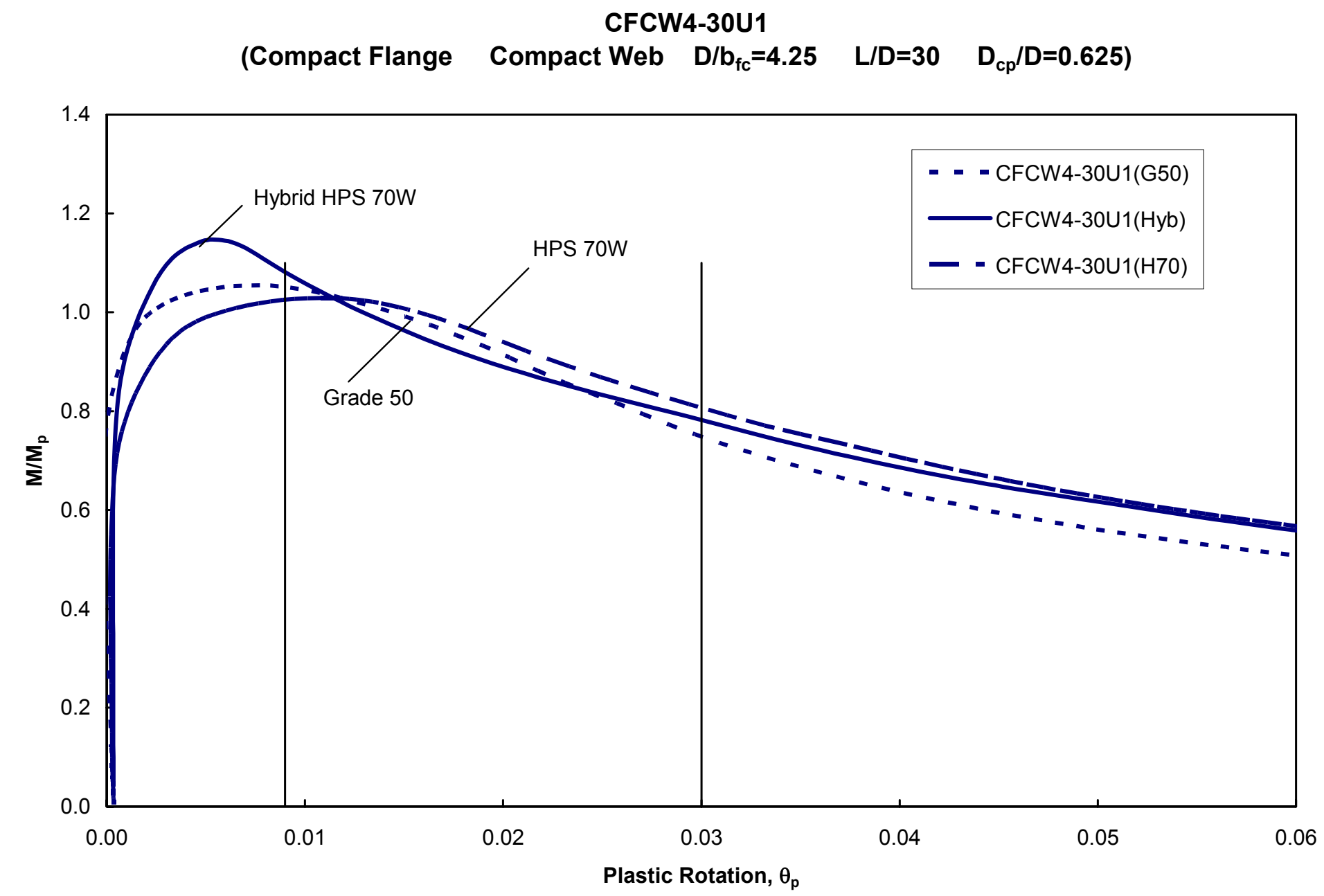

Figure 5.8 Influence of girder material configurations on $\mathrm{M} / \mathrm{M}_{\mathrm{p}}$ vs. $\theta_{\mathrm{p}}$ curves (CFCW4-30U1) 


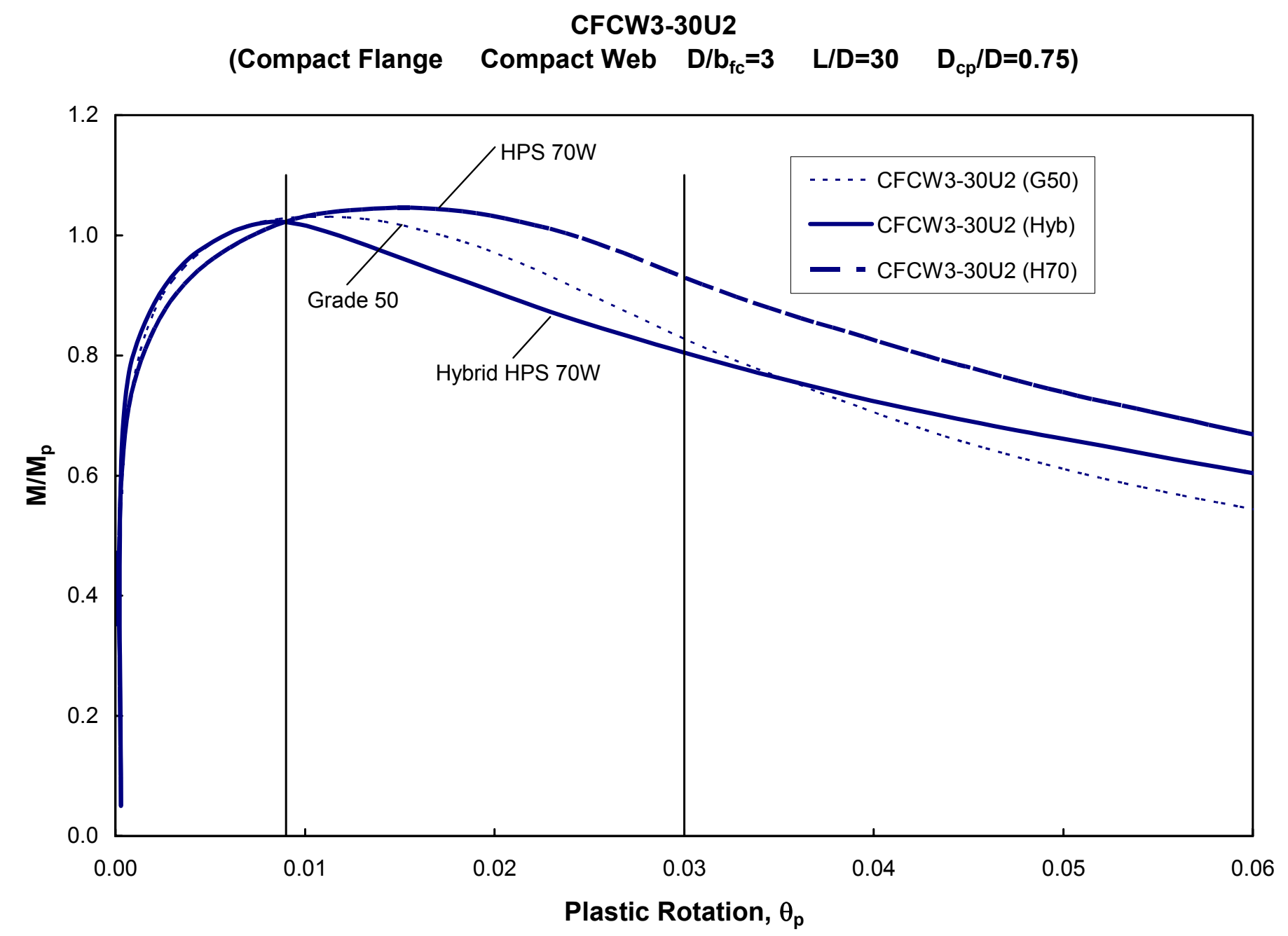

Figure 5.9 Influence of girder material configurations on $M / M_{p}$ vs. $\theta_{p}$ curves $(C F C W 3-30 U 2)$ 


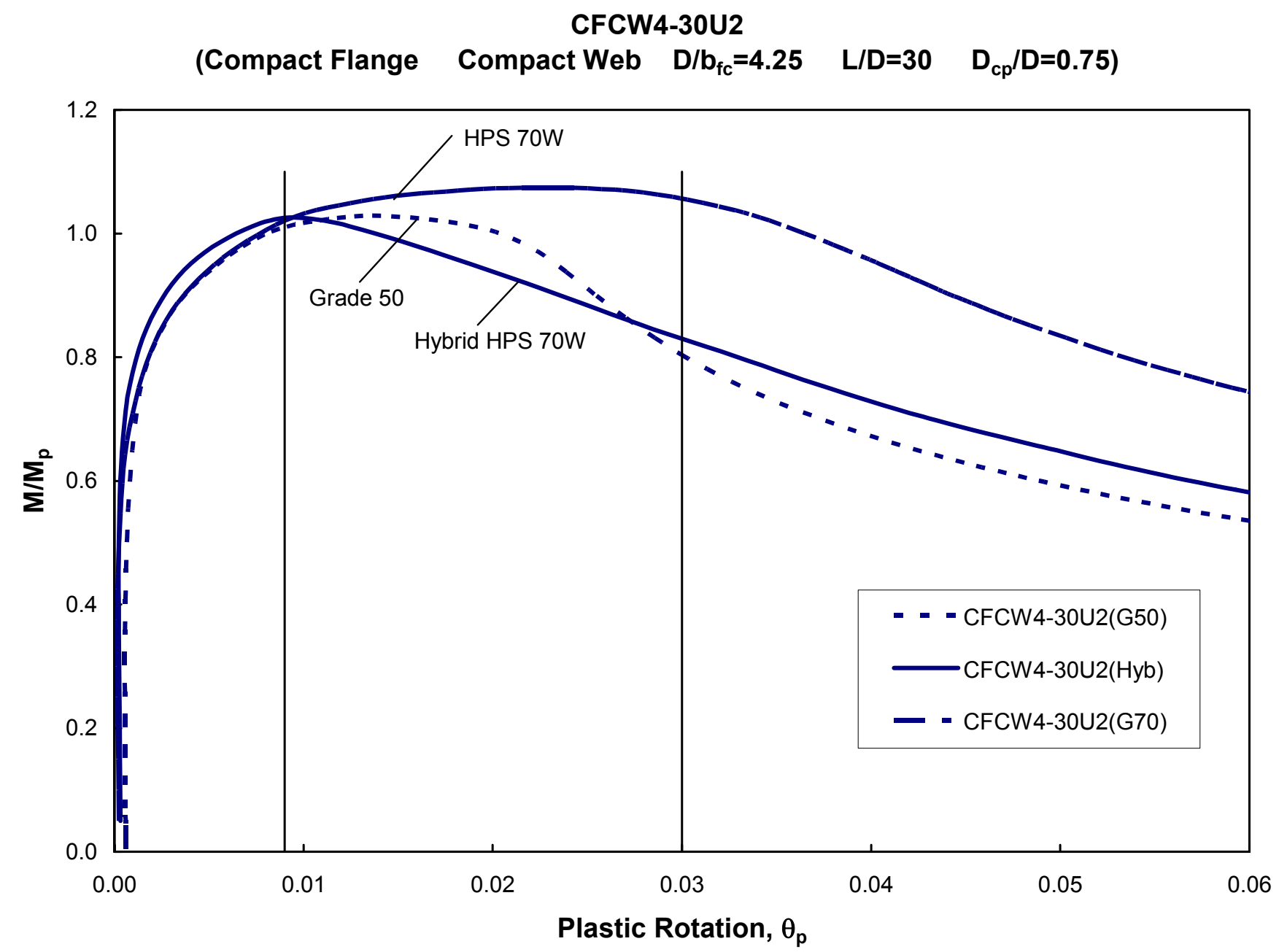

Figure 5.10 Influence of girder material configurations on $\mathrm{M} / \mathrm{M}_{\mathrm{p}}$ vs. $\theta_{\mathrm{p}}$ curves (CFCW4-30U2) 


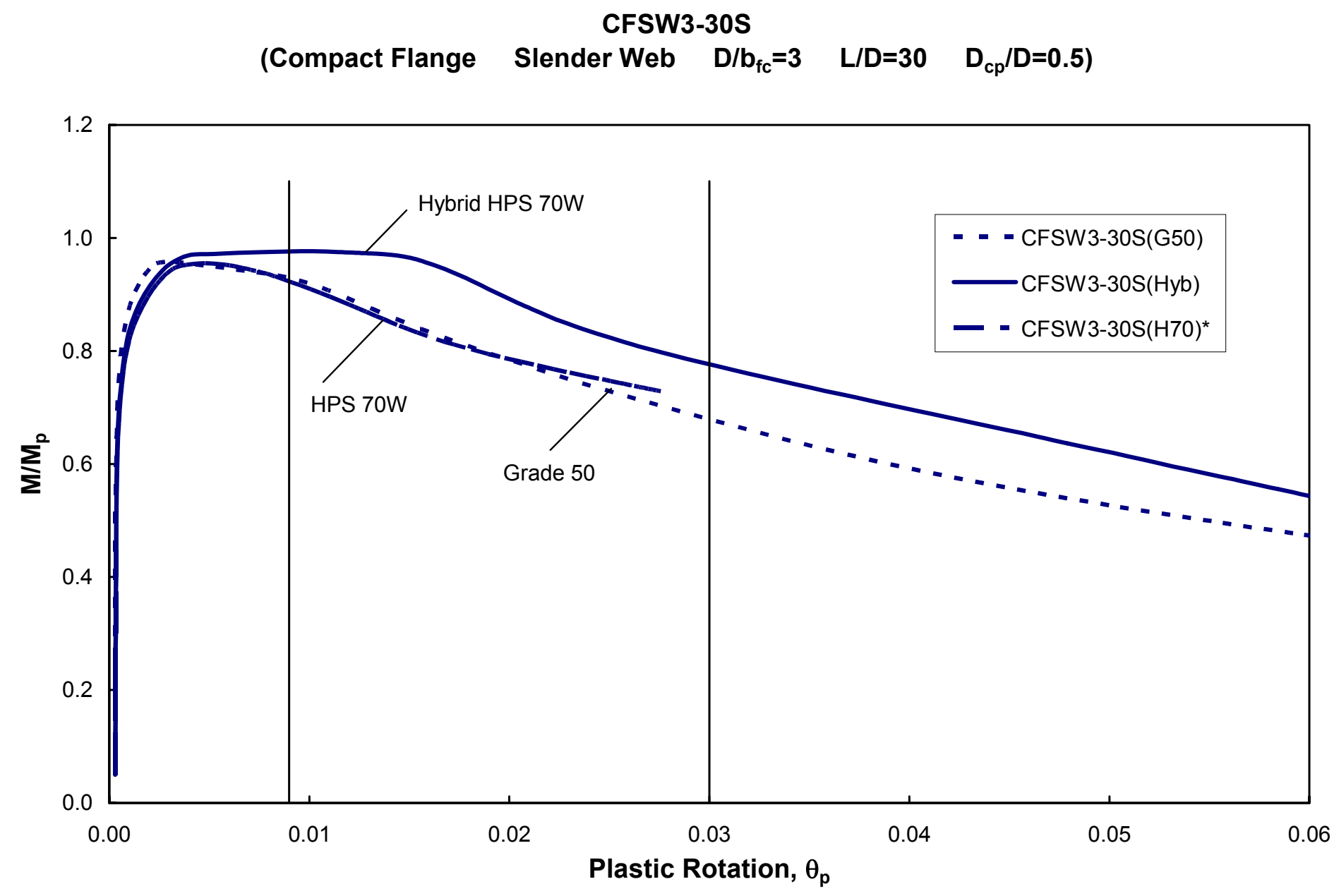

Figure 5.11 Influence of girder material configurations on $\mathrm{M} / \mathrm{M}_{\mathrm{p}}$ vs. $\theta_{\mathrm{p}}$ curves (CFSW3-30S)

* The anlaysis for the girder CFSW3-30S(H70) was not completed. 


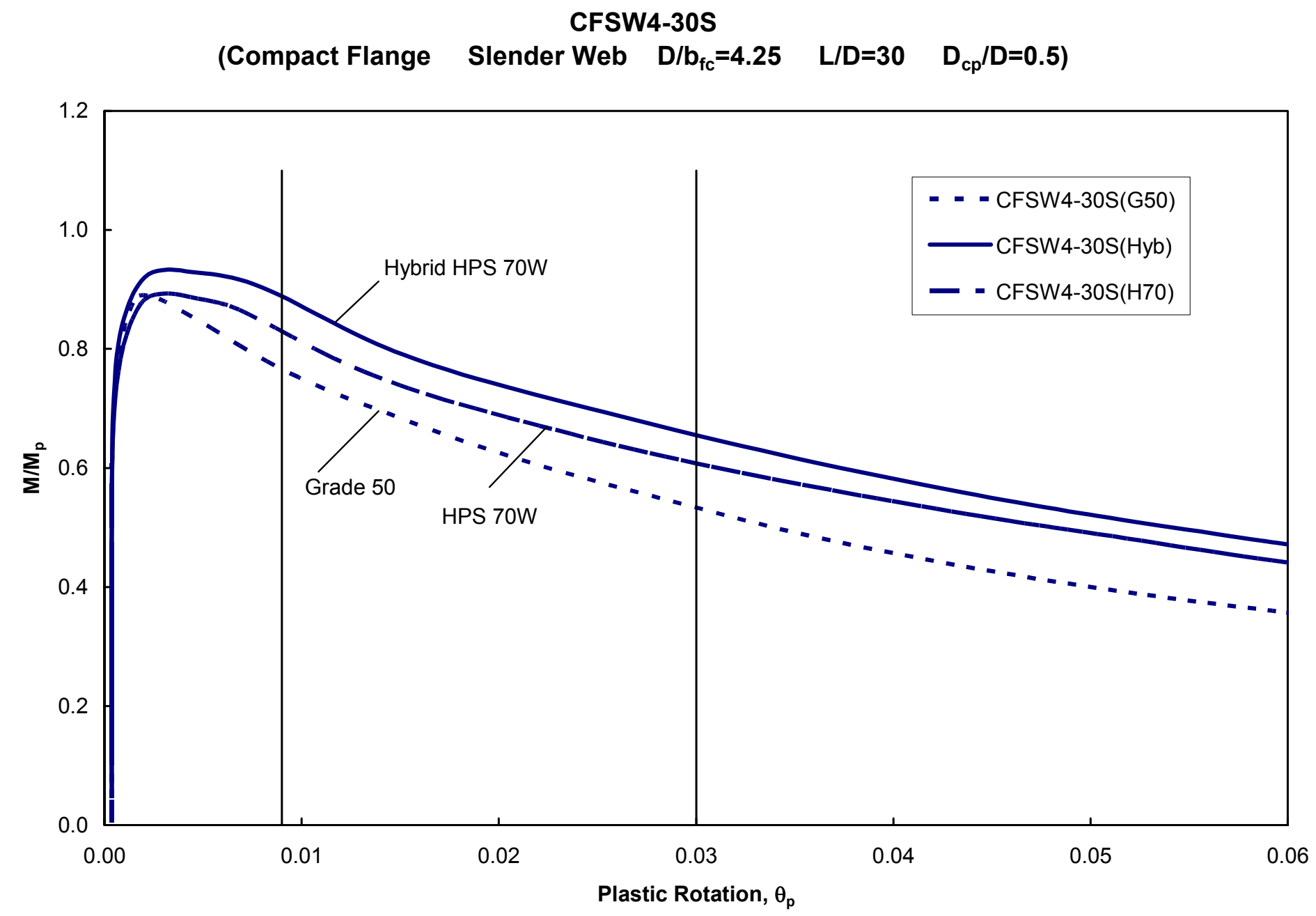

Figure 5.12 Influence of girder material configurations on $\mathrm{M} / \mathrm{M}_{\mathrm{p}}$ vs. $\theta_{\mathrm{p}}$ curves (CFSW4-30S) 
CFSW3-30U1

(Compact Flange Slender Web $\quad D / b_{f c}=3 \quad L / D=30 \quad D_{c p} / D=0.625$ )

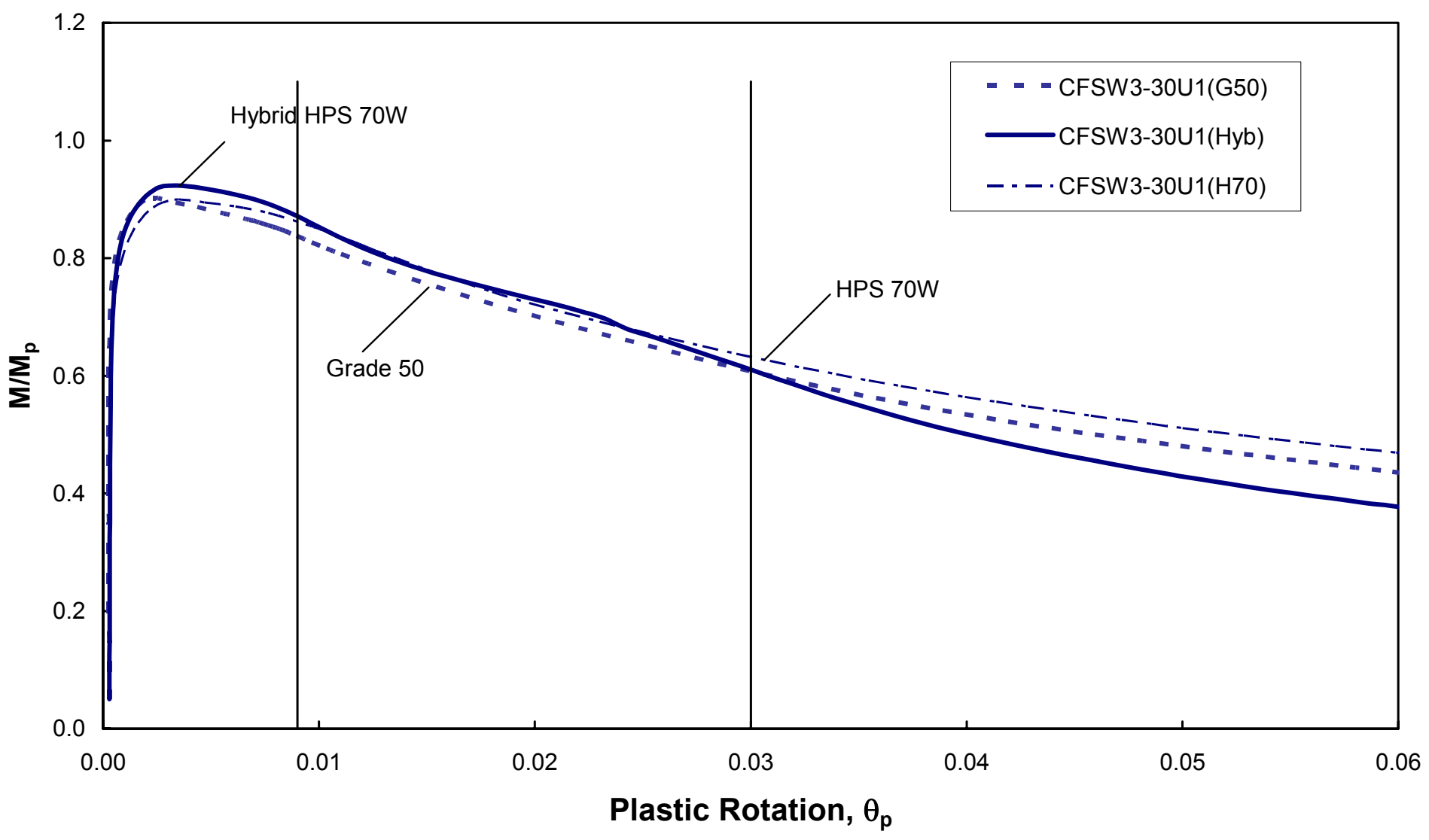

Figure 5.13 Influence of girder material configurations on $M / M_{p}$ vs. $\theta_{p}$ curves $(C F S W 3-30 U 1)$ 


\section{CFSW4-30U1}

(Compact Flange Slender Web $\quad D / b_{f c}=4.25 \quad L / D=30 \quad D_{c p} / D=0.625$ )

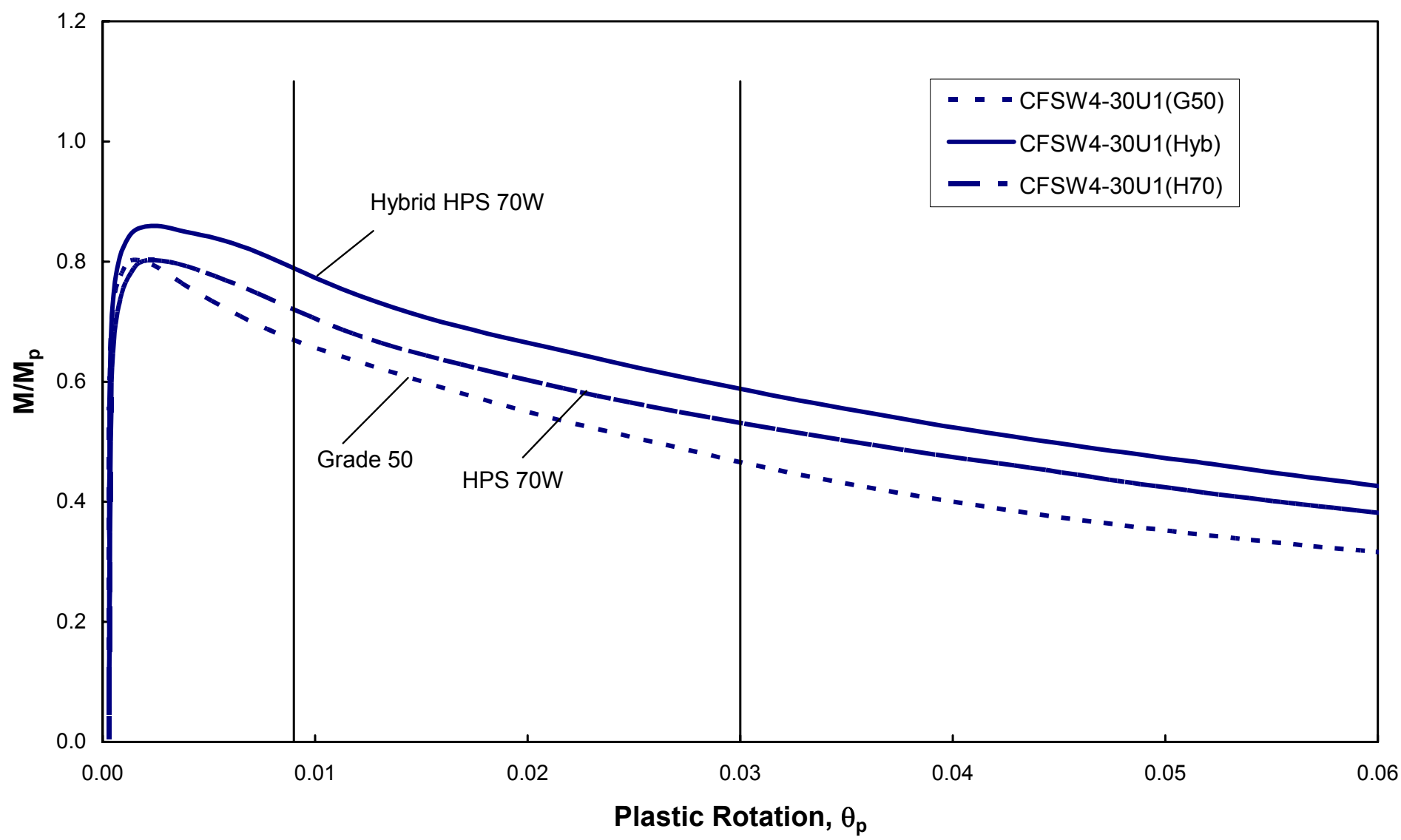

Figure 5.14 Influence of girder material configurations on $\mathrm{M} / \mathrm{M}_{\mathrm{p}}$ vs. $\theta_{\mathrm{p}}$ curves (CFSW4-30U1) 


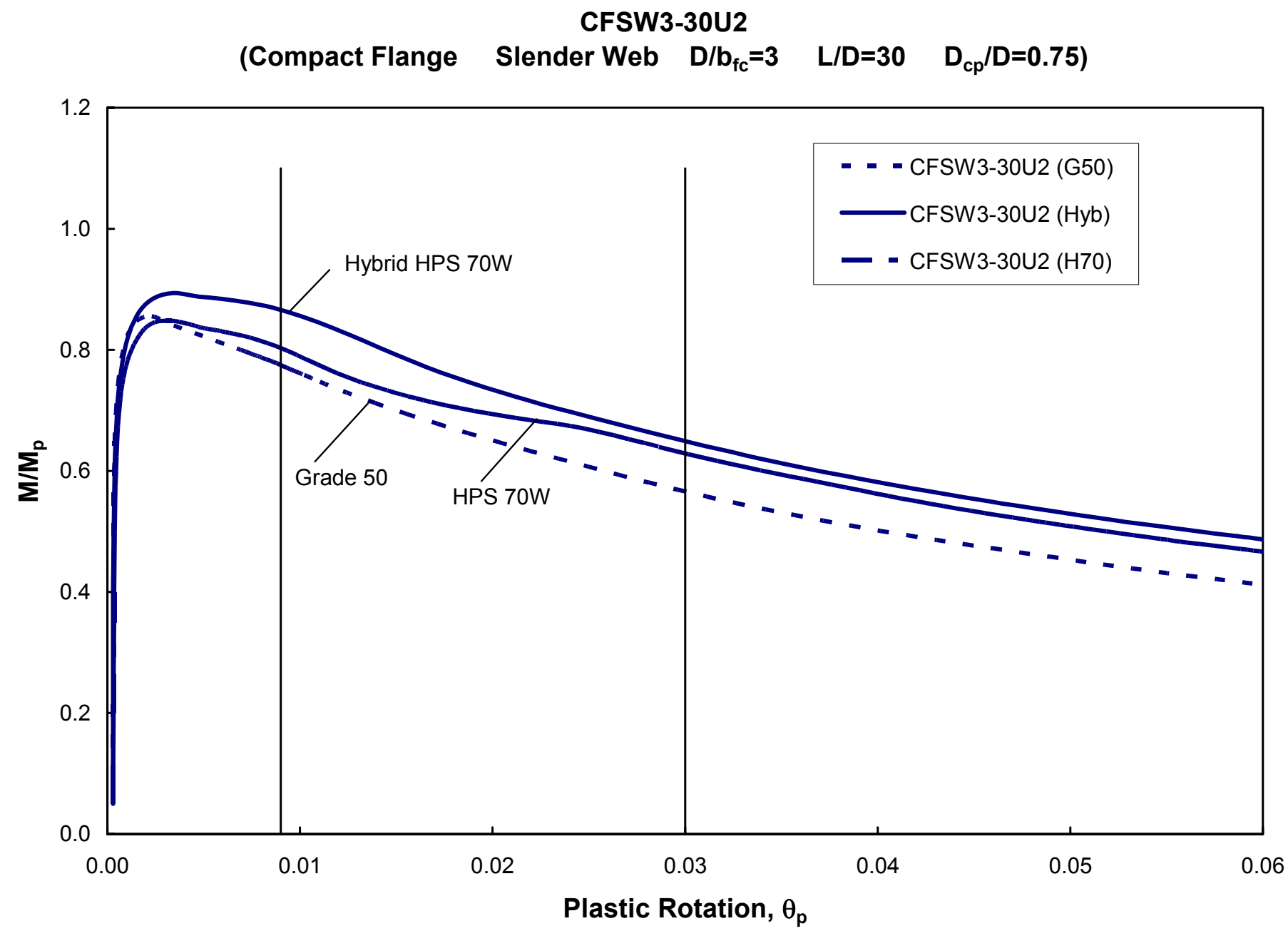

Figure 5.15 Influence of girder material configurations on $M / M_{p}$ vs. $\theta_{p}$ curves (CFSW3-30U2) 


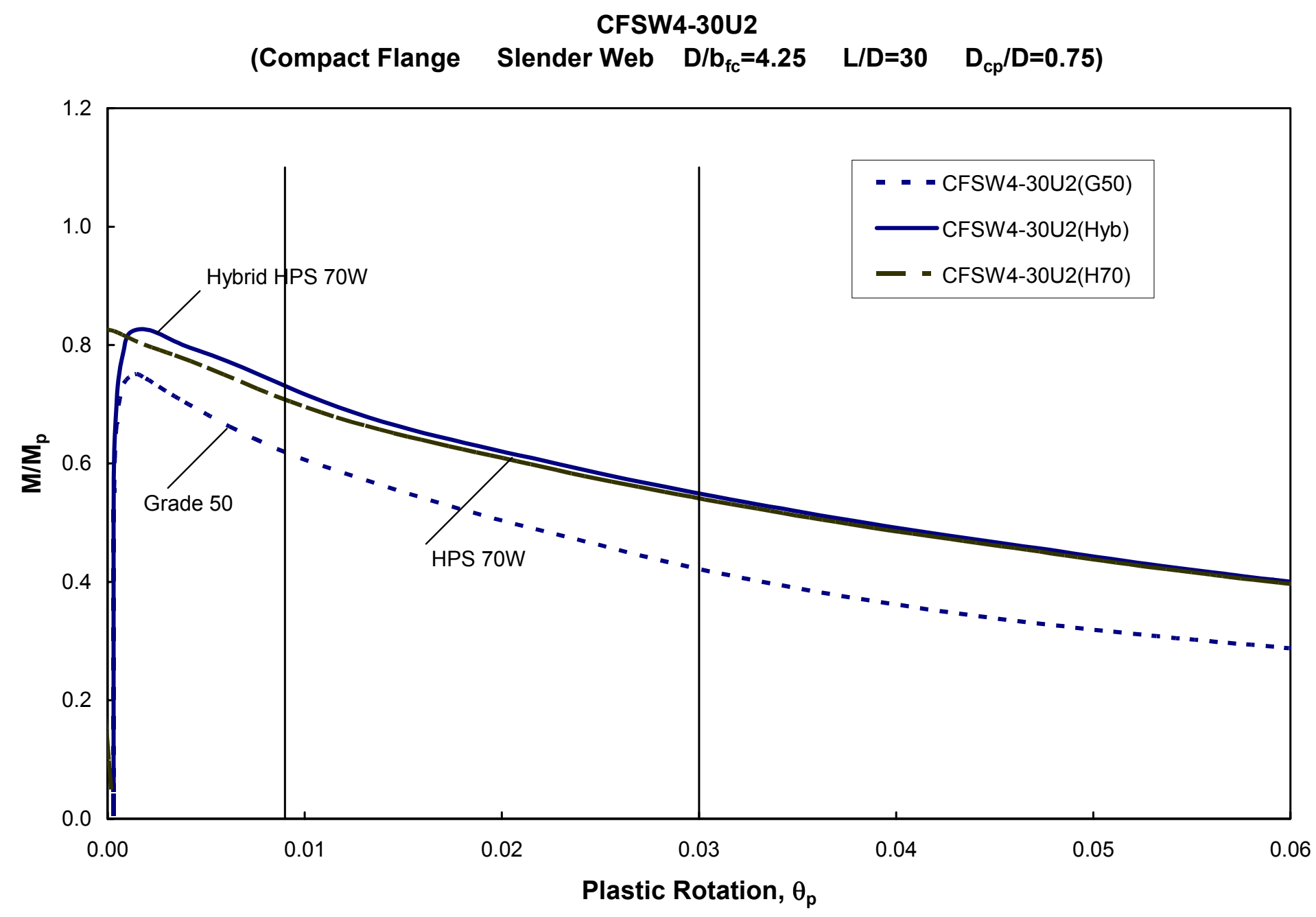

Figure 5.16 Influence of girder material configurations on $M / M_{p}$ vs. $\theta_{p}$ curves (CFSW4-30U2) 
HPS Hybrid Girders

CW3-30

(Compact Web $\quad \mathrm{D} / \mathrm{b}_{\mathrm{fc}}=3.0 \quad \mathrm{~L} / \mathrm{D}=30$ )

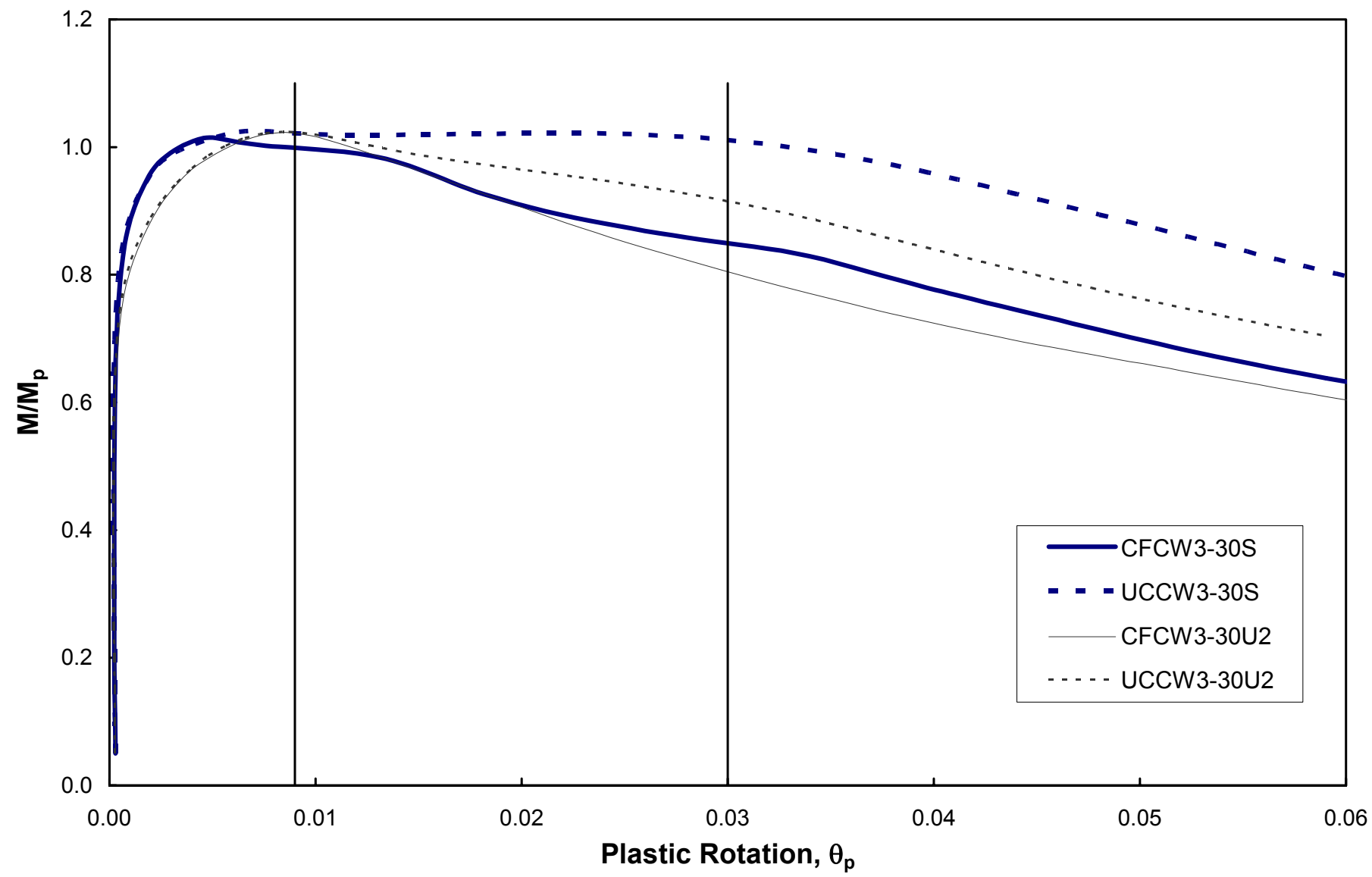

Figure 5.17 Effect of ultra-compact flange on $\mathrm{M} / \mathrm{M}_{\mathrm{p}}$ vs. $\theta_{\mathrm{p}}$ curves (CW3-30) 


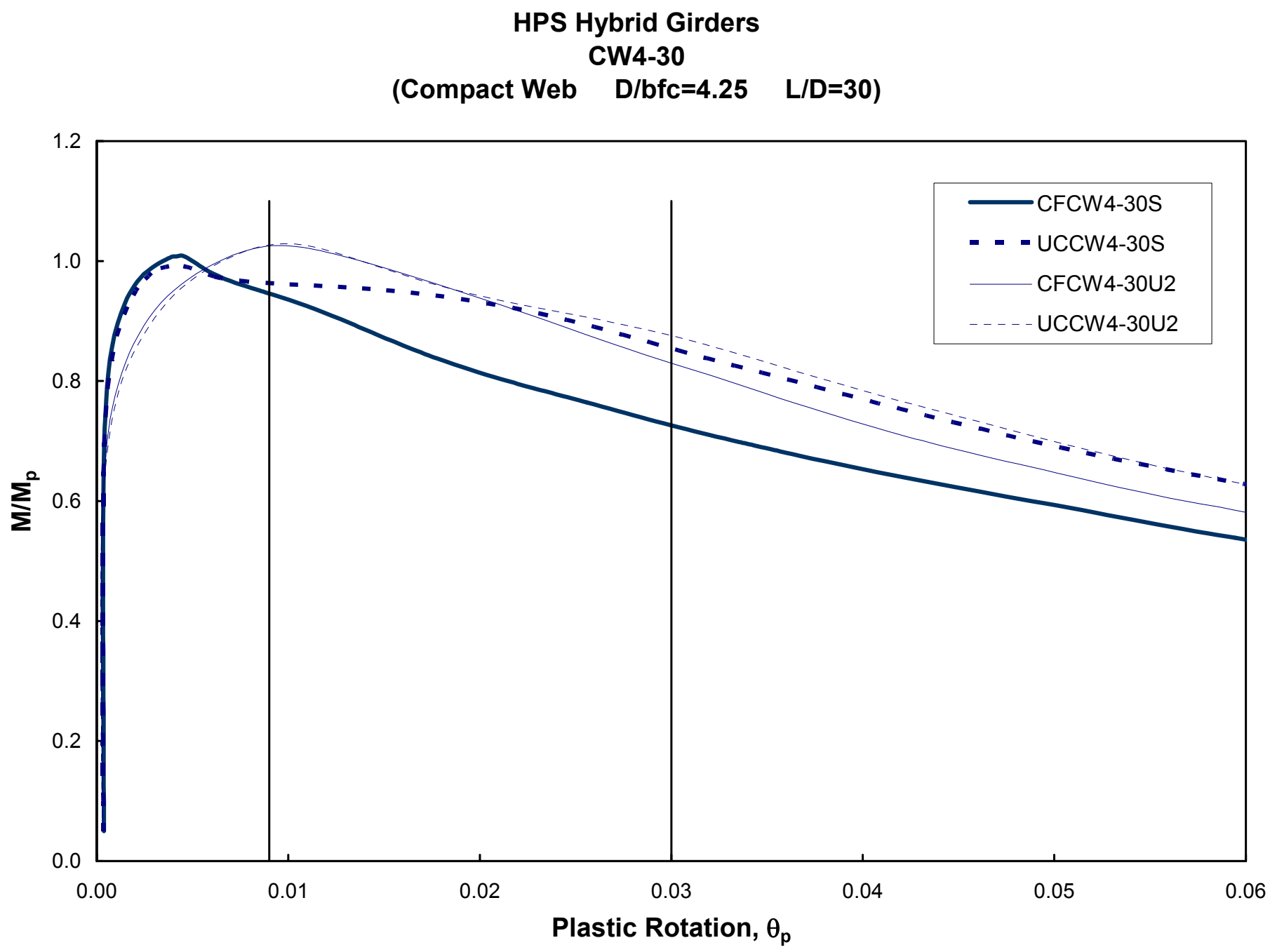

Figure 5.18 Effect of ultra-compact flange on $\mathrm{M} / \mathrm{M}_{\mathrm{p}}$ vs. $\theta_{\mathrm{p}}$ curves (CW4-30) 
HPS Hybrid Girders

SW3-30

(Slender Web $\quad D / b_{f c}=3.0 \quad L / D=30$ )

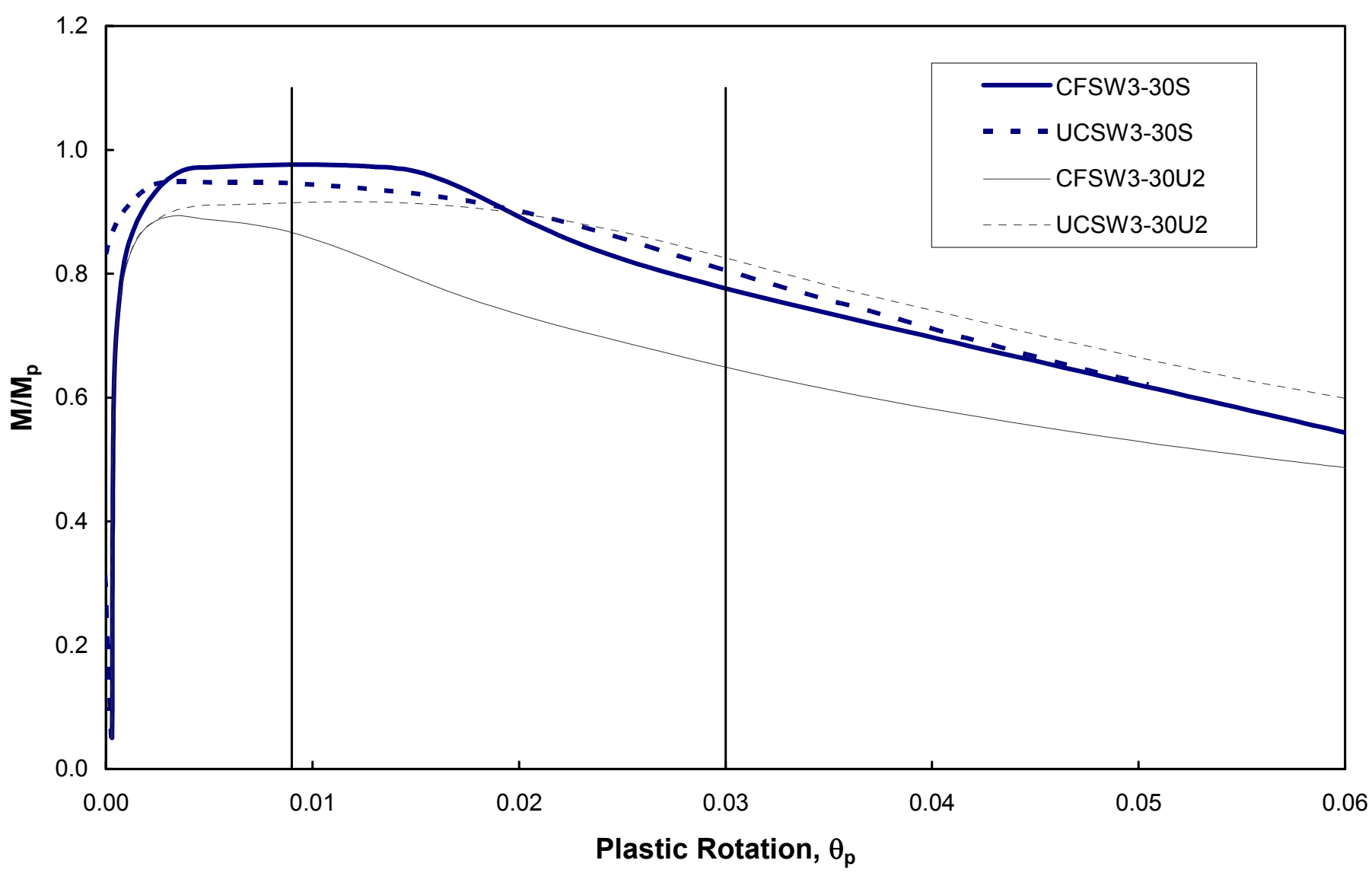

Figure 5.19 Effect of ultra-compact flange on $\mathrm{M} / \mathrm{M}_{\mathrm{p}}$ vs. $\theta_{\mathrm{p}}$ curves (SW3-30) 


\section{HPS Hybrid Girders}

SW4-30

(Slender Web $D / b_{f c}=4.25 \quad L / D=30$ )

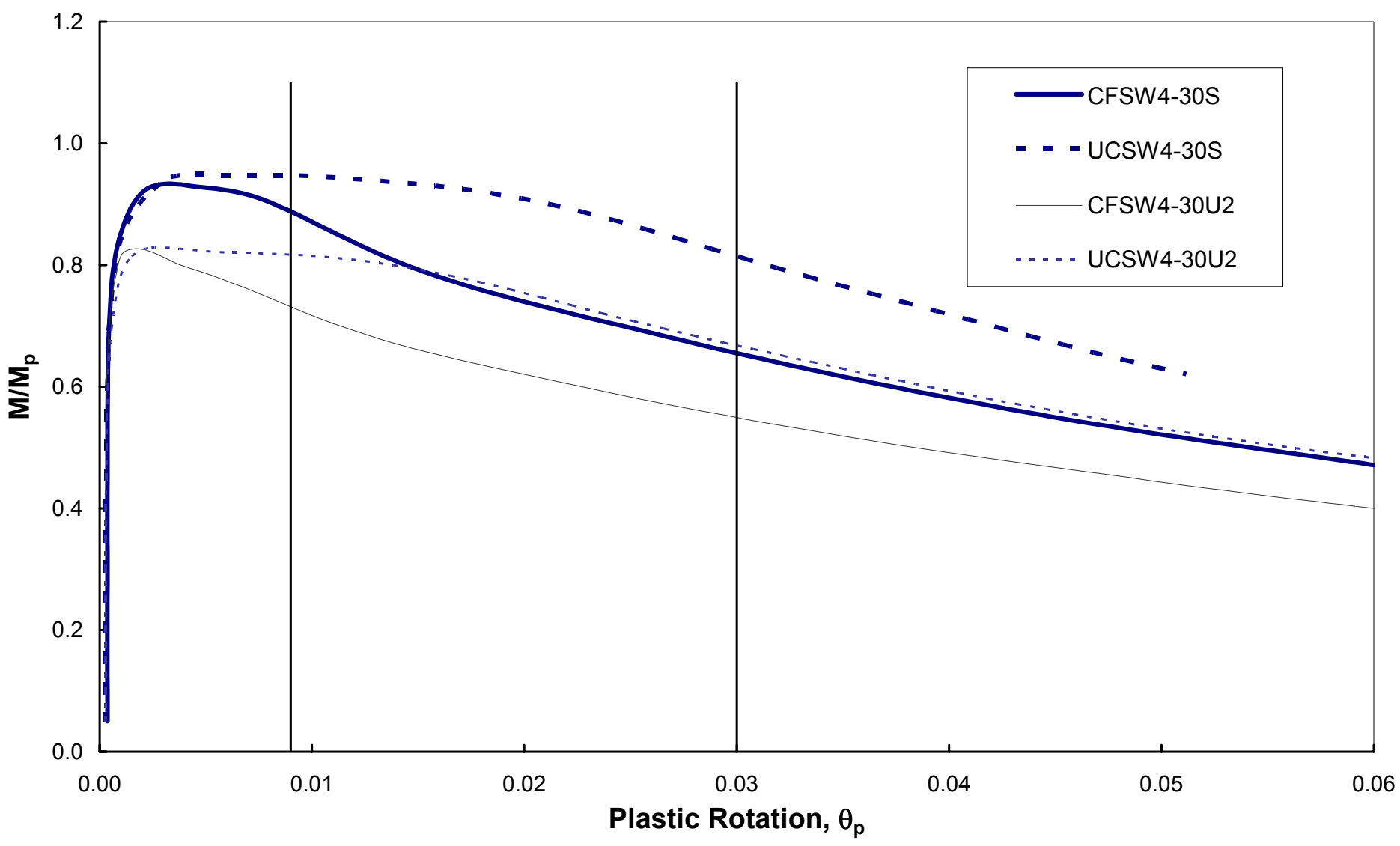

Figure 5.20 Effect of ultra-compact flange on $\mathrm{M} / \mathrm{M}_{\mathrm{p}}$ vs. $\theta_{\mathrm{p}}$ curves (SW4-30) 
HPS Hybrid Girders with Slender Webs $\left(2 \mathrm{D}_{\mathrm{cp}} / \mathrm{t}_{\mathrm{w}}=6.8 \sqrt{\mathrm{E} / \mathrm{F}_{\mathrm{yc}}}\right)$

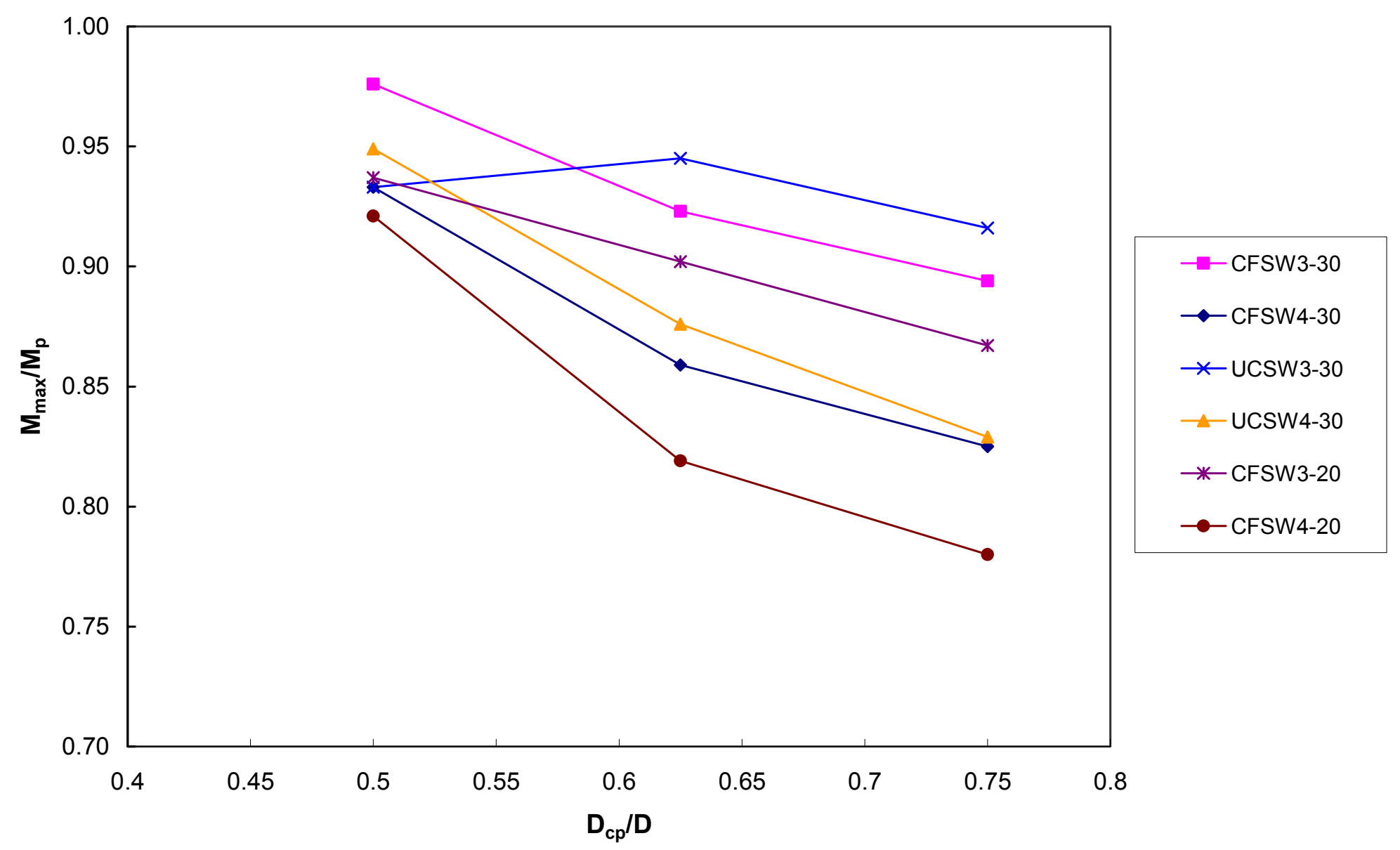

Figure 5.21 Effect of $\mathrm{D}_{\mathrm{cp}} / \mathrm{D}$ on normalized moment capacity with slender webs 
HPS Hybrid Girders with Compact Webs $\left(2 \mathrm{D}_{\mathrm{cp}} / \mathrm{t}_{\mathrm{w}}=\lambda_{\mathrm{pw}\left(\mathrm{D}_{\mathrm{cp}}\right)}\right)$

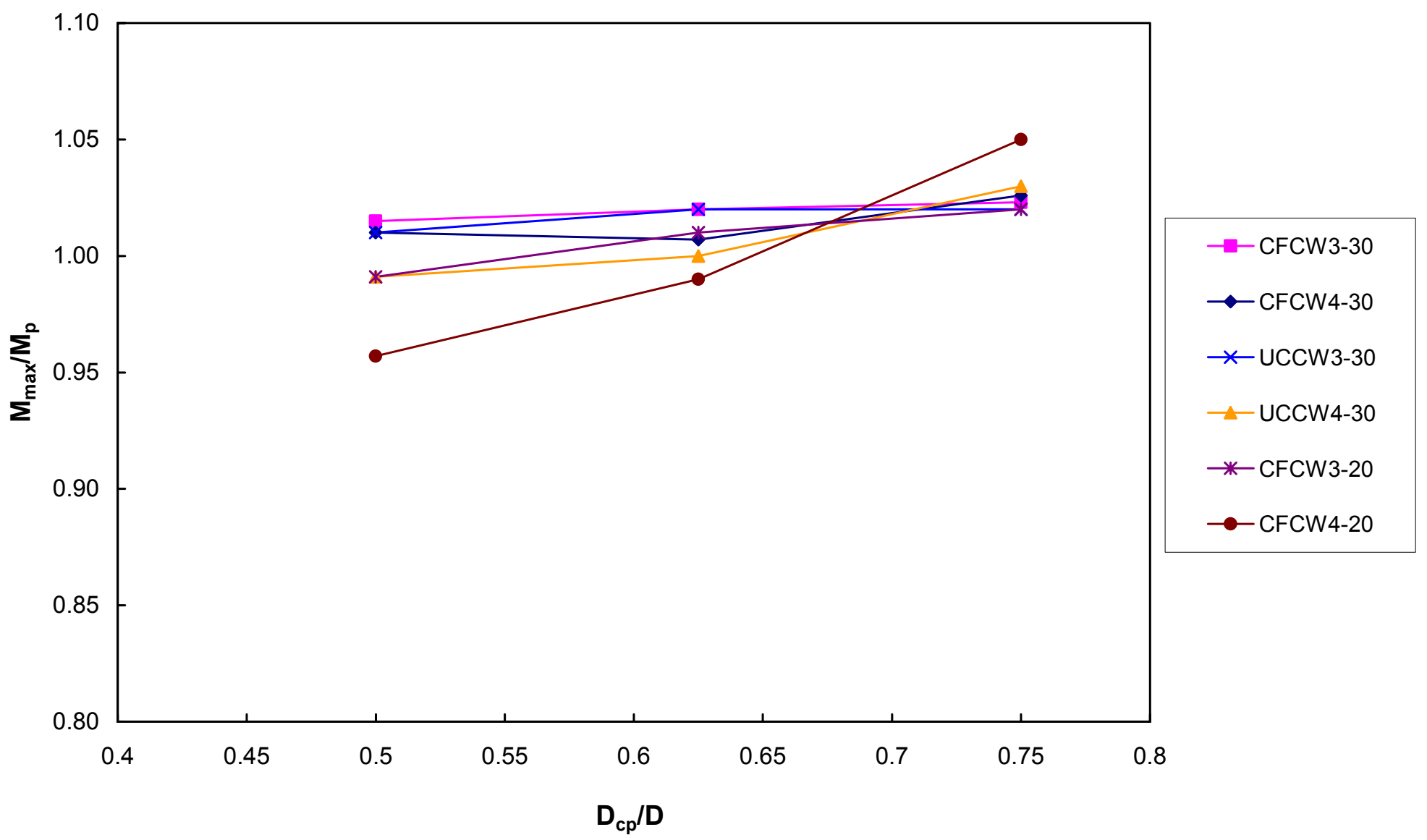

Figure 5.22 Effect of $D_{\mathrm{cp}} / \mathrm{D}$ on normalized moment capacity with compact webs 


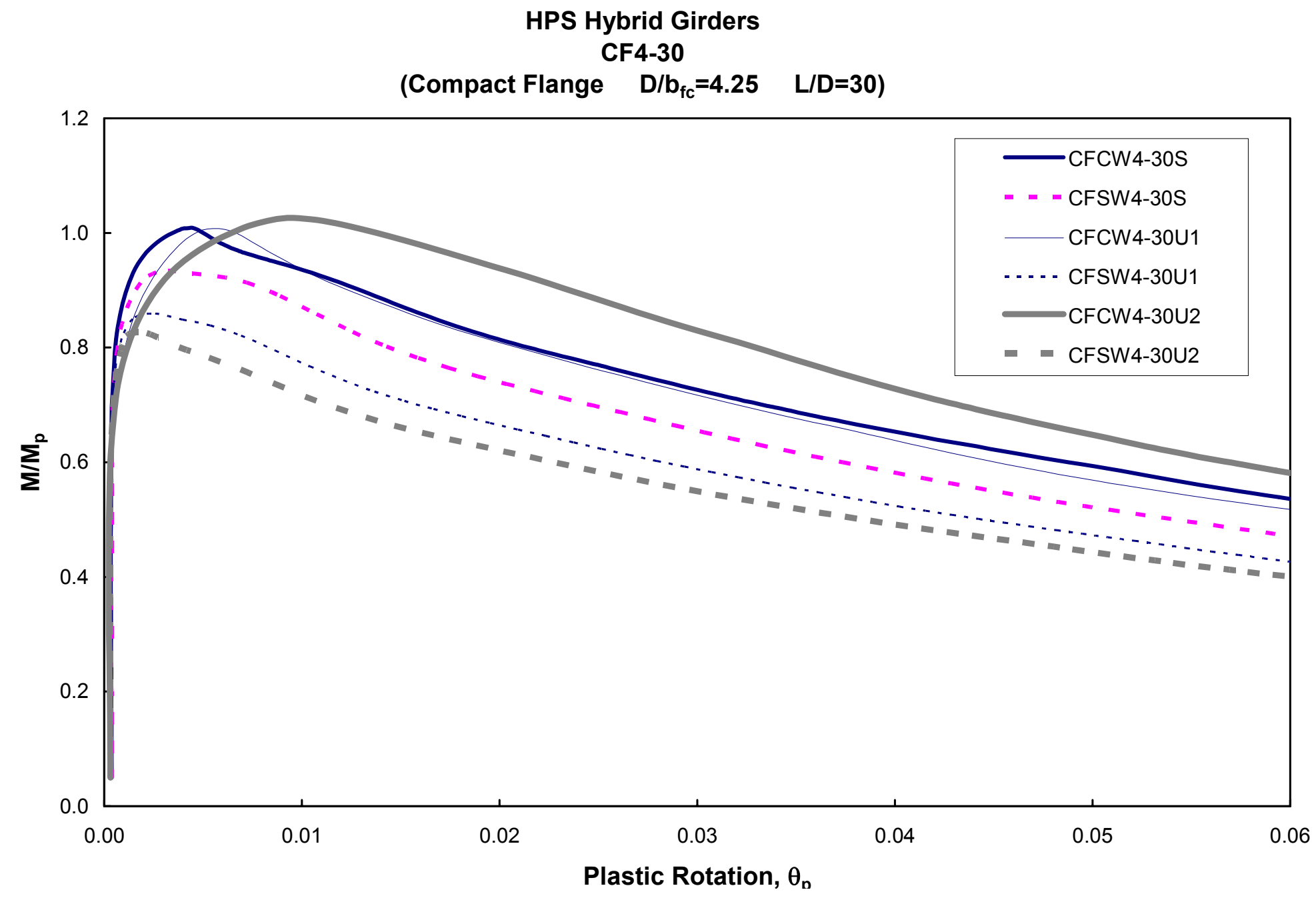

Figure 5.23 Effect of web slenderness on $\mathrm{M} / \mathrm{M}_{\mathrm{p}}$ vs. $\theta_{\mathrm{p}}$ curves (CF4-30) 
HPS Hybrid Girders

CFCW-30

(Compact flange Compact web $L / D=30$ )

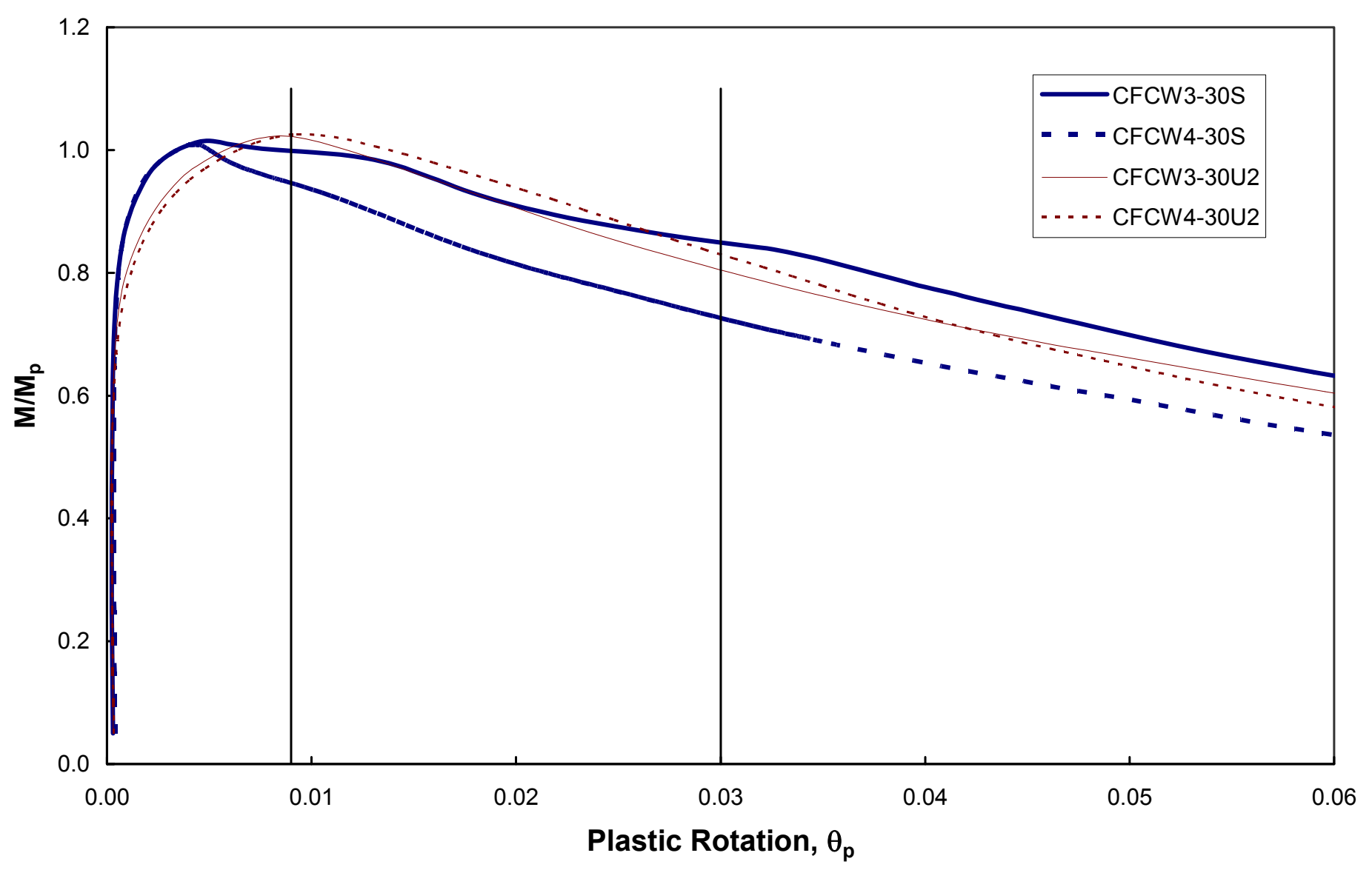

Figure 5.24 Effect of $\mathrm{D} / \mathrm{b}_{\mathrm{fc}}$ on $\mathrm{M} / \mathrm{M}_{\mathrm{p}}$ vs. $\theta_{\mathrm{p}}$ curves $(\mathrm{CFCW}-30)$ 


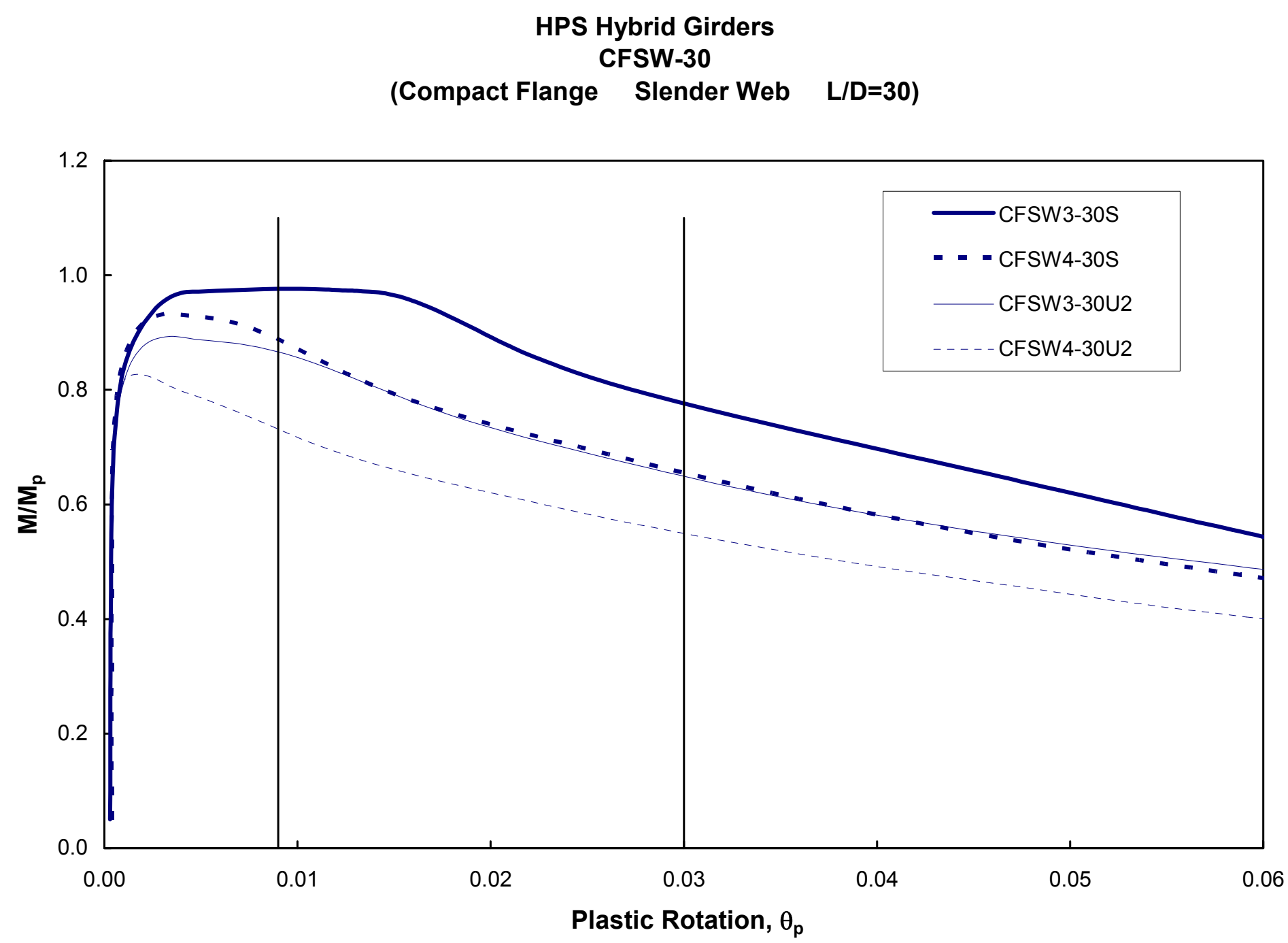

Figure 5.25 Effect of $\mathrm{D} / \mathrm{b}_{\mathrm{fc}}$ on $\mathrm{M}_{\mathrm{p}}$ vs. $\theta_{\mathrm{p}}(\mathrm{CFSW}-30)$ 


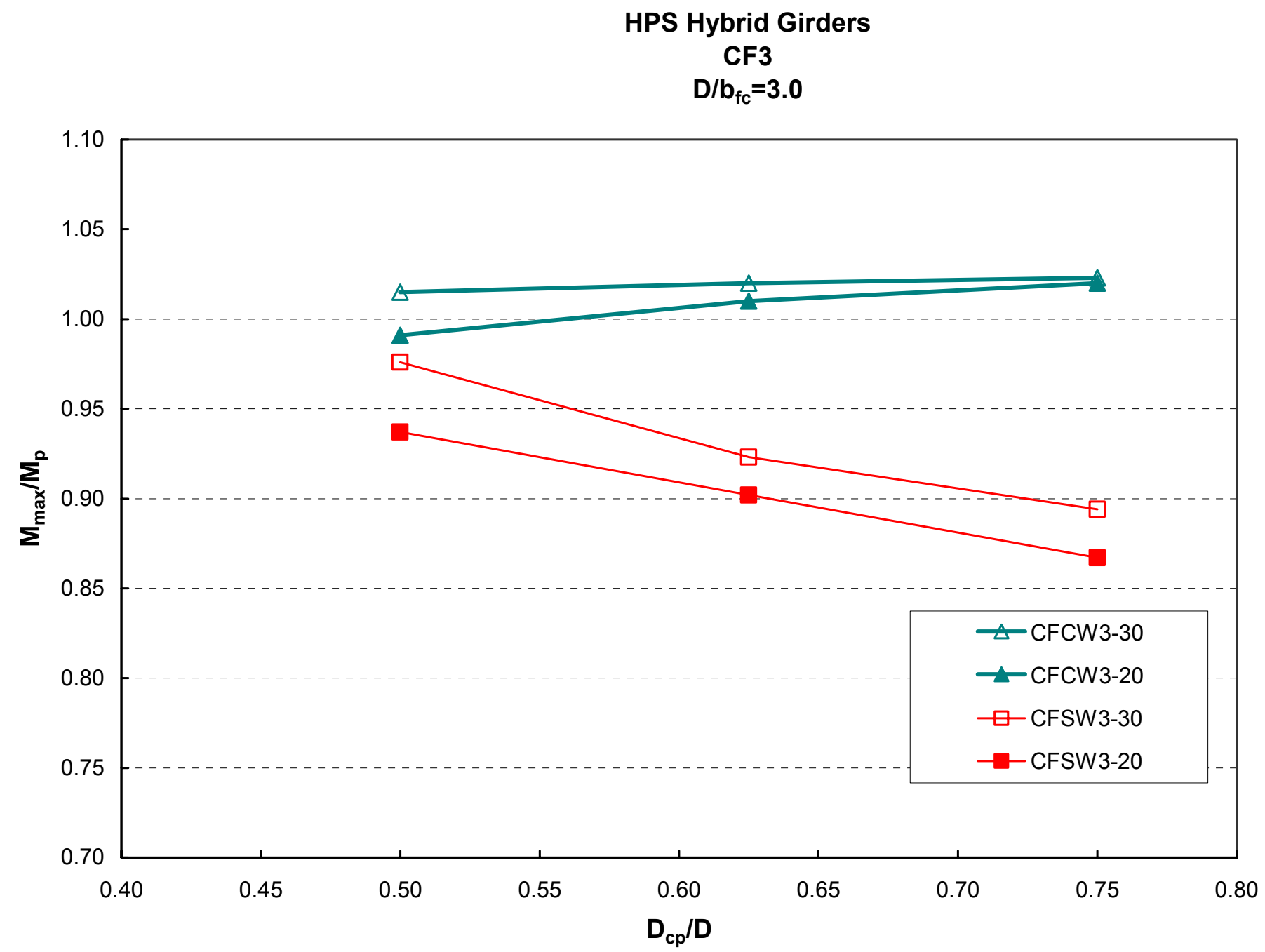

Figure 5.26 Effect of L/D on normalized moment capacity $\left(\mathrm{D} / \mathrm{b}_{\mathrm{fc}}=3.0\right)$ 


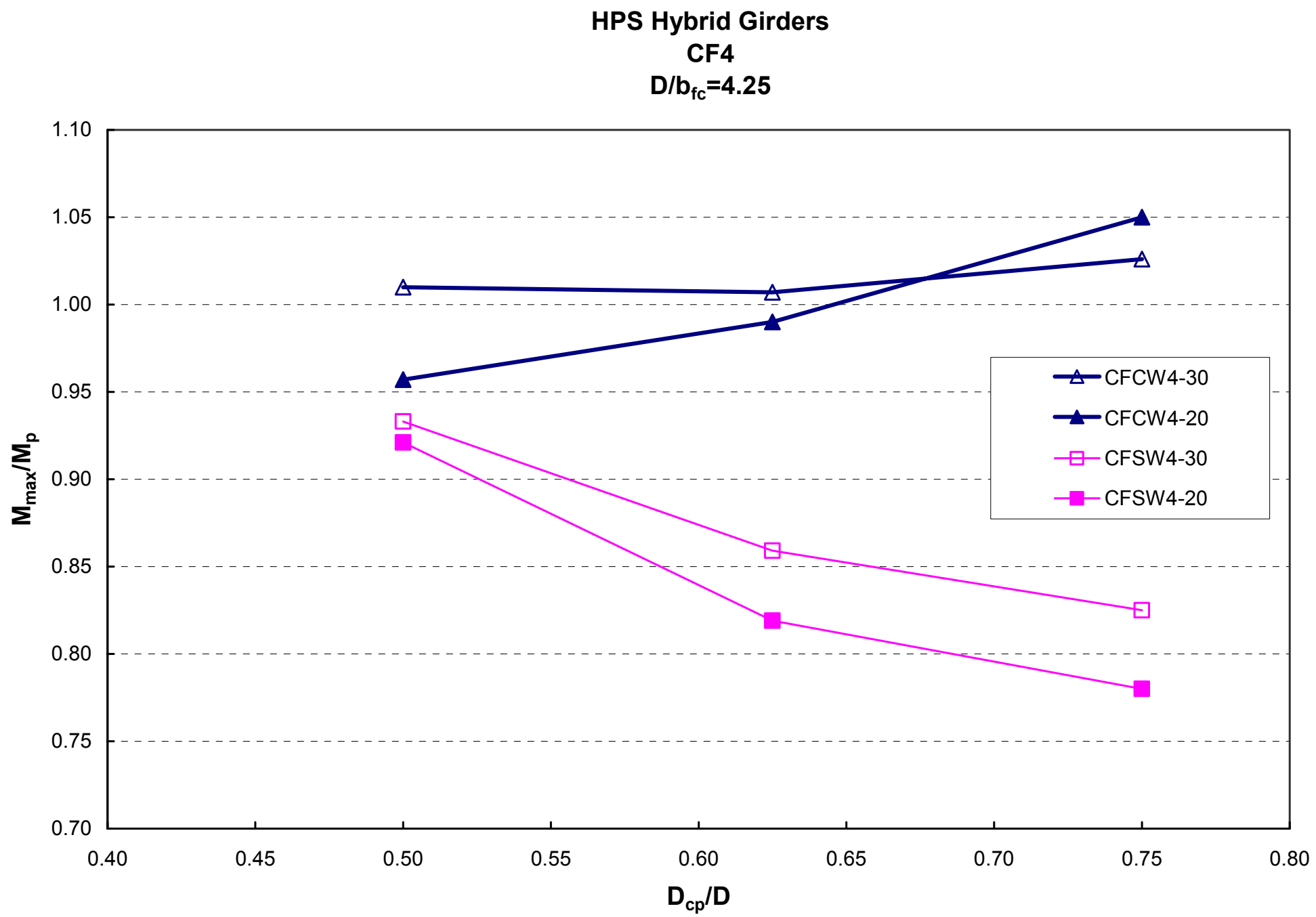

Figure 5.27 Effect of L/D on normalized moment capacity $\left(\mathrm{D} / \mathrm{b}_{\mathrm{fc}}=4.25\right)$ 
HPS Hybrid Girders

CFCW3

(Compact flange Compact web $D / b_{\mathrm{fc}}=3.0$ )

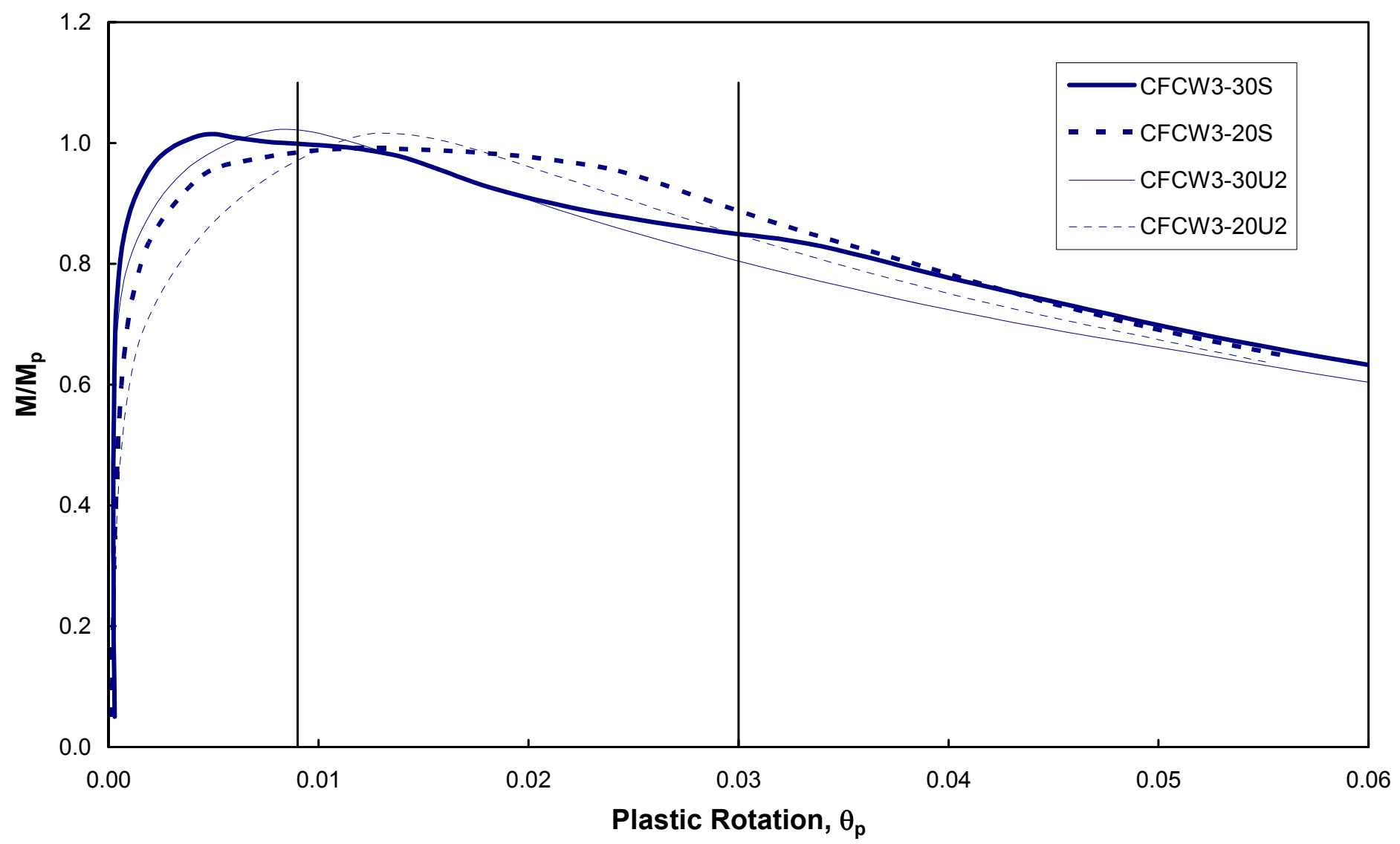

Figure 5.28 Effect of $\mathrm{L} / \mathrm{D}$ on $\mathrm{M} / \mathrm{M}_{\mathrm{p}}$ vs. $\theta_{\mathrm{p}}$ curves (CFCW3) 
HPS Hybrid Girders

\section{CFCW4}

(Compact flange Compact web $\mathrm{D} / \mathrm{b}_{\mathrm{fc}}=4.25$ )

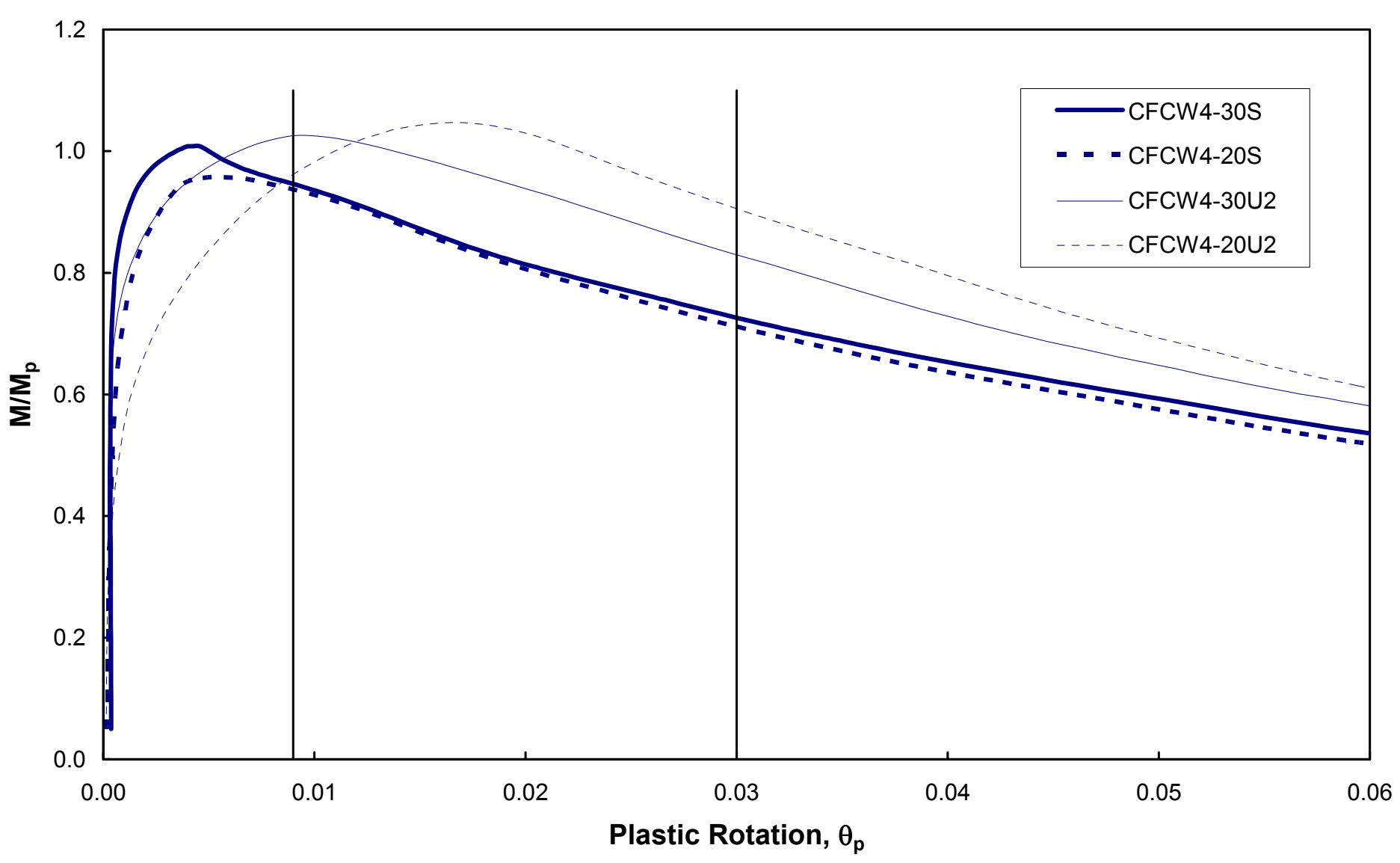

Figure 5.29 Effect of $\mathrm{L} / \mathrm{D}$ on $\mathrm{M} / \mathrm{M}_{\mathrm{p}}$ vs. $\theta_{\mathrm{p}}(\mathrm{CFCW} 4)$ 


\section{HPS Hybrid Girders \\ CFSW3 \\ (Compact flange Slender web $D / b_{\mathrm{fc}}=3$ )}

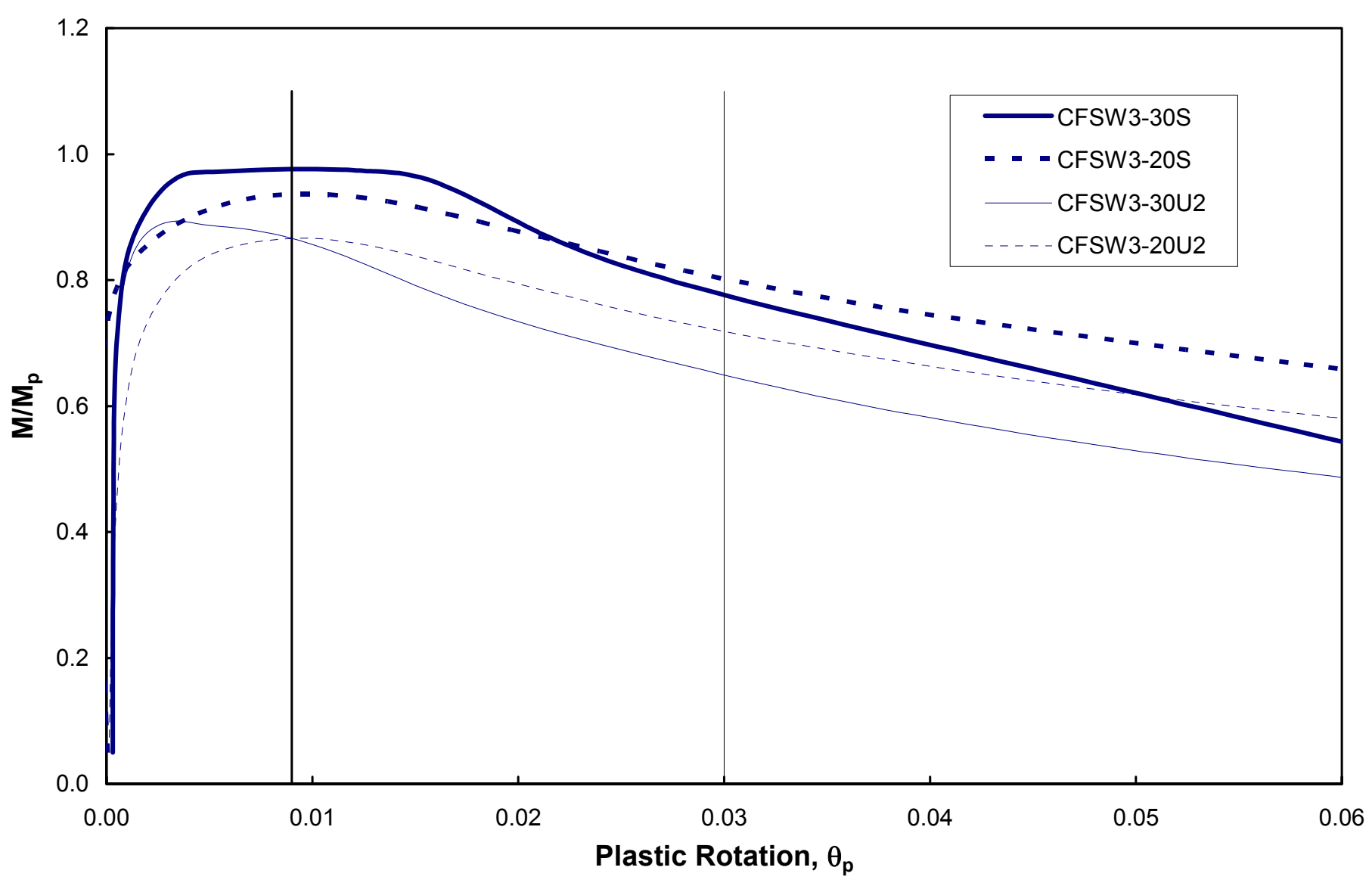

Figure 5.30 Effect of $L / D$ on $M / M_{p}$ vs. $\theta_{p}$ curves (CFSW3) 


\section{Hybrid Girders}

CFSW4

(Compact flange Slender web $D / b_{f c}=4.25$ )

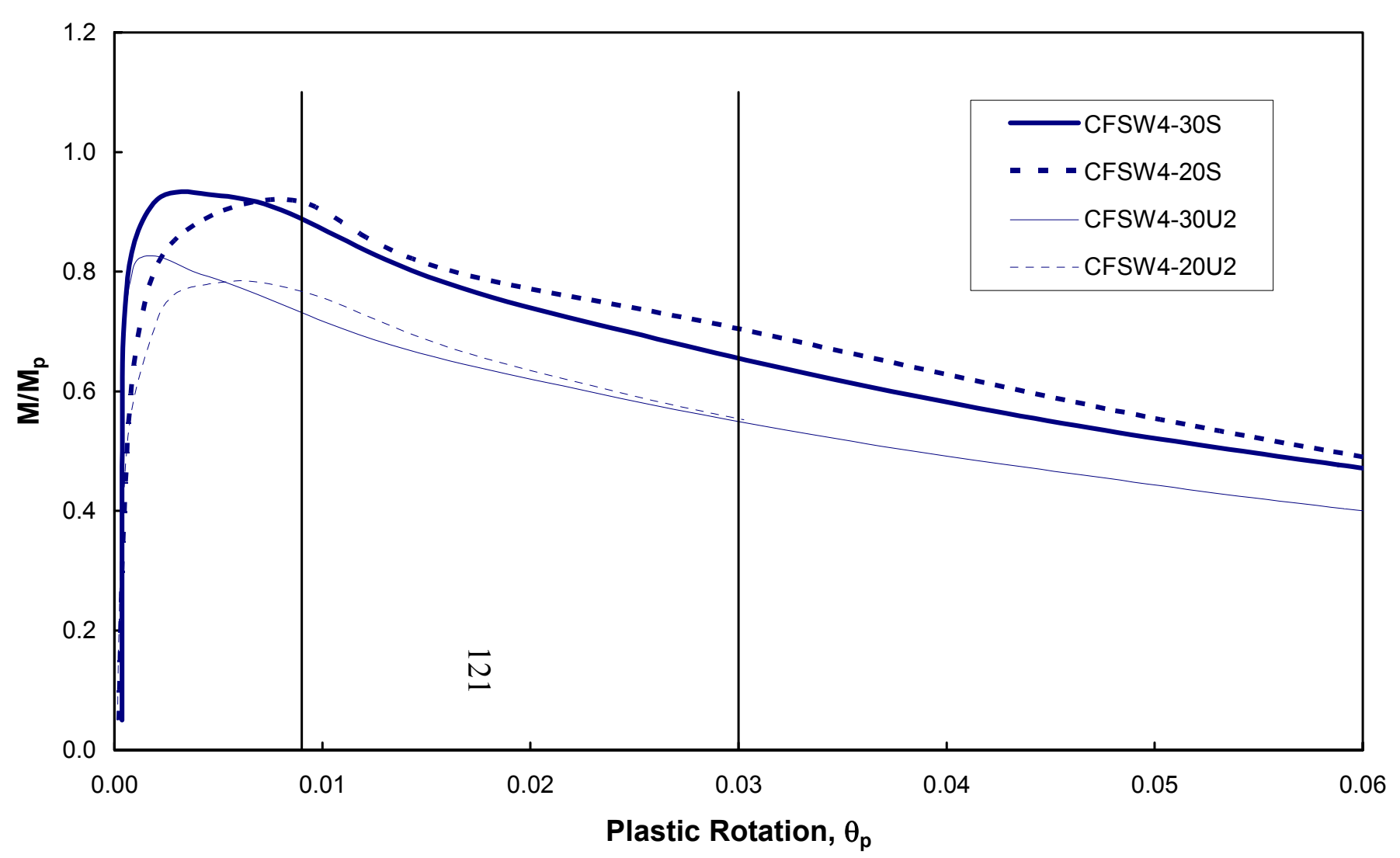

Figure 5.31 Effect of $\mathrm{L} / \mathrm{D}$ on $\mathrm{M} / \mathrm{M}_{\mathrm{p}}$ vs. $\theta_{\mathrm{p}}$ curves (CFSW4) 


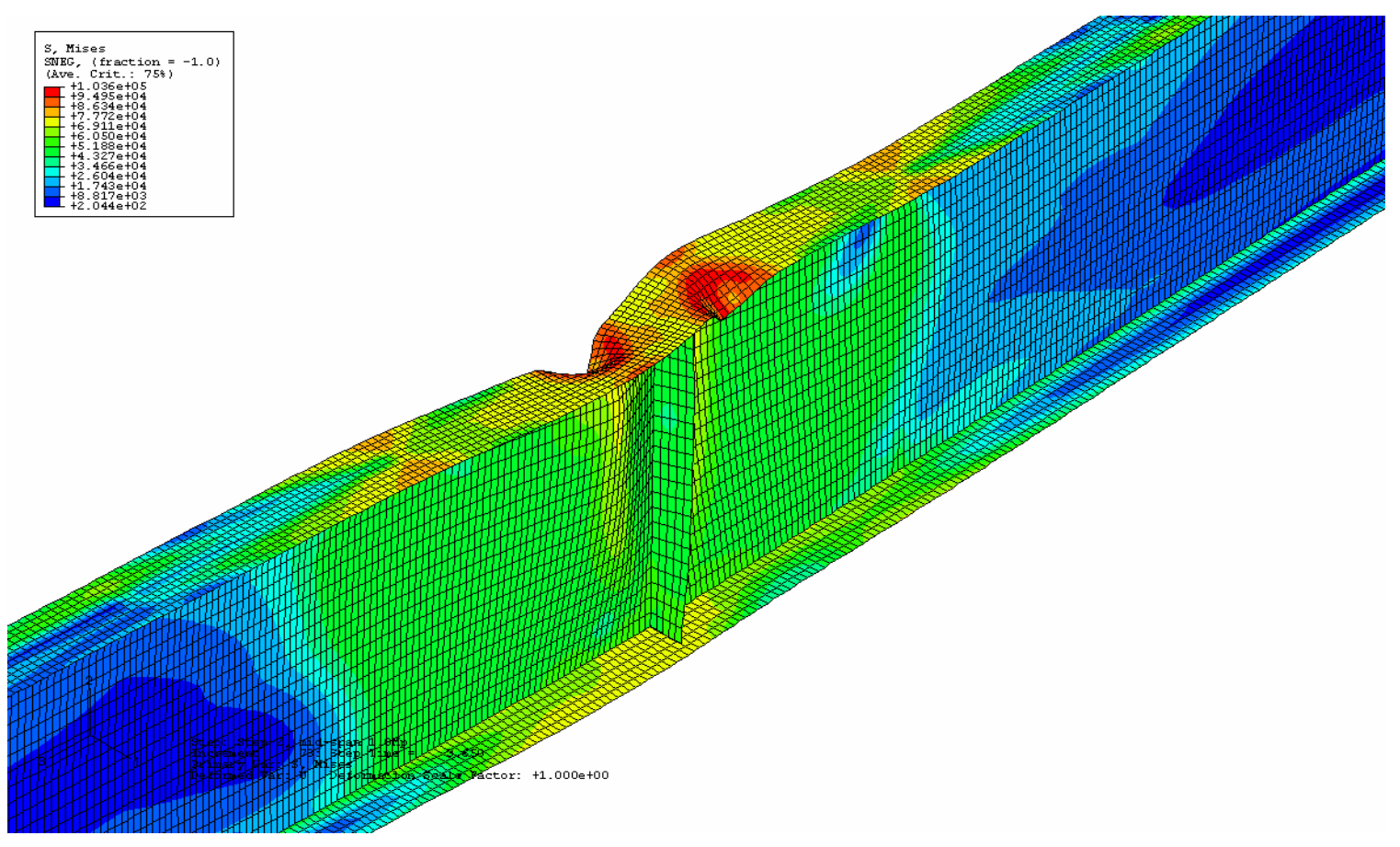

Figure 5.32 Typical failure mode of the girders in this study (at interior-pier region) 


\section{CHAPTER 6}

\section{EVALUATION OF MOMENT REDISTRIBUTION FOR HYBRID HPS 70W BRIDGE GIRDERS}

This chapter first compares the FEA results of effective plastic moments with those calculated from the currently proposed equations for moment redistribution, where the applicability of these equations for hybrid HPS 70W girders is verified. Then a design example of a two-span hybrid HPS 70W girder bridge using moment redistribution is given to illustrate the simplified procedures and its advantages.

\subsection{Evaluation of Effective Plastic Moment Equations}

Three parameters used in this study, lateral bracing, web compactness limit, and moment-shear interaction, are different from those in previous research (Barth and White, 1998; Barth et al., 2000 b). Specifically,

(1) The lateral bracing in the previous work was provided by Eq. 2.20 at adjacent pier sections, while Eq. 2.19 is used herein. Table 6.1 lists several girders designed with CFCW cases (compact flange, compact web, $\mathrm{D} / \mathrm{b}_{\mathrm{fc}}=3,4.25, \mathrm{~L} / \mathrm{D}=20,30, \mathrm{D}_{\mathrm{cp}} / \mathrm{D}=0.5$, $0.625,0.75)$, from which it can be seen that lateral bracing $L_{b}$ used in this research is generally smaller than the AASHTO $\mathrm{L}_{\mathrm{pd}}$ defined in Eq. 2.20 for the same design conditions. Thus, the FEA results are more conservative compared with previous studies when only lateral bracing effect is considered; 
(2) A new web compactness limit (Eq. 2.17) proposed by Barth et al. (2003) to ensure the girders reach $\mathrm{M}_{\mathrm{p}}$ provided other compactness requirements are satisfied, is adopted in this study. Comparisons between the two web compactness are shown in Table 6.2 for CF cases (compact flange, compact web Eq. 2.2 or Eq. 2.17, $\mathrm{D} / \mathrm{b}_{\mathrm{fc}}=3,4.25, \mathrm{~L} / \mathrm{D}=20,30$, $\left.\mathrm{D}_{\mathrm{cp}} / \mathrm{D}=0.5,0.625,0.75\right)$, from which we can see that web compactness from the proposed web equation is smaller than that from AASHTO LRFD specifications (AASHTO, 2001); (3) In previous studies, the moment and shear interaction was considered. Thus the ultimate shear was limited to $60 \%$ of the nominal shear capacity, i. e., $\mathrm{V}_{\mathrm{u}}<0.6 \mathrm{~V}_{\mathrm{n}}$, and web tension field action was also included. However, several researchers have concluded that the moment and shear interaction is negligible. In the new edition of AASHTO LRFD specifications for moment redistribution design, the shear is thereby limited to $\mathrm{V}_{\mathrm{u}}<\phi_{\mathrm{v}} \mathrm{V}_{\mathrm{cr}}$ and no tension field action is permitted, which is also adopted in this study. Barth et al. (2003) showed that the effective plastic equations can predict the experimental results accurately for the maximum shear stress range of $\mathrm{V}_{\mathrm{u}} / \mathrm{V}_{\mathrm{n}}$ as large as 0.8. In this study, the shear capacities for compact section are all less than $0.6 \mathrm{~V}_{\mathrm{n}}$. For girders with slender webs, the maximum $\mathrm{V}_{\mathrm{u}} / \phi_{\mathrm{v}} \mathrm{V}_{\mathrm{cr}}$ is 0.97 (CFSW3-20U1). However, if tension field action is considered, as defined in previous study, the $\mathrm{V}_{\mathrm{u}} / \mathrm{V}_{\mathrm{n}}$ value becomes 0.67, which is less than 0.8. Therefore, the difference of shear demand between the previous and current study is relatively small.

As discussed above, all these changes can either benefit or have little effect on moment rotation behavior of hybrid HPS 70W girders. As the moment-rotation model provides a lower-bound limit for moment-rotation response, it is possible to apply it to 
HPS hybrid girders. As a result, the effective plastic moment equations, derived from the moment-rotation model, are also possible to be extended to hybrid HPS 70W girders.

A comparison study is carried out to evaluate effective plastic moment equations, Eqs. 2.21 through 2.24. The FEA model properties are listed in Table 6.3. The strength ratio is defined as the ratio of effective plastic moments predicted by proposed equations to those from FEA results. Histograms of the strength ratios for Service II and Strength I limit states are shown in Fig. 6.1, where good correlations can be seen for both Service II and Strength I limit state. For Service II limit, the maximum value is 1.07 , the minimum value is 0.81 , the average value is 0.98 , and the standard deviation is $5 \%$; for Strength I limit, the maximum value is 1.17 , the minimum value is 0.72 , the average value is 0.92 , and the standard deviation is $11 \%$. Therefore, it is reasonable to conclude that the effective plastic moment equations can be applied to hybrid HPS 70W girders.

The following section will demonstrate a simplified moment redistribution design example to illustrate such procedures used for hybrid HPS 70W bridge girders.

\subsection{Simplified Moment Redistribution Design Example for Hybrid HPS 70W \\ Girder Bridge}

A hybrid HPS 70W bridge is designed according to simplified moment redistribution procedures. The bridge is a two-span structure with equal span lengths of $90 \mathrm{ft}$. A $37 \mathrm{ft}$ wide deck is supported by four I-shaped plate girders with a spacing of 10 ft. Figure 6.2 shows the cross section of the prototype bridge. The 28-day compression 
strength of the $8-1 / 2$ in. deck (including $1 / 2$ in. wearing surface) is assumed to be $4 \mathrm{ksi}$. The deck is reinforced with standard Grade 60 steel reinforcement.

A positive moment region (Section 1) and an interior-pier support region (Section 2) were designed for this girder as shown in Fig. 6.3. Both sections are 42 in. deep girders, where Section 1 uses homogeneous Grade 50 steel and Section 2 utilizes hybrid girders with HPS 70W flanges and Grade 50 webs. A field splice is located in span 2 between section transitions and an optional field space is also located in span 1. Crosssectional properties of the negative and positive moment regions are shown in Table 6.4. The above designs satisfy all AASHTO design requirements, including fatigue limit state and constructability requirement, as well as the proposed simplified moment redistribution design procedures suggested by Barth et al. (2003).

\section{$\underline{\text { Design Loads }}$}

The LRFD (AASHTO, 2001) dead load, HL-93 live load and dynamic load allowance are used for the design. A future wearing surface load of $25 \mathrm{psf}$ and two barriers (520 plf) are also included in the composite dead load. Specifically, the dead

load of the steel girder and the concrete deck, component dead load DC1, is applied to the non-composite section. The weight of the barrier curbs, DC2, and DW from future wearing surface are applied to the long-term composite section. The moment envelopes for dead and live loads are shown in Fig. 6.4, and the maximum positive and negative bending moments are shown in Table 6.5, which are equal to $4189 \mathrm{k}-\mathrm{ft}$ and $5352 \mathrm{k}-\mathrm{ft}$ for Strength I and $3162 \mathrm{k}-\mathrm{ft}$ and 4065 for Service II, respectively. 
The required design checks according to the simplified moment redistribution procedures (Barth, et al., 2003) are presented below.

\section{Service II Limit}

The Service II limit is intended to control permanent deflections by limiting the maximum flange stresses. Table 6.5 lists the critical Service II moments acting on an interior girder for the positive and negative moment region. From Eq. 2.21, we can calculate effective plastic moment as

$\mathrm{M}_{\mathrm{pe}}=4839 \mathrm{k}-\mathrm{ft}$

Equation 2.30 gives

$$
\mathrm{M}_{\mathrm{rd}}=\left|\mathrm{M}_{\mathrm{e}}\right|-\mathrm{M}_{\mathrm{pe}}=4065-4839=-774 \mathrm{k}-\mathrm{ft}<0 \quad \therefore \mathrm{M}_{\mathrm{rd}}=0
$$

Because the effective plastic moment is greater than the Service II elastic moment, there is no redistribution moment. The Service II limit check at positive bending region is thus the same as an elastic analysis,

$\mathrm{f}_{\mathrm{f}}=\frac{\mathrm{M}_{\mathrm{DC1}}}{\mathrm{S}_{\text {bot. }}}+\frac{\mathrm{M}_{\mathrm{Dw}+\mathrm{DC} 2}}{\mathrm{~S}_{\text {bot._3n }}}+\frac{1.3 \mathrm{M}_{\mathrm{L}+\mathrm{IM}}}{\mathrm{S}_{\text {bot._n }}}=\frac{738}{0.51}+\frac{268}{0.67}+\frac{1662}{0.72}=29 \mathrm{ksi}$

$\mathrm{f}_{\mathrm{f}}=29 \mathrm{ksi}<0.95 \mathrm{R}_{\mathrm{h}} \mathrm{F}_{\mathrm{yf}}=63 \mathrm{ksi}$

where $\mathrm{R}_{\mathrm{h}}=0.95$ and $\mathrm{F}_{\mathrm{yf}}=70 \mathrm{ksi}$.

Hence, the Service II limit is satisfied.

\section{$\underline{\text { Strength I Limit }}$}

The controlling Strength I moments are also listed in Table 6.5. The proposed moment redistribution procedures are based on shakedown, where after redistribution 
from inelastic action, the elastic moment plus the redistribution moment must remain in the elastic range at all sections.

Using Eq. 2.22, we can calculate the effective plastic moment for Strength I limit

as

$$
\mathrm{M}_{\mathrm{pe}}=4397 \mathrm{k}-\mathrm{ft}
$$

The redistribution moment at Strength I limit can be obtained from the larger of Eqs. 2.31 and 2.32, for this design example $\mathrm{f}_{l}=0$, thus both two equations give the same results as

$$
\mathrm{M}_{\mathrm{rd}}=\left|\mathrm{M}_{\mathrm{e}}\right|+\frac{1}{3} \mathrm{f}_{l} \mathrm{~S}_{\mathrm{xc}}-\phi_{f} \mathrm{M}_{\mathrm{pe}}=5352+0-1.0 \times 4397=955 \mathrm{k}-\mathrm{ft}>0
$$

Since $\mathrm{M}_{\mathrm{rd}}$ is greater than zero, a portion of the elastic moment at the pier is redistributed to the positive bending regions; specially, the redistributed moment corresponds to $17.8 \%$ of the total elastic moment at the pier, as shown in Fig. 6.5. All sections of the girder must then be checked for adequate capacity to resist the elastic moments plus redistribution moments. In the negative pier region, the elastic plus redistribution moments are equal to the moment capacity; hence the negative bending requirements are satisfied automatically. In the positive moment region at $0.4 \mathrm{~L}$, the redistribution moment is $40 \%$ of that at the pier. The design check is then carried out as

$$
\begin{aligned}
& \mathrm{M}_{\text {e_pos. }}=\left|\mathrm{M}_{\mathrm{e} \_ \text {pos. }}\right|+\frac{1}{3} \mathrm{f}_{l} \mathrm{~S}_{\mathrm{xc} \_ \text {pos. }}+\phi_{f} \mathrm{M}_{\text {pe_pos. }}=4189+0+1.0 \times(0.4 \times 955)=4571 \mathrm{k}-\mathrm{ft} \\
& \mathrm{M}_{\mathrm{e} \_ \text {pos. }}=4571 \mathrm{k}-\mathrm{ft}<\mathrm{M}_{\mathrm{n} \_ \text {pos. }}=6191 \mathrm{k}-\mathrm{ft}
\end{aligned}
$$

Thus, the Strength I limit is satisfied. 
All other design checks are the same as would be performed for a traditional elastic design, and from the above design procedures, we can see that the recommended moment redistribution is greatly simplified compared with current LRFD inelastic provisions that require a continuity relation between the redistribution moment and the inelastic rotation at the pier section based a plastic collapse mechanism analysis (AASHTO, 2001).

An elastic design was also performed for the example considered above for comparison purposes. The elevation view of the hybrid girder resulting from elastic design is shown in Fig. 6.6. The total weight is 31.4 kips for the elastic design and 30.4 kips for the moment redistribution design, where the simplified moment redistribution design can gain a 3\% total weight saving and 9\% weight saving at interior-pier region. It is noted that fatigue requirements dictate that the same positive bending sections be used in both designs. Furthermore, traditional design practice dictates that a negative bending region smaller than the positive bending region not be used. Consequently, the moment redistribution design is somewhat controlled by this convention for the design example.

\subsection{Summary}

The work presented in this chapter shows that the effective plastic moment equations, Eqs. 2.21 through 2.24, can be successfully applied to hybrid HPS 70W girders. With a design example, it illustrates how the simplified moment redistribution procedures can be applied to hybrid HPS 70W bridge girders and to achieve significant weight and cost savings without extraneous design efforts. 
Table 6.1 Comparison of proposed and current lateral bracing (AASHTO, 2001):

$\mathrm{L}_{\mathrm{b}}$ and $\mathrm{L}_{\mathrm{pd}}$

\begin{tabular}{|l|c|c|c|c|}
\hline \multirow{2}{*}{$\begin{array}{c}\text { Naming } \\
\text { Convention }\end{array}$} & \multicolumn{2}{|c|}{$\mathbf{D} / \mathbf{b}_{\mathbf{f c}}=\mathbf{4 . 2 5}$} & \multicolumn{2}{c|}{$\mathbf{D} / \mathbf{b}_{\mathbf{f c}}=\mathbf{3 . 0}$} \\
\cline { 2 - 5 } & $\mathbf{L}_{\mathbf{b}} \mathbf{( 1 )}(\mathbf{i n})$ & $\mathbf{L}_{\mathbf{p d}} \mathbf{( 1 )}(\mathbf{i n})$ & $\mathbf{L}_{\mathbf{b}}(\mathbf{2}) \mathbf{( i n )}$ & $\mathbf{L}_{\mathbf{p d}} \mathbf{( 2 )}$ (in) \\
\hline CFCW-30S & 67 & 64 & 133 & 139 \\
\hline CFCW-30U1 & 58 & 86 & 120 & 127 \\
\hline CFCW-30U2 & 50 & 95 & 106 & 123 \\
\hline CFCW-20S & 124 & 112 & 275 & 300 \\
\hline CFCW-20U1 & 101 & 198 & 239 & 330 \\
\hline CFCW-20U2 & 83 & 235 & 202 & 427 \\
\hline
\end{tabular}


Table 6.2 Comparison of proposed (Barth, et al., 2003) and current (AASHTO, 2001) web compactness:

$2 \mathrm{D}_{\mathrm{cp}} / \mathrm{t}_{\mathrm{w}}=3.76 \sqrt{\mathrm{E} / \mathrm{F}_{\mathrm{yc}}}$ and $2 \mathrm{D}_{\mathrm{cp}} / \mathrm{t}_{\mathrm{w}}=\lambda_{\mathrm{pw}\left(\mathrm{D}_{\mathrm{cp}}\right)}$

\begin{tabular}{|l|c|c|c|}
\hline \multirow{2}{*}{$\begin{array}{c}\text { Naming } \\
\text { Convention }\end{array}$} & $\mathbf{D} / \mathbf{b}_{\mathbf{f c}}=\mathbf{3}, \mathbf{4 . 2 5}$ & $\mathbf{D} / \mathbf{b}_{\mathbf{f c}}=\mathbf{4 . 2 5}$ & $\mathbf{D} / \mathbf{b}_{\mathbf{f c}}=\mathbf{3 . 0}$ \\
\cline { 2 - 4 } & $2 \mathrm{D}_{\mathrm{cp}} / \mathrm{t}_{\mathrm{w}}=3.76 \sqrt{\mathrm{E} / \mathrm{F}_{\mathrm{yc}}}$ & $2 \mathrm{D}_{\mathrm{cp}} / \mathrm{t}_{\mathrm{w}}=\lambda_{\mathrm{pw}\left(\mathrm{D}_{\mathrm{cp}}\right)}$ & $2 \mathrm{D}_{\mathrm{cp}} / \mathrm{t}_{\mathrm{w}}=\lambda_{\mathrm{pw}\left(\mathrm{D}_{\mathrm{cp}}\right)}$ \\
\hline & $\mathrm{CW} 1$ & $\mathrm{CW}$ & $\mathrm{CW}$ \\
\hline CF-30S & 90.55 & 85.61 & 90.35 \\
\hline CF-30U1 & 90.55 & 63.24 & 72.17 \\
\hline CF-30U2 & 90.55 & 50.61 & 59.15 \\
\hline CF-20S & 90.55 & 85.61 & 90.36 \\
\hline CF-20U1 & 90.55 & 63.19 & 72.07 \\
\hline CF-20U2 & 90.55 & 50.53 & 58.98 \\
\hline
\end{tabular}


Table 6.3 Effective plastic moments for the hybrid HPS 70W girders

\begin{tabular}{|c|c|c|c|c|c|c|c|c|c|c|c|c|c|c|c|c|}
\hline & & & & & & & & & Service II & \begin{tabular}{|l|} 
Strength I \\
\end{tabular} & & & \begin{tabular}{|c|} 
Service II \\
$M_{\mathrm{pe} \text { Eq. }}$ \\
\end{tabular} & $\begin{array}{c}\text { Strength I } \\
M_{\mathrm{pe} \text { Eq. }}\end{array}$ & Service II & Strength I \\
\hline L/D & $\begin{array}{l}\text { Naming } \\
\text { Convention }\end{array}$ & $\begin{array}{c}\text { Flange } \\
\text { Slenderness }\end{array}$ & $\begin{array}{c}\text { Web } \\
\text { Slenderness }\end{array}$ & $2 \mathrm{D}_{\mathrm{cp}} / \mathrm{t}_{\mathrm{w}}$ & $b_{f_{c}}\left(2^{*} t_{t_{c}}\right)$ & $M_{y}$ & $M_{p}$ & $M_{\text {FEA_max }} / M_{p}$ & $\mathrm{M}_{\mathrm{pe}_{-} \mathrm{FEA}}$ & $\mathrm{M}_{\mathrm{Pe}_{-} \mathrm{FEA}}$ & $\begin{array}{c}\Theta_{\mathrm{RL}} \\
\text { Eq. (2.16) }\end{array}$ & $\begin{array}{c}\text { Mn } \\
\text { modified } \\
\text { AASHTO }\end{array}$ & $\begin{array}{c}M_{\text {pe EEq. }} \\
\text { Eq. (2.21) or } \\
(2.23)\end{array}$ & $\begin{array}{c}M_{\text {pe_Eq. }} \\
\text { Eq. (2.22) or } \\
(2.24)\end{array}$ & $\mathrm{M}_{\mathrm{pe} E \mathrm{Eq}} / \mathrm{M}_{\mathrm{pe} \_ \text {FEA }}$ & $\mathrm{M}_{\mathrm{pe} \_ \text {Eq }} / \mathrm{M}_{\mathrm{pe} \_ \text {FEA }}$ \\
\hline & & & & & & (in-kips) & (in-kips) & & (in-kips) & (in-kips) & (rads) & (in-kips) & \begin{tabular}{|l|} 
(in-kips) \\
\end{tabular} & (in-kips) & & \\
\hline \multirow{24}{*}{$L / D=30$} & CFCW4-30S & compact & Compact & 85.61 & 7.73 & 82697 & 86476 & 1.010 & 81807 & 62807 & 0.0054 & 86513 & 79956 & 56597 & 0.98 & 0.90 \\
\hline & CFSW4-30S & compact & non-compact & 138.41 & 7.73 & 71800 & 74445 & 0.933 & 66120 & 48770 & 0.0054 & 68109 & 62946 & 44557 & 0.95 & 0.91 \\
\hline & CFCW4-30U1 1 & compact & Compact & 63.24 & 7.73 & 113819 & 132889 & 1.007 & 126913 & 95279 & 0.0054 & 132820 & 122752 & 86891 & 0.97 & 0.91 \\
\hline & CFSW4-30U1 & compact & non-compact & 138.45 & 7.73 & 80176 & 90206 & 0.859 & 71184 & 53036 & 0.0054 & 76897 & 71069 & 50306 & 1.00 & 0.95 \\
\hline & CFCW4-30U2 & compact & Compact & 50.61 & 7.73 & 157462 & 199129 & 1.026 & 204056 & 165270 & 0.0054 & 199132 & 184037 & 130272 & 0.90 & 0.79 \\
\hline & CFSW4-30U2 & compact & non-compact & 138.35 & 7.73 & 89545 & 106971 & 0.825 & 78236 & 58774 & 0.0054 & 77098 & 71254 & 50438 & 0.91 & 0.86 \\
\hline & CFCW3-30S & compact & Compact & 90.35 & 7.73 & 135408 & 140828 & 1.015 & 140631 & 119633 & 0.0095 & 140828 & 139589 & 101565 & 0.99 & 0.85 \\
\hline & CFSW3-30S & compact & non-compact & 138.41 & 7.73 & 126123 & 130452 & 0.976 & 127335 & 101287 & 0.0185 & 122256 & 122256 & 106509 & 0.96 & 1.05 \\
\hline & CFCW3-30U1 & compact & Compact & 72.17 & 7.73 & 158887 & 179413 & 1.020 & 177925 & 139532 & 0.0095 & 179407 & 177828 & 129388 & 1.00 & 0.93 \\
\hline & CFSW3-30U1 & compact & non-compact & 138.58 & 7.73 & 133844 & 146642 & 0.923 & 127697 & 89469 & 0.0095 & 130887 & 129735 & 94396 & 1.02 & 1.06 \\
\hline & CFCW3-30U2 & compact & Compact & 59.15 & 7.73 & 194115 & 235456 & 1.023 & 240392 & 189464 & 0.0095 & 235456 & 233384 & 169811 & 0.97 & 0.90 \\
\hline & CFSW3-30U2 & compact & non-compact & 138.43 & 7.73 & 142699 & 163762 & 0.894 & 141807 & 106307 & 0.0095 & 126931 & 125814 & 91543 & 0.89 & 0.86 \\
\hline & uccW4-30s & ultra-compact & Compact & 87.00 & 5.92 & 98559 & 103103 & 0.991 & 99301 & 88068 & 0.0126 & 103102 & 103102 & 79241 & 1.04 & 0.90 \\
\hline & UCSW4-30S & ultra-compact & non-compact & 138.41 & 5.92 & 88212 & 91576 & 0.949 & 86732 & 74549 & 0.0126 & 84416 & 84416 & 64879 & 0.97 & 0.87 \\
\hline & uccW4-30U1 & ultra-compact & Compact & 65.89 & 5.92 & 126598 & 146420 & 1.000 & 140360 & 119380 & 0.0126 & 146420 & 146420 & 112534 & 1.04 & 0.94 \\
\hline & UCSW4-30U1 & ultra-compact & non-compact & 138.26 & 5.92 & 96121 & 107264 & 0.876 & 94222 & 77529 & 0.0126 & 92971 & 92971 & 71454 & 0.99 & 0.92 \\
\hline & UCCW4-30U2 & ultra-compact & Compact & 52.95 & 5.92 & 167874 & 210086 & 1.030 & 215577 & 183933 & 0.0126 & 210086 & 210086 & 161465 & 0.97 & 0.88 \\
\hline & UCSW4-30U2 & ultra-compact & non-compact & 138.54 & 5.92 & 105343 & 124277 & 0.829 & 101547 & 82983 & 0.0126 & 91763 & 91763 & 70526 & 0.90 & 0.85 \\
\hline & UccW3-30S & ultra-compact & Compact & 90.63 & 5.92 & 168285 & 175602 & 1.010 & 179426 & 177533 & 0.0221 & 175602 & 175602 & 161964 & 0.98 & 0.91 \\
\hline & UCSW3-30S & ultra-compact & non-compact & 138.41 & 5.92 & 159198 & 165318 & 0.933 & 154750 & 132593 & 0.0311 & 155297 & 155297 & 155297 & 1.00 & 1.17 \\
\hline & uccW3-30U1 & ultra-compact & Compact & 74.77 & 5.92 & 189366 & 212132 & 1.020 & 212861 & 172403 & 0.0221 & 212132 & 212132 & 195658 & 1.00 & 1.13 \\
\hline & UCSW3-30U1 & ultra-compact & non-compact & 138.54 & 5.92 & 166625 & 181655 & 0.945 & 162985 & 138195 & 0.0221 & 163813 & 163813 & 151092 & 1.01 & 1.09 \\
\hline & UCcW3-30U2 & ultra-compact & Compact & 62.52 & 5.92 & 221174 & 264454 & 1.020 & 256833 & 224233 & 0.0221 & 264454 & 264454 & 243917 & 1.03 & 1.09 \\
\hline & UCSW3-30U2 & ultra-compact & non-compact & 138.41 & 5.92 & 175263 & 199004 & 0.916 & 162606 & 142973 & 0.0221 & 157418 & 157418 & 145193 & 0.97 & 1.02 \\
\hline
\end{tabular}


Table 6.3 Effective plastic moments for the hybrid HPS 70W girders (Cont'd)

\begin{tabular}{|c|c|c|c|c|c|c|c|c|c|c|c|c|c|c|c|c|}
\hline & & & & & & & & & Service II & Strength I & & & Service II & Strength I & Service II & Strength I \\
\hline L/D & $\begin{array}{c}\text { Naming } \\
\text { Convention }\end{array}$ & $\begin{array}{c}\text { Flange } \\
\text { Slenderness }\end{array}$ & $\begin{array}{c}\text { Web } \\
\text { Slenderness }\end{array}$ & $2 \mathrm{D}_{\mathrm{cp}} / \mathrm{t}_{\mathrm{w}}$ & $b_{t c} /\left(2^{*} t_{t c}\right)$ & $M_{y}$ & $M_{p}$ & $\mathbf{M}_{\mathrm{FEA} \_ \text {max }} / \mathbf{M}_{\mathrm{p}}$ & $\mathrm{M}_{\mathrm{Pe}_{2} \mathrm{FEA}}$ & $M_{\mathrm{Pe}_{-} \mathrm{FEA}}$ & $\begin{array}{c}\Theta_{\mathrm{RL}} \\
\text { Eq. (2.16) }\end{array}$ & $\begin{array}{c}\text { Mn } \\
\text { modified } \\
\text { AASTOO }\end{array}$ & $\begin{array}{c}\mathrm{M}_{\mathrm{pe} \_\mathrm{Eq}} \\
\text { Eq. (2.21) or } \\
(2.23)\end{array}$ & $\begin{array}{c}\mathrm{M}_{\mathrm{pe} \text { Eqq. }} \\
\text { Eq. (2.22) or } \\
(\mathbf{2 . 2 4})\end{array}$ & $\mathrm{M}_{\mathrm{Pe}_{2}=\mathrm{Eq}} / \mathrm{M}_{\mathrm{Pe}_{-} \mathrm{FEA}}$ & $\mathrm{M}_{\mathrm{Pe} \in \mathrm{Eq}} \cdot \mathrm{M}_{\mathrm{pe}, \mathrm{FEA}}$ \\
\hline & & & & & & (in-kips) & (in-kips) & & (in-kips) & (in-kips) & $(\mathrm{rad})$ & (in-kips) & \begin{tabular}{|l|} 
(in-kips) \\
\end{tabular} & \begin{tabular}{|l|} 
(in-kips) \\
\end{tabular} & & \\
\hline \multirow{12}{*}{$L / D=20$} & CFCW4-20S & compact & Compact & 85.61 & 7.73 & 279103 & 291855 & 0.957 & 273410 & 207538 & 0.0054 & 291852 & 269730 & 190930 & 0.99 & 0.92 \\
\hline & CFSW4-20S & compact & non-compact & 138.41 & 7.73 & 242325 & 251251 & 0.921 & 229972 & 176923 & 0.0144 & 229669 & 229669 & 184700 & 1.00 & 1.04 \\
\hline & CFCW4-20U1 & compact & Compact & 63.19 & 7.73 & 382846 & 446749 & 0.990 & 440826 & 330266 & 0.0054 & 446702 & 412842 & 292232 & 0.94 & 0.88 \\
\hline & CFSW4-20U1 & compact & non-compact & 138.52 & 7.73 & 270290 & 304223 & 0.819 & 242608 & 186391 & 0.0144 & 259141 & 259141 & 208401 & 1.07 & 1.12 \\
\hline & CFCW4-20U2 & compact & Compact & 50.53 & 7.73 & 529801 & 670422 & 1.050 & 644501 & 606855 & 0.0054 & 670422 & 619604 & 438590 & 0.96 & 0.72 \\
\hline & CFSW4-20U2 * & compact & non-compact & 138.46 & 7.73 & 301690 & 360548 & 0.780 & & & 0.0054 & 259600 & 239923 & 169830 & & \\
\hline & CFCW3-20S & compact & Compact & 90.36 & 7.73 & 456991 & 475283 & 0.991 & 467980 & 421783 & 0.0095 & 475278 & 471095 & 342770 & 1.01 & 0.81 \\
\hline & CFSW3-20S & compact & non-compact & 138.41 & 7.73 & 425666 & 440275 & 0.937 & 412130 & 353121 & 0.0185 & 412613 & 412613 & 359469 & 1.00 & 1.02 \\
\hline & CFCW3-20U1 & compact & Compact & 72.07 & 7.73 & 535559 & 605374 & 1.010 & 607453 & 491995 & 0.0095 & 605179 & 599854 & 436455 & 0.99 & 0.89 \\
\hline & CFSW3-20U1 & compact & non-compact & 138.59 & 7.73 & 450794 & 494082 & 0.902 & 443299 & 375873 & 0.0185 & 440897 & 440897 & 384110 & 0.99 & 1.02 \\
\hline & CFCW3-20U2 & compact & Compact & 58.98 & 7.73 & 651149 & 790820 & 1.020 & 768030 & 670541 & 0.0095 & 790820 & 783860 & 570339 & 1.02 & 0.85 \\
\hline & CFSW3-20U2 & compact & non-compact & 138.51 & 7.73 & 480336 & 551448 & 0.867 & 450589 & 396184 & 0.0095 & 427095 & 423337 & 308021 & 0.94 & 0.78 \\
\hline \multirow{12}{*}{$L / D=30$} & CFCW14-30S & compact & Compact & 76.53 & 7.73 & 86086 & 90217 & 1.270 & 95849 & 82323 & 0.0054 & 90030 & 83206 & 58898 & 0.87 & 0.72 \\
\hline & CFCW14-30U1 & compact & compact & 76.41 & 7.73 & 102719 & 118736 & 1.120 & 116434 & 97376 & 0.0144 & 113696 & 113696 & 91435 & 0.98 & 0.94 \\
\hline & CFCW14-30U2 & compact & Compact & 76.45 & 7.73 & 120785 & 149574 & 1.080 & 137752 & 113993 & 0.0054 & 136224 & 125899 & 89118 & 0.91 & 0.78 \\
\hline & CFCW13-30S & compact & compact & 76.53 & 7.73 & 140236 & 146224 & 1.03 & 148779 & 123143 & 0.0095 & 146037 & 144752 & 105322 & 0.97 & 0.86 \\
\hline & CFCW13-30U1 & compact & Compact & 76.45 & 7.73 & 155814 & 175382 & 1.010 & 170785 & 133240 & 0.0095 & 172873 & 171352 & 124676 & 1.00 & 0.94 \\
\hline & CFCW13-30U2 & compact & compact & 76.47 & 7.73 & 173395 & 206874 & 0.981 & 194854 & 138135 & 0.0095 & 195707 & 193985 & 141144 & 1.00 & 1.02 \\
\hline & uccW14-30s & ultra-compact & Compact & 76.53 & 5.92 & 102370 & 107348 & 1.290 & 131725 & 109704 & 0.0126 & 107161 & 107161 & 82360 & 0.81 & 0.75 \\
\hline & UCCW14-30U1 & ultra-compact & compact & 76.35 & 5.92 & 118372 & 135857 & 1.160 & 153768 & 127426 & 0.0216 & 131387 & 131387 & 120687 & 0.85 & 0.95 \\
\hline & UCCW14-30U2 & ultra-compact & Compact & 76.40 & 5.92 & 136244 & 166917 & 1.120 & 175366 & 144309 & 0.0126 & 153959 & 153959 & 118328 & 0.88 & 0.82 \\
\hline & UCCW13-30S & ultra-compact & compact & 76.53 & 5.92 & 173135 & 181090 & 1.020 & 185113 & 183172 & 0.0311 & 180903 & 180903 & 180903 & 0.98 & 0.99 \\
\hline & UCCW13-30U1 & ultra-compact & Compact & 76.43 & 5.92 & 188186 & 210522 & 1.020 & 209912 & 195354 & 0.0221 & 209085 & 209085 & 192848 & 1.00 & 0.99 \\
\hline & UCCW13-30U2 & ultra-compact & compact & 76.36 & 5.92 & 205459 & 242300 & 0.992 & 235006 & 210217 & 0.0221 & 232117 & 232117 & 214091 & 0.99 & 1.02 \\
\hline \multirow{5}{*}{\multicolumn{14}{|c|}{ * The analysis for girder CFSW4-20U2 was not completed, thus it is not included for the calibration of Mpe. }} & Maximum & 1.07 & 1.17 \\
\hline & & & & & & & & & & & & & & Median & 0.98 & 0.91 \\
\hline & & & & & & & & & & & & & & Minimum & 0.81 & 0.72 \\
\hline & & & & & & & & & & & & & & Average & 0.97 & 0.93 \\
\hline & & & & & & & & & & & & & & Stdev(\%) & 0.05 & 0.11 \\
\hline
\end{tabular}


Table 6.4 Prototype girder section properties

\begin{tabular}{|c|c|c|c|}
\hline $\begin{array}{l}\text { Design } \\
\text { condition }\end{array}$ & Property & Mid-span & Interior-pier \\
\hline \multirow[t]{2}{*}{ Non-composite } & $\mathrm{I}\left(\mathrm{in}^{4}\right)$ & 15969 & 16400 \\
\hline & $\mathrm{S}_{\text {bot. }}\left(\mathrm{in}^{3}\right)$ & 887 & 901 \\
\hline \multirow{2}{*}{$\begin{array}{l}\text { Live load } \\
\text { composite } \\
n=8\end{array}$} & $\mathrm{I}_{\mathrm{n}}\left(\mathrm{in}^{4}\right)$ & 48885 & 48957 \\
\hline & $\mathrm{S}_{\text {bot._n }}\left(\mathrm{in}^{3}\right)$ & 1242 & 1279 \\
\hline \multirow{2}{*}{$\begin{array}{l}\text { Dead load } \\
\text { composite } \\
3 n=24\end{array}$} & $\mathrm{I}_{3 \mathrm{n}}\left(\mathrm{in}^{4}\right)$ & 34789 & 35336 \\
\hline & S & 1152 & 1180 \\
\hline \multirow{2}{*}{ Slenderness ratio } & $\mathrm{b}_{\mathrm{fc}} / 2 \mathrm{t}_{\mathrm{fc}}$ & N/A & $\begin{array}{l}6.4 \\
\text { (ultra-compact) }\end{array}$ \\
\hline & $2 \mathrm{D}_{\mathrm{cp}} / \mathrm{t}_{\mathrm{w}}$ & N/A & $\begin{array}{l}80.7 \\
\text { (compact) }\end{array}$ \\
\hline
\end{tabular}


Table 6.5 Design moments

\begin{tabular}{|l|l|l|l|l|}
\hline Limit state & $\begin{array}{l}\text { Moment } \\
\text { region }\end{array}$ & $\begin{array}{l}\mathbf{M}_{\mathbf{e}} \\
\text { (Kips-ft) }\end{array}$ & $\begin{array}{l}\mathbf{M}_{\mathbf{p e}} \\
\text { (Kips-ft) }\end{array}$ & $\begin{array}{l}\mathbf{M}_{\mathbf{p}} \\
\text { (Kips-ft) }\end{array}$ \\
\hline \multirow{2}{*}{ Service II } & Positive & 3162 & Stress limit & Stress limit \\
\cline { 2 - 5 } & Negative & 4065 & 4839 & 8124 \\
\hline \multirow{2}{*}{ Strength I } & Positive & 4189 & N/A & 6393 \\
\cline { 2 - 5 } & Negative & 5352 & 4397 & 8124 \\
\hline
\end{tabular}




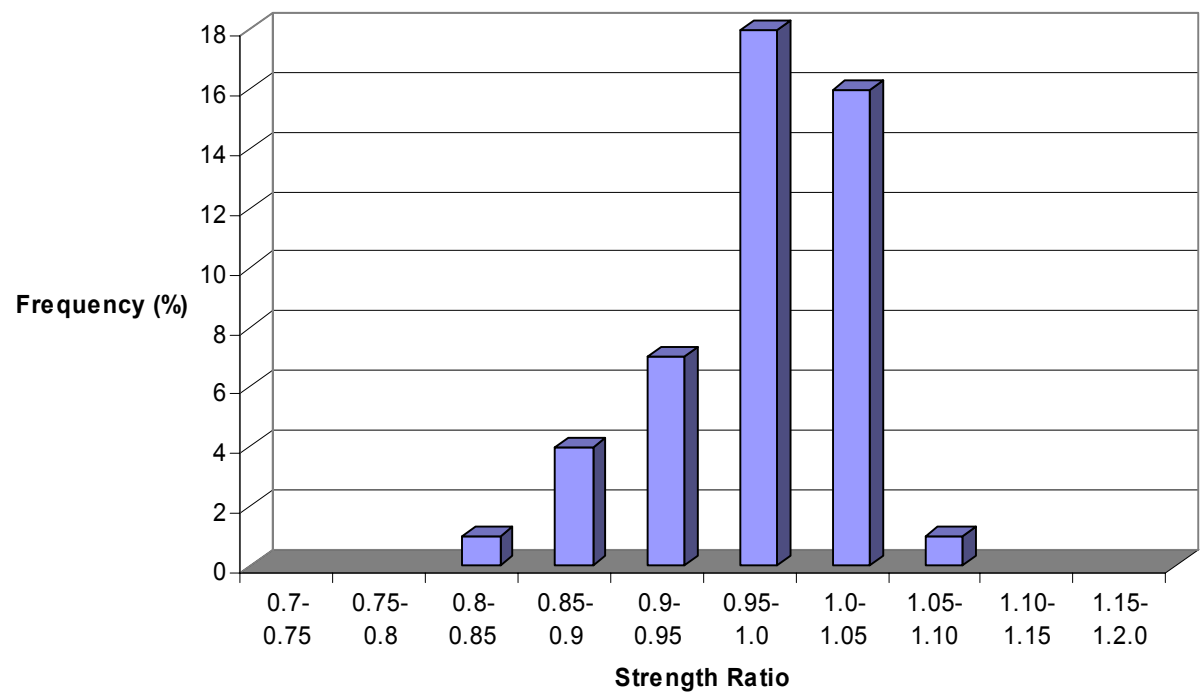

(a) Service II limit state

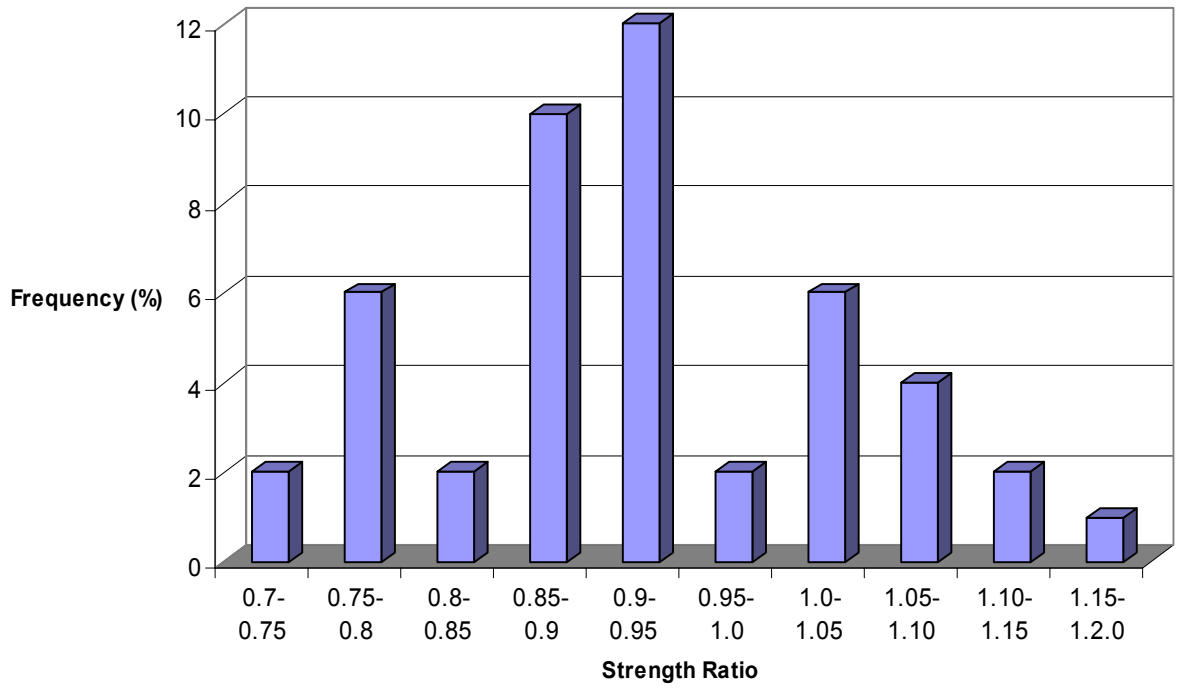

(b) Strength I limit state

Strength ratio= predicted strength/ FEA strength, 47 FEA tests.

Figure 6.1 Histograms of the strength ratios for FEA tests, based on the effective plastic moment equations proposed by Barth et al. (2003). 


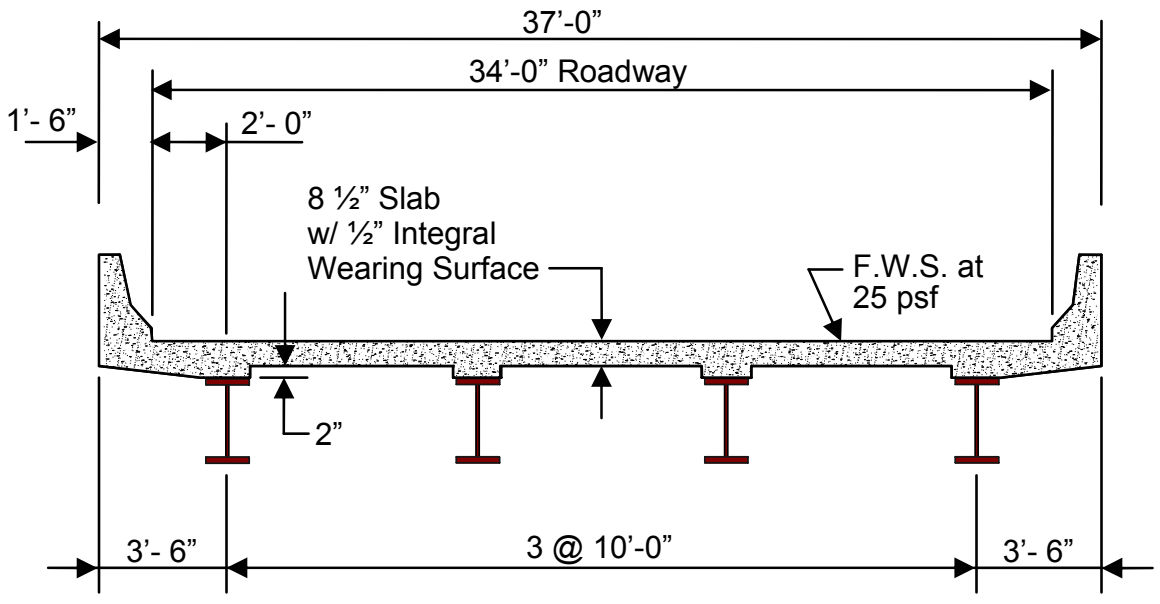

Figure 6.2 4-girder system prototype bridge cross section 
Section 1

Section 2

Section 1

$\longleftarrow 63$

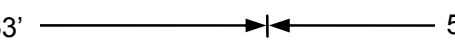

$54 \longrightarrow 63$
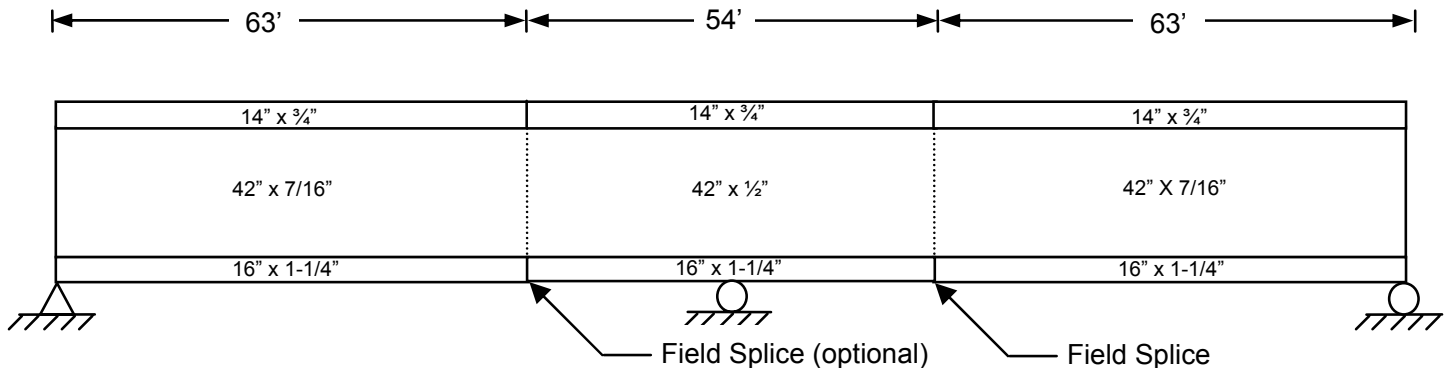

$\stackrel{8^{\prime}}{\rightarrow} K-20.5^{\prime} \rightarrow 1 \leftarrow 20.5^{\prime} \rightarrow K \leftarrow 20.5^{\prime} \rightarrow K \leftarrow 20.5^{\prime} \rightarrow 1 \begin{aligned} & \text { X-Frame } \\ & \text { Spacing }\end{aligned}$ (sym)

(a)

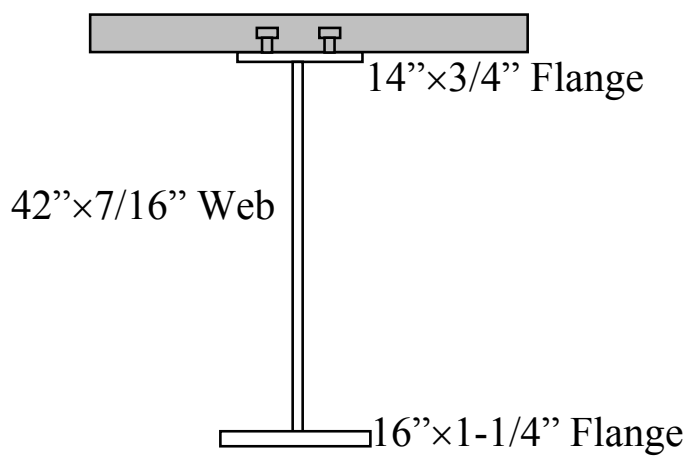

Section 1

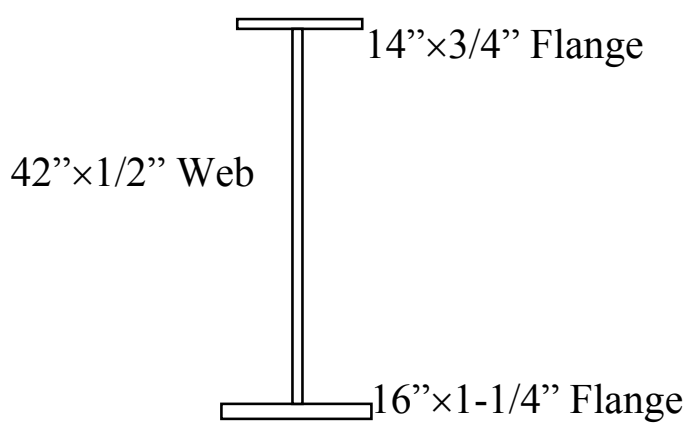

Section 2

(b)

Figure 6.3 Prototype hybrid HPS 70W girder elevation view and cross sections -Simplified moment redistribution design

(a) Prototype girder elevation view

(b) Cross sections 


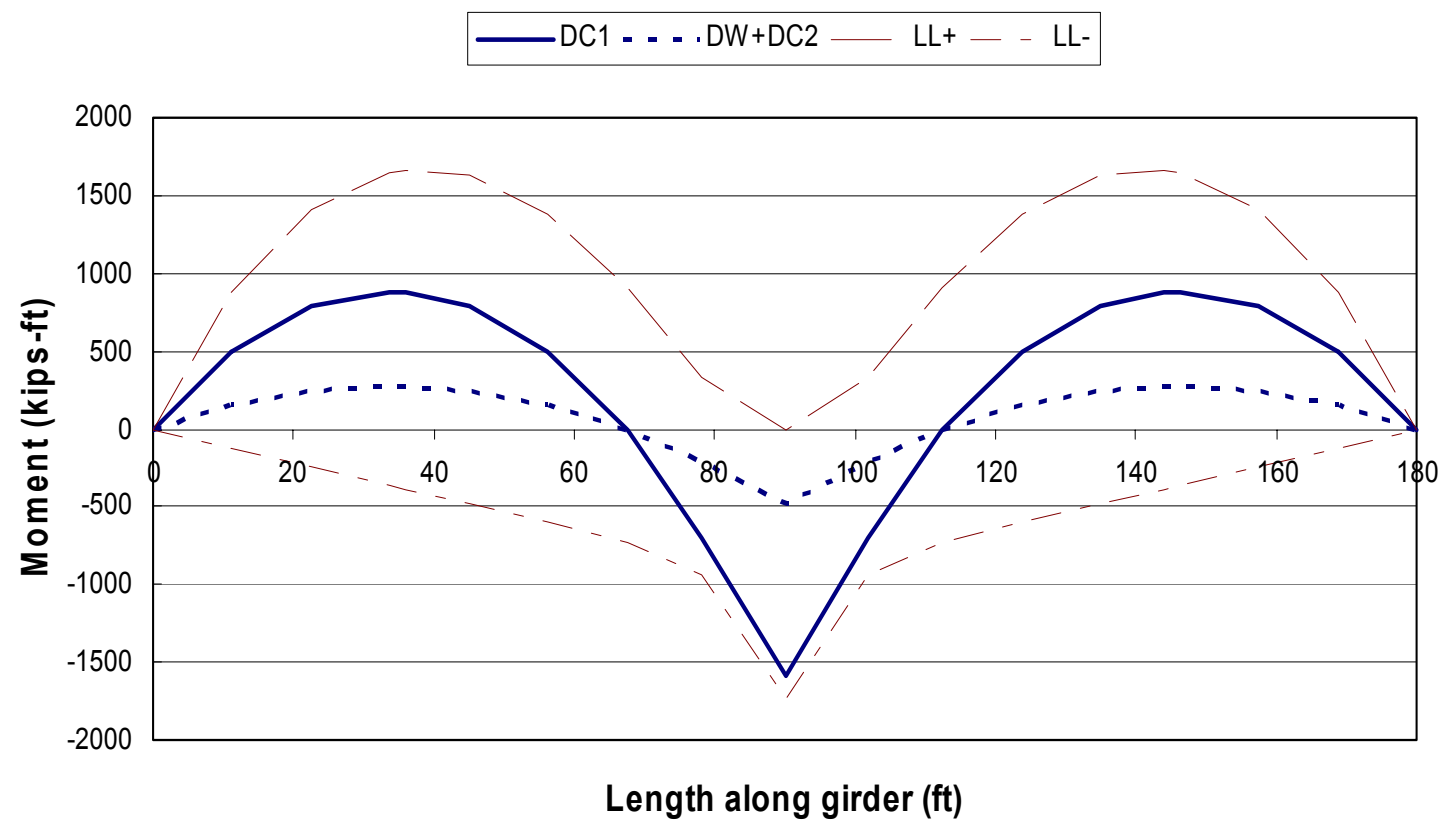

Figure 6.4 Moment envelopes for the prototype girder 


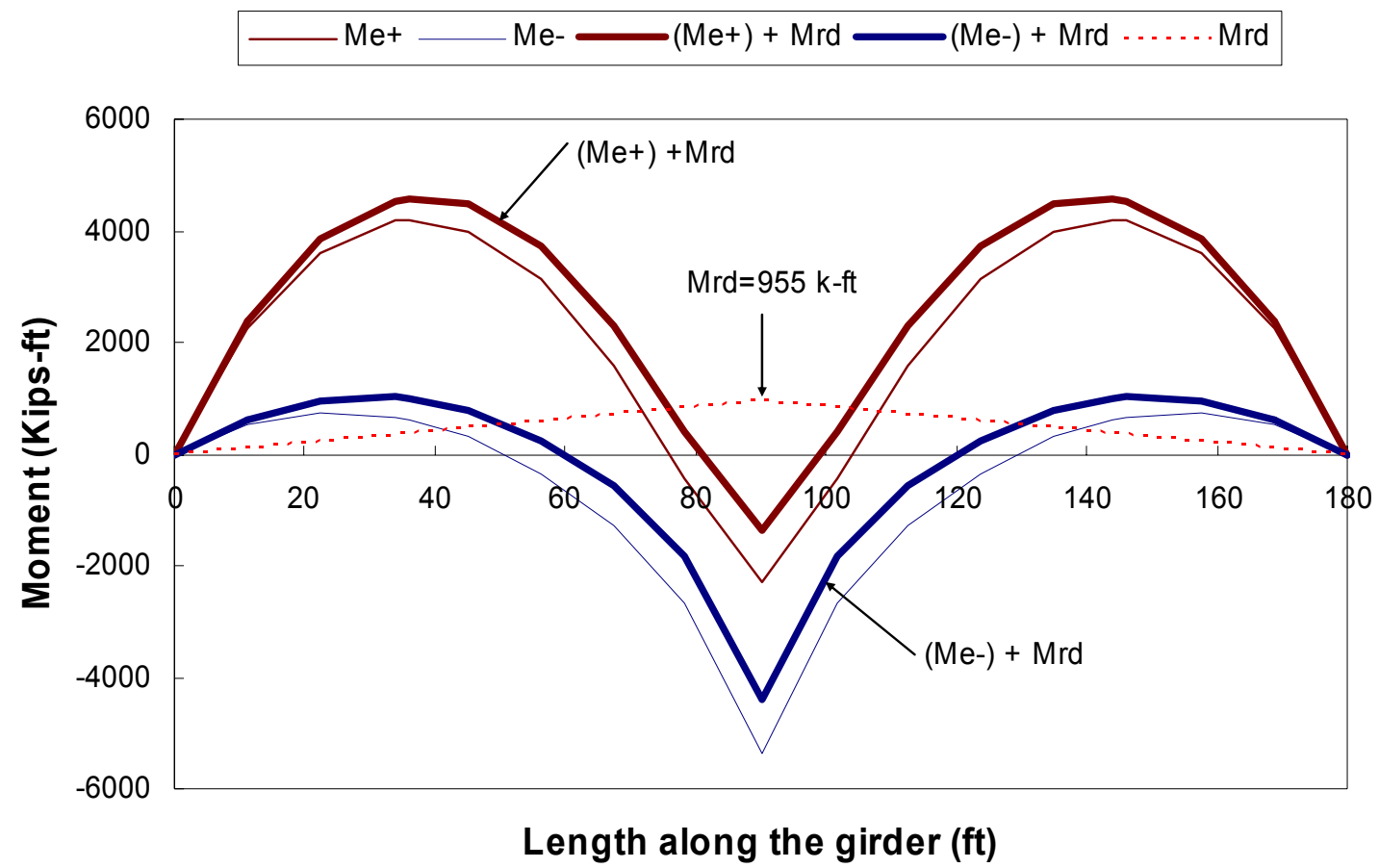

Figure 6.5 Strength I design limit moments for the prototype girder by simplified moment redistribution design 
$\begin{array}{lll}\text { Section } 1 & \text { Section } 2 & \text { Section } 1\end{array}$

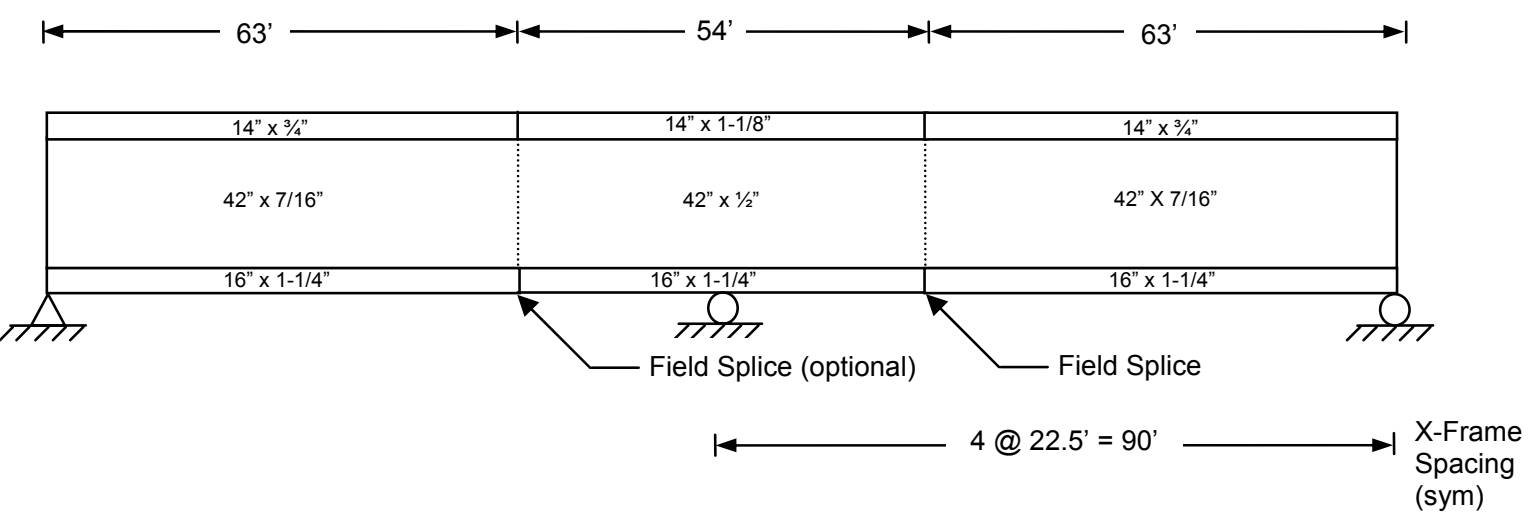

(a)

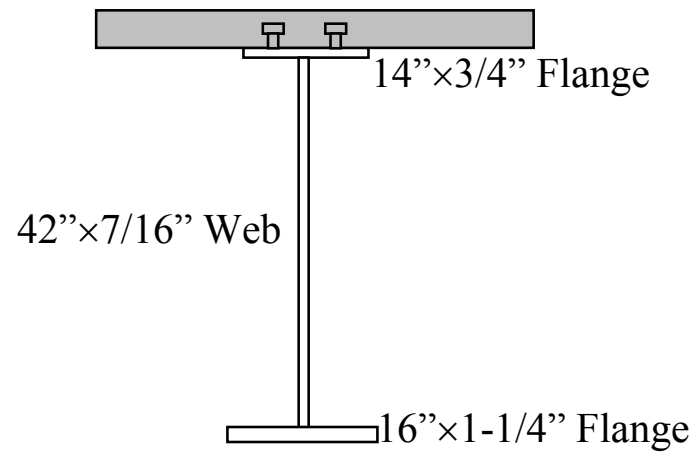

Section 1

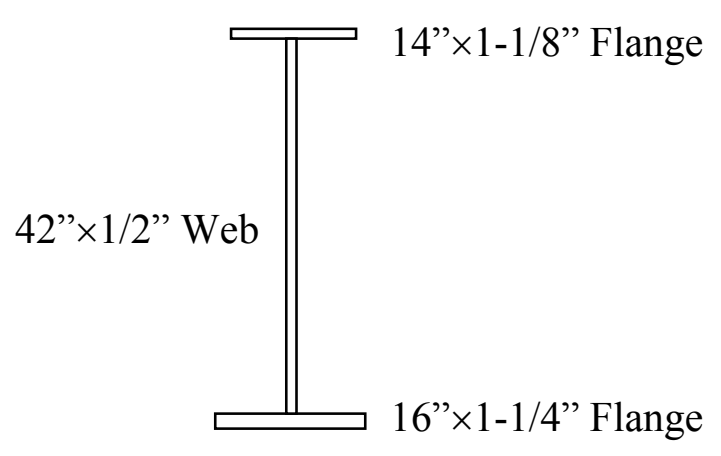

Section 2

(b)

Figure 6.6 Hybrid girder elevation view and cross sections by elastic design

(a) Elastic hybrid girder design elevation view

(b) Elastic design cross sections 


\section{CHAPTER 7}

\section{CONCLUSIONS AND RECOMMENDATIONS}

\subsection{Summary of the Work}

This research has investigated a reasonably comprehensive set of finite element parametric studies to fill the knowledge gaps in the available data pertaining to the moment-rotation behavior of hybrid HPS 70W bridge girders. As discussed, this issue is of great interest to inelastic design so that the benefits offered by the use of HPS 70W steel may be fully realized.

A literature review that summarized previous experimental test and finite element analysis work was provided in Chapter 2. It also included a historical overview of inelastic design procedures and their incorporation into AASHTO specifications. The simplified moment redistribution method based on proposed inelastic design procedures (Schilling et al., 1997; Barth et al., 2000 a) and improved effective plastic moment equations by Barth (Barth et al., 2003) were described in detail.

The finite element analysis technique used in this study was introduced in Chapter 3. It discussed the element selection, solution strategies, geometric imperfections and residual stresses considered in this study. The accuracy of the FEA model was validated against existing experimental test results in Chapter 4.

A FEA parametric study focused on the moment rotation behavior of HPS hybrid girders was performed in Chapter 5. A sufficient range of parameters was considered 
which include girder material configures, flange slenderness, web slenderness, crosssection aspect ratio, depth of web in compression, span-to-depth ratio, etc. Among them, hybrid HPS 70W girders show some benefits on the normalized strength and ductility compared with homogeneous Grade 50 and HPS 70W girders, Depth of web in compression $\mathrm{D}_{\mathrm{cp}} / \mathrm{D}$ has a significant effect on moment capacity. Within these studies, flange slenderness was not found to show any benefit on moment capacity, but it can improve moment rotation shape, i. e., smooth the unloading part of the curve. The crosssection aspect ratio $\left(\mathrm{D} / \mathrm{b}_{\mathrm{fc}}\right)$ was found to have significant influence on moment rotation properties for girders with slender webs; while for compact webs, it had little effect on moment capacity but did have some effect on the girder ductility. It is also concluded that the newly proposed web compactness limit (Barth et al., 2003) is better than the current one provided in the AASHTO LRFD specifications for singly symmetric girders, and the currently proposed lateral bracing is also better than the current limit in the AASHTO LRFD specifications, which can more effectively capture the effect of $\mathrm{D} / \mathrm{b}_{\mathrm{fc}}$, $\mathrm{D}_{\mathrm{cp}} / \mathrm{D}$ and $\mathrm{L} / \mathrm{D}$ on moment-rotation response.

The effective plastic moment results calculated from the effective plastic moment equations provided in Eqs. 2.21 to 2.24, were compared with those from FEA results in Chapter 6. It is shown that the results from effective plastic equations correlate quite well with those from FEA for the girders studies both at Service II and Strength I limit check. A design example was provided in Chapter 6 to illustrate the use of recommended simplified moment redistribution for hybrid HPS 70W bridge girders. 


\subsection{Conclusions}

From this study, the following conclusions regarding the inelastic behavior of hybrid HPS 70W girders and evaluation of the simplified moment redistribution procedures for HPS hybrid girders can be drawn:

1. The FEA model adopted in this study is suitable to study the inelastic behavior of steel girders.

2. The parameters that may affect a girder's moment-rotation properties are evaluated in detail in the parametric studies. It is found that

- hybrid HPS 70W girders improve the normalized strength (with slender webs)and ductility (with slender or compact webs)compared with homogeneous Grade 50 and HPS 70W girders.

- Ultra-compact flanges have little benefit on moment capacity, but can improve the inelastic rotation capacity.

- Web slenderness may affect the strength, but has little effect on a girders' moment-rotation shape.

- Depth of web in compression $\left(\mathrm{D}_{\mathrm{cp}} / \mathrm{D}\right)$ has significant effect on the girder strength, but has little effect on the post-peak regions of the moment-rotation curves.

- The cross-section aspect ratio $\left(\mathrm{D} / \mathrm{b}_{\mathrm{fc}}\right)$ has significant effect on both strength and rotation capacity for girders with compact flanges and slender webs. For compact flange and compact web cases, the effects of these factors are negligible, but may still affect the girder's ductility. 
- The proposed web compactness (Barth et al., 2003) and lateral bracing equations more accurately capture the influence of $\mathrm{D}_{\mathrm{cp}} / \mathrm{D}, \mathrm{D} / \mathrm{b}_{\mathrm{fc}}$ and $\mathrm{L} / \mathrm{D}$ ratios than current limits.

3. The proposed effective plastic moment equations by Barth et al. (2003) can be applied for hybrid HPS 70W girders.

4. The recommended simplified moment redistribution procedures are easy to implement, as illustrated by the design example for a hybrid HPS 70W girder bridge.

\subsection{Recommendations for Future Work}

The following recommendations for future work are given based on this study:

1. This research is based on the finite element analysis of all-steel hybrid girders. Thus, experimental investigation on hybrid girder at negative bending especially at high moment gradient, with and without composite action, should be conducted to further validate the FEA results provided in this study.

2. The effective moment equation is based on the assumption that the girders at the interior-pier sections has 0.009 rads plastic rotation at the Service II limit check, and 0.030 rads plastic rotation at Strength I limit check. Further work is suggested to evaluate these two rotation limits by comparing design requirements.

3. This research is devoted to hybrid girders comprised of 70ksi flanges and 50ksi webs. Further research on HPS 100W girders is suggested to validate whether the results from this study can be applied to hybrid HPS 100W girders. 
4. Beyond the present work, both experimental and FEA study on inelastic behavior of curved hybrid girders is recommended. 


\section{References}

AASHTO (1973). Standard Specifications for Highway Bridges, eleventh ed., American Association of State Highway and Transportation Officials, Washington, D. C.

AASHTO (1986). Guide Specifications for Alternate Load Factor Design Procedures for Steel Beam Bridges using Braced Compact Sections. American Association of State Highway and Transportation Officials, Washington, D. C.

AASHTO (1991). Guide Specifications for Alternate Load Factor Design Procedures for Steel Beam Bridges using Braced Compact Sections. American Association of State Highway and Transportation Officials, Washington, D. C.

AASHTO (2001). LRFD Bridge Design Specifications, $2^{\text {nd }}$ ed. , American Association of State Highway and Transportation Officials, Washington, D. C (with 2001 interims).

ABAQUS/Standard User's Manual, Version 6.3 (2002). Hibbitt, Karlsson \& Sorensen, Inc.

AISC (1973). Specifications for the Design, Fabrication and Erection of Structural Steel for Buildings, AISC.

AISI (2003, Sept.). A High-Performance Steel Scoreboard, AISI Website, http://www.steel.org/infrastructure/pdfs/hpsscoreboard09-22-03.xls

Alpsten, G. A. (1972). Variation in Mechanical and Cross-sectional Properties of Steel. Int. Conf. Planning Des. Tall Buildings, Lehigh University, ASCE-IABSE International Conference Preprints: Reports 1b-9, 1-51.

AWS Bridge Welding Code (1995). ANSI/AASHTO/AWS D1. 5-95, joint publication of American Association of State Highway and Transportation Officials and American Welding Society, 1995, 236pp.

Barker, M. G. and Schrage, S. D. (2000, June). High Performance Steel: Design and Cost Comparisons. Model Steel Construction, 16, 35-41.

Barker, M. G. and Zacher, J. A. (1997). Reliability of Inelastic Load Capacity Rating Limits for Steel Bridges. Journal of Bridge Engineering, ASCE, 2(3), 45-52.

Barth, K. E. (1996). Moment-rotation Characteristics for Inelastic Design of Steel Bridge Beams and Girders. Ph. D. Dissertation, Purdue University, West Lafayette, Indiana. 
Barth, K. E., and White, D. W. (1998). Finite Element Evaluations of Pier Momentrotation Characteristics in Continuous-span Steel I-girders. Engineering Structures, Elsevier, 20(8), 761-778.

Barth, K. E. and White, D. W. (2000 a). Inelastic Design of Steel I-Girder Bridges. Journal of Bridge Engineering, 2000, 179-190.

Barth, K. E., White, D. W. and Bobb, D. W. (2000 b). Negative Bending Resistance of HPS 70W Girders. Journal of construction Steel Research, Elsevier, 53 (1), 1-31.

Barth, K. E., Hartnagel, B. A., White, D. W., and Barker, M. G. (2003). Recommended Procedures for Simplified Inelastic Design of Steel I-girder Bridges (accepted).

Carskaddan, P. S. (1980). Autostress Design of Highway Bridges, phase 3: Interiorsupport-model test (AISI Project 188). Technical Rep. 97-H-045 (019-5), United States Steel Corporation Research Laboratory, 52 pp.

Carskaddan, P. S., Haaijer, G., and Grubb, M. A. (1982). Computing the Effective Plastic Moment, Engineering Journal, AISC, 21(4).

Climenhaga, J. J. and Johnson, R. P. (1972). Local Buckling in Continuous Composite Beams, The Structural Engineer, 50 (9), 367-374.

Clingenpeel, B. F. (2001). The Economical Use of High Performance Steel in Slab-onSteel Stringer Bridge Design. Master Thesis, Department of Civil and Environmental Engineering, West Virginia University, Morgantown, West Virginia.

Crisfield, M. A. (1983). An Arc-Length Method Including Line Searches and Accelerations. International Journal for Numerical Methods in Engineering, 19, 1269-1289.

Croce, D. A. F. (1970). The Strength of Continuous Welded Girders with Unstiffened Webs, Thesis, University of Texas at Austin, Austin, TX.

Disque, R. O. (1964). Wind Connections with Simple Framing, Engineering Journal, AISC, 1(3).

Earls, C. J. and Shah, B. J. (2000, August). Compactness and Bracing Requirements for Use in the Analysis and Design of High Performance Steel Highway Bridges. Report No. CE/ST17, Department of Civil and Environment Engineering, University of Pittsburgh. 
Grubb, M. A., and Carskaddan, P. S. (1979). Autostress Design of Highway Bridges, phase 3: Initial Moment Rotation Tests. Research Laboratory Report, United States Steel Corporation Research Laboratory.

Grubb, M. A., and Carskaddan, P. S. (1981). Autostress Design of Highway Bridges, phase 3: Moment Rotation Requirements. Research Laboratory Report, United States Steel Corporation Research Laboratory.

Haaijer, G., Carskaddan, P. S., and Grubb, M. A. (1980). Plastic Design with Noncompact Sections Including Composite Bridge Members, Structural Stability Research Council Annual Meeting.

Haaijer, G., Carskaddan, P. S., and Grubb, M. A. (1987). Suggested Autostress Procedures for Load Factor Design of Steel Beam Bridges, Bulletin No. 29, AISC.

Hartnagel, B. A., Barker, M. G., and Unterreiner, K. C. (1995). Monotonic and Cyclic Moment-Inelastic Rotation Behavior for Inelastic Design of Steel Girder Bridges. Transportation Research Record, 1594, Transportation Research Board, Washington, D. C., 42-49.

Hartnagel, B. A., Barker, M. G., and Weber, D. C. (1995). Experimental Verification of Load and Resistance Factor Inelastic Design Limits. Transportation Research Record, 1476, Transportation Research Board, Washington, D. C., 14-21.

Hartnagel, B. A. and Barker, M. G. (2000). Inelastic Design and Testing of Steel Bridges Comprising Noncompact Sections. AISC Engineering Journal, 37(1), 3-12.

Horton, R., Power, E., Van Ooyen, K., and Azizinamini, A. (2000). High Performance Steel Cost Comparison Study. Steel Bridge Design and Construction for the New Millennium with Emphasis on High Performance Steel Conference Proceeding, 120-137.

Huang, P. C. (1994). Finite Element Analysis of Inelastic Behavior of Structural Steel Beams and Bridge Girders. Ph. D. Dissertation, Cornell University, Ithaca, NY.

Lukey, A. F. and Adams, P. F. (1969). Rotation Capacity of Beams under MomentGradient, Journal of Structural Division, ASCE, 96(ST6), 1173-1188.

Righman, J. E., Barth, K. E., White, D. W. and Barker, M. G. (2004). On the Inelastic Design of Steel I-Girder Bridges. Structural stability research council, conference proceeding, Long Beach, California. 
Riks, E. (1979). An Incremental Approach to the Solution of Snapping and Buckling Problems. International Journal of Solids and Structures, 15, 529-551.

Schilling, C. G. (1985). Moment-rotation Tests of Steel Bridge Girders. Report on Project 188, American Iron and Steel Institute, Washington, D. C.

Schilling, C. G. (1986). Exploratory Autostress Girder Designs. Project 188-Autostress Design of Highway Bridges, American Iron and Steel Institute.

Schilling, C. G. and Morcos, S. S. (1988, July). Moment-rotation Test of Steel Girders with Ultracompact Flanges. Project 188-Autostress Design of Highway Bridges, American Iron and Steel Institute.

Schilling, C. G. (1989, Nov.). A Unified Autostress Method. Project 51- Development of Design Specifications for Continuous Composite Plate-Girder Bridges, American Iron and Steel Institute.

Schilling, C. G., Barker, M. G., Dishongh, B. E., and Hartnagel, B. A. (1997). Inelastic Design Procedures and Specifications, Final Report submitted to American Iron and Steel Institute, Washington, D. C.

White, D. W., and Dutta, A. (1993). Numerical Studies of Moment-rotation Behavior in Steel and Composite Steel-concrete Bridge Girders. Transportation Research Record, No. 1380, Transportation Research Board, National Academy Press, Washington D. C.

White, D. W., and Barth, K. E. (1998). Strength and Ductility of Compact-Flange Igirders in Negative Bending, Journal of Construction Steel Research, Elsevier, 45(3), 241-280.

White, D. W., Ramirez, J. A., and Barth, K. E. (1997). Moment Rotation Relationship for Unified Autostress Designs of Continuous-Span Bridge Beams and Girders. Final Report, Joint Transportation Research Program, West Lafayette, Indiana.

Wright, W. J. (1997). Personal communication. 